Synergies and trade-offs between yield, quality, resource use efficiency and environmental impact of potato production in China

Na Wang

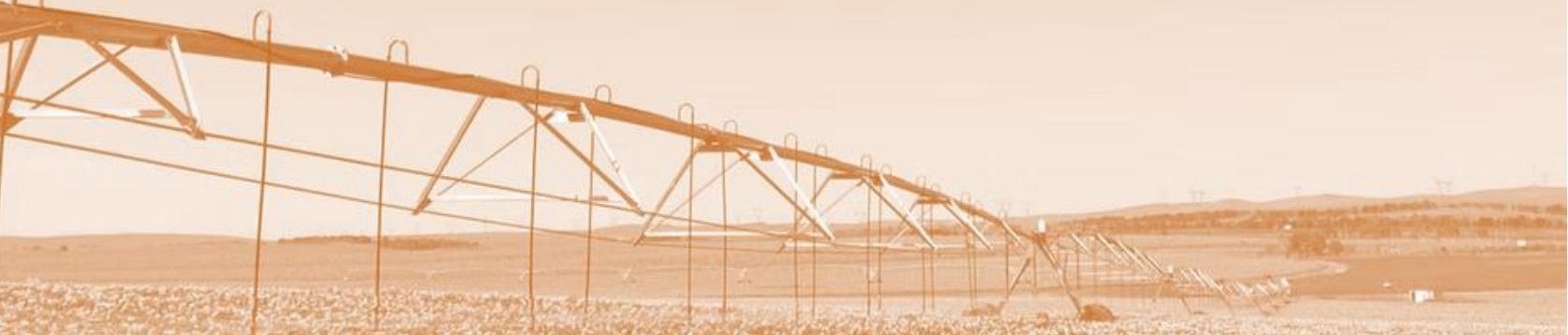



Synergies and trade-offs between yield, quality, resource use efficiency and environmental impact of potato production in China

Na Wang 


\section{Thesis committee}

\section{Promotor}

Prof. Dr Martin K. van Ittersum

Personal chair, Plant Production Systems

Wageningen University \& Research

\section{Co-promotor}

Dr Pytrik Reidsma

Associate Professor, Plant Production Systems

Wageningen University \& Research

\section{Other members}

Prof. Dr Wim de Vries, Wageningen University \& Research

Prof. Dr Ping He, Chinese Academy of Agricultural Sciences, Beijing, China

Dr Willemien Lommen, Wageningen University \& Research

Dr Peter Kooman, Solynta, Wageningen 


\title{
Synergies and trade-offs between yield, quality, resource use efficiency and environmental impact of potato production in China
}

\author{
Na Wang
}

Thesis

Submitted in fulfilment of the requirements for the degree of doctor at Wageningen University by the authority of the Rector Magnificus,

Prof. Dr A. P. J. Mol, in the presence of the

Thesis Committee appointed by the Academic Board to be defended in public on Tuesday 25 August 2020 at 11.00 a.m. in the Aula. 
Na Wang

Synergies and trade-offs between yield, quality, resource use efficiency and environmental impact of potato production in China

204 pages

PhD thesis, Wageningen University, Wageningen, the Netherlands (2020)

With references, with summary in English and Dutch

ISBN: 978-94-6395-450-1

DOI: https://doi.org/10.18174/525939 
The "Post-80s" ("80 局" in Chinese), a terminology in People's Republic of China used to refer to the generation born in the 80s (1980-1989 years). Since the 1980s, the government of People's Republic of China began the implementation of the "family planning policy" (also known as birth control). The "Post-80s" thus became the synonym of "the single child". 



\begin{abstract}
Potato is the fourth most important food crop in China. However, the yield is relatively low and the production is associated with high resource inputs and serious environmental problems. Potato production should be enhanced with sustainable practices that strike the right balance between multiple sustainable development objectives (agronomic, economic and environmental). The major aim of the present study was to explore the theoretical possibilities and demonstrate pathways for sustainable intensification of potato cultivation in China that optimize yield and quality, use natural resources efficiently, and minimize environmental impacts simultaneously. Crop modelling and farm surveys were used to assess these objectives at national and regional level, while on-farm experiments were performed to evaluate sustainable practices at local level.
\end{abstract}

The biophysical potential of the potato crop in China was explored and the scope for enhancing yield was estimated. There is large potential to improve potato yield across the country under both irrigated and rainfed conditions (the yield gap is $66 \%$ and $61 \%$, respectively, for irrigated and rainfed potato crops). A great improvement in yield can be achieved under rainfed conditions with current precipitation levels, especially in Qinghai and Heilongjiang in the north, and Guizhou in the southwest. Enhancing yield from actual to the potential yield level (under irrigated conditions) is associated with improved water productivity (from 7.9-22.3 to 30.7-54 $\mathrm{kg}$ dry matter ha-1 $\mathrm{mm}^{-1}$ ). Compared to the major cereals, potatoes have a larger potential to contribute to future food self-sufficiency in China as implied by the remarkable energy production gap (i.e., the additional calories provided by potatoes by closing the yield gaps to $80 \%$ of the potential yield under irrigated conditions and water-limited potential yield under rainfed conditions are $1.110^{14}$ and $0.910^{14} \mathrm{kcal}$ calories, respectively).

Improving environmental sustainability of potato cultivation should also be economically viable, and both yield and quality are key components driving the revenues for farmers. A framework was developed to assess the interrelationships between yield, quality and the influences on revenue. The framework was applied in a case study of commercial French Fries potato production in Inner Mongolia in the north. Farmers obtained low revenue (the gap between the revenue from the best performing farmers and actual revenue was $43 \%$ ) as a consequence of moderate yield gap (the gap between the maximum farmers' yield and actual yield was $26 \%$ ) and poor tuber quality (i.e., low dry matter percentage of tubers, and high percentage of weight of the small-sized tubers). It was found that enhancing yield up to the maximum yield obtained by farmers in the case study ( 55 ton fresh matter ha-1) was strongly associated to improvement in quality and revenue, suggesting synergies for reaching different objectives.

An integrated assessment on yield, resource use efficiencies (nitrogen use efficiency and water productivity) and environmental impacts (nitrogen surplus and water surplus) was performed for large-scale commercial farms in three major potato production regions in northern China (Inner Mongolia, Gansu and Heilongjiang). Potato production was associated with moderate resource use efficiencies (nitrogen use efficiency was 47-68\%, and water 
productivity was 23-35 $\mathrm{kg}$ dry matter $\mathrm{ha}^{-1} \mathrm{~mm}^{-1}$ ) and substantial environmental impacts (nitrogen surplus was $50-156 \mathrm{~kg} \mathrm{ha}^{-1}$, water surplus was $52-570 \mathrm{~mm}$ ) due to the application of excessive amounts of fertiliser and irrigation. We assessed that a higher nitrogen use efficiency (exceeding $90 \%$ in the short-term and up to $84 \%$ in the long-term) was achievable with more efficient nitrogen management. Water productivity can be increased to 29-44 kg dry matter ha-1 $\mathrm{mm}^{-1}$, and water surplus can be reduced with more efficient irrigation systems.

The pathways towards sustainable intensification were explored experimentally on large-scale commercial farms in Inner Mongolia in two years (2017-2018). In both years, irrigation contributed significantly to a higher yield and better quality in comparison with rainfed conditions. Under irrigated conditions, reducing nitrogen fertiliser from the current rates (189$252 \mathrm{~kg} \mathrm{ha}^{-1}$ ) to lower levels (109-181 kg ha-1) did not affect yield nor quality, while it largely improved nitrogen use efficiency (from $67 \%$ to $89 \%$ ) and reduced $\mathrm{N}$ surplus (from 81 to $28 \mathrm{~kg}$ $\mathrm{ha}^{-1}$ ). Yet, further reducing nitrogen fertiliser inputs (to 9-117 kg ha-1) should be done cautiously, accounting for different growing conditions of fields. Farmers found the reduction of nitrogen fertiliser input by $10-20 \%$ acceptable, while they noted that the widespread adaptation to more efficient irrigation practice (drip irrigation) was hindered by high cost and labor demands.

The present study provides crucial knowledge and contextualized suggestions to underpin sustainable intensification of potato production in China.

Keywords: Potato; sustainable intensification; yield; quality; nitrogen use efficiency; water productivity; environmental impacts; synergy; trade-off 


\section{Table of contents}

Chapter 1 General introduction.

Chapter 2 Can potato add to China's food self-sufficiency? The scope for increasing potato production in China.

Chapter 3 Synergy or trade-off? A framework and application to benchmark yield, quality and revenue of potato production

Chapter 4 Scope and strategies for sustainable intensification of potato production in northern China.

Chapter 5 Enhancing sustainable potato production - a case study in northern China.... 75

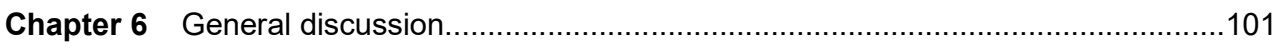

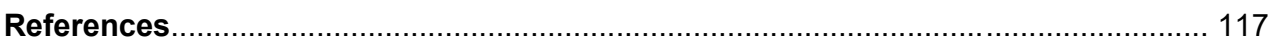

Appendix A Calibration and validation of two crop models for potato in China (Chapter

2).

Appendix B Yield gap analysis of the potato crop in different regions in China (Chapter

2) 151

Appendix C Supplementary material (Chapter 4) 161

Appendix D Supplementary material (Chapter 5). 167

Summary. 177

Samenvatting 181

Acknowledgements. 185

About the author. 189

PE\&RC PhD Education Certificate 191 



\section{Chapter 1}

\section{General Introduction}

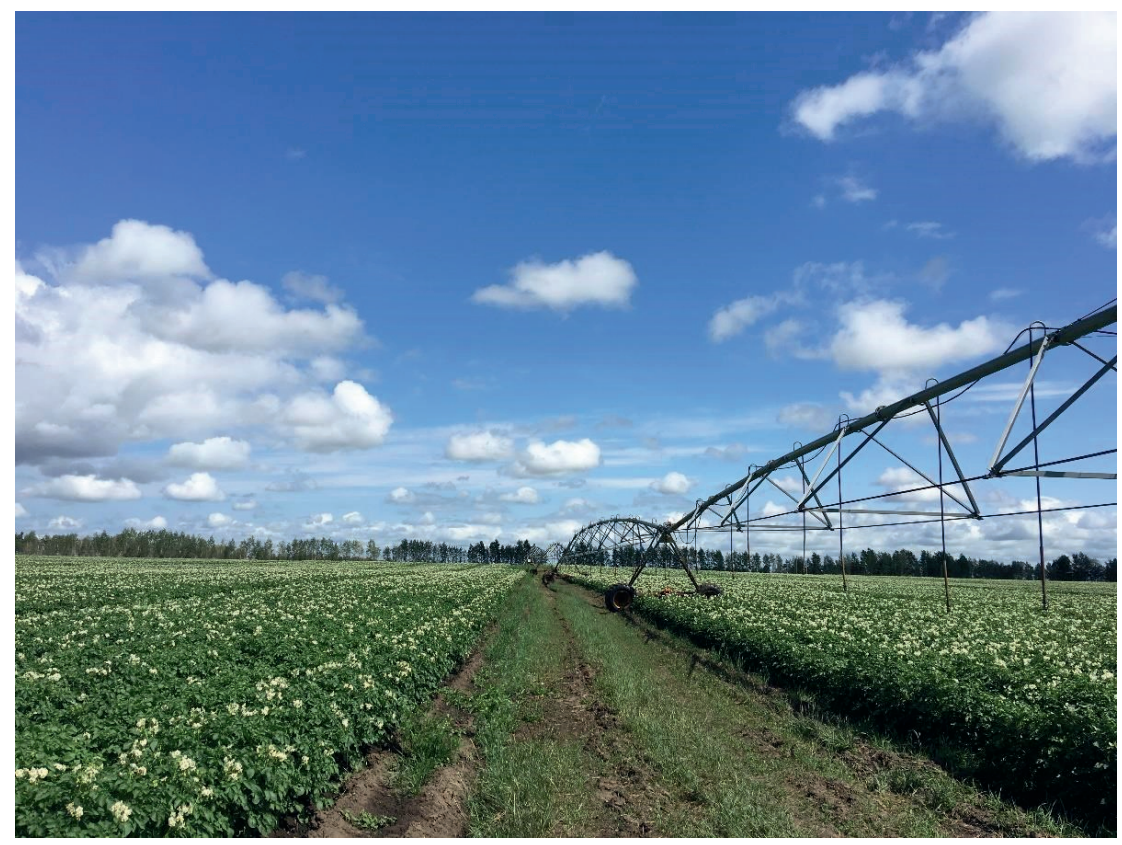




\subsection{Food production, resource use and environmental problems}

Meeting the future food demand while keeping environmental impacts at acceptable level has become a global challenge (Foley et al., 2011; Godfray et al., 2010; Mueller et al., 2012). To deal with such challenge, the concepts of "ecological intensification" (Cassman, 1999), "ecoefficient agriculture" (Keating et al., 2010) or "sustainable intensification" (Godfray et al., 2010; Mueller et al., 2012) were proposed as pathways for sustainable agricultural development. The general goal is to enhance food production while maintaining or increasing other sustainability performance aspects (i.e., natural resource use efficiency, environmental and ecosystem protection, economic and social development). To achieve such goal globally, the current geographical variation of agricultural intensification (in terms of resource input, production technology, and yield) should be considered (Tilman et al., 2011; Van Noordwijk and Brussaard, 2014). For instance, crop yield is low and production is limited by both nutrient and water constraints in some African countries, where there is a large scope for improving crop production through resource enhancement and technological improvement (Liu et al., 2010; Mueller et al., 2012; Ten Berge et al., 2019). On the other hand, nutrients are being overused in highly intensified cereal production systems in China, which is associated with enormous environmental problems domestically and globally (Ju et al., 2006; Keating et al., 2010; Mueller et al., 2012). In this context, efficient nutrient management practice is the key to improve production efficiency and reduce environmental problems associated with crop production (Foley et al., 2011; Liu et al., 2010).

\subsection{Agriculture in China: accomplishments and environmental costs}

Sustaining domestic food self-sufficiency has long been one of the most important strategic goals of China. The yield of three major staple crops (i.e., rice, maize and wheat) has been increasing markedly in the past 50 years (Fig. 1.1). The achievement in yield increase was mainly attributed to the improvement in genotypes and production techniques (irrigation, weeds, pest and disease management), and to the substantial inputs of synthetic fertilisers (Yuan and Peng, 2017; Zhu and Chen, 2002). At the same time, agricultural production in China is related to excessive inputs of natural resources, which has caused severe environmental issues (Jin, 2012; Ju et al., 2006; Yuan and Peng, 2017).

China is a global hotspot for excessive fertiliser application (Liu et al., 2010; Mueller et al., 2012). The rate of increase in fertiliser input (512\%) was much higher than the gain in grain yield $(65 \%)$ in the period from 1980 to 2010 (Shen et al., 2013). Over-exploitation of synthetic fertiliser has generated serious soil degradation (Hao et al., 2019), air pollution (Cai, 1997; Liu et al., 2013; Wang et al., 2018a), and water pollution (Ju et al., 2006; Le et al., 2010; Yu et al., 2019). Furthermore, agricultural production takes as much as $62 \%$ of the total water consumption of the country, which is much higher than the water use for domestic (14\%) and industrial production (22\%) (MWR, 2016). The groundwater, which makes a large contribution to agricultural irrigation in northern China, has been over-extracted so excessively that the groundwater table has decreased at astonishing rates in some regions in the central area 
(COWI, 2013; Shen et al., 2013). Such unsustainable irrigation management practice enhanced the already high competition of water use between different sectors in the north (e.g., agriculture, domestic, industrial use, ecosystems conservation) (COWI, 2013).
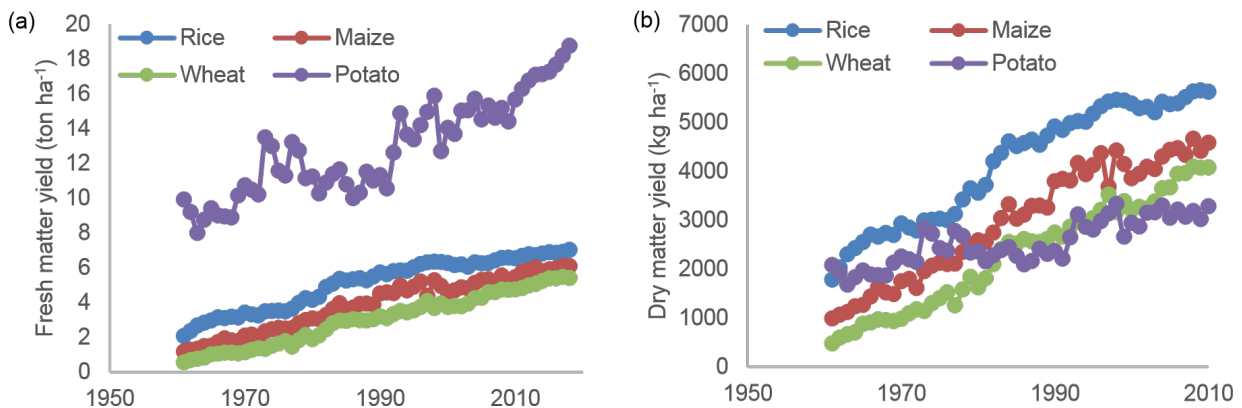

Figure 1.1. The crop yield in fresh matter (a) and dry matter (b) of the three major cereals (i.e., rice, maize and wheat) and potato in China from 1960 to 2017 (FAO, 2020). For the estimation of dry matter yield, I assumed the dry matter percentage of harvested product was $86 \%, 84 \%, 86 \%$ and $21 \%$ for rice, maize, wheat, and potato, respectively (Chapter $\mathbf{2}$ ).

\subsection{Potato production in China}

Potato was introduced to China 400 years ago in the Ming dynasty. Since then, the crop has been an important food ingredient in Chinese cuisine. The most common name of potato in Chinese is "Malingshu", and it has various local names such as "Tudou" in the northeast, "Shanyao" in central, "Yangyu" in the northwest, and "Didan" in southern China. China is the largest country of potato production in the world both in terms of production area (i.e., 4.81 million ha in 2018, $27 \%$ of the world area) and quantity (i.e., 90 million ton fresh matter (FM) in $2018 ; 25 \%$ of the world production) (FAO, 2020). Potato production mainly occurs in four agroecological zones (Fig. 1.2) (USDA, 2018; Zhang, 2016). Frequent potato cropping is common, i.e., farmers plant potatoes in the same field for two out of three years or year after year without using other rotation crops.

- Zone I - northern single crop zone. Zone I accounts for $49 \%$ of the total potato production area. Potatoes are grown mainly for table consumption, processing and seed tuber production. One potato crop is planted annually in the spring season (Fig. 1.3). Farmers rotate potatoes with cereals (e.g., wheat, maize, oat, and barley) and legumes (e.g., soybean). Zone I includes Qinghai, Gansu, Ningxia, Xinjiang, Inner Mongolia, Shanxi, Shaanxi, Hebei, Heilongjiang, Jilin and Liaoning provinces.

- Zone II - southwestern mixed single and multiple crop zone. Zone II covers $39 \%$ of national potato production area, and production is mainly for table consumption. Potatoes are planted mainly in the mountainous regions with large variation in altitude and climatic conditions, which allows one potato cultivation in high altitude areas and multiple potato crops in lowland areas (Fig. 1.3). Potatoes are rotated with corn, wheat, soybeans, and 
sweet potato (Jansky et al., 2009). The zone consists of Sichuan, Chongqing, Guizhou, Yunnan, Tibet, Hubei and Hunan provinces.

- Zone III - central double crop zone. Zone III explains $5 \%$ of the potato area and potato cultivation is feasible in both spring and autumn (Fig. 1.3). Zone III comprises Jiangxi, Jiangsu, Zhejiang, Anhui, Shandong, and Henan provinces.

- Zone IV - winter and single crop zone. Zone IV accounts for $7 \%$ of the potato area. Potatoes are cultivated in winter after harvesting rice in Guangdong, Guangxi, Fujian, Taiwan, and Hainan provinces (Fig. 1.3). Potato production in Zone III and Zone IV is mainly for table consumption and export (fresh potatoes) to Malaysia, Vietnam and Russia (USDA, 2018).

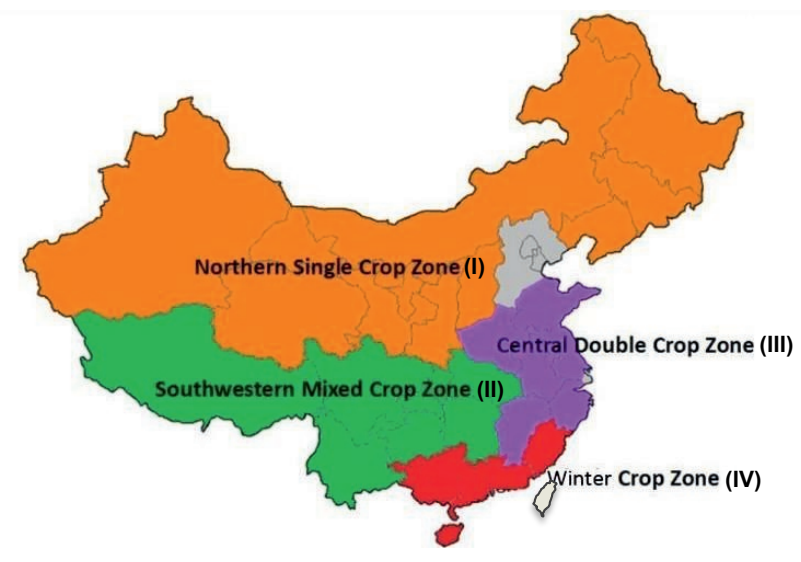

Figure 1.2. Four agroecological zones of potato production in China (USDA, 2018).

\begin{tabular}{|l|l|l|l|}
\hline & Jan. Feb. Mar. Apr. May June July Aug. Sep. Oct. & Nov. & Dec. \\
\hline Zone I (summer) & & & \\
\hline Zone II (spring) & & \\
\hline Zone II (summer) & & \\
\hline Zone II (autumn) & & \\
\hline Zone II (winter) & & \\
\hline Zone III (spring) & & \\
\hline Zone III (autumn) & & \\
\hline Zone IV (winter) & & \\
\hline
\end{tabular}

Figure 1.3. Potato growing seasons in the four agroecological zones in China (China, World Potato Atlas, CIPcollab, https://research.cip.cgiar.org; USDA, 2018).

Table potato accounts for $60 \%$ of the total production, followed by processing that makes up $15 \%$, seed potatoes and animal feeding each constitute $5 \%$, and the rest (5\%) is loss (USDA, 2018). Table potatoes are cultivated mainly under rainfed conditions by farmers who grow potatoes as food and cash crop, while processing potatoes are often cultivated by farmers who 
have a contract with factories to offer products with a pre-defined quantity. Those farmers commonly manage large-scale farms with irrigation facilities and have adequate financial means for intensive resource inputs (Jansky et al., 2009). The major potato processing products are starch, dehydrated potatoes (potato flakes, potato granules), French Fries, and crisps (sliced and fabricated) (Qu et al., 2001; USDA, 2018). Coarse starch is traditionally the dominant processed product, i.e., starch and the related products such as vermicelli ("Fensi" in Chinese) account for $90 \%$ of the processed potatoes (Qu et al., 2005; Zhang, 2016). Yet, it was seen to decrease in recent years due to the strict environmental regulations in processing (waste water management) (USDA, 2018). On the other hand, the production of French Fries and crisps has been increasing, which is facilitated by the rapid growth of the country's economy and the rising demand for diversified diets (USDA, 2018). Processing factories for those products are mainly located in the northern single crop zone (Zone I, Fig. 1.2), where the potatoes can meet the requirement for processing in both yield and quality (i.e., dry matter content, sugar content). However, the actual production is often lower than the production capacity of the factories due to the limited supply of raw materials and limited storage capacity.

\subsection{Opportunities and challenges for potatoes}

Food demand is expected to increase in China in response to the increasing population and changed diet. Meanwhile, the scope for further improving the yield of the three major cereals (i.e., rice, wheat and maize) is limited, as the actual yield is approaching the biophysical potential of current cultivars. This is revealed by the small yield gaps, i.e., the difference between potential yield (Yp) under irrigated conditions and actual yield (Ya) (Yg-p) and between water-limited potential yield $(\mathrm{Yw})$ and actual farmers' yield (Ya) under rainfed conditions (Yg-w) (Chapter 2; GYGA, 2020; Van Ittersum et al., 2013). The estimated yield gap (i.e., the ratio between $Y g-p$ and $Y p$, or $Y g-w$ and $Y w$ ) was $27 \%$ and $44 \%$, respectively, for irrigated and rainfed rice (GYGA, 2020), 33\% for rainfed maize (GYGA, 2019), and $11 \%$ for irrigated wheat (Liu et al., 2011).

In 2015, the Ministry of Agriculture in China (MOA) defined a "Potato Staple Food Strategy" in order to improve the national food self-sufficiency, enhance dietary diversification, and release the pressure on land and water resources (MOA, 2015a). The policy aimed to promote potato as the fourth most important staple after the three cereals through enhancing potato production in terms of both area (mainly in winter fallow lands in Zone IV) and quantity (MOA, 2016). The policy set ambitious goals to increase the potato area to 6.7 million ha (increase by 25\%) and enhance the yield to 19.5 ton $\mathrm{FM} \mathrm{ha}^{-1}$ (increase by 15\%) from 2015 to 2020 (MOA, 2016).

At this moment, the productivity of potato in China (18.8 ton FM ha-1) is low compared to that in other important potato producing countries (e.g., United States, European countries) (FAO, 2020). This is remarkable given the strong increase in yields and the relatively small yield gaps of cereal crops in China. The biophysical potential of the potato crop across the country and the scope for yield improvement is unclear. Additionally, considering the limited water resources in arid and semiarid regions in northern China (Zone I in Fig. 1.2), future intensification should aim to use the available water resources as efficiently as possible. The 
enhancement of potato production is likely to be economically and environmentally viable in regions with high biophysical possibilities and relatively low water demand.

Potatoes are often grown as a cash crop in China, and the primary objective of potato growers is high economic return. The revenue (i.e., the gross income received by the growers by selling the products, without accounting for the cost) depends on both yield and quality. Potato production should aim at maximizing yield and quality simultaneously in order to obtain high revenue. If there is a trade-off between yield and quality, pursuing high yield may not be a recommended target for farmers. Concepts of different production levels in yield (i.e., potential, water-limited and nutrient-limited potential, and actual yield) are well defined (Van Ittersum and Rabbinge, 1997). However, the application of such concepts to quantify the important quality traits and the scope for their improvement is less advanced.

As a cash crop, potato often receives large amounts of inputs (i.e., fertiliser, chemicals, irrigation) to obtain high yield and quality. On the other hand, the future enhancement of potato production can no longer depend on greater resource input due to the limited resource availability and environmental concerns. Potato production should be enhanced with sustainable practices that aim at improved resource use efficiencies and reduced environmental impacts. An integrated assessment of the multiple sustainability objectives is essential to provide insights into the scope and strategies of sustainable intensification of potatoes in the context of current developments and possible future changes.

It has been recognized in many studies that crop yield can be maintained or enhanced with no increase or even a reduction in nitrogen fertiliser inputs through more efficient fertiliser management and improvement in other agronomic practices (Chen et al., 2011; Cui et al., 2008; Peng et al., 2010; Zhang et al., 2019). However, little empirical evidence is available on the effects of reduced nitrogen fertiliser inputs and alternative irrigation management practices on potato production, taking into consideration the physical (soil water holding capacity) and chemical (soil nitrogen supply) properties of soils in farmers' fields. Despite the rising environmental concerns, excessive fertiliser application remains a common practice in most farms. Better understanding the willingness and constraints of farmers to move to more sustainable management practices is particularly important in order to make sustainable intensification operational.

\subsection{Research objectives}

The main research objective of this study was to apply a quantitative analytical approach to assess the possibilities and demonstrate pathways of enhancing potato production in China through balancing the agronomic (i.e., enhancing yield, quality), economic (i.e., enhancing revenue) and environmental objectives (i.e., improving resource use efficiencies and reducing environmental impacts). The specific research objectives were:

- Identifying the potential to enhance potato yield under both irrigated and rainfed conditions, the additional water required to achieve high yield, and the contribution of potato to maintain 
food self-sufficiency in China by assessing the yield gap, water input gap and energy gap for the major potato production regions in China.

- Enhancing the yield gap concept by considering quality aspects of crop production, by developing a framework that allows an integrated assessment of yield, quality and revenue, and applying the framework to a case study of potato for French Fries processing in northern China.

- Systemically assessing the current performance of potato production in terms of yield, resource input, resource use efficiency and environmental impacts based on farm surveys in northern China, and estimating the possible targets both in the short-term and the longterm.

- Exploring the options for farmers to achieve sustainable intensification of potato production through demonstrating the contribution of more efficient nitrogen fertiliser and water management practices.

\subsection{Research methods}

Generic methods are needed to allow for a quantitative benchmarking of different aspects of sustainable intensification of potato in China (yield, quality, revenue, resource use efficiency, environmental impacts). For crop yield, crop growth models have been widely applied to assess the production capacity of a crop in a given area, i.e., Yp under irrigated conditions and Yw under rainfed conditions (Van Ittersum et al., 2013). The yield gap analysis (Van Ittersum et al., 2013) based on concepts of crop production ecology (Van Ittersum and Rabbinge, 1997) has been extensively used to benchmark the scope for improving actual production under both rainfed and irrigated growing conditions (GYGA, 2020).

One of the methodological challenges in this thesis was to extend the yield gap notion to quality aspects to allow for benchmarking yield, quality, and the associated gain in economic return simultaneously. Such framework should account for the important quality traits of a particular crop for a specific market. Benchmarks should be defined, and the quality traits and their critical values in relation to the revenue should be identified. In this way, the production performance in terms of yield (yield gaps), quality (quality gaps) and revenue (revenue gaps) can be assessed, and the scope of improvement in these aspects can be evaluated.

To benchmark the nitrogen use efficiency and environmental impacts of nitrogen fertiliser inputs, the framework by the EU Nitrogen Expert Panel (2015) provides a good basis. The framework assesses the nitrogen use efficiency based on the balance of nitrogen input (i.e., nitrogen that enters the field via fertiliser and deposition) and nitrogen output (i.e., nitrogen removed from the field by harvesting), and benchmarks the environmental impact based on the difference between input and output (nitrogen surplus), assuming that the soil nitrogen stock is in a state of equilibrium (a typical situation for the EU). However, for potato farms in China, the soil nitrogen stock may not be stable over years due to high soil organic matter contents and a long period of excessive nitrogen fertiliser input. The framework should be 
adjusted to account for soil nitrogen supply and the soil nitrogen dynamics. To address the environmental impacts caused by (over-)irrigation, the framework needs extension for water.

Finally, a methodological challenge was to bridge the conceptual benchmarking frameworks with farmers' practice. For that purpose, I proposed to conduct farm surveys and on-farm experiments to understand the current sustainability performance of potato farms and the scope for improvement. The advantages of conducting experiments in farmers' fields rather than in experimental stations is that the variability among farmers' fields can be addressed, and that it allows to assess results together with farmers in order to understand their willingness and constraints of adapting to efficient management practices. Nevertheless, on-farm experiments are less controlled than on-station experiments, which poses challenges.

\subsection{Outline of the thesis}

The first part of the thesis (Chapters 2 and 3) focuses on the outputs of potato production to fulfill the agronomic objectives (i.e., yield, quality and revenue) (Fig. 1.4). In Chapter 2, the biophysical production potential of the potato crop was explored (Yp under irrigated conditions and $\mathrm{Yw}$ under rainfed conditions), which provided guidance on the feasible target production levels in the major potato production regions in the country. It also allowed the quantification of water inputs (water input gaps) that are required to achieve the potential production level (from $Y w$ to $Y p$ ). The scopes for improving yield and energy production (i.e., in terms of calorie production) were identified to provide insights in the contribution of potatoes in securing China's food self-sufficiency. The estimated Yp (for irrigated potatoes) were applied in the subsequent chapters as benchmarks to assess the current production performance (Chapter $3,4)$ and as targets for future intensification (Chapter 4,5 ).

Chapters 3, 4 and 5 focus on large-scale commercial potato farms in northern China that commonly apply large amounts of inputs (i.e., irrigation, fertiliser, plant protection agency) and produce relatively much outputs (yield). Chapter 3 aimed to answer the question whether yield and quality can be maximized at the same time so that the revenue can be optimized. A conceptual framework was developed to assess the relationships between yield and critical quality indicators, and subsequently to evaluate the integrated effects of yield and quality on production revenue. The framework was applied in a case study of potato production for French Fries processing in Inner Mongolia in northern China. The relationships between yield, quality and revenue were assessed at field level based on farm surveys over three years (2015-2017).

The second part of the thesis (Chapters 4 and 5) reveals the relationships between the targeted outputs (agronomic objectives) and the non-targeted outputs (environmental objectives) (Fig. 1.4). In Chapter 4, an integrated assessment of resource inputs (water and nitrogen fertiliser), resource use efficiencies and environmental impacts was performed based on farm surveys for three major potato regions in northern China (Inner Mongolia, Gansu and Heilongjiang). Comparison of the current production performance and the target values in a sustainable 
domain indicated the inefficiency in resource use (i.e., land, water and nitrogen fertiliser) and revealed environmental risks of potato production in the regions.

The technical options for sustainable intensification of potato production in the short-term were explored based on field experiments in Inner Mongolia in 2017 and 2018 (Chapter 5). The response of yield and quality of potato to lower nitrogen fertiliser inputs (compared to the amount applied by farmers) and improved irrigation management (drip irrigation) were tested on farmers' fields. The resource use efficiencies (nitrogen and water) and the environmental impacts of different combinations of nitrogen fertiliser and irrigation treatments were investigated. Finally, we performed interviews with farmers which provided farmers' perspectives on the efficient management practices. Understanding these helps the transition to a sustainable intensification of potato production.

The results of the four chapters were synthesized in Chapter 6. Further increase in yield, quality and revenue is only feasible with a thorough understanding of various biophysical and socio-economic constraints. The synergies and trade-offs between the agronomic and environmental goals are discussed. The understanding of the production constraints and the trade-offs between multiple objectives of sustainable intensification provides explicit input for decision makers.

\begin{tabular}{|c|c|}
\hline $\begin{array}{c}\text { Agronomic objectives } \\
\text { targeted outputs }\end{array}$ & $\begin{array}{l}\text { Environmental objectives } \\
\text { non-targeted outputs }\end{array}$ \\
\hline $\begin{array}{l}\text { Chapter } 2 \\
\text { Goal: Identifying the potential to } \\
\text { enhance yield and water use efficiency } \\
\text { of potatoes under irrigated and rainfed } \\
\text { conditions in China. } \\
\text { Method: Crop modeling + yield gap } \\
\text { analysis }\end{array}$ & $\begin{array}{l}\text { Chapter } 4 \\
\text { Goal: Assessing the current sustainable } \\
\text { performance of potato farms and } \\
\text { possible improvement in the short-term } \\
\text { and long-term. } \\
\text { Method: Farm surveys + model-based } \\
\text { estimation }\end{array}$ \\
\hline $\begin{array}{l}\text { Chapter } 3 \\
\text { Goal: Exploring the relationships } \\
\text { between yield, quality and revenue } \\
\text { of potato production. } \\
\text { Method: Framework + farm surveys }\end{array}$ & $\begin{array}{l}\text { Chapter } 5 \\
\text { Goal: Balancing multiple sustainable } \\
\text { goals of potato production through } \\
\text { better nitrogen fertiliser and irrigation } \\
\text { management. } \\
\text { Method: On-farm field experiments + } \\
\text { farm surveys }\end{array}$ \\
\hline
\end{tabular}

Figure 1.4. Summary overview of the thesis. An integrated assessment of the scope and pathways of sustainable intensification of potato production in China aiming at maximizing targeted outputs (agronomic objectives) and minimizing non-targeted outputs (environmental objectives). 



\section{Chapter 2}

\section{Can potato add to China's food self-sufficiency? The scope for increasing potato production in China}

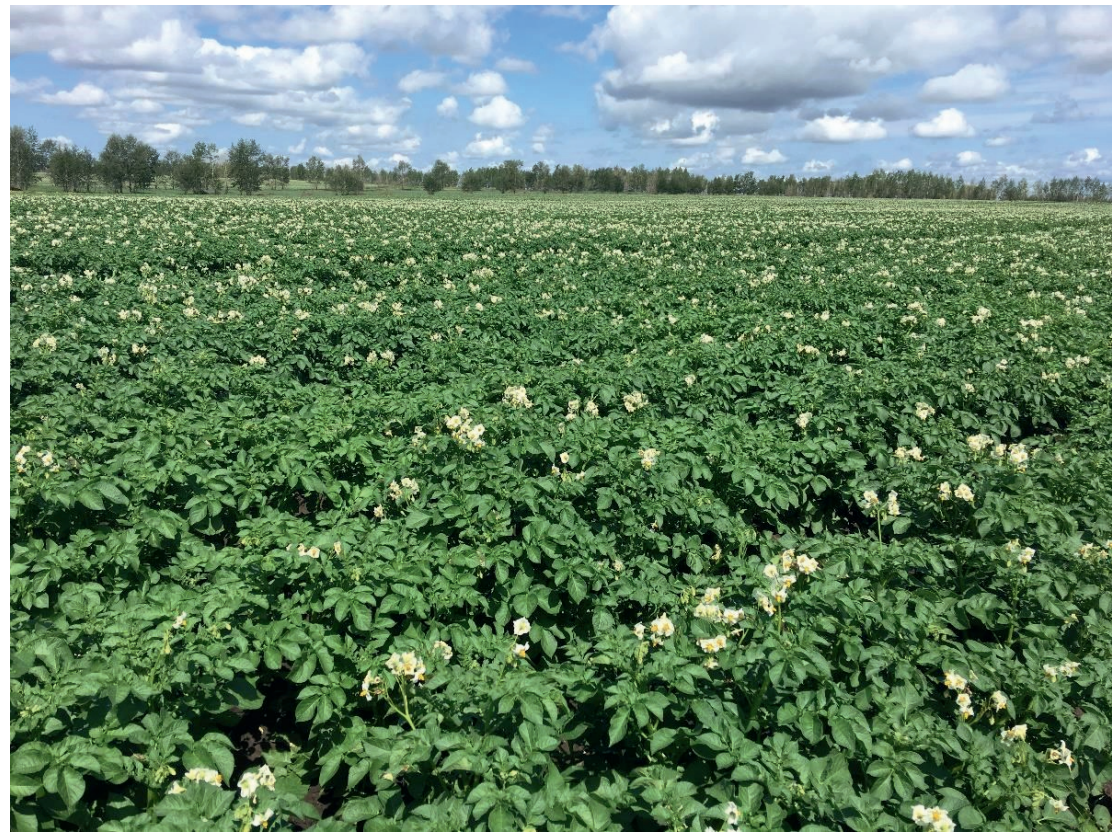

This chapter is published as:

Wang N., Reidsma P., Pronk A.A., de Wit A.J.W., Van Ittersum M.K., 2018. Can potato add to China's food selfsufficiency? The scope for increasing potato production in China. European Journal of Agronomy, Volume 101, Pages 20-29.

ISSN 1161-0301, https://doi.org/10.1016/j.eja.2018.07.002. 


\section{Abstract}

China is enhancing potato production in both area and quantity. While the potato area is large, the actual yields remain low. Besides, the water resources used for irrigation are increasingly under pressure in potato production areas. This study aimed to assess the scope for increasing potato production in China. The key climate zones in China were identified, for which the potential yield $(Y p)$ and water limited yield ( $Y w$ ) of potato (expressed in fresh matter (FM)) were estimated by two crop growth models over 10 years (2006-2015). The Yp and Yw and yield gaps (i.e., the difference between $Y p$ and actual yield (Ya) under irrigated conditions (Yg-p) and between $Y w$ and $Y a$ under rainfed conditions ( $Y g-w)$ ) were evaluated at local, provincial and national level, for potatoes under both irrigated and rainfed conditions. The water availability through rainfall, water productivity (WP) and the water input gaps to realize potential rather than water-limited potato yields were identified at provincial level. The $Y p$ in the country was on average 50.1 ton $\mathrm{FM} \mathrm{ha}{ }^{-1}$, and $\mathrm{Yg}$-p as a percentage of $\mathrm{Yp}$ was $66 \%$. At provincial level, the Yp varied from 38.8 ton $\mathrm{FM} \mathrm{ha}^{-1}$ in Sichuan in the southwest to 66.4 ton $\mathrm{FM} \mathrm{ha}^{-1}$ in Qinghai in the north. At national level, the $\mathrm{Yw}$ was 43.7 ton $\mathrm{FM} \mathrm{ha}^{-1}$ and $\mathrm{Yg}-\mathrm{w}$ as a percentage of $\mathrm{Yw}$ was $61 \%$. At provincial level, the $\mathrm{Yw}$ was lowest in Shaanxi $\left(27.7\right.$ ton $\mathrm{FM} \mathrm{ha}^{-1}$ ) and highest in Qinghai (57.9 ton FM ha-1). Water productivity for potential yield (WP-p) ranged between 30.7 and $54 \mathrm{~kg}$ dry matter (DM) $\mathrm{mm}^{-1} \mathrm{ha}^{-1}$ in Shaanxi and Qinghai, respectively, and for actual yield (WP-a) between $7.9 \mathrm{~kg} \mathrm{DM} \mathrm{mm}^{-1} \mathrm{ha}^{-1}$ (Shanxi) and $22.3 \mathrm{~kg} \mathrm{DM} \mathrm{mm}^{-1} \mathrm{ha}^{-1}$ (Sichuan). Water supply through rainfall is close to sufficient for non-water limiting potato growth in the southwest. The water input gap in the north was highest in Shaanxi (i.e., $243 \mathrm{~mm}$ ) and lowest in Heilongjiang (i.e., $39 \mathrm{~mm}$ ). There is a large scope to improve potato yields at current rainfall levels, especially in Qinghai and Heilongjiang in the north and in Guizhou in the southwest. By closing the exploitable yield gap (i.e., difference between $80 \%$ of $\mathrm{Yp}$ - or of $\mathrm{Yw}$ - and $\mathrm{Ya}$ ) for the current production area, potato could contribute to an additional $1.110^{14}$ and $0.910^{14} \mathrm{kcal}$, respectively, under irrigated and rainfed conditions. This is much more than that for rice $\left(0.210^{14} \mathrm{kcal}\right.$ extra energy due to yield gap closure) under irrigated conditions, and similar or more than for maize under irrigated $\left(1.010^{14} \mathrm{kcal}\right)$ and rainfed $\left(0.510^{14} \mathrm{kcal}\right)$ conditions. We conclude that compared with the cereal staple crops, potato has a larger potential to maintain domestic food security and self-sufficiency, and to enhance water use efficiency.

Keywords: Potential yield, water limited yield, yield gap analysis, water productivity, irrigation 


\subsection{Introduction}

Potato (Solanum tuberosum L.) is the fourth most important crop in the world in terms of global production quantity in fresh matter (FAO, 2016a, 2016b). The crop is increasingly important for maintaining food security and stability, particularly in intensive agricultural regions in developing countries (He et al., 2012; Hijmans and Spooner, 2001; DeFauw et al., 2012). Being the number one country in terms of potato production area (i.e., $30 \%$ of world production area) and production (i.e., $24 \%$ of world production), China has taken a dominant position in the global potato industry (FAO, 2016b, Jansky et al., 2009; Wang and Zhang, 2004). Yet, the continuous increase in population density and pressure on land in China drives a further intensification of potato production.

Potatoes are mainly grown in four agro-ecological zones in China: in the north (49\% of total area), southwest (39\%), south (7\%) and Central Plains (5\%) (MOA, 2008). There are various production systems across the country: summer cultivation in the north; two cultivations in the central plains; winter cultivation in the south and both summer and winter production systems in the southwest. Table potato is widely cultivated across the country. Coarse starch is traditionally the dominant processed product, while the area under varieties processed to flakes, French fries and crisps is quickly expanding, which is facilitated by the rapid growth of the country's economy and rising demand for diversified diets.

The fresh matter yield (FM) of potatoes (18.7 ton FM ha-1 in 2015, Fig. 2.1) is low compared to other dominant potato production countries such as the United States (47.1 ton $\mathrm{FM} \mathrm{ha}^{-1}$ ), the Netherlands (45.7 ton FM ha-1), Poland (27.7 ton FM ha-1), and India (22.9 ton FM ha-1) (NBSC, 2016; FAO, 2016a). This is remarkable given the strong increase in yields and the relatively small yield gaps of cereal crops in China (Cassman et al., 2003; Lobell et al., 2009; Lu and Fan, 2013; Meng et al., 2013; Qu et al., 2005; Van Ittersum and Rabbinge, 1997; Van Ittersum et al., 2013; Van Wart et al., 2013; Zhang et al., 2014), which are estimated to be ca. $33 \%$ for rainfed maize, $27 \%$ and $44 \%$, respectively, for irrigated and rainfed rice (GYGA, $2017 a$ ), and $11 \%$ for irrigated wheat (Liu et al., 2011).

Agricultural production is estimated to use as much as $73 \%$ of total fresh water resources in China (Qu et al., 2005). Water resources to maintain the continuously increasing agricultural production are under severe pressure in many arable lands of the country. In arid and semiarid regions of China (i.e., north and northwest), potatoes are mainly produced under rainfed conditions, and irrigation is sometimes applied, mainly on large-scale farms (personal communication with the local potato processing companies). With the extension of potato processing industry in China, it is likely that irrigation will become more profitable in the current rainfed areas to satisfy the demand. Thus a critical question is how much water is needed to increase yields from water limited to potential (water input gap).

The production capacity of a crop in a given area can be derived by evaluating the potential yield $(Y p)$ under irrigated conditions or the water limited yield $(Y w)$ under rainfed conditions, and calculating the so-called yield gap (i.e., Yg-p refers to the difference between Yp and the 
actual yield (Ya), and Yg-w to the difference between $\mathrm{Yw}$ and $\mathrm{Ya}$ ) (Van Ittersum and Rabbinge, 1997; Van Ittersum et al., 2013). Crop growth models have been argued to be the most robust tool for simulating potential yield under diverse climatic conditions (Van Ittersum et al., 2013). So far, there is however little literature on estimating potential yield of potatoes in China.

To safeguard domestic food supply, China is enhancing potato production as the fourth most important staple crop after rice, wheat and maize (MOA, 2016). The expansion of potato production is likely to be economically and environmentally viable in regions with high biophysical possibilities and low irrigation requirements. In this study, crop models (i.e., WOFOST, LINTUL POTATO DSS) were used to estimate potential and water limited yield of potato in China as well as yield gaps and water input gaps. We compare the slack in production of potato on the present potato area with the slack in cereal production on the existing cereal area to assess possible contributions to food self-sufficiency in China.
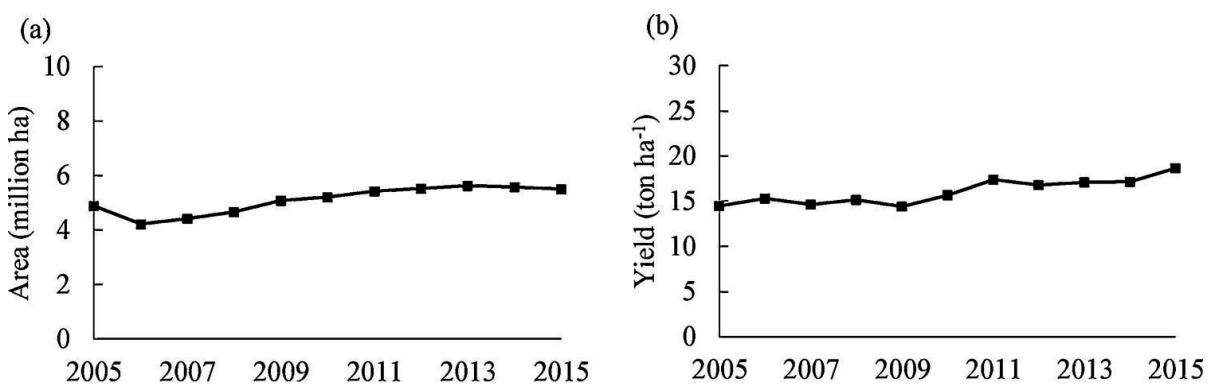

Figure 2.1. Annual production area (a) and fresh matter yield (b) of potato in China from 2005 to 2015.

\subsection{Methods}

We followed the protocol developed for the Global Yield Gap Atlas (Global Yield Gap Atlas (GYGA), www.yieldgap.org) (Van Ittersum et al., 2013; Grassini et al., 2015; Van Bussel et al., $2015)$ to estimate potato yield gaps. The important climate zones for potato in China and socalled reference weather stations (RWSs) within these climate zones were identified following the procedure described by Van Bussel et al. (2015). The two crop growth models WOFOST and LINTUL POTATO DSS were applied to estimate potential dry matter (DM) yield, which was then converted to fresh matter (FM) (Yp). The water limited DM yield was only estimated by WOFOST and converted to FM (Yw). Two crop growth models were used, because model comparisons have shown that simulated yields may vary between models (Asseng et al., 2013; Fleisher et al., 2017). For potato, two or three models are recommended, depending on the site-specific conditions (Fleisher et al., 2017). Comparing simulations of different models improves understanding of yield potentials due to inherent uncertainty of model simulations. The Yp, Yw, Yg-p and Yg-w were estimated using the weather data from the RWSs, and scaled up to climate zones, provincial and national level. The results will also be published on www.yieldgap.org. Water input gaps for irrigated potatoes were assessed at provincial level, based on the extra water needed to obtain $Y p$, rather than $Y w$, assuming that irrigation would be viable in the current dryland systems in the future. Finally, the additional food (expressed 
in kcal) that can be obtained by closing the exploitable yield gap (Van Ittersum et al., 2013), i.e. the gap between $80 \%$ of $\mathrm{Yp}$ and $\mathrm{Ya}$ (under irrigated conditions) or between $80 \%$ of $\mathrm{Yw}$ and Ya (under rainfed conditions), was assessed and compared with the amount (in kcal) that can be added through exploitable yield gap closure (to $80 \%$ of $Y w$ or $Y p$ ) of rice, maize and wheat. In this way we estimated the possible contribution of the potato crop to future food security and self-sufficiency of China.

\subsubsection{Important climate zones and reference weather stations}

The locations and area of potato production in China (i.e., both irrigated and rainfed) were retrieved from SPAM2005 (You et al., 2014) and were compiled and schematically interpreted using ArcGIS (Fig. 2.2). Information on the potato area under irrigation according to SPAM2005 was not used, as it was deemed not accurate enough due to the fact that many potato processing companies (which mainly apply irrigation systems) have been established recently in China (personal communication with the companies) and this was not included in the SPAM2005 database yet. Yield gaps were benchmarked against both Yp and Yw for the entire country due to the lack of good spatial data for irrigated potato areas.

In the country, a total of 136 climate zones were identified based on the climate zonation procedure in GYGA (Van Wart et al., 2013). Designated Climate Zones (DCZs) were selected as zones covering more than $2.5 \%$ of total potato area in the country. A weather station was selected when its buffer zone of $100 \mathrm{~km}$ radius, was within or intersected with the DCZs. Among the weather stations, a reference weather station (RWS) was selected when its buffer zone covered more than $0.5 \%$ of the total potato area in the country (i.e., $22.810^{3}$ ha). The weather data used were obtained from the China Meteorological Data Service Centre (CMDC, 2016). 


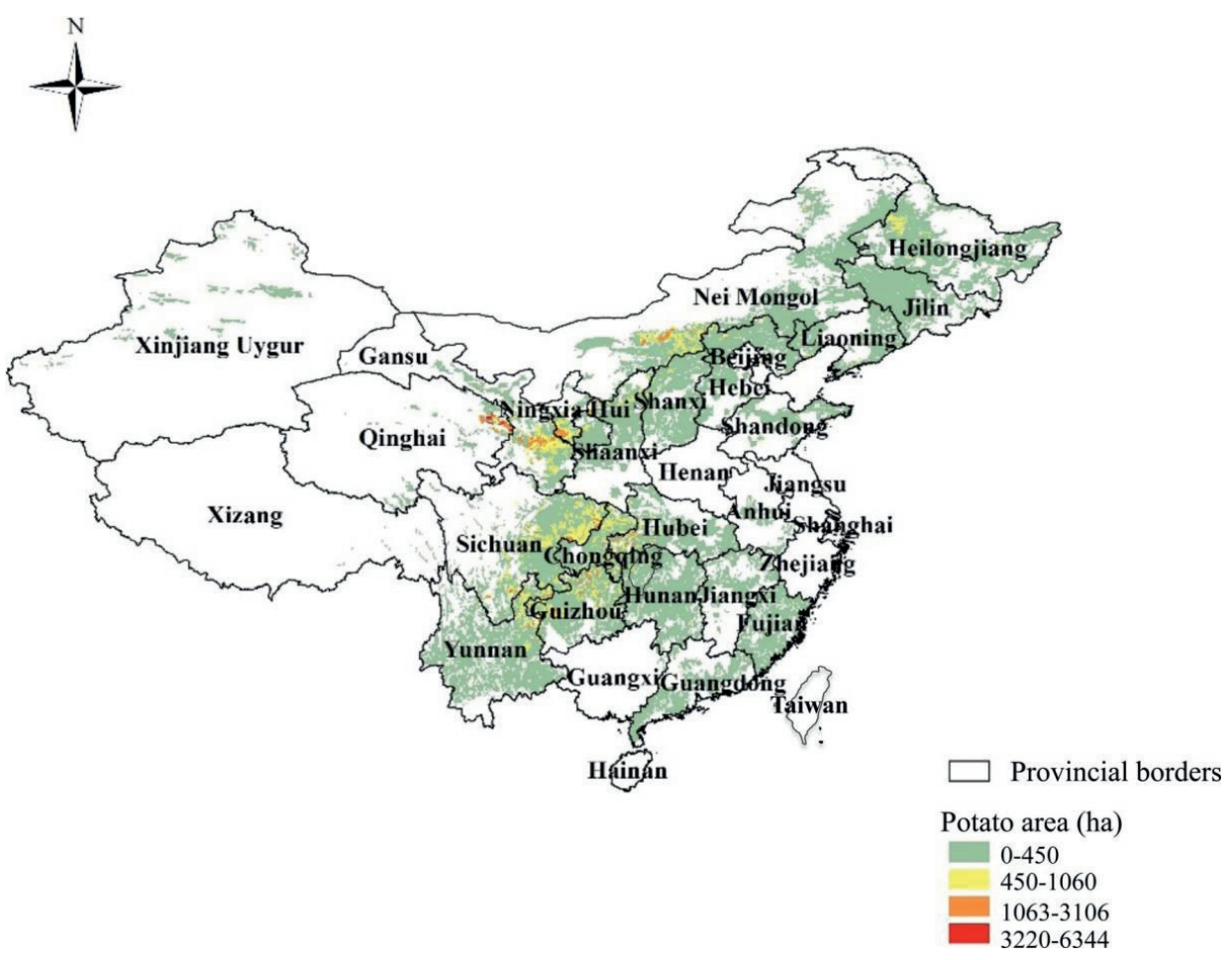

Figure 2.2. The distribution of production area (ha per grid cells at $10 \times 10 \mathrm{~km}$ resolution) for potatoes in China in 2005. Data were derived from SPAM2005 (You et al., 2014). The scale of the map is 1: 40,000,000.

\subsubsection{Model calibration and validation}

The models were calibrated using results of irrigated potato experiments in Shuangcheng, Heilongjiang, China in 2010, with potato variety Innovator (Wang, 2014). The calibration followed the procedure described by Wolf and de Wit (2003), with an amendment in calibration order following the GYGA protocol (GYGA, 2017b). The same experiment in 2011 was used to evaluate the calibrated model parameters. When the simulated value was within $+/-15 \%$ range of the observed value, the calibrated model was considered to perform acceptably (GYGA, 2017b). Detailed information of the experimental set up, and model calibration and evaluation is provided in Appendix A of this thesis "Calibration and validation of two crop models for potato in China". 


\subsubsection{Estimating potential yield $(Y p)$ and yield gaps under irrigated conditions (Yg-p)}

\section{Crop growth models}

The model WOrld FOod STudies (WOFOST) was originally developed to estimate the growth and development of annual crops under tropical conditions (Diepen et al., 1989; Van Keulen and Van Diepen, 1990). WOFOST simulates photosynthesis and water limitation. The model has been validated and widely applied to simulate crop production under field conditions worldwide (Boogaard et al., 2014; De Koning et al., 1995; Dua et al., 2014; Wolf and de Wit, 2003; Supit and Van der Goot, 2003). LINTUL POTATO DSS is a simplified version of LINTUL POTATO that allows the simulation of potato yield and quality in commercial production using the light use efficiency concept (Kooman, 1995; Kooman and Haverkort, 1995; Haverkort et al., 2015). It can simulate potential growing conditions (i.e. no water limitation). That model has been applied in European, African, and South American countries for yield gap analysis, ideotyping, climate zonation and climate change studies (Kooman, 1995; Haverkort et al., 2004; Haverkort et al., 2013b; Haverkort et al., 2014; Haverkort and Grashoff, 2004).

\section{Phenological characteristics of potatoes in different regions}

A phenological database was derived from the China Meteorological Data Service Center (CMDC, 2016). The database contained observations of 52 potato field experiments that were performed close to the national weather stations over a period of 10 years (2006-2015). When a RWS buffer zone contained no phenology observation stations, the nearby observation stations (i.e., within $200 \mathrm{~km}$ of the RWSs) were selected, and the observation station in the same province was used if no observation station near the RWS existed. For each RWS, the averages of the phenological calendar of the selected observation stations over the 10 years were used for both WOFOST (i.e., emergence and harvest date) and LINTUL POTATO DSS (i.e., planting and emergence date). While early, medium and late cultivars are grown in China with growing days varying between 60 to 120 days, it is assumed that the typical growing period for the simulated cultivars is 95 days from emergence to maturity (China Potato Website, 2017). The phenological calendar of potato production of the selected RWSs is provided in Table B1 in Appendix B.

\section{Estimating potential yield (Yp)}

The potential yield (Yp) was estimated for the selected RWSs from 2006 to 2015 for potato cultivated under irrigated conditions, so assuming no water limitation. Tuber dry matter yields (DM) were simulated and were converted to tuber fresh matter yields (FM) using a dry matter concentration of $20.8 \%$. For each RWS in each year, the Yp was estimated by the two models. The annual and average Yp estimated by the two models were compared. Finally, the average Yp of both models (2006-2015) was used as Yp of a RWS. At provincial level, the Yp of the province equals the Yp of the corresponding RWS; in case there is more than one RWS in a province, the $\mathrm{Yp}$ of a province was estimated by the weighted average of the RWSs (i.e., 
according to the potato area of the corresponding DCZs in the province). At national level, the Yp of the selected RWSs was first scaled up to the corresponding DCZs. If the DCZ includes only one RWS, the Yp of that DCZ equals the Yp of the corresponding RWS. If the DCZs cover more than one RWSs, the Yp of that DCZ was estimated by weighing the production area covered by the RWSs in that DCZ. Finally, the Yp at national level was obtained by weighing the production area covered by each DCZ.

\section{Estimating yield gaps for potato production under irrigated conditions (Yg-p)}

The yield gap under irrigated conditions (Yg-p) was defined as the difference between the potential yield (Yp) and actual yield (Ya). The Ya of potato were derived from the National Bureau of Statistics of China (NBSC, 2016) for representative farmers (i.e., for potato production in China, the number of smallholder farmers is much larger than that of large-scale farmers, and therefore, Ya may be biased towards yields of smallholders). Ya was available at provincial level for each year from 2006 to 2015 and Ya of the location of each RWS refers to the yield of the province where the RWS is located in. Yg-p was estimated for each RWS, and was then scaled up to provincial level and finally to national level following the same procedure as for Yp (Section 2.2.3, Estimating potential yield). The relative yield gap (Yg-p, \%) was estimated as a percentage of Yp.

\subsubsection{Estimating water limited yield $(\mathrm{Yw})$, and yield gaps under rainfed conditions} (Yg-w)

\section{Water limited yield $(Y w)$ and related yield gap $(Y g-w)$}

Water limited yield (Yw) was estimated only by WOFOST for potatoes cultivated under rainfed conditions. The water limited yield gap ( $Y g-w)$ was defined as the difference between $Y w$ and Ya. The Yw and Ygw were estimated with data for the RWSs for potato production under rainfed conditions, and scaled up to regional and national level (Section 2.2.3, Estimating potential yield). It was assumed that the maximum rooting depth is $50 \mathrm{~cm}$ (Kempenaar et al., 2015), and the initial available soil water (i.e., at the first day of the simulated calendar year) was the soil moisture content for the maximum rooting depth at field capacity. Daily evapotranspiration under water limited conditions (ET-w) was estimated based on the Penman equation (Penman, 1956). Soil water characteristics (i.e., wilting point and field capacity) of the three dominant soil in the potato growing zones of the selected RWSs were derived from "The China dataset of soil hydraulic parameters using different Pedotransfer Functions" (Dai et al., 2013).

\section{Water availability and water productivity (WP)}

Water availability and water productivity (WP) were estimated for the location of selected RWSs. Cumulative rainfall $(\mathrm{mm})$ during the potato growing season is the rainfall between emergence and maturity. The cumulative rainfall $(\mathrm{mm})$ was derived from weather data for each RWS, and then scaled up to provincial level (Section 2.2.3, Estimating potential yield). Water productivity for potential yield (WP-p) is calculated as the ratio between the potential DM yield 
( $\mathrm{kg} \mathrm{DM} \mathrm{ha}^{-1}$, tuber DM was estimated by WOFOST) and the potential evapotranspiration (ET$\mathrm{p}, \mathrm{mm}$, from emergence to maturity, estimated by WOFOST) and expressed as $\mathrm{kg}_{\mathrm{DM}} \mathrm{ha}^{-1}$ $\mathrm{mm}^{-1}$ (Grassini et al., 2011). Water productivity for actual yield (WP-a) under rainfed conditions is calculated as the ratio between the actual DM yield $\left(\mathrm{kg} \mathrm{DM} \mathrm{ha}^{-1}\right.$, tuber DM was converted from FM using the dry matter concentration of $20.8 \%)$ and the ET-w ( $\mathrm{mm}$, from emergence to maturity, estimated by WOFOST), assuming that the evapotranspiration of actual yield (ET-a) equals that of water limited yield under rainfed conditions (ET-w).

\section{Water input gaps and irrigation requirements}

Water input gaps $(\mathrm{mm})$ were calculated as the additional water required to increase yields from the water limited to potential yield levels divided by the irrigation efficiencies. It was calculated as the difference between the ET-p and ET-w ( $\mathrm{mm}$, both were estimated by WOFOST). The irrigation requirement $(\mathrm{mm})$ for obtaining potential production is then assumed to be two times the water requirement $(\mathrm{mm})$ assuming an irrigation efficiency of $50 \%$ for loamy soil with sprinkler irrigation (Brouwer et al., 1989).

\subsubsection{Energy gaps under both irrigated and rainfed conditions}

The energy gaps (kcal) were defined as the additional calories (kcal) that a potato crop could provide by closing the exploitable yield gap (i.e., difference between $80 \%$ of $Y p$ or $Y w$ and $Y a$ ) for the current potato production area. The potato energy gap was compared with energy gaps of other staple crops in China (i.e., rice, wheat and maize). The energy provided by $100 \mathrm{~g}$ crop edible organs is $87 \mathrm{kcal}$ for potatoes (i.e., flesh after skin peeling and boiling), $130 \mathrm{kcal}$ for rice (i.e., non-enriched regular long-grain white rice, after cooking without salt), $364 \mathrm{kcal}$ for wheat (i.e., bleached white wheat flour for all-purpose), and $365 \mathrm{kcal}$ for maize (i.e., white and yellow grain) (USDA, 2017). The energy gaps were identified for the four crops cultivated under both irrigated and rainfed conditions at national level. The yield gap for rice and maize was estimated for irrigated rice and rainfed and irrigated maize at national level in China using data from the Global Yield Gap Atlas (2004-2014; GYGA, 2017a). The yield gap for irrigated wheat in China was based on Liu et al. (2011) who compared differences in wheat yield under best management conditions and farmers' practice.

\subsection{Results}

\subsubsection{Important climate zones for potato cultivation}

At national level, 11 climate zones were selected as Designated Climate Zones (DCZs), and 15 stations were selected as Reference Weather Stations (RWSs) (i.e., some DCZs include more than one RWSs) (Table B2 in Appendix B). Seven DCZs and the associated ten RWSs are located in northern China, and four DCZs and the associated five RWSs are in southwestern China. The 11 DCZs cover 2.4 million ha of potato area, representing $53 \%$ of the total potato area in the country. The 15 RWSs cover 0.98 million ha of potato area, representing $21 \%$ of the national potato area. 


\subsubsection{Calibration and validation of the two crop growth models for potatoes in China}

For WOFOST, the most important adapted parameter is a new table for the daily increase in temperature sum as a function of average daily temperature (DTSMTB), affecting the rate of tuber initiation and maturation. An optimum temperature range was defined as $19-25^{\circ} \mathrm{C}$, while originally the degree days continued to increase from 2 to $30^{\circ} \mathrm{C}$. In addition, the maximum leaf $\mathrm{CO}_{2}$ assimilation rate as a function of development stage (AMAXTB) was increased from 30 to $35 \mathrm{~kg} \mathrm{ha}^{-1} \mathrm{hr}^{-1}$ at early stages (between DVS 0 and 1.1), and from 0 to $20 \mathrm{~kg} \mathrm{ha}^{-1} \mathrm{hr}^{-1}$ at harvest (between DVS 1.1 and 2), as the tubers were harvested while the haulm was still partially green. For LINTUL POTATO DSS, the maximum average daily temperature for photosynthesis was increased from 28 to $33^{\circ} \mathrm{C}$. The sprout growth rate is sitespecific (Haverkort et al., 2015) and was calibrated for the experimental region. The adapted model parameters, their description, default values, and plausible ranges are given in Appendix A. With the calibrated parameters, the crop phenology was simulated well (see Appendix A for details).

\subsubsection{Potential yields (Yp) and yield gaps (Yg-p)}

Potential yield (Yp) estimated by the two models

The Yp estimated by the two models for the selected RWSs from 2006 to 2015 are shown in Fig. 2.3 (see also details in Fig. B1 and Table B3 in Appendix B). Differences between the two models were on average 5.5 ton $\mathrm{FM} \mathrm{ha}^{-1}$ (ranging from 0.1 to 10.9 ton $\mathrm{FM} \mathrm{ha}^{-1}$ ), which equals $11 \%$ of average $\mathrm{Yp}$.

In general, $\mathrm{Yp}$ is larger in the north (i.e., Heilongjiang, Inner Mongolia, Gansu, Qinghai) compared to the southwest (i.e., Sichuan, Chongqing, Hubei, Guizhou). To explain these differences, Fig. B2 in Appendix B presents the average daily temperature, radiation, crop dry matter increase and LAI development in the potato growing season in Sichuan Wanyuan (i.e., $\mathrm{Yp}=39.6$ ton $\mathrm{FM} \mathrm{ha}{ }^{-1}$ ) and Qinghai Xining (i.e., $\mathrm{Yp}=65.4$ ton $\mathrm{FM} \mathrm{ha}^{-1}$ ) in 2006. The average daily temperature in Sichuan was generally beyond the optimum range of $19-25^{\circ} \mathrm{C}$ for potato, while it was within the optimum range in Qinghai (Fig. B2a). The high temperature, especially later in the growing season in Sichuan resulted in early senescence of leaves and reduction of canopy cover (Fig. B2d). In addition, the daily radiation in Qinghai is higher than in Sichuan for most of the potato growing season (Fig. B2b), which together with the optimum temperature, resulted in larger daily DM increase (Fig. B2C) and a larger and longer period of canopy cover (Fig. B2d). 


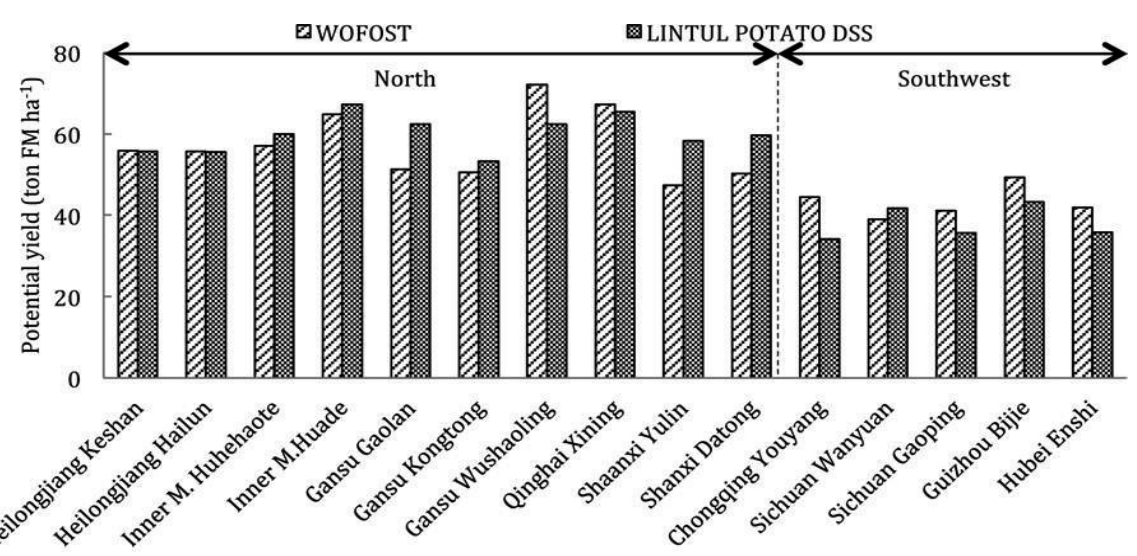

Figure 2.3. Average (2006-2015) potential yield (Yp) of potato estimated by WOFOST and LINTUL POTATO DSS for the important production regions in northern and southwestern China.

Potential yield (Yp) and yield gaps (Yg-p) at provincial and national level

The Yp varies largely between different regions and between years within regions (Fig. 2.4a, Table 2.1). The differences between the maximum and minimum $Y p$ in a period of ten years varied from 5.3 ton $\mathrm{FM} \mathrm{ha}^{-1}$ (i.e., Inner Mongolia) to 14 ton $\mathrm{FM} \mathrm{ha}^{-1}$ (i.e., Shaanxi). The largest average $\mathrm{Yp}$ was obtained for Qinghai in the north (66.4 ton $\left.\mathrm{FM} \mathrm{ha}^{-1}\right)$, while the lowest average Yp was simulated for Sichuan in the southwest (38.8 ton $\left.\mathrm{FM} \mathrm{ha}^{-1}\right)$. The average Ya was largest in Sichuan (21.2 ton FM ha-1), and lowest in Shanxi (8.2 ton FM ha-1). In general, the average $\mathrm{Yg}-\mathrm{p}$ is larger in the north (i.e., from 34.7 ton $\mathrm{FM} \mathrm{ha}^{-1}$ in Heilongjiang to 48.9 ton $\mathrm{FM} \mathrm{ha}^{-1}$ in Inner Mongolia) compared to the southwest (i.e., from 17.6 ton $\mathrm{FM} \mathrm{ha}^{-1}$ in Sichuan to 33.9 ton $\mathrm{FM} \mathrm{ha}^{-1}$ in Guizhou), indicating a larger scope for enhancing the yield in northern China (Fig. 2.4c, Table 2.1). The potential for relative yield increase is largest in Shanxi (85\%) and lowest in Sichuan (45\%). 
(a) + i

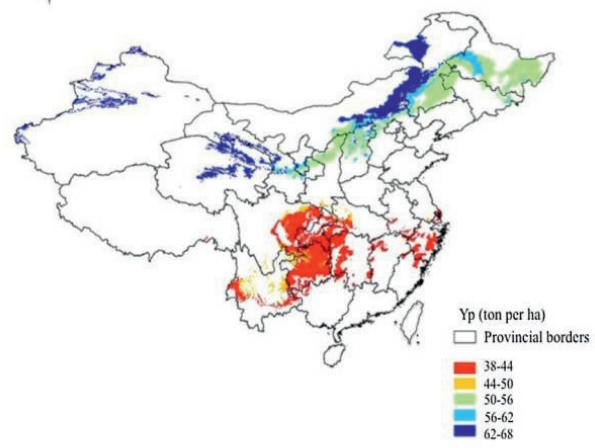

(b)<smiles>C1CC2(C1)CC2</smiles>

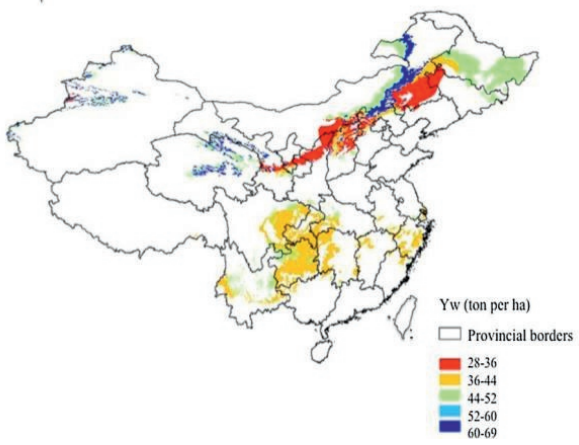

(c)

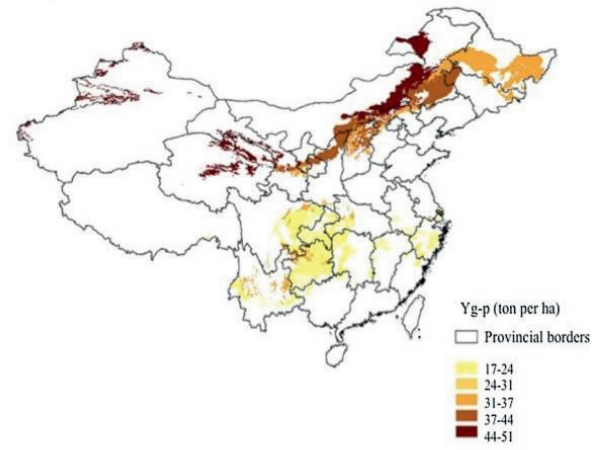

(d)

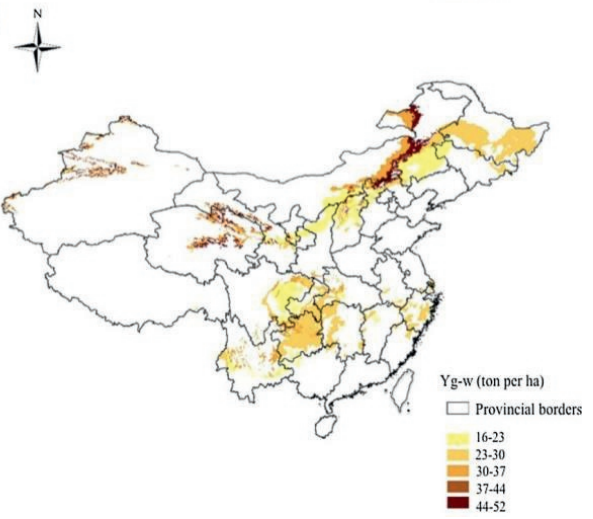

Figure 2.4. The average (2006-2015) potential yield ( $Y p)(a)$, water limited yield $(Y w)(b)$, yield gap under irrigated conditions ( $\mathrm{Yg}-\mathrm{p})(\mathrm{c})$, and yield gap under rainfed conditions $(\mathrm{Yg}-\mathrm{w})(\mathrm{d})$ of potato in the important potato producing regions in China. Yp and Yg-p were estimated by WOFOST and LINTUL POTATO DSS, while Yw and Yg-w were estimated by WOFOST. The scale of the map is 1: 40,000,000.

At national level, Yp, Ya and Yg-p did not show large variation across the past ten years (Fig. 2.5). Yp was on average 50.1 ton $F M h^{-1}$ from 2006 to 2015 , and varied from 47.2 ton FM $\mathrm{ha}^{-1}$ in 2014 to 53.2 ton $\mathrm{FM} \mathrm{ha}^{-1}$ in 2008 . Ya of the country was 16.9 ton $\mathrm{FM} \mathrm{ha}^{-1}$ on average, with a maximum value of 17.6 ton $\mathrm{FM} \mathrm{ha}^{-1}$ in 2006 and minimum of 15.4 ton $\mathrm{FM} \mathrm{ha}^{-1}$ in 2009. Ya obtained through weighing the potato production area in the DCZs (16.9 ton FM ha ${ }^{-1}$ ) is slightly larger than that reported by NBSC (16.2 ton $\mathrm{FM} \mathrm{ha}^{-1}$ ), indicating a slightly lower Ya in the parts of the country not included in this study. The average Yg-p was 33.2 ton FM ha-1, and $\mathrm{Yg}-\mathrm{p}$ as a percentage of $\mathrm{Yp}$ was on average $66 \%$, which indicates the large scope of increasing potato yields across the country. 


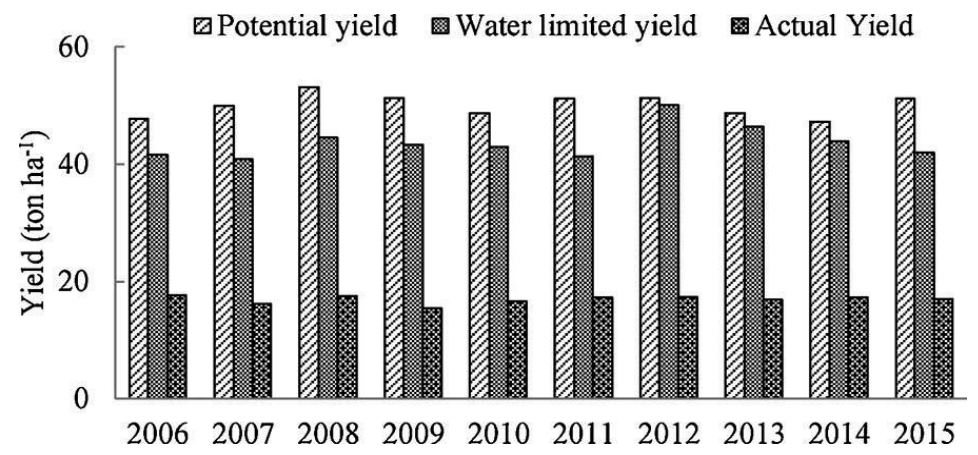

Figure 2.5. Potential $(Y p)$, water limited $(Y w)$, and actual fresh matter yield $(Y a)$ of potato in China (2006-2015).

Yp was estimated by WOFOST and LINTUL POTATO DSS, while Yw was estimated by WOFOST only. 


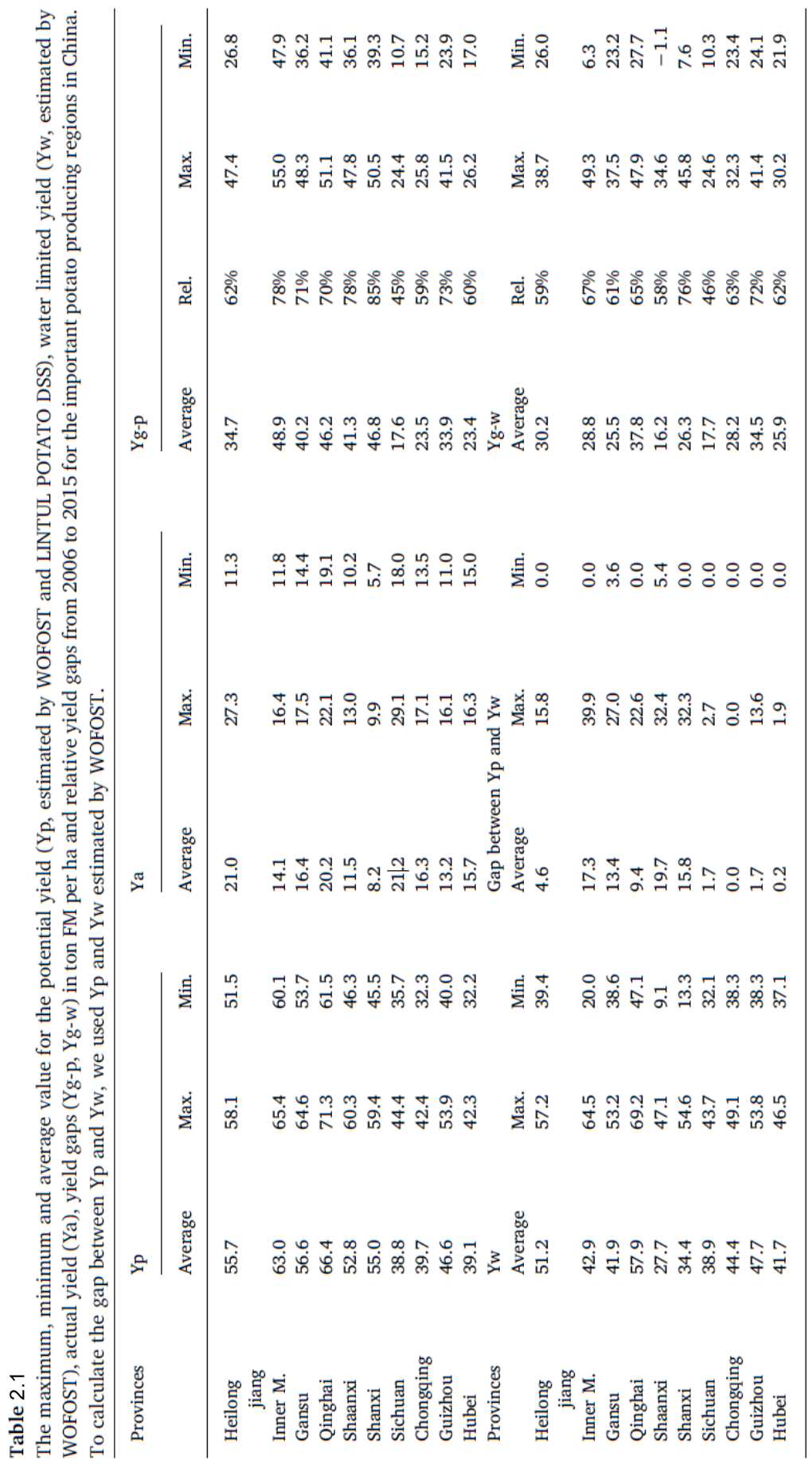




\subsubsection{Water limited yield $(\mathrm{Yw})$ and yield gaps $(\mathrm{Yg}-\mathrm{w})$ for potato production under rainfed conditions}

Water limited yield $(Y w)$ and yield gaps $(Y g-w)$ at provincial and national level

In the southwest (i.e., Sichuan, Chongqing, Guizhou, Hubei), Yw is close to Yp (average difference is between 0 and 1.7 ton $\mathrm{FM} \mathrm{ha}^{-1}$, Table 2.1), indicating sufficient rainfall to meet the demand of the potato crop for potential growth. In the north, Yw varied from 27.7 ton FM $\mathrm{ha}^{-1}$ in Shaanxi to 57.9 ton FM ha-1 in Qinghai. The difference between Yp and Yw is smallest in Heilongjiang (4.6 ton FM ha-1) and Qinghai (9.4 ton FM ha-1) (see also Fig. B3 in Appendix B). The difference between $\mathrm{Yw}$ and $\mathrm{Ya}(\mathrm{Yg}-\mathrm{w})$ is high in Heilongjiang, Qinghai and Inner Mongolia (i.e., 30.2, 37.8 and 28.8 ton $\mathrm{FM} \mathrm{ha}^{-1}$ respectively) compared to the other regions, indicating that high yields can be obtained with current rainfall (Table 2.1). The difference between the Yp and $\mathrm{Yw}$ is largest in Shaanxi (i.e., 19.7 ton $\mathrm{FM} \mathrm{ha}^{-1}$ ) while $\mathrm{Yg}$-w (i.e., 16.2 ton $\mathrm{FM} \mathrm{ha}^{-1}$ ) is the lowest in that region, indicating that extra water can substantially enhance yield. At national level, $\mathrm{Yw}$ is on average 43.7 ton $\mathrm{FM} \mathrm{ha}^{-1}$, and varies between 40.9 ton $\mathrm{FM} \mathrm{ha}^{-1}$ (2007) and 50.4 ton $\mathrm{FM} \mathrm{ha}^{-1}$ (2012) (Fig. 2.4b, Fig. 2.5). The Yg-w at national level is 26.9 ton $\mathrm{FM} \mathrm{ha}^{-1}$, which is $61 \%$ of $\mathrm{Yw}$ (Fig. $2.4 \mathrm{~d}$ ).

Water productivity for potential (WP-p) and actual yield (WP-a)

In general, potential water productivity (WP-p) is larger in the north (i.e., Heilongjiang, Inner Mongolia, Gansu, Qinghai, Shaanxi and Shanxi) compared to the southwest (i.e., Sichuan, Chongqing, Guizhou and Hubei) (Fig. 2.6). WP-p ranged between $30.7 \mathrm{~kg} \mathrm{DM} \mathrm{ha}^{-1} \mathrm{~mm}^{-1}$ in Shaanxi to $54 \mathrm{~kg} \mathrm{DM} \mathrm{ha}^{-1} \mathrm{~mm}^{-1}$ in Qinghai. The actual water productivity (WP-a) is much lower than WP-p (i.e., WP-a as a percentage of WP-p was on average $37 \%$ ). WP-a is higher in the southwest compared to that in the north, with the lowest value of $7.9 \mathrm{~kg} \mathrm{DM} \mathrm{ha}^{-1} \mathrm{~mm}^{-1}$ in Shanxi and largest of $22.3 \mathrm{~kg} \mathrm{DM} \mathrm{ha}^{-1} \mathrm{~mm}^{-1}$ in Sichuan. 


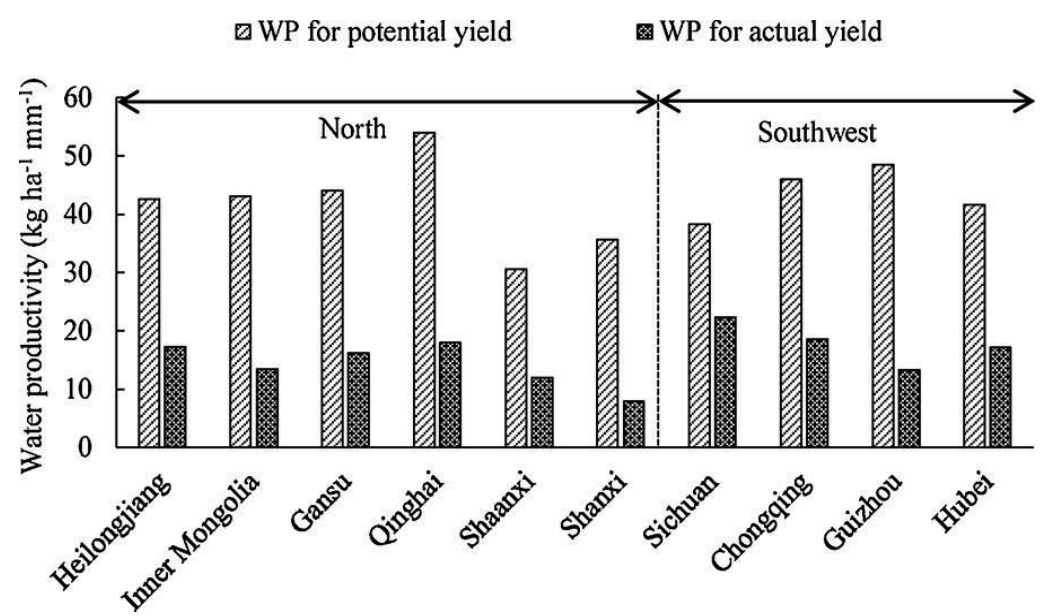

Figure 2.6. Average (2006-2015) water productivity of potato for potential (WP-p) and actual dry matter yield (WP-a) for provinces in China.

Water availability and water input gaps

In general, average rainfall during the potato growing season in southwestern China (337-495 $\mathrm{mm}$ ) is larger than that in the north $(201-360 \mathrm{~mm})$ (Fig. 2.7). The potential ET during the potato growing season is largest in Shaanxi $(322 \mathrm{~mm})$ in the north and lowest in Chongqing $(201 \mathrm{~mm})$ in the southwest (Fig. 2.7). As already indicated in Section 2.3.4 (Water limited yield and yield gaps at provincial and national level), irrigation is not necessary in southwestern China (i.e., Sichuan, Chongqing, Guizhou, Hubei). Irrigation requirements in the north vary largely across regions, with low requirements in Heilongjiang $(39 \mathrm{~mm})$ and Qinghai $(51 \mathrm{~mm})$ and large requirements in Shanxi $(157 \mathrm{~mm})$ and Shaanxi $(243 \mathrm{~mm})$.

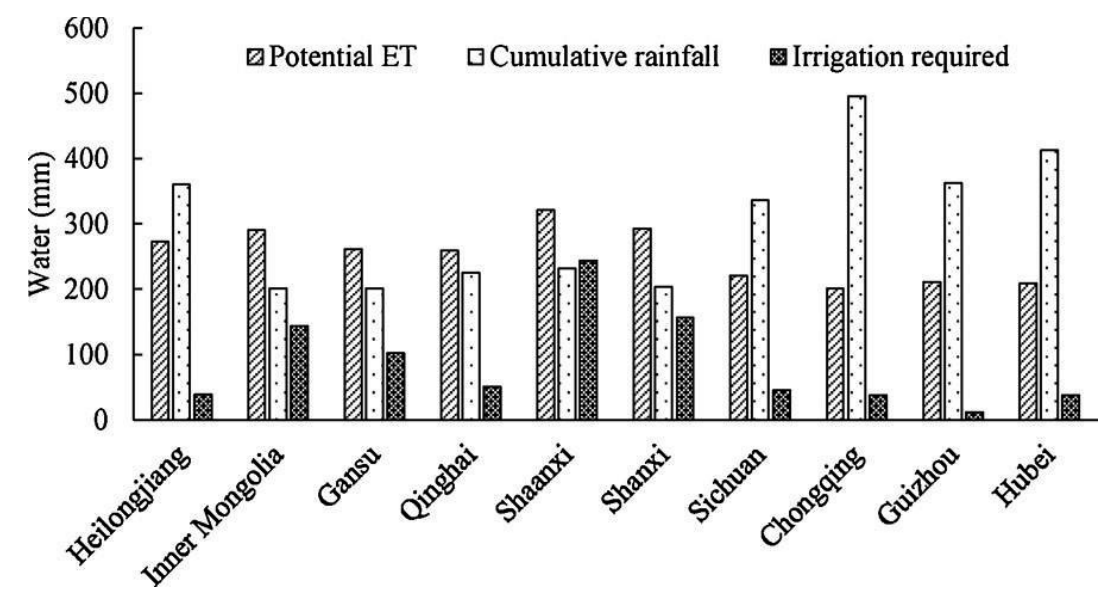

Figure 2.7. Potential evapotranspiration (ET-p), cumulative rainfall during the growing season, and irrigation requirement for potential yield production (FM) estimated for the important potato producing regions in China. 


\subsubsection{Energy gaps of potato under irrigated and rainfed conditions}

At national level, the differences between $80 \%$ of $Y p$ and $Y a$ and $80 \%$ of $Y w$ and $Y a$ over the past 10 years were 23.1 and 18.7 ton $\mathrm{FM} \mathrm{ha}^{-1}$, respectively (Table 2.2). Yg-p (non-water limited conditions) was 0.7 and 3.1 ton $\mathrm{FM} \mathrm{ha}^{-1}$, respectively, for rice and maize (GYGA, 2017a). For wheat, available data have no national coverage and only apply to irrigated condition (Liu et al., 2001). This source points at full yield gap closure. Yg-w (rainfed conditions) was 1.4 ton FM ha ${ }^{-1}$ for maize (GYGA, 2017a). If the $80 \%$ of Yp was to be attained in the future, potato could provide an additional $1.110^{14} \mathrm{kcal}$ energy given the current production area. Assuming $80 \% \mathrm{Yw}$ as the benchmark allows an additional $0.910^{14} \mathrm{kcal}$ energy. By closing the exploitable Yg-p (80\% Yp), rice cultivated under irrigated conditions provides much less extra energy than potato (i.e., $0.210^{14} \mathrm{kcal}$ ). For maize, the scope of providing additional energy is similar as than for potato under irrigated conditions (i.e., $1.010^{14} \mathrm{kcal}$ ) but less than potato under rainfed conditions (i.e., $0.510^{14} \mathrm{kcal}$ ).

Table 2.2 Difference between $80 \%$ of $Y p$ (or $80 \%$ of $Y w$ ) and $Y a$, and the corresponding energy gaps of the four most important staple crops in China.

\begin{tabular}{lllllll}
\hline Crop & $\begin{array}{l}\text { Yg-p (ton FM } \\
\left.\mathrm{ha}^{-1}, 80 \% \mathrm{Yp}\right)\end{array}$ & $\begin{array}{l}\text { Yg-w (ton FM } \\
\left.\mathrm{ha}^{-1}, 80 \% \mathrm{Yw}\right)\end{array}$ & $\begin{array}{l}\text { Energy } \\
(\mathrm{kcal} / 100 \mathrm{~g} \\
\mathrm{FM})\end{array}$ & $\begin{array}{l}\text { Area in } \\
2015 \\
\text { (million ha) }\end{array}$ & $\begin{array}{l}\text { Energy gap } \\
\text { for Yp } \\
\left(10^{14} \mathrm{kcal}\right)\end{array}$ & $\begin{array}{l}\text { Energy } \\
\text { gap for Yw } \\
\left(10^{14} \mathrm{kcal}\right)\end{array}$ \\
\hline Potato & 23.1 & 18.7 & 87 & 5.5 & 1.1 & 0.9 \\
Rice & 0.7 & - & 130 & 28.9 & 0.2 & - \\
Wheat & -0.6 & - & 364 & 24.1 & -0.1 & - \\
Maize & 3.1 & 1.4 & 365 & 38.1 & 1.0 & 0.5 \\
\hline
\end{tabular}

Note: Here we assume a moisture content of $79.2 \%$ for potato, $14 \%$ for rice, $13.5 \%$ for wheat and $15.5 \%$ for maize (GYGA, 2017a). Rice is mainly cultivated under irrigated conditions or conditions with no water limitation, thus only Ygp was considered when estimating energy gap. For wheat, only data for irrigated conditions are available and only for northern and central China.

\subsection{Discussion}

\subsubsection{Comparison of two potato models}

The simulation results demonstrate that both models can be used to estimate potential potato yields in China. Compared to WOFOST, LINTUL POTATO DSS requires less calibration and uses fewer parameters. The difference between Yp estimated as the average of the two models for a particular RWS varied across regions and years. This is largely related to the difference in handling the effect of sub-optimum temperature on daily dry matter accumulation of the crop. In WOFOST, the optimum temperature range refers to the average day temperature (i.e., $\mathrm{Td}=((\max . \mathrm{T}+\min . \mathrm{T}) / 2+\max . \mathrm{T}) / 2)$ and influences the maximum photosynthesis rate, while respiration is computed separately. In LINTUL POTATO DSS, the 
optimum temperature range is based on the daily average temperature (i.e., $\mathrm{Ta}=(\max . \mathrm{T}+\min$. $\mathrm{T}$ /2)) and it influences the net dry matter accumulation (i.e., dry matter as a result of photosynthesis minus respiration losses). In both cases, the optimal daily temperature range for dry matter accumulation is between 19 and $25{ }^{\circ} \mathrm{C}$. However, when using the same temperature input, $\mathrm{Td}$ is roughly $3{ }^{\circ} \mathrm{C}$ higher than Ta. In regions where Ta is between 19 and $25^{\circ} \mathrm{C}$, the Yp estimated by the two models is quite close (i.e., Heilongjiang, Inner Mongolia and Qinghai). When Ta is lower than $19^{\circ} \mathrm{C}$, daily $\mathrm{DM}$ accumulation is more negatively affected in LINTUL POTATO DSS than in WOFOST (i.e., this occurs most in southwestern regions). On the other hand, daily dry matter accumulation is more reduced in WOFOST than in LINTUL POTATO DSS when Ta is higher than $25^{\circ} \mathrm{C}$ (i.e., this occurs most in Gansu, Shanxi and Shaanxi).

\subsubsection{Actual yield (Ya) and critical yield constraints}

Actual potato yields ( $\mathrm{Ya}$ ) in China were on average 16 ton $\mathrm{FM} \mathrm{ha}^{-1}$ and did not change much over the last 10 years. They vary widely among different production regions (i.e., 8.2-21.2 tons $\mathrm{FM} \mathrm{ha}^{-1}$ ), and $\mathrm{Ya}$ in the north (i.e., 8.2-21 ton $\mathrm{FM} \mathrm{ha}^{-1}$ ) is generally lower than in the southwest (i.e., 13.2-21.2 ton FM ha ${ }^{-1}$ ). The larger $\mathrm{Ya}$ in the southwest is probably partly due to a higher water (rainfall) supply. While Ya of potato in China is larger than in some of the African countries (i.e., less than 7.5 ton FM ha ${ }^{-1}$ ) (Haverkort and Struik, 2015), it is below the world average (i.e., ranging from 16.7 ton $\mathrm{FM} \mathrm{ha}^{-1}$ in 2006 to 20 ton $\mathrm{FM} \mathrm{ha}^{-1}$ in 2014) (FAO, 2016a), and far below that in other dominant potato production regions such as northwest Europe (i.e., 35 ton FM ha ${ }^{-1}$ and above) (Van Evert et al., 2013; Haverkort and Struik, 2015; Monfreda et al., 2008). Ya in the Netherlands is about 65 ton FM ha-1 on rich clay soils (Haverkort and Struik, 2015). For the Colombian Basin in the United States, yields as high as 120 ton FM ha ${ }^{-1}$ have been reported (Haverkort and Struik, 2015; Kunkel and Campbell, 1987).

The low actual yields in China are attributed to various abiotic and biotic constraints of potato production in the country. Potatoes are grown continuously without rotation with other crops in northern China, and this causes severe pest and disease problems. Pests and diseases such as late blight (Phytophthora infestans) and scab (Streptomyces scabies) have increased drastically and are amongst the most severe constraints to potato productivity and quality (Jansky et al., 2009). In addition, the availability of affordable certified, high quality seed potatoes is considered a major limiting factor (Jansky et al., 2009). To minimize production costs, farmers commonly cut seed tubers and/or use farm saved seeds. Both practices accelerate the degeneration of seed quality with lower yields as a result (Jansky et al., 2009). Water availability and management practices have been identified as major production constraints in irrigated areas (Xie et al., 2012; Wang et al., 2005; Wang et al., 2009). Lastly, but importantly, potato is often regarded a minor crop, and is mainly cultivated on small-scale farms with poor management practices and low mechanization levels (MOA, 2008). 


\subsubsection{Potential $(\mathrm{Yp})$ and water limited yield $(\mathrm{Yw})$ as compared to experimental yields}

The maximum Yp simulated for northern China of 71.3 ton $\mathrm{FM} \mathrm{ha}^{-1}$ (Qinghai) is in line with the maximum yield of 75 ton $\mathrm{FM} \mathrm{ha}^{-1}$ measured in field experiments for irrigated conditions in the same region ( $\mathrm{Li}$ et al., 2014b, 2015). The maximum yield obtained from the 116 field experiments in Inner Mongolia varied between 5 and 60 ton FM ha-1 (Duan et al., 2014), which is reasonably consistent with our estimation of $\mathrm{Yp}$ for that region (60.1-65.4 ton FM ha-1). The maximum yield obtained from field experiments under irrigated conditions in Gansu (i.e., 53.764.6 ton $\mathrm{FM} \mathrm{ha}^{-1}$ ) (Wang et al., 2009) is very similar to our assessments for the Yp in the same region (54 to 65 ton $\mathrm{FM} \mathrm{ha}^{-1}$ ). For the southwest, $\mathrm{He}$ (1997) modelled Yp of potatoes at various altitudes and compared results with experimental field data; their simulated Yp ranged between 23 to 94 ton $\mathrm{FM} \mathrm{ha}^{-1}$. Our study identified a much lower Yp (38.9 to 47.7 ton $\mathrm{FM} \mathrm{ha}^{-1}$ ), which is fairly close to the experimental yields (i.e., 12 to 49 ton FM ha-1) of $\mathrm{He}$ (1997). The higher yield simulated by $\mathrm{He}(1997)$ may be due to a different temperature considered, as potato production occurs at different elevations in this region.

As for $\mathrm{Yw}$, our simulated yields for Gaolan, Gansu (15-45 ton FM ha-1) were higher than the maximum yield obtained from field experiments under rainfed conditions in the region (18-30 ton FM ha-1) (Wang et al., 2005; Tian et al., 2003). The Yw estimated in Inner Mongolia in our study (20-64.5 ton $\mathrm{FM} \mathrm{ha}^{-1}$ ) was also higher than the experimental yield obtained under rainfed conditions (9.4-10.4 ton FM ha-1) (Li et al., 2015). The lower yields obtained from experimental stations compared to those estimated by models are possibly due to suboptimal management practices applied and poor seed tuber quality used in the experiments.

The agro-ecological conditions in the northern potato production area in China are comparable to those of European countries and North America (Jansky et al., 2009), suggesting similar theoretical biophysical potentials. However, the largest estimated Yp in this study (71.3 ton FM $\mathrm{ha}^{-1}$ ) is much lower than that for other dominant potato countries such as Poland (i.e., 75-100 ton FM ha ${ }^{-1}$, Verhagen et al., 2000) and the Netherlands (i.e., 110 ton FM ha ${ }^{-1}$, Beukema and Van der Zaag (1990); 82 ton FM ha ${ }^{-1}$, Kooman (1995); 90 ton $\mathrm{FM} \mathrm{ha}^{-1}$, Haverkort and Struik (2015)). The lower Yp in northern China may be attributed to relatively high temperatures early in the growing season, which delay tuber initiation and subsequently reduce the growing period of tubers, and decrease yields (Liang et al., 1998; Wang et al., 2009; Kar and Kumar, 2007). In the southwest, potatoes are cultivated as a winter crop and planted between December and February. The low radiation level early in the winter season may contribute to low Yp (Van Evert et al., 2013). For late planting potato, the high temperatures late in the growing season (June, July) accelerate the senescence of the canopy, which reduces the total growing period and the yields. 


\subsubsection{Scope of increasing food self-sufficiency and enhancing water productivity}

The Chinese population is projected to reach 1.5 billion by 2033 , and it will be challenging to maintain food self-sufficiency of cereal grains at the current level of $95 \%$ (i.e., the ratio between demand and actual domestic production) (Ghose, 2015). There has been a decrease in the production area of the three major cereal crops in China, and further increases in crop productivity will be limited as their yields are already very high compared to the global average, and yield gaps are relatively small (Lu and Fan, 2013; Meng et al., 2013; Van Ittersum et al., 2013; Van Wart et al., 2013; Zhang et al., 2014). By contrast, the cultivated area and total production of potato have been increasing over the past years. According to our analysis of the potato yield gap at regional and national level, we identified a large scope for increasing potato yield and production across the country under both irrigated and rainfed conditions. In many regions, yield can be doubled by improving management practices. The national energy gap of potatoes on present area (1.1 and $0.910^{14}$ million kcal for irrigated and rainfed conditions, respectively) is much larger than that of rice $\left(0.210^{14}\right.$ million kcal for $80 \%$ of $\left.Y p\right)$ and maize (1 and $0.510^{14}$ million kcal for $80 \%$ of $Y p$ or $Y w$ respectively) (Table 2.2). The calculation of the energy gaps was done for the current crop production area (i.e., 5.5 million ha for potatoes, and 28.9, 24.1 and 38.1 million ha for rice, wheat and maize, respectively). The production area for potato is much less than the area allocated to the other three staple crops. However, the scope to increase the potato production area is large, and if combined with yield gap closure, this would even further contribute to food self-sufficiency.

The expansion of the potato production area over the past 10 years mainly took place in southwestern China. In this region, the difference between $Y p$ and $Y w$ is small, while $Y g-w$ is relatively large, implying a large scope for increasing potato production with natural water supply. In the southwest, potatoes are grown as a winter crop between two rice crops or intercropped with spring maize; reducing pest and disease infection is critical to enhance yield (Jansky et al., 2009).

In northern China, additional water input may be used to increase production due to large difference between $Y p$ and $Y w$. Due to the lack of accurate data on the area and location of potato under rainfed and irrigated conditions, we used both $Y p$ and $Y w$ to benchmark yield potential of potato in the north. Both Yg-p and Yg-w are substantial in northern regions such as Heilongjiang, Inner Mongolia, Gansu and Qinghai. With current rainfall, the scope of yield increase is larger in these regions than in Shaanxi and Shanxi (also in the north). Higher yields can be achieved and water use efficiency can be improved through conservation of soil moisture and water saving practices (e.g., straw mulching, rainfall harvesting) and introduction and use of drought resistant varieties (Cheng and Zhang, 2000; Kar and Kumar, 2007; Tian et al., 2003; Wang et al., 2009; Zhao et al., 2012). There has been a decline in water resources for agricultural production in the country due to groundwater depletion (Liu et al., 2001). Thus, irrigation must be targeted on regions where water productivity (WP-p) is high and water supply is sustainably available. 


\subsection{Conclusion}

This study aimed to investigate the scope for increasing potato production in China, and to assess its contribution to domestic food self-sufficiency. The potential yield (Yp) and water limited yield (Yw) and yield gaps (Yg-p and Yg-w) of potato in China were estimated. We have shown that there are large gaps in potato yields under both irrigated (Yg-p) and rainfed conditions (Yg-w). The potential contribution of potato to domestic food self-sufficiency in terms of providing additional energy by narrowing the yield gap is much larger than the potential contribution of the three main cereals rice, wheat or maize. Improving potato production is thus of high importance to safeguard the country's domestic food supply.

\subsection{Acknowledgements}

This work was supported by the China Scholarship Council (CSC) [grant number 201506610003]. We would like to thank Prof. Anton Haverkort, for sharing the LINTUL POTATO DSS model. We thank Joost Wolf for his contribution to model calibration and validation, and Joop Kroes and Iwan Supit, Wageningen University \& Research (the Netherlands) for their contribution to interpreting model results.

\subsection{Appendix A and B. Supplementary Material}

Supplementary material related to this article can be found, in the online version, at doi: https://doi.org/10.1016/j.eja.2018.07.002. The calibration and validation of the crop growth models (WOFOST and LINTUL DSS) are provided in Appendix A of this thesis. Detailed results regarding the modeling results for the study regions in China are available in Appendix $B$. 



\section{Chapter 3}

\section{Synergy or trade-off? A framework and application to benchmark yield, quality and revenue of potato production}

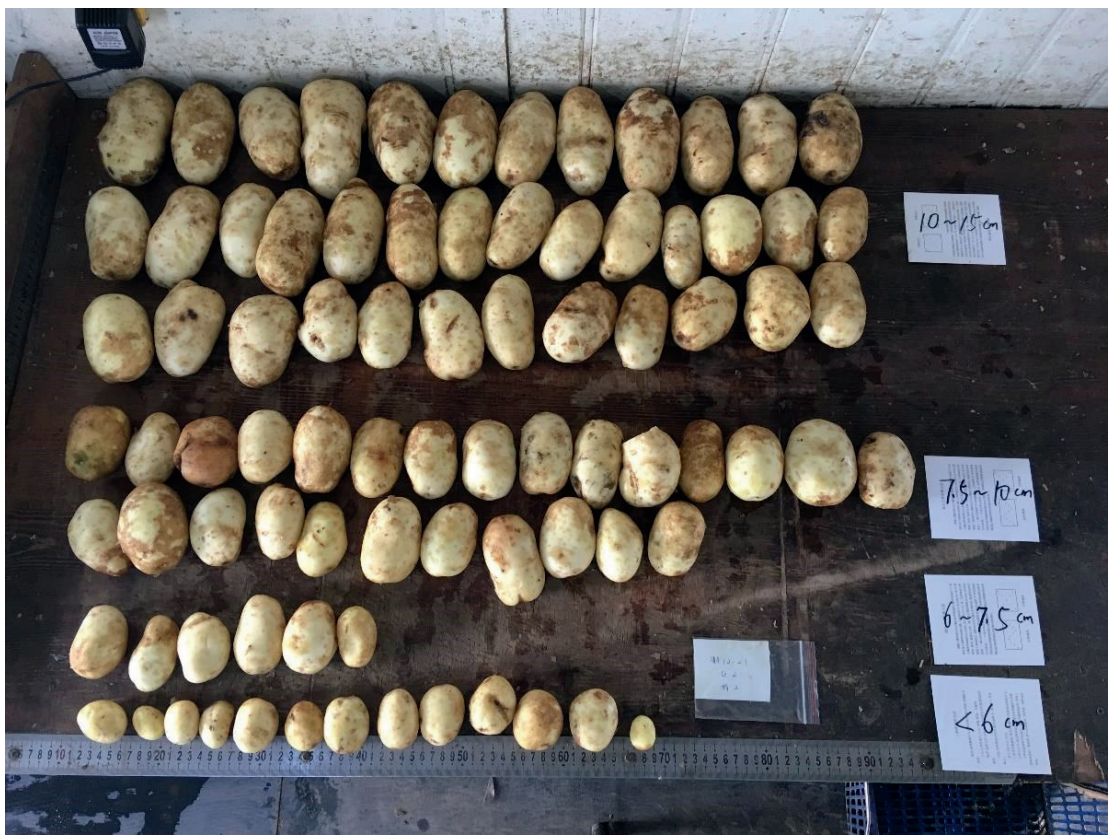

This chapter is published as:

Wang N., Reidsma P., Wang Z.Q., Van Ittersum M.K., 2019. Synergy or trade-off? A framework and application to benchmark yield, quality and revenue of potato production. Field Crops Research, Volume 240, Pages 116124.

ISSN 0378-4290, https://doi.org/10.1016/j.fcr.2019.05.020. 


\section{Abstract}

The concept of yield gap is well-known to benchmark yields of crops. However, quality is another major aspect that influences farm revenues and drives management. Increasing yield may not be economically viable if this is at the expense of degrading quality such that revenue is negatively influenced. This study aimed to answer the question whether yield and quality could be maximized at the same time. A framework was developed to assess crop performance based on yield, quality, and revenue. The framework includes seven steps from identifying the important quality traits to quantifying quality gaps and yield gaps and their influence on revenue. The framework enriches the yield gap notion by adding quality aspects. The concept of optimum quality (Qp) was introduced as the quality value (range) of a particular quality trait that is most desired for a specific market. The framework was applied to a case study concerning potato production for a French Fries factory in China. Three quality traits of potato were assessed (i.e., dry matter percentage, tuber size classes, and number of tubers in $10 \mathrm{~kg}$ ). No tradeoff between yield and quality was found for the tested quality traits. The results indicated that there was large scope to improve quality for some of the quality traits. The relative revenue gap (Eg-f) was large (43\%), and was attributed to both the relative yield gap (Yg-f, 26\%), and quality aspects (i.e., low dry matter percentage and high small tuber weight percentage). Enhancing yield towards its current maximum level (55 ton fresh matter $\mathrm{ha}^{-1}$ ) was associated with improvement in quality and revenue.

Keywords: Potato, yield, yield gap analysis, quality, revenue, trade-off 


\subsection{Introduction}

Potato (Solanum tuberosum) is the most important non-cereal crop in the world in terms of production volume (USDA, 2016). China is the largest potato producing country, both in terms of production area and quantity (FAO, 2019). In China, potato has been argued to be critical for maintaining domestic food security as a supplement to rice, wheat and maize (MOA, 2015a). The scope to further increase potato yield is large, which was reflected by the large yield gap, i.e., the difference between potential yield of a cultivar grown under optimum management to avoid abiotic and biotic stresses, and the average actual farm yield (Chapter 2; Van Ittersum and Rabbinge, 1997; Van Ittersum et al., 2013). With the increasing domestic market for table potatoes and processed potato products, growing attention has been given to quality aspects of potatoes (MOA, 2017). Both yield and quality are important for revenue. Enriching the yield gap notion with quality aspects would allow an easier linkage of yield gaps to economic considerations.

The quality aspects of potatoes mainly concern four broad criteria, i.e. appearance, cooking performance, processing performance and nutrition (Storey and Davies, 1992). The acceptability of potato for table consumption is mainly associated with its morphological characteristics (i.e., small, medium or large tuber size, smooth skin and shallow eyes), and with absence of surficial and internal defects (Storey and Davies, 1992). The cooking qualities are related to the texture and color of cooked potato, which determine the suitability of potato for various culinary methods (i.e., boiling, stewing, steaming, stir-frying, roasting) (Storey and Davies, 1992). The processing quality describes the suitability of potato for various processing purposes (Lisinska et al., 2009). The dry matter content, reducing sugar content, tuber shape and size are crucial quality traits for the processing industry. The nutritional quality relates to the content of proteins, vitamins, carbohydrates and mineral nutrients (Lisinska et al., 2009).

The quality aspects of a crop product can influence the selling price (Ahmed and Stepp, 2016). For a particular crop, the important quality traits, the desired values, and the influence on revenue (i.e., the gross income growers receive by selling the products, without accounting for the cost) are typically determined by the production purpose, preference of local consumers and requirements of processing factories. For table potatoes, for instance, the farm gate price and market price are greatly affected by the appearance, while the morphological features are less important for potatoes intended for starch production. For starch processing, very high dry matter content is preferred, while for French Fries processing too high dry matter content reduces the flavour of products (Van Loon, 2005).

Theoretically, it would be ideal to have both yield and quality at optimum levels to obtain the maximum revenue. However, this can only be achieved if the maximum yield and desirable quality can be obtained simultaneously. If trade-offs exist between yield and quality, the same revenue may be obtained with either high yields and lower quality or with lower yields and high quality. It has been argued that the breeding effort as well as agronomic practice that favour particular quality traits are associated with lower yield or less yield increase (Mackay et al., 
2011; Rijk et al., 2013). Understanding relationships between yield, quality and revenue is critical for both farmers and processing industries. Therefore, the objectives of this study were to develop a generic framework, enriching the yield gap notion with quality traits, that allows the assessment of crop production performance based on yield, quality and revenue, and to apply the framework to a case study of potato production in northern China.

\subsection{Material and methods}

In the next sections, the concepts of potential yield (Yp), and those concerning quality aspects that are relevant to the revenue (i.e., optimum quality ( $Q p)$, acceptability, base price, price penalty, and bonus price) are introduced. The framework consists of seven steps from identifying important quality traits to quantifying the quality gaps and yield gaps and their influence on revenue. Finally, crop performance is assessed based on yield, quality, and revenue. The framework was applied to a case study of potato production for a French Fries factory in northern China, where three quality traits of potato were considered (i.e., tuber dry matter percentage, tuber size classes, and number of tubers in $10 \mathrm{~kg}$ ). Crop performance of potato fields was assessed based on yield, quality, and revenue and the scope for improving production was evaluated.

\subsubsection{Generic framework for yield, quality and revenue}

\section{Potential yield}

Potential yield $(Y p)$ indicates the yield of a crop cultivar obtained under non-limited conditions (or the water-limited potential yield (Yw) under rainfed conditions) (Van Ittersum et al., 2013). The yield gap $(\mathrm{Yg})$, calculated as the difference between $\mathrm{Yp}$ (or $\mathrm{Yw}$ ) and the actual yield obtained by farmers ( $\mathrm{Ya}$ ), indicates how much yield can be increased by implementing better management practices. Yield gap under irrigated conditions can be assessed based on the difference between potential (Yp) and actual average farmers' yield (Ya) (Fig. 3.1A) (Van Ittersum et al., 2013). Using the maximum farmers' yield (Yf) is one of the methods to estimate potential yield $(Y p)$ (or $Y w$ ), assuming that all biotic and abiotic constraints are eliminated in best performing farmers' field. On the other hand, Yf will be lower than $\mathrm{Yp}$ if particular production constraints exist in all studied fields. Yf is derived from farmer surveys, and can be defined as the 95th upper percentile of Ya (Van Ittersum et al., 2013).

\section{Optimum quality}

The concept of optimum quality can be used in a manner analogous to the concept of potential yield (Fig. 3.1B). However, it should be emphasized that the desired quality for a specific market may not necessarily be the biophysical potential for a given trait. For example, for the production of French Fries there is an optimum range of dry matter content: either too high or too low has undesirable impacts on production quality. Therefore, we defined an optimum quality $(\mathrm{Qp})$ as the quality value (or range) of a particular quality trait that is most desired for a specific market. Corresponding to the Yf of yield, Qf represents the highest achieved quality 
value obtained by the best performing farmers. Various quality traits are important depending on specific crops and production purposes. The relationship between a quality trait and revenue is determined by three items: acceptability, base price and bonus price.

(A)

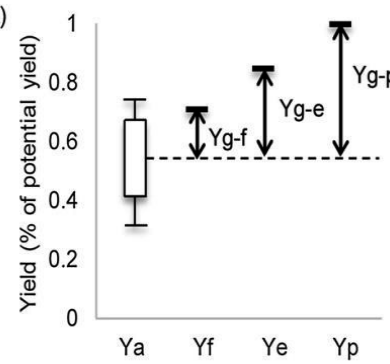

(B)

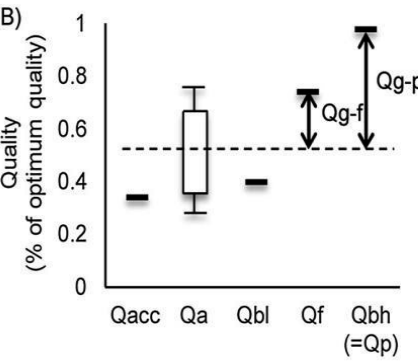

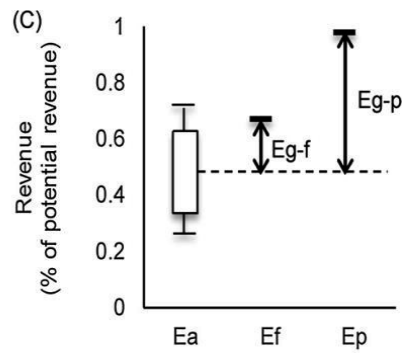

Figure 3.1. Benchmarking yield, quality and revenue. (A) Actual yield (Ya) as compared with the potential yield

$(Y p)$, maximum farmers' yield (Yf), yield for maximum revenue (Ye) and yield gaps (Yg-p, Yg-f, Yg-e).

(B) Actual quality levels (Qa) as compared to the optimum quality (Qp), optimal quality obtained by best performing farmers (Qf), acceptable quality (Qacc), higher and lower threshold for bonus price (Qbh, Qbl), and quality gap (Qg-p, Qg-f). (C) Actual revenue (Ea), potential revenue (Ep), the maximum revenue of the best performing farmers (Ef), and revenue gaps (Eg-p, Eg-f).

\section{Acceptability}

For particular quality traits, there is an acceptable level (Qacc) (Fig. 3.1B), below (or beyond) which the product is not qualified to be used for a specific market (e.g., minimum (or maximum) dry matter content of potato tubers for processing French Fries). Such quality traits determine whether or not the product will be bought by the buyer. If one of the quality traits does not meet the acceptable level (Qacc), the product will be rejected.

\section{Base price or penalty}

Once all relevant quality traits meet the Qacc, a base price (price per unit product) is guaranteed for the product. For many agricultural products, the buyer pays a higher base price for superior quality products and a lower base price for inferior ones (continuous scale in Fig. 3.2A). In some other cases, the product with the preferred quality trait receives a base price, which we call PA (stepwise scale in Fig. 3.2A), while the product with a lower quality trait receives a lower price than the base price as a penalty, which we call PB (Fig. 3.2A).

\section{Bonus}

In addition to the base price, growers may receive a bonus (i.e., a higher price per unit product in addition to the base price) from buyers as an incentive for excellent quality. To receive a bonus, the quality trait should be between a lower ( $\mathrm{Qbl}$ ) and upper (Qbh) threshold, within which the bonus differs in a stepwise manner (Fig. 3.2B, C). In other cases, a bonus applies when a number of quality traits meet required standards simultaneously (e.g., long term storability of French Fries potatoes, which requires a low percentage of damaged or rotten tubers, but also a low sugar content to obtain a good fry color). 

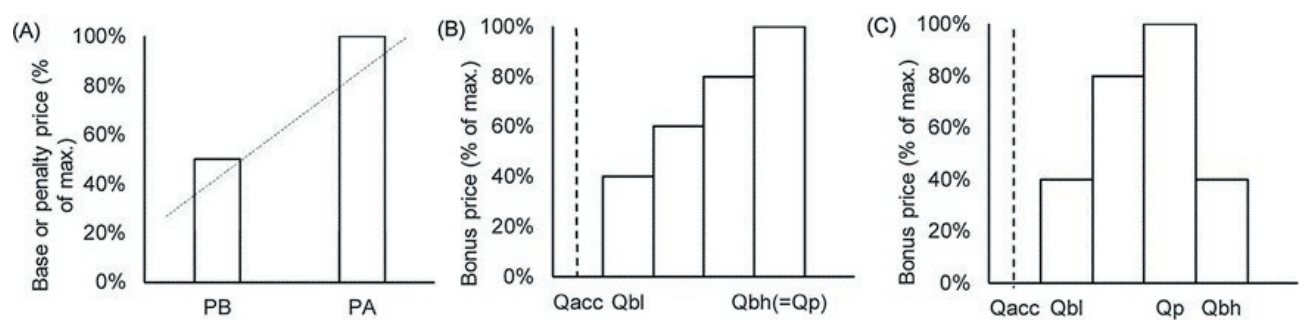

Figure 3.2. Quality aspects that are relevant to the revenue. (A) Base price on a continuous scale (dashed line), and base (PA) and penalty price (PB) for a product with different quality traits. (B) Stepwise (discontinuous) increase in bonus price for quality values between $\mathrm{Qbl}$ and $\mathrm{Qbh}$, up to an optimum level. (C) Stepwise change in bonus price with an optimum for quality values between $\mathrm{Qbl}$ and $\mathrm{Qbh}$.

\section{Revenue}

The revenue $(E)$ (money per unit area of land) is calculated as:

$$
E=\text { Yield } \times \text { Price }
$$

Where: Price $=f($ Quality $)$

Where yield is the harvested product per unit area land, and price is the price per unit product at the relevant quality point. Quality is associated with the base price (price per unit product) and the bonus (extra amount of money per unit product). Bonus is offered if particular quality traits meet the bonus level (i.e., between $\mathrm{Qbl}$ and $\mathrm{Qbh}$ ) (Fig. 3.2B, C). In practice, there can be bonus values for different quality traits. The actual revenue (Ea) can be estimated based on actual yield and quality trait values. The maximum farmer's revenue (Ef) can be evaluated by the 95th quantile of the Ea distribution (Fig. 3.1C). By further improving and balancing yield and quality, the potential revenue (Ep) can be obtained (Fig. 3.1C).

\section{Assessing crop performance based on yield, quality and revenue}

The revenue is a function of yield, quality, and pricing structure; the optimum revenue (Ep) depends on the precise relationships between the three. If there is no trade-off between yield and quality, obtaining maximum yield $(\mathrm{Yp})$ is associated with highest revenue (Ep). If yield and quality are not positively associated along the entire range of yields, obtaining maximum yield does not guarantee highest revenue. In those cases revenue may be highest (Ep) at a yield level (Ye) below the biophysical potential (Yp) (Fig. 3.1A). It is important to assess crop performance based on yield, quality, and revenue of crop production in order to discuss the pathways of improving production economically. In summary, we propose the following steps to attain this aim:

1. Identification of quality traits and critical levels.

2. Identify the important quality traits that are relevant to the revenue for the target crop produced for specific markets. 
3. Identify the acceptable level (Qacc), the base price, price penalty, and the bonus levels (Qbl, $\mathrm{Qbh}$ ) of the quality traits.

4. Analysis of quality, yield and revenue.

5. Assess the relationships between yield and the quality traits.

6. Quality performance: Estimate the actual quality (Qa), best performing farmers' quality (Qf), optimum quality (Qp), and assess the quality performance by comparing Qa with Qacc, Qbl, Qbh, Qf and Qp.

7. Yield performance: Estimate the actual yield (Ya), the maximum farmers' yield (Yf), potential yield ( $Y p$ or $Y w$ ), and assess the yield performance by estimating yield gaps (difference between $Y a$ and $Y f$, and $Y p(o r ~ Y w))$.

8. Revenue performance: Estimate the actual revenue (Ea), the maximum farmers' revenue $(\mathrm{Ef})$, and potential revenue (Ep) and assess the economic performance by estimating revenue gaps (difference between Ea and Ef, and Ep).

9. Assessment of synergy or trade-off.

10.Assess the relationship between yield and revenue, taking into consideration the influence of the quality aspects, and explore the possibilities for improving yield, quality and revenue simultaneously and balancing the three aspects (if a trade-off exists).

\subsubsection{Applying the framework to the case study}

\section{Identification of quality traits and critical levels}

We applied the framework to a case study on a French Fries processing factory in northern China. The quality traits, levels and prices were obtained by interviewing experts from the local processing factory. There were three quality traits for the variety Innovator processed for French Fries: (1) dry matter percentage of tubers (DM\%), (2) tuber size classes (i.e., weight percentage (WP) of small tubers (<60 mm), small-medium $(60-75 \mathrm{~mm})$, medium $(75-175 \mathrm{~mm})$, and extra-large (>175 mm) tubers), and (3) number of tubers in $10 \mathrm{~kg}$. In practice, the product was sold per truck load, and 3-6 samples were taken from each truck for assessing the quality. The average of the sample results was used to judge the acceptability (or rejection), and to determine the base and the bonus price for the product per truck.

The first step was to assess the acceptability. Based on the interviews, the lower acceptable level (Qacc) for DM\% was 18\% (Fig. 3.3B); potato lots with DM\% below 18\% were rejected. The upper Qacc for the WP of small tubers (<60 mm) was $10 \%$. The upper Qacc for extralarge tubers $(>175 \mathrm{~mm}$ ) was also $10 \%$. If one of these two traits for the batch does not fulfill the Qacc, the product would be rejected. Secondly, the base price needed to be defined, which depended on the tuber size (Fig. 3.3A). The medium tubers $(75-175 \mathrm{~mm}$ ) got a higher base price $\left(\mathrm{PA}=1380 \mathrm{RMB}\right.$ ton $\left.^{-1} \mathrm{FM}\right)$, while the small-medium $(60-75 \mathrm{~mm})$ and extra-large tubers $(>175 \mathrm{~mm})$ received a lower base price as penalty $\left(\mathrm{PB}=800 \mathrm{RMB} \operatorname{ton}^{-1} \mathrm{FM}\right)$. Small tubers (< 
$60 \mathrm{~mm}$ ) received no price. Thirdly, bonus prices were estimated. An increasing bonus was given for DM\% between 18.5\% (Qbl) and 21.5\% (Qbh) (Fig. 3.3B). No bonus was applicable if DM\% was between $18 \%$ and $18.5 \%$, and above $21.5 \%$. A bonus was also given if the number of tubers in $10 \mathrm{~kg}$ varied between $44(\mathrm{Qbl})$ and 62 (Qbh) (Fig. 3.3C).
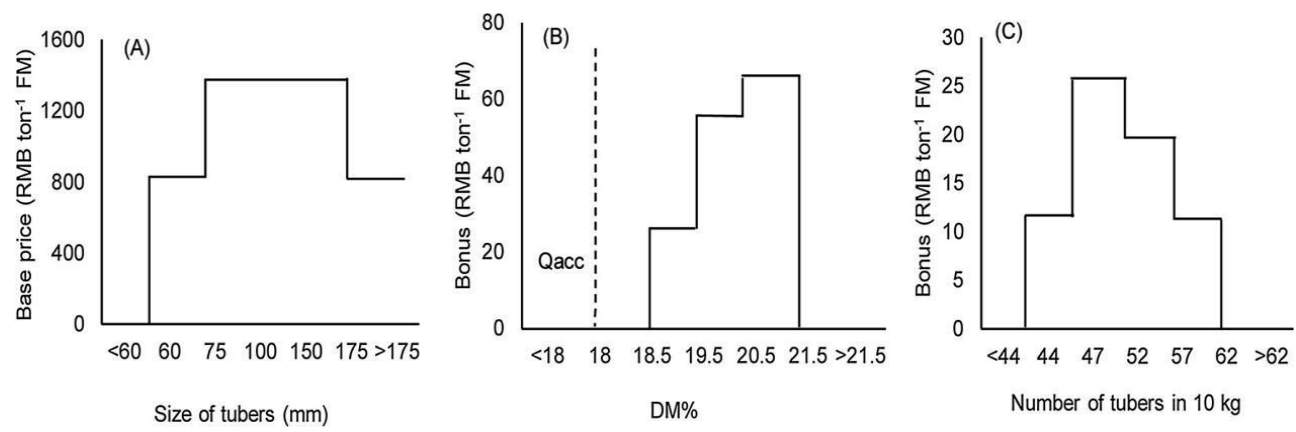

Figure 3.3. Quality traits and their values related to base and bonus prices. (A) Medium tubers $(75-175 \mathrm{~mm})$ received a higher base price (1380 RMB ton $\left.{ }^{-1} \mathrm{FM}\right)$ than small-medium $(60-75 \mathrm{~mm})$ and extra-larger ones (> 175 $\mathrm{mm}$ ) (800 RMB ton ${ }^{-1} \mathrm{FM}$ ); small tubers (<60 mm) received no price. (B) Bonus for DM\% increased for DM \% between $18.5 \%$ and $21.5 \%$, with $29 \mathrm{RMB}$ ton ${ }^{-1} \mathrm{FM}$ for $\mathrm{DM} \%$ from 18.5 to $19.5 \%, 59 \mathrm{RMB}$ ton $^{-1} \mathrm{FM}$ for $\mathrm{DM} \%$ from 19.5 to $20.5 \%$, and $69 \mathrm{RMB}$ ton ${ }^{-1} \mathrm{FM}$ for DM\% from 20.5 to $21.5 \%$. Product with DM\% below $18 \%$ was rejected.

(C) Bonus for the number of tubers in $10 \mathrm{~kg}$ was $11 \mathrm{RMB}^{-1} \mathrm{ton}^{-1} \mathrm{FM}$ for a number of tubers in $10 \mathrm{~kg}$ between 44 and 47, $24 \mathrm{RMB}$ ton $^{-1} \mathrm{FM}$ for $48-52,17 \mathrm{RMB}$ ton $^{-1} \mathrm{FM}$ for $53-57$, and $11 \mathrm{RMB}$ ton $^{-1} \mathrm{FM}$ for $58-62$.

\section{Data collection}

The study region Hulunbuir city, was in Inner Mongolia, China, where 10 large-scale commercial farms were investigated by the local agronomists over three years (2015-2017). Each farm had multiple fields with variable size. In total, 195 fields were surveyed, and the area of a field was on average 33.5 ha (varied between 5 and 115 ha). The potato variety was Innovator (bred by HZPC, the Netherlands) for French Fries processing. The ridges were 90 $\mathrm{cm}$ in width, and the distance between the two seed tubers was between $18-22 \mathrm{~cm}$. The potato yield in fresh matter (FM) and quality aspects were tested for "3meter samples" (3 $\mathrm{m}$ of one ridge) taken from the fields. One 3-meter sample was taken for a land area of $33.3 \mathrm{ha}$. If a field had a larger area than 33.3 ha, more samples were taken, and the average value was used to represent the field. If a field was smaller than 33.3 ha, one 3-meter sample was taken to represent the field. Plant samples of $3 \mathrm{~m}$ length were taken along a ridge randomly selected in the field between $23^{\text {rd }}$ and $28^{\text {th }}$ of August (i.e., approximately 1-2 weeks before harvesting the field). The tubers were cleaned and the soil and skins were removed. The specific gravity of tubers was measured by measuring the underwater weight (i.e., $3500 \mathrm{~g}$ of tubers was used for measurement). The specific gravity was used to estimate the DM\% by using the conversion factors used by the processing factory. For each 3-meter sample, tubers were graded by size into six groups (i.e., < $60 \mathrm{~mm}, 60-75 \mathrm{~mm}, 75-100 \mathrm{~mm}, 100-150 \mathrm{~mm}, 150-175 \mathrm{~mm}$, and > 175 $\mathrm{mm}$ in length). For each grade group, the tubers were weighed and the number of tubers were counted. The percentage of number and weight of tubers of different size groups were 
calculated. The yield, quality and revenue of the individual fields (ton $\mathrm{FM} \mathrm{ha}^{-1}$ ) was estimated based on the yield (ton FM) of the 3-meters samples.

\section{Analysis of quality, yield and revenue}

Relationships between yield and quality. For the surveyed fields, potato yield was plotted against the three quality traits. The relationships between yield and quality traits were evaluated for the three years jointly (2015-2017). The correlations between yield and each quality trait were tested with correlation tests. Linear and quadratic relationships were tested to find out the most suitable one based on the goodness of fit.

Quality performance. For each quality trait, the actual quality value (Qa) per year (2015-2017) was assessed by averaging the $\mathrm{Qa}$ of the surveyed fields. The optimum quality ( $Q p)$ of the proportion of tubers of different size classes was hypothesized to be $0 \%$ or $100 \%$, depending on whether a size class was preferred or not. Qp of DM\% and number of tubers in $10 \mathrm{~kg}$ was assumed to be the same as the levels with the highest bonus price (Qbh). The quality value of the best performing farmers (Qf) per year was assessed as the 95th upper percentile of Qa for the quality trait. For quality traits of which Qp was a range, Qf was the same as Qp if the 5\% best fields were within this range. The Qa was compared with the acceptable level (Qacc), bonus level (Qbl, Qbh), Qf and Qp (if not equal to Qbh). Considering all three years, the proportion of fields that failed to meet the acceptable levels (Qacc) was identified. In addition, the proportion of fields that fulfilled the bonus level (Qbl, $\mathrm{Qbh}$ ) was assessed.

Yield performance. The average yield of potatoes across all surveyed fields was calculated to represent the actual yield (Ya, ton FM ha ${ }^{-1}$ ) of each year (2015-2017). The potential yield (Yp, ton $\mathrm{FM} \mathrm{ha}^{-1}$ ) was used as benchmark, as all surveyed fields applied irrigation. For each year, one $Y p$ was used to represent $Y p$ of all fields as they were close to each other, assuming homogenous weather. Yp of each year was estimated using the crop growth model WOrld FOod STudies (WOFOST) (de Wit et al., 2018; Van Keulen and Van Diepen, 1990). The model was calibrated and validated using field experiments conducted in northern China (Chapter 2). Climate data of the study region (2015-2017) was derived from the China Meteorological Data Service Centre (CMDC, 2018). The maximum farmers' yield (Yf) of each year was estimated with the 95th quantile of the Ya per field. The yield gap $(\mathrm{Yg})$ was estimated for each year as the difference between $Y p$ and $Y a(Y g-p)$, and between $Y f$ and $Y a(Y g-f)$. The relative yield gap was calculated as the ratio between $Y g-p$ and $Y p$, and between $Y g-f$ and $Y f$.

Revenue performance. The actual revenues (Ea) of surveyed fields were assessed (Equation 3.1). The base price was different for tubers with different sizes (Fig. 3.3A). The bonus price (for $\mathrm{DM} \%$ and tuber number in $10 \mathrm{~kg}$ ) was determined based on the actual quality value (Fig. $3.3 \mathrm{~B}, \mathrm{C})$. The average Ea across fields was calculated per year. The maximum revenue obtained by the best performing farmers (Ef) was estimated per year as the 95th quantile of the range of Ea of the surveyed fields. The revenue gap (Eg-f) was the difference between Ef and Ea, and was estimated per year. The relative Eg-f was also estimated for each year as the ratio between Eg-f and Ef. 
Assessment of synergy or trade-off

The relationship between potato yield and price per ton FM tuber was estimated for all fields of three years. The relationship between yield, quality and revenue was assessed across all fields of all three years. This helped to identify how much the revenue gap was associated with yield, and with quality aspects.

\subsection{Results}

\subsubsection{Analysis of quality, yield and revenue}

\section{Relationships between yield and quality}

We found a quadratic relationship between yield and DM\% (Fig. 3.4A). At the highest obtained yield level, average DM\% was not yet at Qp (20.5-21.5\%), while the relationship did not suggest a further increase of DM\% with yield. The WP of small tubers ( $<60 \mathrm{~mm}$ ) (Fig. 3.4B) and small-medium (Fig. 3.4D) were negatively correlated with yield, while WP of medium tubers $(75-175 \mathrm{~mm}$ ) (Fig. 3.4E) was positively correlated with yield and WP of extra-large tubers (> $175 \mathrm{~mm}$ ) was weakly positively correlated with yield (Fig. 3.4C). Higher yields thus generally led to higher quality regarding tuber size class, excepted for a slight increase in extralarge (> $175 \mathrm{~mm}$ ) tubers. The number of tubers in $10 \mathrm{~kg}$ showed a quadratic relationship with yield (Fig. 3.4F). The highest yield levels corresponded to quality that attracted bonus, and a further yield increase did not affect quality. In conclusion, no significant trade-offs were observed between yield and the tested quality traits, and aiming at high yield was associated with higher quality values within the range of yield levels in this study (9.2-55 ton FM ha-1). 

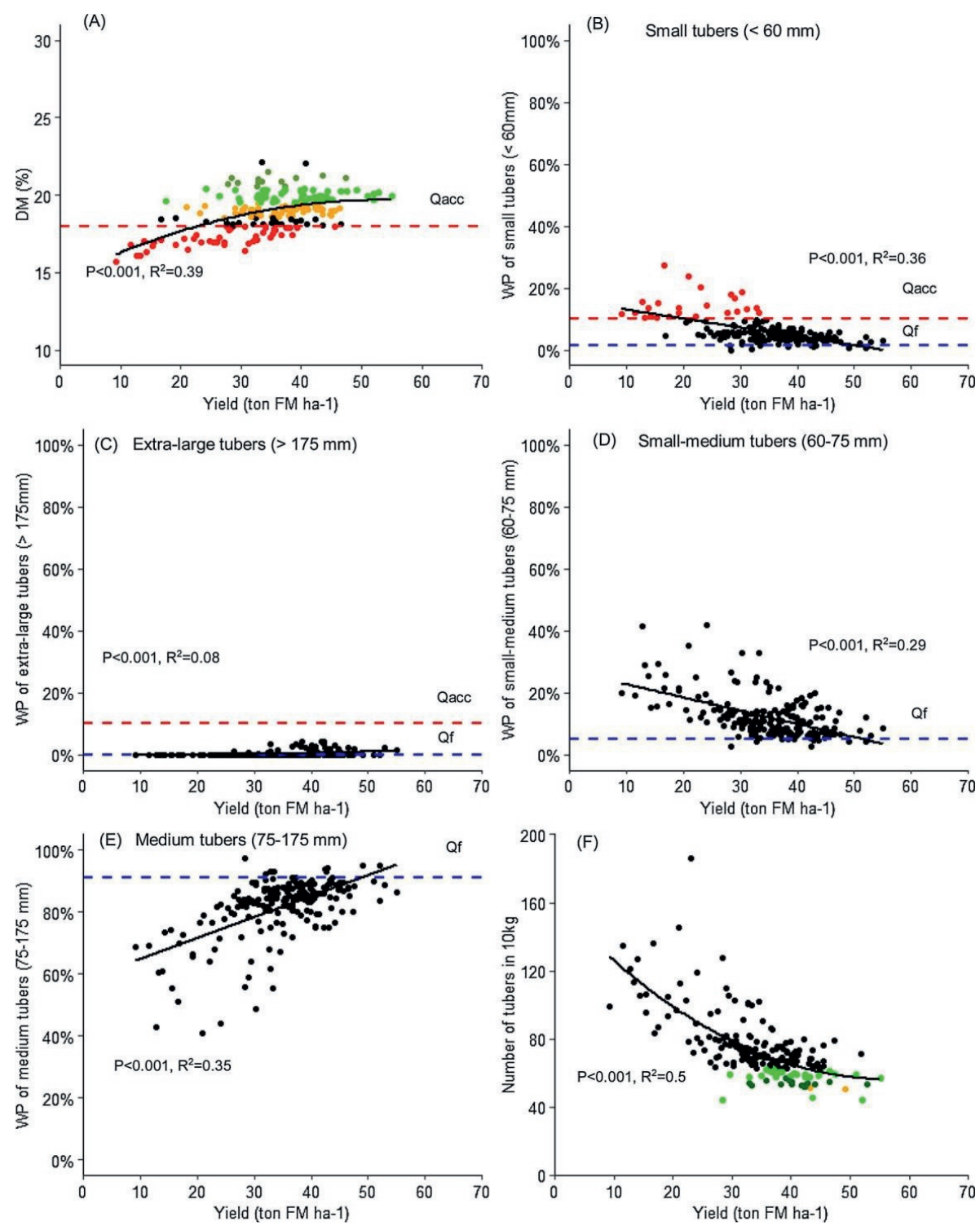

Figure 3.4. Relationships between yield and quality traits of 195 fields across three years (2015-2017) (A) dry matter percentage of tubers (DM\%), (B) weight percentage (WP) of small tubers $(<60 \mathrm{~mm}),(C)$ WP of extra-large tubers (> $175 \mathrm{~mm}),(\mathrm{D})$ WP of small-medium tubers $(60-75 \mathrm{~mm}),(E)$ WP of medium tubers $(75-175 \mathrm{~mm}),(\mathrm{F})$ number of tubers in $10 \mathrm{~kg}$. (A) and (F) are quadratic relationships, and (B), (C), (D), (E) are linear relationships. The horizontal dashed red line indicates acceptable level (Qacc), and the blue dashed line indicates the quality level of best performing farms (Qf). The different colors in $(A),(B),(F)$ indicate the acceptability and bonus price for particular quality values: $(A)$ potatoes with $\mathrm{DM} \%$ less than $18 \%$ were rejected (red); growers received a bonus of $29 \mathrm{RMB}$ ton $^{-1} \mathrm{FM}$ for DM\% between 18.5-19.5\% (orange), 59 RMB ton ${ }^{-1} \mathrm{FM}$ for DM\% between 19.5-20.5\% (green), 69 RMB ton ${ }^{-1} \mathrm{FM}$ for DM\% between 20.5-21.5\% (dark green); the rest (black) were accepted but no bonus was applicable; $(B)$ when the WP of small tubers $(<60 \mathrm{~mm})$ was larger than $10 \%$, the potatoes were rejected (red); (F) growers got a bonus of $11 \mathrm{RMB} \mathrm{ton}^{-1} \mathrm{FM}$ when the number of tubers in $10 \mathrm{~kg}$ was between 44 and 47 and between 58 and 62 (green), $17 \mathrm{RMB} \mathrm{ton}^{-1} \mathrm{FM}$ when it was between 53 and 57 (dark green), $24 \mathrm{RMB}$ ton $^{-1} \mathrm{FM}$ when it was between 48 and 52 (orange); for other numbers (black) no bonus price was applicable. 


\section{Quality performance}

The average actual DM\% across fields of each year (18.6-19.7\%) was above the acceptable level $(18 \%)$ in all three years, and met the requirement for a bonus (18.5-21.5\%) (Table 3.1). The DM\% of best performing farmers (Qf) of 2015 and 2016 were in the optimum range (Qp = 20.5-21.5\%), while Qf in 2017 was lower than Qp. Among the 195 surveyed fields in the three years, $22 \%$ of the fields failed to meet the Qacc for DM\%, and $67 \%$ of the fields obtained a bonus for DM\% (Fig. 3.4A, Table 3.1). The rest of the fields $(100 \%-22 \%-67 \%=11 \%)$ obtained no bonus for DM\%.

The average WP of small tubers ( $<60 \mathrm{~mm}$ ) across fields, 5.4-6.7\%, was below the upper Qacc $(10 \%)$ in all three years (Table 3.1). For all three years jointly, the fields that failed to meet the Qacc accounted for $12 \%$ of the surveyed fields (Fig. 3.4B, Table 3.1). The average WP of extra-large tubers (> $175 \mathrm{~mm}$ ) across fields of each year $(0.3-0.5 \%)$ was below the Qacc $(10 \%)$ (Fig. 3.4C, Table 3.1). For all three years jointly, only $18 \%$ of the surveyed fields had extralarge tubers (> $175 \mathrm{~mm}$ ), and the weight percentages of these were all below the upper Qacc (Fig. 3.4C).

The quality value obtained by best performing farmers (Qf) for WP of small ( $<60 \mathrm{~mm}$ ), smallmedium (60-75 mm), medium $(75-175 \mathrm{~mm})$ and extra-large $(>175 \mathrm{~mm})$ tubers $(1.6 \%, 5.2 \%$, $91.1 \%$ and $0 \%$, respectively) were fairly close to the hypothesized Qp $(0 \%, 0 \%, 100 \%$, and $0 \%$, respectively) (Table 3.1 ).

The average number of tubers in $10 \mathrm{~kg}$ across all fields per year (70-80) did not meet the requirements for the bonus in any year (44-62) (Table 3.1). The quality value obtained by the $5 \%$ best performing farmers (Qf) in each year did not meet the criteria (48-52) for the highest bonus either. For all three years jointly, $25 \%$ of the fields obtained a bonus for the number of tubers in $10 \mathrm{~kg}$ (Fig. 3.4F). Only 1\% of the fields obtained the highest bonus for the value between 48-52. 


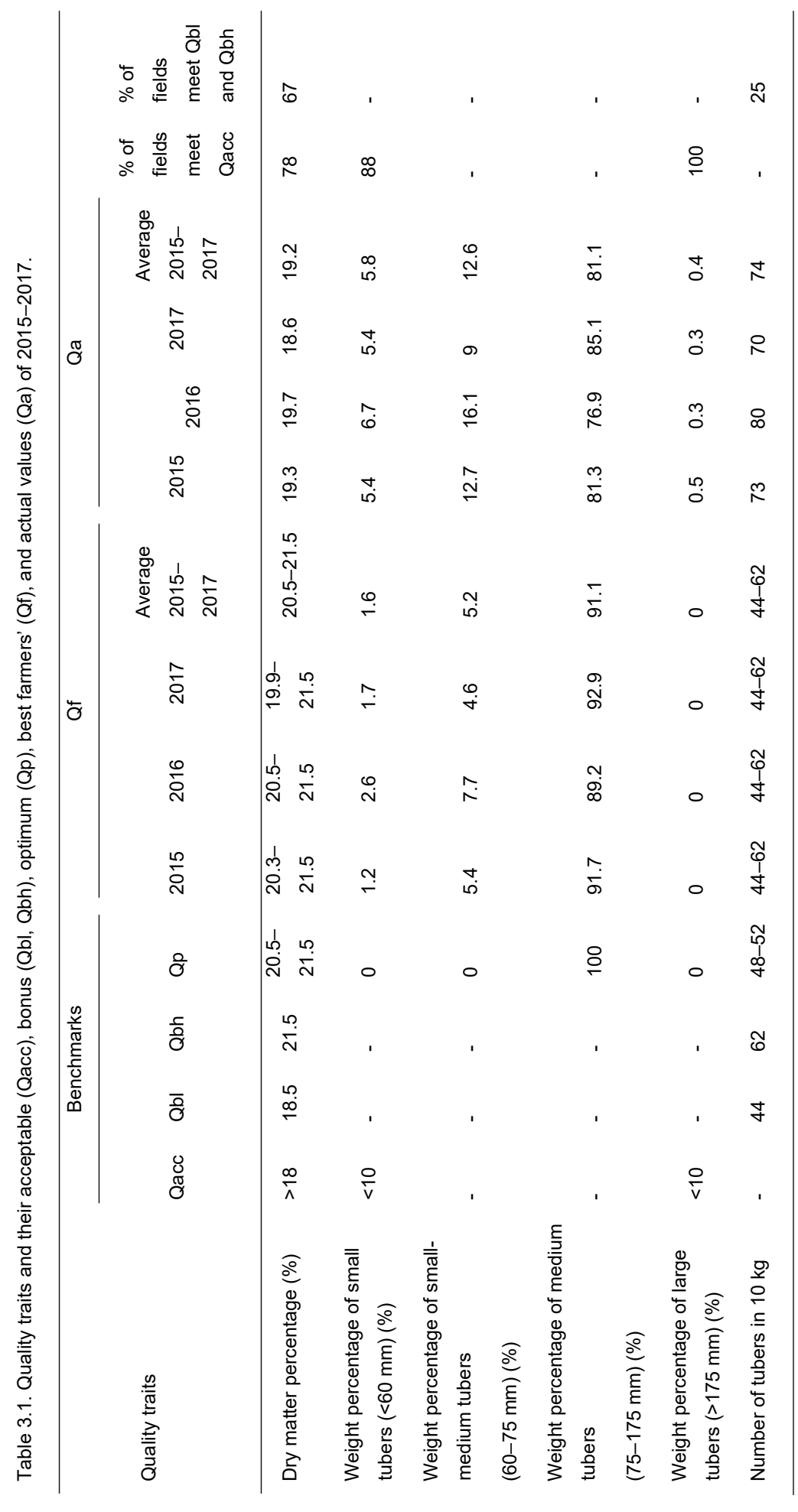




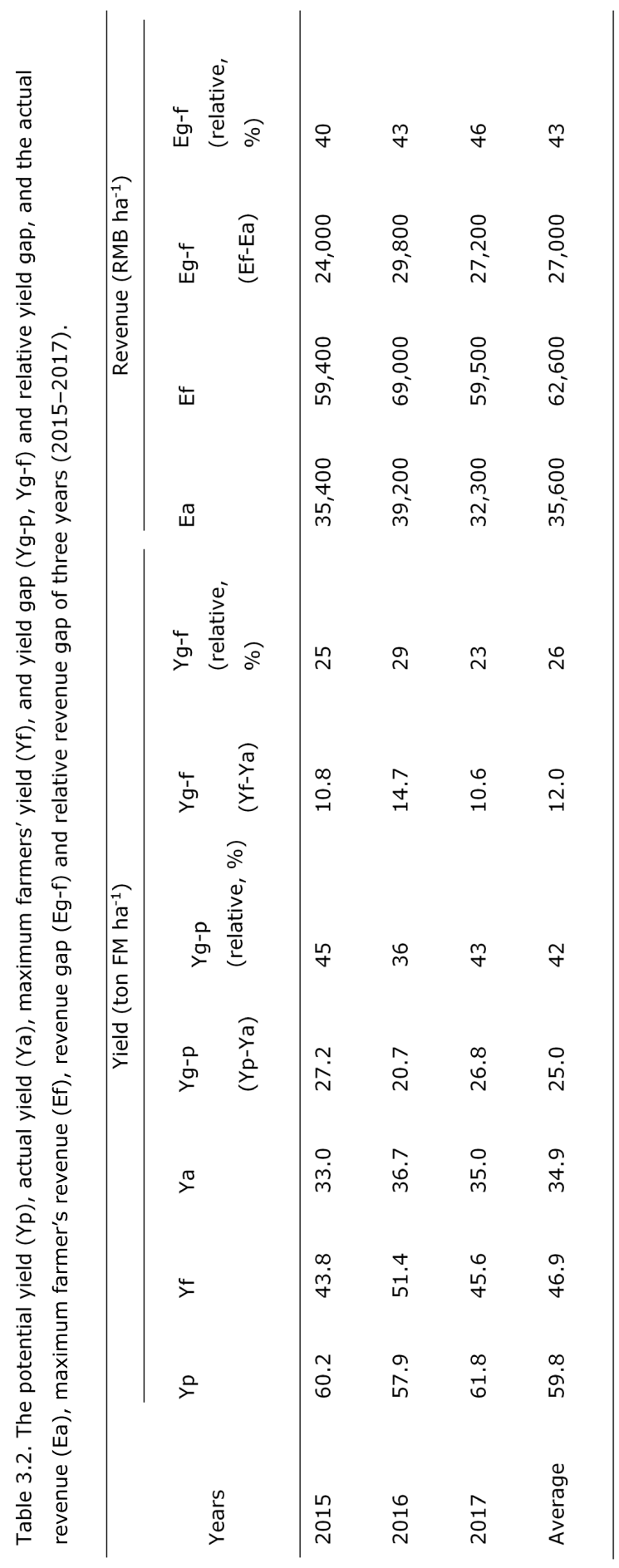




\section{Yield performance}

The simulated potential yield (Yp) of potato in the production region from 2015 to 2017 was on average 59.8 ton $\mathrm{FM} \mathrm{ha}^{-1}$ (Table 3.2). The actual yield (Ya) was on average 34.9 ton $\mathrm{FM} \mathrm{ha}^{-1}$. The maximum yield obtained by farmers (Yf) was on average 46.9 ton $\mathrm{FM} \mathrm{ha}^{-1}$. The difference between $\mathrm{Yp}$ and $\mathrm{Ya}(\mathrm{Yg}-\mathrm{p})$ was on average 25 ton $\mathrm{FM}^{-1}$ hacross the three years, and the relative yield gap was on average $42 \%$. The gap between $\mathrm{Yf}$ and $\mathrm{Ya}$ (Yg-f) was on average 12 ton $\mathrm{FM} \mathrm{ha}^{-1}$, and the relative gap between the two was $26 \%$.

\section{Revenue performance}

The average actual revenue (Ea) across years (2015-2017) was 35,600 RMB ha-1 (Table 3.2). The revenue was relatively low in 2015 and 2017 and high in 2016 . Ca. $21 \%$ of the surveyed fields in 2016 received no price, while it was $28 \%$ in 2015 and $35 \%$ in 2017 . The fewer fields with zero revenue and higher actual yield in 2016 was the main reason behind the highest Ea (Table 3.2). The revenue from best performing farmers (Ef) was on average $62,600 \mathrm{RMB} \mathrm{ha}^{-1}$. The gap between Ef and Ea (Eg-f) was on average 27,000 RMB ha-1. The relative revenue gap was $43 \%$, which was higher than the yield gap $(\mathrm{Yg}-\mathrm{f}=26 \%$ ) due to quality issues.

\subsubsection{Assessing synergy or trade-off}

A positive correlation was found between the potato yield and price per ton fresh matter $(\mathrm{FM})$ tuber $\left(P<0.05, R^{2}=0.18\right)($ Fig. 3.5A), which indicated that higher yield was associated with better quality aspects. Revenue was strongly influenced by acceptability (Fig. 3.5B). When excluding fields that received no price, the yield and revenue were highly linearly related $(P<$ $0.001, R^{2}=0.96$ ); apparently the weak relationship between yield and price (Fig. 3.5A) was not enough to lead to nonlinear relationship between yield and revenue. Some $29 \%$ of the fields obtained no price due to failure to meet the Qacc for DM\% and/or for WP of small tubers (<60 $\mathrm{mm}$ ) (Fig. 3.5B). Ca. $16 \%$ of the fields were rejected due to the too low $\mathrm{DM} \%, 7 \%$ due to failure to meet the Qacc for WP of small tubers $(<60 \mathrm{~mm}$ ), and $6 \%$ due to failure to meet the Qacc for both traits. 

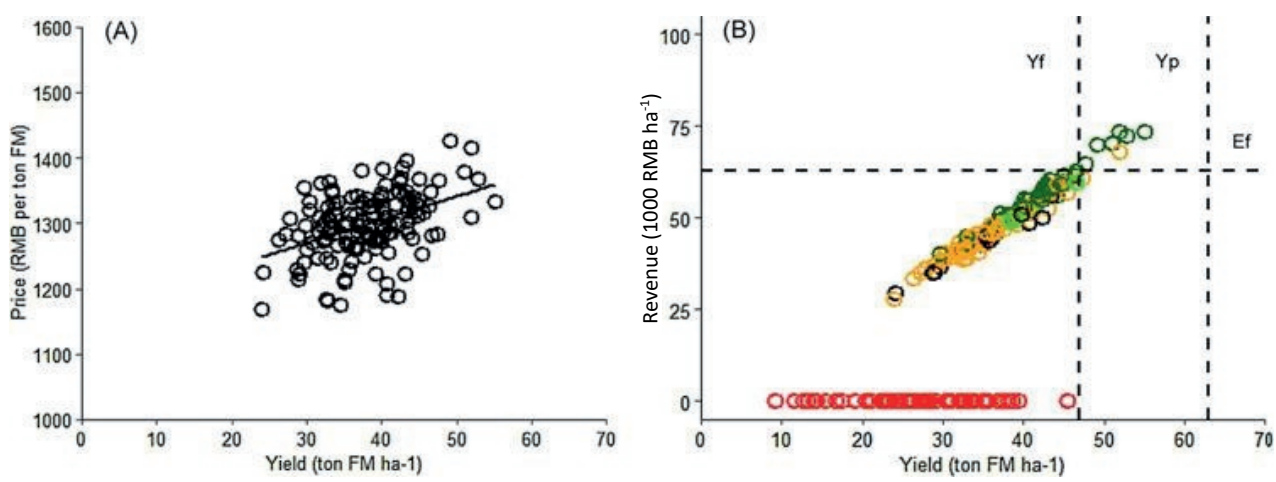

Figure 3.5. (A) The relationship between yield and price per ton fresh matter (FM) tubers for all of the surveyed fields across three years (2015-2017) when the zero revenue fields were removed. (B) Relationship between actual revenue ( $\mathrm{Ea}$ ) and actual yield (Ya). The dashed line in horizontal direction indicates the highest revenue (95th percentile) of the surveyed fields (Ef) across three years (2015-2017). The left dashed vertical line indicates highest yields (95th percentile) obtained from the surveyed fields (Yf) across the three years. The right dashed vertical line indicates the average potential yield (Yp) across the three years. Ca. $29 \%$ of the fields (56 out of 195) were rejected due to failure to meet Qacc (red points); $66 \%$ of the fields received a bonus for DM\% (orange), $25 \%$ for number of tubers in $10 \mathrm{~kg}$ (green), and $21 \%$ for both quality traits (dark green). The rest of the fields (9\%) were accepted but received no bonus (black).

\subsection{Discussion}

\subsubsection{Application to French Fries potato production in northern China}

\section{Data collection}

The case study was based on quality and yield data obtained from 3-meter samples. In practice, yield, quality and revenue are assessed for each truck delivered to the factory (see Section 3.2.2, Identification of quality traits and critical levels) and we recognize that the 3-meter samples may not be representative for the large fields. Sample size was too small to allow a good upscaling (i.e., to field, region). However, the samples do allow us to look at the relationships between yield and quality and revenue, and we do not link these traits to other characteristics of the field. Moreover, we found that the total production per farm estimated by the 3-meter samples represented well the total production per farm as measured in the factory (data not shown). The 3-meter samples were taken 1-2 weeks before the harvest of the field took place. At final harvest, the fresh matter yield and DM\% are expected to be higher than in our samples (Storey and Davies, 1992). This may explain the fact that the percentage of fields that are rejected by the factory is in general less $(<5 \%)$ than the results showed $(29 \%)$ (personal communication). Another possible reason is that potatoes are harvested manually and/or mechanically and the unacceptable tubers (small, extra-large, defected, etc.) are removed. 


\section{Important quality traits and their critical values}

In addition to the three major traits tested in the case study (i.e., dry matter percentage, tuber size, number of tubers in $10 \mathrm{~kg}$ ), there are many other quality traits that determine the acceptability (e.g., color of fried chips, reducing sugar content, and maximum weight percentage of defected tubers such as green, common scab, mechanical damage, insect damage, and misshape) and the bonus price (e.g., middle and long term storability) for potatoes processed for French Fries (Storey and Davies, 1992). Those traits were not considered in the case study due to the lack of data. For another potato production purpose than French Fries, the important traits may be different from the tested ones. For starch processing, for instance, the dry matter content is the major consideration, while tuber size distribution is less important. For crisps processing, dry matter content is an important trait, while the critical value is higher than that for French Fries (20\%) (Kumari et al., 2018). For potatoes consumed freshly, the external quality such as tuber size, skin and flesh color, and eye depth are important for customers to determine purchase at a first glance. The cooking quality (i.e., dry matter content, texture) and nutritional values are other considerations from the customers' side.

\section{Yield, quality and revenue of potato production}

The yield gap between the actual and potential yield (Yg-p) (relative yield gap was 42\%) was rather high compared to the yield gap of other staple crops in the country (i.e., $41 \%$ for irrigated maize, 32\% for irrigated rice) (Global Yield Gap Atlas, GYGA, http://www.yieldgap.org/ china). This was surprising to us as the surveyed fields represent the current advanced agronomic practice in the potato sector in China, for which the investment in production inputs and techniques (particularly in seed tubers and irrigation facilities) is higher than that of smallholders. The main reasons for the relatively low yield may relate to (1) lack of specifically adapted cultivars (Jansky et al., 2009), (2) insufficient production input (e.g., irrigation, labor) (Wang et al., 2018b) and (3) disease problems, i.e., late blight (USDA, 2016). We assumed that it is possible to achieve no small $(<60 \mathrm{~mm})$, and extra-large $(>175 \mathrm{~mm})$ tubers, and thus that $100 \%$ of the tubers can be in the medium-size $(75-175 \mathrm{~mm})$ class. We indeed found no small tubers in a few surveyed fields, but no field had $100 \%$ medium-sized tubers.

The results showed that there were no trade-offs between yield and any of the three quality traits tested in the case study over the range of yields and quality values observed. We assessed the relationship between yield (Ya), quality (Qa) and revenue (Ea) up to the maximum farmers' yield, and the influence of further yield increase up to the potential level (Yp) could not be assessed due to the lack of observations of higher yield and the associated quality. However, a wider yield range may lead to different results. For instance, it was found that yield can be increased by enhancing planting density, which may result in decreased average tuber size (Beukema and Van der Zaag, 1990). In addition, the results may differ if other quality traits and their influence on selling price are considered. For instance, the risk of mechanical damage and bruising, which is associated with acceptability (personal communication) is higher for heavy tubers than for less heavy ones (Storey and Davies, 1992). The incidence of tuber defects (e.g., hollow heart, growth cracking), which is an important 
consideration for acceptability particularly in climate-abnormal years, is associated with tuber size distribution (Storey and Davies, 1992).

The relationship between yield and revenue was linear and there was little scatter around the regression line due to the quality traits (Fig. 3.5B). The high correlation between yield and revenue indicated that yield was the primary driver of revenue. One might have expected an exponential relationship as increasing yield was associated with improved quality values and significantly higher prices. However, the difference in yield and quality had weak impact on price per unit product (Fig. 3.5A). Thus, it was hard to see that quality aspects contributed to the variation in revenue.

\section{Strategies of improvement}

The variation in yield was much larger than the variation in quality for all quality traits (Fig. 3.4). Factors associated with climate and soil conditions and management practice explain the variation in yield, while genetic features play a more important role in determining the quality values (particularly for DM\%) than the environmental and management factors (Storey and Davies, 1992). The DM\% of surveyed fields was generally low in all years (19.2\%). According to the breeder of the cultivar that we investigated (HZPC, 2018), the DM\% of Innovator is around $20.8 \%$. The low DM\% in the surveyed fields may be attributed to excessive application of nitrogen fertiliser (200-300 kg ha-1 ${ }^{-1}$ personal communication) (Storey and Davies, 1992) and a large proportion of small tubers, which have a lower DM\% than medium and large ones (Beukema and Van der Zaag, 1990). The variation in weight percentage of tubers of different size was larger than in DM\%, which indicated the importance of agronomic practice on modifying tuber size. The extra-large tubers were limited in all fields, and the number of tubers in $10 \mathrm{~kg}$ of the majority of fields did not reach the bonus level, which points at the generally smaller tuber size than desired. Enhancing yield was found to be associated with a lower proportion of small $(<60 \mathrm{~mm})$ and small-medium $(60-75 \mathrm{~mm})$ tubers, and a higher proportion of medium tubers (75-175 mm) (Fig. 3.4B, D, E). This is in agreement with the argument that the average tuber size increases with the increase of yield (Beukema and Van der Zaag, 1990).

\subsubsection{Framework}

The assessment of yield potential and yield gaps is essential to evaluate crop production capacity and the potential to meet future food demand (Van Ittersum et al., 2013). This has been done for major cereal crops (rice, maize and wheat) and non-cereal crop like potato (Chapter 2; Deng et al., 2019; Li et al., 2014a; Meng et al., 2013). The demand for high quality crop products has increased significantly in the recent years due to rapid urbanization and the increased income of the people in China (MOA, 2017). Yet, hitherto not much attention was given to quality potential and quality gaps of crop production.

We argue that understanding quality and quality gaps is equally important as evaluating yield and yield gaps. The framework proposed in this study provides guidelines for assessing the difference between actual and optimum levels in yield and quality performance which allows to evaluate the scope of improvement in both aspects and the associated gain in economic 
return. Understanding the actual and best farmers' quality performance also allows industries to develop better plans regarding the quality requirement and pricing structure (acceptability, bonus). The quality aspects of a crop are largely driven by genetic features (Lisinska et al., 2009), but management practices and environmental conditions play also important roles (Storey and Davies, 1992). Some management practices in favour of yield increase may deteriorate product quality (e.g., high nitrogen fertiliser input was associated with high reducing sugar content of potato tubers which is not desirable for processing purposes) (Lisinska et al., 2009). The consideration of quality aspects thus affects decisions on land use, and input investment, which also affect yield, and vice versa. By understanding the synergy or trade-off between yield and quality, farmers can implement better management practice and select the optimum varieties.

The framework proposed in this study can also be applied to other food crops, forages, and animal products. Different cultivars may also be compared. The important quality traits, and their critical values with regard to economic return must then be identified. In general, the appearance, cooking quality, processing quality and nutritional values are widely used to describe crop quality traits (Fernie et al., 2006; Guardia et al., 2018). In the framework, the production revenue (economic value) was regarded as the target to benchmark yield and quality, assuming that quality is translated into the price of the product. Due to data limitations, the costs of production of the surveyed field were not considered in the estimation of economic performance. Clearly, the economically optimum yield, quality and the input rate (i.e., fertiliser, irrigation, seed tubers) are influenced by the cost of production. The marginal return to inputs decreases or becomes negative as yield approaches the maximum (Yp) (Harris, 1992; Van Ittersum et al., 2013).

\subsection{Conclusion}

The aim of this work was to enrich yield gap analysis by including quality aspects and an assessment of revenue. A framework of seven steps was developed to assess the synergy or trade-off between yield, quality and revenue of crop production. The framework was then applied to a case study of French Fries potato production in northern China. The relative revenue gap between average and best performing farmers (Eg-f) across three years was 43\%, which was partly due to a relative yield gap (Yg-f) of $26 \%$, and the remainder was largely associated with the acceptability of the quality traits (i.e., dry matter percentage). The most important quality constraint was the low dry matter percentage; in $22 \%$ of the fields it was below $18 \%$. The average tuber size was also smaller than desired. Enhancing average yield to the current maximum that we observed ( 55 ton $\mathrm{FM} \mathrm{ha}^{-1}$ ) was associated with improved quality in all quality traits tested in the case study, and thus would increase revenue. The framework can be applied to various agricultural products (for crops, single or multiple cultivars), for which the important quality traits and their critical values can be identified. 


\subsection{Acknowledgements}

This work was supported by the China Scholarship Council (CSC) [grant number 201506610003]. We would like to thank the potato processing factory for sharing the data. We thank local farmers for their cooperation in farm interviews, and for their contribution in providing information. 


\section{Chapter 4}

\section{Scope and strategies for sustainable intensification of potato production in northern China}

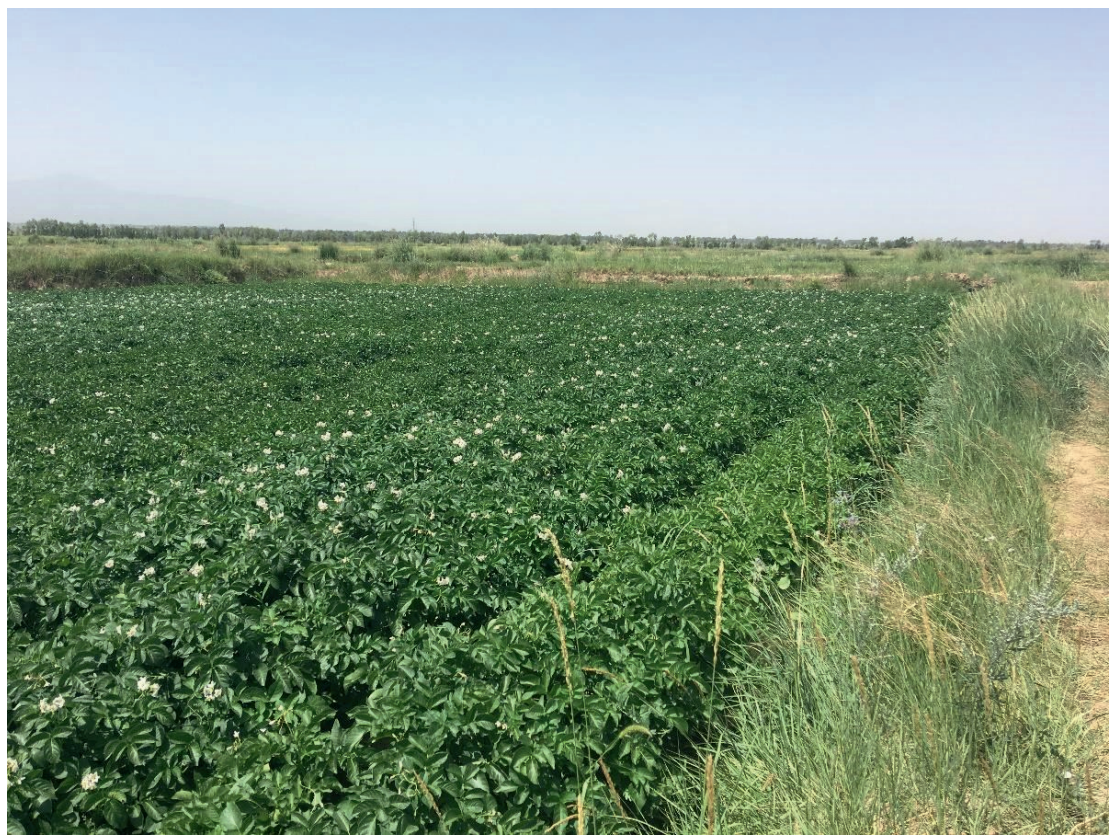

This chapter is published as:

Wang N., Reidsma P., Van Ittersum M.K., 2020. Scope and strategies for sustainable intensification of potato production in northern China. Agronomy Journal.

https://doi.org/10.1002/agj2.20269. 


\begin{abstract}
Potato (Solanum tuberosum) is an important staple crop in China, however, potato yields are low, and thus a general aim is to produce more crop with fewer resources and minimal environmental effects. This study aimed to assess the relationships between yield, resource use efficiencies, and environmental performance of potato production in China. Three major potato production regions (Inner Mongolia, Gansu, and Heilongjiang) were surveyed. The current production performance was evaluated, and the scope for improvement was assessed based on a lower and upper target for yield (financial breakeven point and $85 \%$ of the potential yield, respectively), water productivity (upper target is $85 \%$ of the potential water productivity), nitrogen use efficiency ( $50 \%$ and $90 \%$ ) and nitrogen surplus (upper target is $80 \mathrm{~kg} \mathrm{ha}^{-1}$ ). Longterm situations were evaluated to identify the target values of nitrogen use efficiency and nitrogen surplus based on currently available technologies. The results indicate that in the short-term nitrogen fertiliser input can be reduced by allowing for soil nitrogen mining to improve the nitrogen use efficiency and reduce nitrogen surplus. Water productivity can be increased by enhancing yield, and water surplus can be reduced by more efficient management of irrigation and rainfall water. In the long-term, with good agronomy, we assess it is feasible to improve yield (from $33-43$ to $46-57$ ton FM ha-1), improve nitrogen use efficiency (to $84 \%$ ), and reduce nitrogen surplus (from $50-156$ to $16-34 \mathrm{~kg} \mathrm{~N} \mathrm{ha}^{-1}$ ) simultaneously. The latter should be validated experimentally.
\end{abstract}

Keywords: Potato, yield, nutrient use efficiency, nutrient surplus, water use efficiency, sustainable intensification 


\subsection{Introduction}

The concept of ecological footprint in agricultural production refers to the negative effects of food production on ecosystems (Van Noordwijk and Brussaard, 2014). The resource use efficiency concept in agricultural production allows the connection of agronomic objectives (high yield and economic benefit) and environmental objectives (more output with less input and low environmental pollution; EU Nitrogen Expert Panel, 2015). The question whether food demand can be fulfilled while keeping the environmental effects at an acceptable level (sustainable intensification), has to be addressed for different cropping systems at various spatial-temporal scales (Cassman, 1999; Van Noordwijk and Brussaard, 2014).

Agricultural production in China is associated with substantial inputs and undesirable environmental effects. The dominant type of nitrogen $(\mathrm{N})$ input shifted from biological fixation and manure to synthetic fertilisers over the past 50 years (Conant et al., 2013). The excessive application of synthetic fertilisers resulted in large amounts of mineral $\mathrm{N}$ accumulated in the soil profile (up to $1230 \mathrm{~kg} \mathrm{NO}_{3}-\mathrm{N} \mathrm{ha}^{-1}$ in 0 to $400 \mathrm{~cm}$ depth) in northern China (Fan et al., 2010). The accumulated mineral $\mathrm{N}$ may be permanently lost from the soil-plant system and constitutes a risk for environmental pollution (water contamination, greenhouse gas emission; Fan et al., 2010; Zhou et al., 2016; Zhu and Chen, 2002). Water resources for agricultural production are under increasing pressure because of high extraction rates, particularly in arid and semi-arid areas in the northern region of China (Deng et al., 2006).

Potato (Solanum tuberosum) is one of the most important noncereal crops in the world. China is the number one potato producing country in terms of total production (FAO, 2019). Potato in China is cultivated as cash crop which often receives large amounts of fertiliser input, and irrigation is needed in dry areas and in dry seasons of other areas to ensure yield and quality. With the rapid growth of the potato market for both table and processed products in China, intensive potato production systems are expanding. It is our assertion that potato production must be enhanced with sustainable practices that aim to produce more crop per hectare and use the available natural resources as efficiently as possible while minimizing undesirable environmental effects.

This study is the first to identify the relationships among yield, resource use efficiencies, and environmental effects of potato production in major potato production regions in northern China, and to assess the scope and strategies to enhance these simultaneously. First, the current system's performance was assessed, and the scope for improvement was evaluated based on target values in terms of yield, resource use efficiencies, and an environmentally safe upper limit for $\mathrm{N}$ surplus. Long-term situations of $\mathrm{N}$ fertiliser management and yield were then evaluated, considering currently feasible technologies, to derive future target values of nitrogen use efficiency (NUE) and N surplus, taking into account the long-term soil $\mathrm{N}$ dynamics. Finally, the strategies for improving yield, water use efficiency, and NUE and reducing water and $\mathrm{N}$ surplus under both short-term and long-term conditions are discussed. 


\subsection{Materials and methods}

\subsubsection{Data collection}

The study was conducted in three major potato producing regions in northern China: Inner Mongolia (a French Fries processing factory), Gansu (a flakes processing industry), and Heilongjiang (a starch processing factory). For each region, farmers with a production contract with the local potato processing industries were interviewed during and after the potato growing season (Apr.-Sept.) in 2017 and 2018. Irrigation is commonly applied in Inner Mongolia (annual rainfall is between $78-470 \mathrm{~mm}$; Li et al., 2019) and Gansu (39-783 mm; Yang et al., 2004), where all surveyed fields applied irrigation. In Heilongjiang, rainfall is considered sufficient (386-647 mm; Wang et al., 2011), and irrigation was applied only in a few surveyed farms and fields (6 out of 21 farmers in 2017 and 6 out of 19 farmers in 2018).

The soil texture and chemical (soil organic matter, SOM; $\mathrm{pH}$, total $\mathrm{N}$, soil $\mathrm{N}$ uptake) parameters were measured for 14 fields in 2013 (after harvesting) and 15 fields in 2014 (before planting) in Inner Mongolia, and 75 fields in Heilongjiang in 2016 (before planting; Table C1 and C2 in Appendix $C$ of this thesis). The soil samples were taken for a depth of $0-25 \mathrm{~cm}$, which is the ploughing depth of the surveyed regions. The soil samples were tested in the laboratory of Eurofins Agro, the Netherlands (http://eurofins-agro.com/nl-nl/). Soil characteristics were not measured for the surveyed fields in Gansu, and for this region we refer to soil analysis data from other studies available in the literature (Shang et al., 2012). The soil texture of the surveyed fields in Inner Mongolia was either sandy loam, loam or silt loam; in Gansu silt loam (Wang et al., 2010), and in Heilongjiang either clay loam, silty clay, or silty clay loam. For fields in Inner Mongolia and Heilongjiang, the soil $\mathrm{N}$ uptake was estimated from measured total $\mathrm{N}$, $\mathrm{C} / \mathrm{N}$ ratio, $\mathrm{pH}$, and soil biological parameters by the Eurofins laboratory (Brolsma, personal communication, 2019). It is assumed to reflect the $\mathrm{N}$ uptake by plants from the soil mineral $\mathrm{N}$ supply in an unfertilized soil. The soil mineral $\mathrm{N}$ supply accounts for both mineral $\mathrm{N}$ (nitrate- $\mathrm{N}$ and ammonium-N) in the soil at the time of soil sample collection and mineralizable $\mathrm{N}$ from SOM becomes available as mineral $\mathrm{N}$ during the growing season. We refer to the lab based soil $\mathrm{N}$ uptake as SNU.

The data and information concerning farm, field, potato variety, fertiliser, irrigation, and other management practices were collected during farmer interviews in 2017 and 2018. For Inner Mongolia, the data were collected by the local agronomists; the lead author also participated in the data collection. The data was collected from 25 farms in 2017 and 22 farms in 2018. Some farms were at the border of Inner Mongolia and Hebei province and belonged to Hebei from an administrative view; hereafter we refer to Inner Mongolia only, for brevity. The major potato variety was Innovator. Each farm had multiple fields, and in total 181 and 172 fields were surveyed in 2017 and 2018, respectively. The tuber fresh matter (FM) yield of each field was measured approximately 10 days before harvesting, by taking samples of $3 \mathrm{~m}$ along a ridge randomly selected in a land unit of 33.3 ha in each field (one sample was used for a field of maximum 33.3 ha; if the field was larger than 33.3 ha, multiple samples were collected and 
the average yield value of the land units was taken to represent the yield of an individual field). We verified whether the yield (ton FM ha ${ }^{-1}$ ) estimated by the 3-m samples represented well the total production for all fields per farm at harvest as measured in the factory (see Fig. C1 in Appendix C). For each farm, irrigation amount $(\mathrm{mm})$ per application was monitored (3-5 rain gauges were randomly allocated in the field and the average value was calculated) for one of the fields and assumed equal for the other fields sampled per farm). The daily rainfall over the growing season (from sowing to harvesting) was obtained at farm level (one or multiple rain gauges were allocated to each farm - usually close to the farmer's house - to monitor the daily rainfall).

In Gansu, 20 farms (65 fields) were interviewed in 2017, and 19 farms (28 fields) were surveyed in 2018 by the lead author. The major potato variety was Atlantic. In Heilongjiang, 21 farms (62 fields) were surveyed in 2017, and 19 farms (43 fields) were surveyed in 2018 by the lead author. Various potato varieties were planted such as Kexin, Yanshu, and Qingshu. For both regions, the yield data (in FM) was surveyed based on farmers' recall through a phone call after harvesting. Based on farmers' recall, the yield (ton $\mathrm{FM} \mathrm{ha}^{-1}$ ) was estimated by dividing the total production of the field by the field area (or for a particular variety in the field if multiple varieties were planted). The total production was measured at the local processing factory when delivering the product. For both regions, irrigation type and amount ( $\mathrm{mm}$ ) per application were surveyed for each field based on farmers' recall (information such as duration of irrigation per application, water volume over time, and water volume per land area were collected). The daily rainfall of the surveyed regions in Gansu and Heilongjiang in the two years was obtained from online sources (NASA, 2019, for Gansu; National Meteorological Information Center, 2019, for Heilongjiang). For both regions, the weather station that was nearest to the surveyed regions was selected.

\subsubsection{Assessing yield, resources use efficiencies and environmental impacts}

We used target values (upper and lower) for resource use efficiencies, and the environmentally safe threshold for $\mathrm{N}$ surplus based on the EU Nitrogen Expert Panel (2015) and model simulations. We defined the minimum $\mathrm{N}$ yield based on the yield at the economic break-even point (lower target yield), and added a maximum $\mathrm{N}$ yield based on the exploitable yield (upper target yield, $85 \%$ of the potential yield, see the below Section). The distance between current and target values in yield, nitrogen use efficiency (NUE) and water productivity (WP) were identified to evaluate the scope for improvement. Based on our analysis using farm level data and accounting for the measured soil $\mathrm{N}$ uptake (SNU), we provide suggestions for sustainable $\mathrm{N}$ fertiliser management in the short-term. In addition, taking into account the long-term soil $\mathrm{N}$ dynamics and currently feasible technologies, we provide suggestions for the NUE and $\mathrm{N}$ surplus targets in the long-term for potato production in northern China. Finally, we add targets for sustainable water management (WPe). The statistical analysis was performed using $\mathrm{R}$ Statistical Software. 
Yield

The average actual yield ( $\mathrm{Ya}$ ) was calculated per region per year. Potential yield (Yp) was defined as the yield obtained under non-water-limiting growing conditions (Van Ittersum et al., 2013). The Yp was estimated per region per year using the World Food Studies (WOFOST) model (de Wit et al., 2018). The model was calibrated and validated based on a field experiment conducted in Heilongjiang for the Innovator cultivar (Chapter 2). It estimates dry matter (DM) yield, which was converted to FM with a DM percentage of $20.8 \%$ (Chapter 2). The weather data were obtained from online sources (National Meteorological Information Center, 2019, for Inner Mongolia and Heilongjiang; NASA, 2019, for Gansu) for the nearest weather stations (reference weather stations, RWS) to the surveyed area. For Inner Mongolia, two RWS were selected, whereas for Gansu and Heilongjiang, one RWS was used per region. For each year, two Yp estimations (based on the two RWS) were obtained for Inner Mongolia (average value was used to represent the Yp), and one Yp estimation (based on one RWS) was obtained for Gansu and Heilongjiang, respectively.

Although $Y p$ is achievable theoretically, it is generally not cost-effective to obtain $100 \%$ of $Y p$ due to the diminishing returns principle (Cassman et al., 2003). Thus $85 \%$ of Yp (exploitable yield, Ye) was used as upper target yield for all regions (Van Ittersum et al., 2013; www.yieldgap.org). The exploitable yield gap (Yg-e) was estimated as the difference between Ye and Ya (Van Ittersum et al., 2013). The Yg-e was estimated per region and per year. The lower target yield was assumed the financial breakeven point (at this point the production neither makes profit nor suffers loss). As the breakeven point differs for different regions and for various production purposes (starch, flakes, and French Fries processing) and the market price, the lower target yield (ton $\mathrm{FM} \mathrm{ha}^{-1}$ ) was estimated based on production costs (renminbi [official currency of China, RMB] ha ${ }^{-1}$ ) and sale prices (RMB ton ${ }^{-1} \mathrm{FM}$ ) of surveyed farms per region.

\section{Water productivity and water surplus}

Water productivity (WP), defined as the ratio between crop dry matter yield $\left(\mathrm{kg} \mathrm{DM} \mathrm{ha}^{-1}\right)$ and water use via evapotranspiration (ET, mm), represents the food production at the cost of water use in the hydrological domain (Van Halsema and Vincent, 2012; www.yieldgap.org). Water productivity connects yield formation directly with crop water consumption and allows to compare across varieties, time, and locations. A lower WP implies more water evapotranspired to produce the same amount of DM. The actual water productivity (WPa) was calculated per region and per year as the ratio between actual tuber DM yield and the actual ET. The model estimates the potential ET, and we assumed that under non-water-limiting conditions, the actual ET equals the potential ET. The potential water productivity (WPp) was estimated per region and per year based on the Yp and potential ET. The exploitable water productivity (WPe) was estimated as $85 \%$ of WPp. It was used as the upper target for WP. The water productivity gap (WPg) was estimated per region and per year, as the difference between the WPe and WPa, to indicate the scope for improvement. 
For potato growers in northern China, irrigation (irrigation water and irrigating) is one of the costliest management practices and requires a lot of labor, thus high water surplus implies unnecessary costs and waste of labor. To also address the waste part, the water surplus was estimated. Water surplus is proposed in this study as the water input minus actual ET per growing season (from sowing till harvesting). Water input included both irrigation water and rainfall during the growing season. The irrigation amount $(\mathrm{mm})$ of surveyed fields was the sum of the irrigation volumes across all applications. Due to data limitations, plant available water in the soil at sowing was not considered in calculating water input. The average ET $(\mathrm{mm})$, irrigation $(\mathrm{mm})$, rainfall $(\mathrm{mm})$, and water surplus $(\mathrm{mm})$ were estimated per region and per year.

\section{Nitrogen use efficiency and nitrogen surplus}

The input-output framework of nitrogen use efficiency (NUE) as proposed by the EU Nitrogen Expert Panel (2015) was used to evaluate the NUE, and the environmental impacts of $\mathrm{N}$ use in potato production. The NUE was estimated based on the mass balance principle (Equations 4.1-4.3). NUE $\left(\mathrm{kg} \mathrm{kg}^{-1}\right)$ was defined as the ratio between $\mathrm{N}$ output and $\mathrm{N}$ input.

$$
\begin{gathered}
N \text { input }=N \text { fertiliser }+N \text { deposition } \\
N \text { output }=N \text { removed in harvested product }
\end{gathered}
$$

$N$ surplus $=N$ input $-N$ output $=N$ losses + change in soil mineral $N$ supply Equation 4.3

$$
\begin{gathered}
N^{\text {avail }}=N \text { input }+ \text { soil } N \text { uptake } \\
N \text { surplus }^{\text {avail }}=N \text { surplus }+ \text { soil } N \text { uptake }
\end{gathered}
$$

Equation 4.1

Equation 4.2

Equation 4.4

Equation 4.5

$\mathrm{N}^{\text {avail }}$ indicates the total amount of available $\mathrm{N}$ after accounting for the SNU as $\mathrm{N}$ input; $\mathrm{N}$

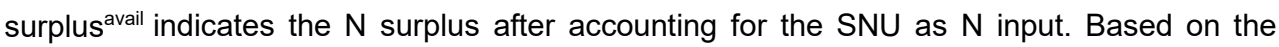
framework, the $\mathrm{N}$ input ( $\mathrm{kg} \mathrm{ha}^{-1}$; Equation 4.1) is the total amount of $\mathrm{N}$ that enters the field via fertiliser and atmospheric deposition. The only $\mathrm{N}$ fertiliser used in the study regions was mineral fertiliser (often urea 46-0-0 and/or compound fertiliser with various combinations of NPK). Organic fertiliser was not applied in any of the surveyed fields. The $\mathrm{N}$ input from atmospheric deposition $\left(\mathrm{kg} \mathrm{ha}^{-1} \mathrm{yr}^{-1}\right)$ for the three regions was assumed equal to the estimation by $\mathrm{Xu}$ et al., (2015a) for the northeast (Heilongjiang, $28 \mathrm{~kg} \mathrm{ha}^{-1}$ ) and the northwest (Inner Mongolia and Gansu, $19 \mathrm{~kg} \mathrm{ha}^{-1}$ ) of China.

The $\mathrm{N}$ output ( $\mathrm{kg} \mathrm{ha}^{-1}$; Equation 4.2) was the $\mathrm{N}$ removed from the field with the harvestable product (tubers), and was calculated based on tuber FM yield ( $\mathrm{kg} \mathrm{FM} \mathrm{ha}^{-1}$ ), a default DM percentage (20.8\%; Chapter 2) and an assumed $\mathrm{N}$ concentration in dry tubers (1.62\%). The $\mathrm{N}$ surplus (kg ha-1; Equation 4.3) is the difference between $\mathrm{N}$ input and $\mathrm{N}$ output. It consists of $\mathrm{N}$ losses ( $\mathrm{N}$ leaching, $\mathrm{N}$ runoff, and gaseous $\mathrm{N}$ losses such as $\mathrm{NH}_{3}, \mathrm{~N}_{2}, \mathrm{NO}_{\mathrm{x}}$ ), and changes in the soil mineral $\mathrm{N}$ supply. $\mathrm{N}$ surplus is a critical component in judging the environmental effect (EU Nitrogen Expert Panel, 2015). The average $\mathrm{N}$ input, $\mathrm{N}$ output, NUE, and $\mathrm{N}$ surplus were assessed for each of the fields surveyed per region and per year. 
The upper target value for NUE was assumed to be $90 \%$ for all regions and years, implying very efficient use of $\mathrm{N}$ fertiliser (EU Nitrogen Expert Panel, 2015). A NUE higher than $90 \%$ may be associated with soil mining, but this need not be problematic in regions with high soil mineral $\mathrm{N}$ supply or could even be desirable to decrease the risk of $\mathrm{N}$ losses. We defined the NUE gap as the difference between the upper target NUE value $(90 \%)$ and the actual NUE and calculated its value per region and per year. The lower target value of NUE was assumed to be $50 \%$, and the upper target value for $\mathrm{N}$ surplus was assumed to be $80 \mathrm{~kg} \mathrm{ha}^{-1}$ (EU Nitrogen Expert Panel, 2015). These values were assumed the same as tentatively set for Europe. We use these target values as a starting point and will discuss their relevance for potato production in northern China when considering long-term soil $\mathrm{N}$ dynamics and currently available technologies.

The soil mineral $\mathrm{N}$ supply is not considered as $\mathrm{N}$ input by the EU Nitrogen Expert Panel framework as it is assumed stable over years (thus the change in soil mineral $\mathrm{N}$ supply [Equation 4.3] is small and $\mathrm{N}$ surplus reflects the $\mathrm{N}$ losses well). However, we argue that it should be taken into account in giving short-term recommendations if current soil mineral $\mathrm{N}$ supply is high due to high SOM (which will inevitably decrease in time under arable cropping), and excessive past mineral $\mathrm{N}$ fertiliser or manure use (thus soil mineral $\mathrm{N}$ supply changes over years, and $\mathrm{N}$ surplus reflects $\mathrm{N}$ losses correctly only if the net change in soil mineral $\mathrm{N}$ supply over years is considered). The SNU by the crop was estimated for fields in each region (Table C1 in Appendix C, also see Data collection). To account for the variation in SNU, the average, 5th or 95th percentiles of SNU per region and year (Table C2 in Appendix C) were added to the $\mathrm{N}$ input, to arrive at the total amount of available $\mathrm{N}$ ( $\mathrm{N}^{\text {avail; }}$; Equation 4.4). With this amount as reference, the corresponding NUE and $\mathrm{N}$ surplus are denoted as NUE ${ }^{\text {avail }}$ and $\mathrm{N}$ surplus ${ }^{\text {avail }}$ (Equation 4.5), respectively.

\subsubsection{Assessing yield, nitrogen use efficiency and environmental impacts for current conditions (short-term)}

Relationships between $\mathrm{N}$ input, $\mathrm{N}$ output, NUE, and $\mathrm{N}$ surplus were expressed in scatter plots for the three regions and the two years. This was done without (Current Situation I) or with (Current Situation II) considering the measured soil $\mathrm{N}$ uptake (for the average, 5th and 95th percentiles of SNU) as $\mathrm{N}$ input. Note, that for Current Situation I, the terms related to soil $\mathrm{N}$ were removed from Equations 4.3-4.5. For Current Situations I and II, the target values for yield (lower and upper yield target), NUE (50\% and $90 \%)$, and $\mathrm{N}$ surplus (80 kg ha ${ }^{-1}$ ) were visualized in the plots. It should be noted that the upper and lower targets of NUE $(90 \%$ and $50 \%$ ) and $\mathrm{N}$ surplus ( $80 \mathrm{~kg} \mathrm{~N} \mathrm{ha}^{-1}$ ) were defined for a soil $\mathrm{N}$ supply in equilibrium, which is not the case in our conditions. Thus, these targets should not be used when including SNU in the total $\mathrm{N}$ input, but we use them as a reference to allow direct comparison of NUE and N surplus between the Current Situations I and II. For Current Situation I, the proportion of fields that meets the lower target values for yield (yield > lower target yield), resource use efficiency (NUE $>50 \%$ ), and the environmental effect ( $\mathrm{N}$ surplus $<80 \mathrm{~kg} \mathrm{ha}^{-1}$ ) were identified for each region (of two years jointly). This assessment was not performed for Current Situation II, as the target values (NUE and N surplus) should be changed when SNU is considered. The 
compromise between achieving acceptable levels of yield, NUE, and environmental effects (N surplus) provides a basis for improved strategies of $\mathrm{N}$ fertiliser management in the short term.

\subsubsection{Evaluating long-term situations}

Earlier we showed a large scope for improving potato yield in northern China (Chapter 2). To understand whether and how sustainable intensification can be achieved, we chose two situations that aim at different target yields, that is, current yield level (Ya), and a higher yield level (Ye). We considered long-term soil $\mathrm{N}$ dynamics and currently available technologies to estimate the optimal feasible NUE and $N$ surplus in the long term. The annual $N$ input requirement (from $\mathrm{N}$ fertiliser input and $\mathrm{N}$ deposition) was estimated for the different target yields based on a simple equilibrium model developed by Ten Berge et al. (2019). The model assumed that under highly efficient $\mathrm{N}$ management, a given target yield can be sustained by an annual total $\mathrm{N}$ input (AT; from both fertilisers and atmospheric $\mathrm{N}$ deposition) that is equal to the corresponding annual total crop N uptake (UT). Another assumption is that in the long term, the soil mineral $\mathrm{N}$ supply is constant (steady state equilibrium), which means that once equilibrium has been reached, the outflow from the soil mineral $\mathrm{N}$ supply (annual $\mathrm{N}$ mineralization) is equal to the annual inflow. The latter inflow is expressed as a fraction (retention efficiency, RETE) of all $\mathrm{N}$ that becomes available for uptake but is not exported in harvested product: non- absorbed fertiliser- $\mathrm{N}$, non-absorbed $\mathrm{N}$ from the soil mineral $\mathrm{N}$ supply, and $\mathrm{N}$ in crop residues. For simplicity, we assumed a potato monoculture as crop rotation.

To fulfill the above condition ( $A T=U T$ ), the recovery efficiency of $N$ from $N$ fertiliser (REF), the recovery efficiency of $\mathrm{N}$ from the soil mineral $\mathrm{N}$ supply (RES), and the RETE all have to be maintained at a certain high level. Based on the principle of the response of yield to the interactions between different macronutrients (N, P, K; Janssen et al., 1990), Ten Berge et al. (2019) developed a protocol to estimate the recovery efficiency of $N(R E)$ and internal use efficiency of $\mathrm{N}$ (IE) for a target yield for a balanced nutrient supply $(N, P, K)$ and non-nutrient limited production. An initial value of RE and IE is assumed for a situation when the nutrient (in our case, $\mathrm{N}$ ) is managed most efficiently and the macronutrients $(\mathrm{N}, \mathrm{P}, \mathrm{K})$ are in balanced supply (medium dilution; Ten Berge et al., 2019). With highly efficient $\mathrm{N}$ fertiliser management, the REF for the potato crop was assumed to be $55 \%$ (Vos, 2009). This value refers to production practice in Europe at economically optimum $\mathrm{N}$ fertiliser input. The RES was assumed to be equal to the REF. The IE of potato was assumed $71.5 \mathrm{~kg}$ tuber DM per $\mathrm{kg}$ crop $\mathrm{N}$ uptake (Janssen, 2017; Ten Berge et al., 2019). Both RE and IE are assumed constant (the initial values), regardless of the target yield (Yt) when the ratio between the $\mathrm{Yt}$ and the $\mathrm{Yp}$ $(\mathrm{Yt} / \mathrm{Yp}$ ) is below a critical value (Fig. C2 in Appendix C). Beyond that critical yield ratio, both $\mathrm{RE}$ and IE decrease following a quadratic relationship and become zero when the $\mathrm{Yp}$ is obtained (Yt/Yp = 1; Fig. C2 in Appendix C).

Based on the approach described by Ten Berge et al. (2019) and data from Janssen (2017) and Vos (1997), RE and IE for different target yields (Ya and Ye) in the three regions were estimated (Table C3 in Appendix C). The $\mathrm{N}$ concentration in tuber dry matter of the two target yields was based on a fixed nitrogen harvest index $(\mathrm{NHI}=84 \%$; Janssen, 2017; Velthof and 
van Erp, 1999) and on IE. A fixed NHI was assumed based on data from Janssen (2017) and Vos (1997) and the harvest index (HI) for the potato dry matter was assumed .87 for both yield targets (Vos, 1997). Having set these parameters, it follows that to fulfill the assumptions of the simple equilibrium model, the RETE attains the value of 86 and $88 \%$ for $\mathrm{Ya}$ and $\mathrm{Ye}$, respectively (Table C3 in Appendix $\mathrm{C}$ ). The $\mathrm{N}$ input, $\mathrm{N}$ output, NUE, and $\mathrm{N}$ surplus for the two target yields ( $\mathrm{Ya}$ and $\mathrm{Ye}$ ) in the long-term situation were identified and compared with those derived from the Current Situation I (2018) for the three regions.

\subsection{Results}

\subsubsection{Yield}

The average $\mathrm{Ya}$ of the surveyed regions over 2 years was 37.4 ton $\mathrm{FM} \mathrm{ha}^{-1}$ (Table 4.1). The average $\mathrm{Ya}$ in Inner Mongolia (40.5 ton FM ha ${ }^{-1}$ ) and Gansu (40.7 ton FM ha-1) was higher than that in Heilongjiang (31.2 ton FM ha ${ }^{-1}$ ). The average Ya in all three regions was higher than the lower target yields in both years (Table 4.1). The percentage of fields that meet the lower target value for yield in the three regions (based on all year and field combinations) was $74 \%$ in Inner Mongolia, 88\% in Gansu, and 76\% in Heilongjiang (Figure 4.1). The average Yp across all regions and years was 51.8 ton FM ha-1 (Table 4.1). The Yp in Inner Mongolia and Gansu was higher than that in Heilongjiang in both years, reflecting more favourable climatic conditions for potato production in the two regions (i.e., lower temperature). There was a large scope for improving yield in all regions (the average relative $\mathrm{Yg}$-e was $24 \%$ ). 


\section{Current Situation I}

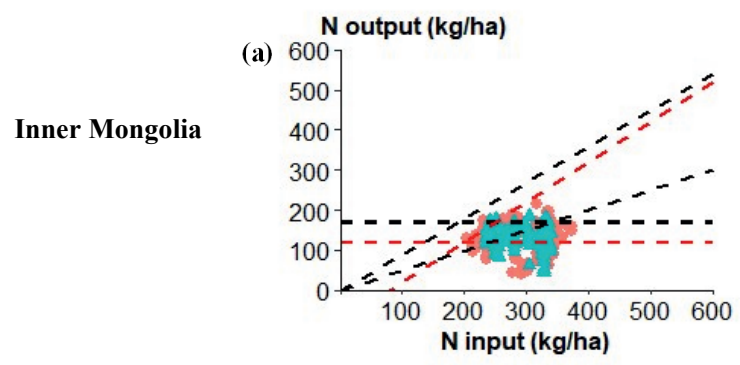

Gansu

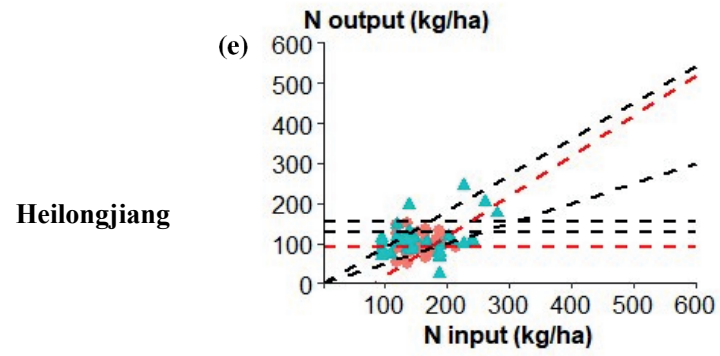

(c) 600

N output (kg/ha)

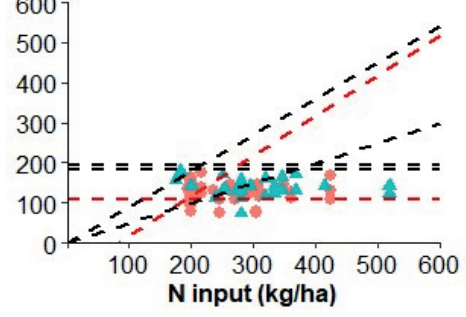

\section{Current Situation II}

$\mathrm{N}$ output (kg/ha)

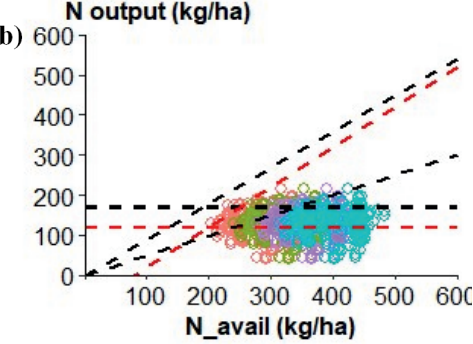

N output (kg/ha)

(f) 600 output $(\mathrm{kg} / \mathrm{ha})$

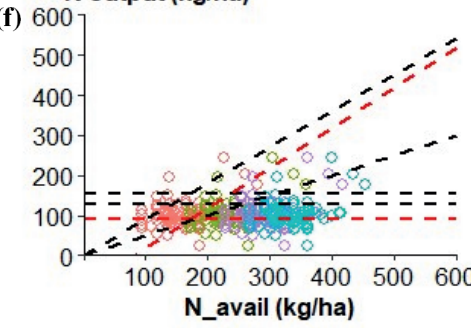

Figure 4.1. The nitrogen $(\mathrm{N})$ balance of potato production ( $\mathrm{N}$ input, $\mathrm{N}$ output, nitrogen use efficiency (NUE) and $\mathrm{N}$ surplus) in Inner Mongolia (a, b), Gansu (c, d) and Heilongjiang (e, f) and two years $(2017,2018)$. In the Current Situation I, $(\mathrm{a}, \mathrm{c}, \mathrm{e})$, the soil $\mathrm{N}$ uptake (SNU) was not considered in $\mathrm{N}$ input, and different colors indicate different years (red 2017, blue 2018). In the Current Situation II, (b, d, f), the various values of SNU (0, $5^{\text {th }}$, average, and $95^{\text {th }}$ SNU) were included in the $\mathrm{N}$ input for 2017 and 2018 jointly, and different colors indicate various SNU (red 0 , green $5^{\text {th }}$, purple average, and blue $95^{\text {th }} \mathrm{SNU}$ ). The two black horizontal lines indicate, respectively, the upper target level for $\mathrm{N}$ output per region for 2017 and 2018 (calculated based on 85\% of the Yp per region per year) and the red horizontal line indicates the lower target levels of $\mathrm{N}$ output per region (calculated based on the lower target yield for each region). The black diagonal dashed lines indicate the upper (90\%) and lower (50\%) target values for NUE. The red diagonal dashed lines indicate the target level for $\mathrm{N}$ surplus $\left(80 \mathrm{~kg} \mathrm{ha}^{-1}\right)$. 


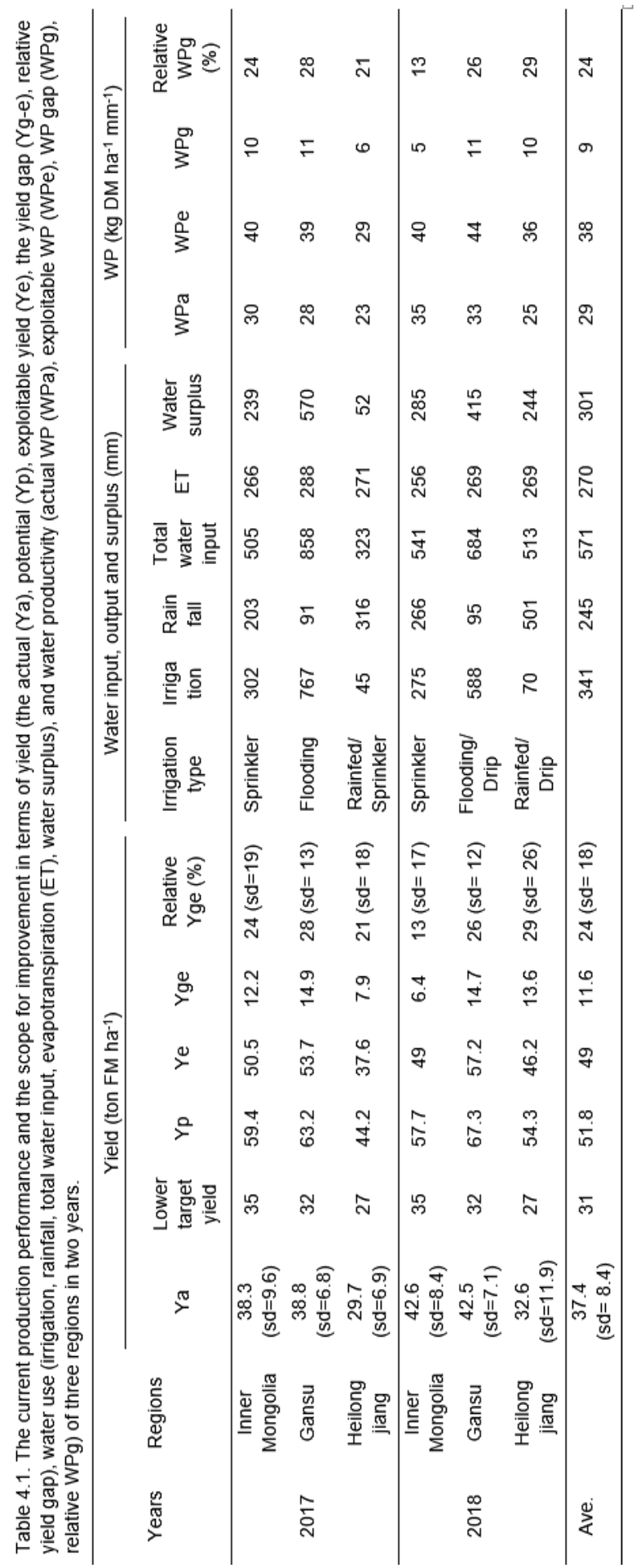




\subsubsection{Water input, water productivity and water surplus}

The irrigation amount was highest in Gansu and lowest in Heilongjiang in both years, where rainfall was lowest in Gansu and highest in Heilongjiang (Table 4.1). For all regions and years, the total water input was much higher than the estimated ET (Table 4.1). The water surplus was highest in Gansu in both years due to the high irrigation input, implying that water was not used efficiently and was lost through runoff and/or deep drainage. The WPa was lowest in Heilongjiang in both years due to the low Ya obtained in the region. For the three regions, WP can be increased to $29-44 \mathrm{~kg} \mathrm{DM} \mathrm{ha}^{-1} \mathrm{~mm}^{-1}$ (WPe) by enhancing yield. Water surplus can be reduced by more efficient management of irrigation and rainfall water (drip irrigation, mulching). It should be noted that the initial soil water content at sowing was not taken into consideration when estimating total water input, and thus the water surplus may have been underestimated or overestimated.

\subsubsection{Nitrogen input, nitrogen use efficiency and nitrogen surplus (short-term)}

Both $\mathrm{N}$ fertiliser and total $\mathrm{N}$ input (including $\mathrm{N}$ deposition) were highest in Inner Mongolia, lowest in Heilongjiang, and intermediate in Gansu (Table 4.2). For the Current Situation I (SNU was excluded from N input), the average NUE across years in Gansu (51\%) and Heilongjiang $(68 \%)$ were above the lower target value of NUE (50\%), whereas NUE in Inner Mongolia (47\%) was below that target (Table 4.2). The $\mathrm{N}$ surplus in Inner Mongolia (156 kg N ha-1) and Gansu (132 $\mathrm{kg} \mathrm{N} \mathrm{ha}^{-1}$ ) was beyond the target value $\left(80 \mathrm{~kg} \mathrm{ha}^{-1}\right)$, whereas $\mathrm{N}$ surplus in Heilongjiang $\left(50 \mathrm{~kg} \mathrm{~N} \mathrm{ha}^{-1}\right.$ ) was well below the target. The percentage of fields that met the lower target NUE (50\%) was 33\% in Inner Mongolia, $48 \%$ in Gansu, and $88 \%$ in Heilongjiang; and the percentage of fields that met the target $\mathrm{N}$ surplus $\left(80 \mathrm{~kg} \mathrm{ha}^{-1}\right)$ was $3 \%$ in Inner Mongolia, $32 \%$ in Gansu, and $77 \%$ in Heilongjiang (Figure 4.1a, c, e).

The SNU was estimated to vary largely across fields within a region (Table 4.2). It was much higher in Heilongjiang than in the other two regions. The average SNU in Heilongjiang was higher than the $\mathrm{N}$ output, indicating that $\mathrm{N}$ fertiliser could be omitted in the short-term, perhaps without compromising yield. For Current Situation II (various SNU values were added to N input), the data points move towards the right, further away from the desired space (Figure $4.1 \mathrm{~b}, \mathrm{~d}, \mathrm{f}$ ). The average NUE ${ }^{\text {avail }}$ (between $32 \%$ and $45 \%$ ) became lower for all three regions, but particularly for Heilongjiang, and the average $\mathrm{N}$ surplus ${ }^{\text {avail }}$ became higher $(128-265 \mathrm{~kg}$ $\left.\mathrm{ha}^{-1}\right)$. The differences in NUE $\mathrm{E}^{\text {avail }}$ across different regions became smaller, yet $\mathrm{N}$ surplus ${ }^{\text {avail }}$ was still higher in Inner Mongolia than in the other two regions (Table 4.2). 


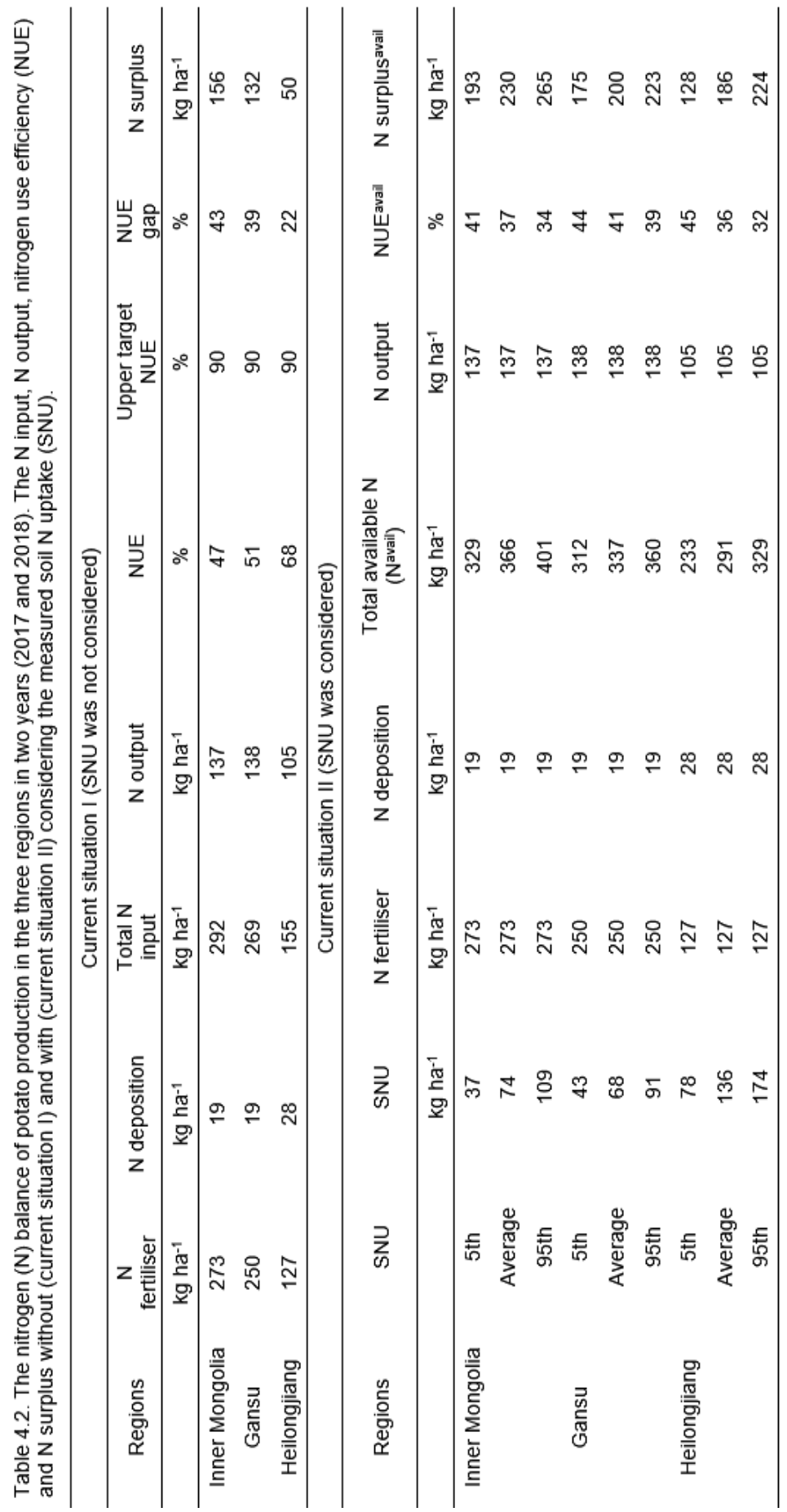




\subsubsection{Evaluating different situations based on the long-term soil nitrogen balance}

For Inner Mongolia, following our long-term approach, the $\mathrm{N}$ fertiliser requirement for both target yields (for Ya, $126 \mathrm{~kg} \mathrm{ha}^{-1}$; for $\mathrm{Ye}, 167 \mathrm{~kg} \mathrm{ha}^{-1}$ ) was much less than the actual $\mathrm{N}$ fertiliser input in 2018 (276 kg ha-1; Table 4.3). When the target yield approaches Yp, both the recovery efficiency and internal use efficiency decreased (REF was 0.55 for $Y a$ and 0.52 for $Y e$; IE was $62 \mathrm{~kg} \mathrm{DM} \mathrm{kg}^{-1} \mathrm{~N}$ for Ya and $55 \mathrm{~kg} \mathrm{DM} \mathrm{kg}^{-1} \mathrm{~N}$ for Ye; Table C3 in Appendix C). Therefore, the agronomic efficiency of $\mathrm{N}$ fertiliser (i.e., the gain in dry matter yield per unit of $\mathrm{N}$ fertiliser input) decreased with a yield increase from $\mathrm{Ya}$ to $\mathrm{Ye}$, and thus the requirement for $\mathrm{N}$ fertiliser increased. Compared to Current Situation I (2018), the NUE increased from 49 to $84 \%$ for both target yields ( $\mathrm{Ya}$ and $\mathrm{Ye}$ ), and $\mathrm{N}$ surplus decreased from 151 to 23 and $29 \mathrm{~kg} \mathrm{ha}^{-1}$ for $\mathrm{Ya}$ and $\mathrm{Ye}$, respectively. The increase in NUE ( $\mathrm{N}$ output/ $\mathrm{N}$ input) and the decline in $\mathrm{N}$ surplus ( $\mathrm{N}$ input $-\mathrm{N}$ output) can be attributed primarily to the reduced $\mathrm{N}$ fertiliser input (Table 4.3). The higher $\mathrm{N}$ output in the current situation than in the long-term situation, for the same target yield (Ya) was due to the lower $\mathrm{N}$ concentration in tuber dry matter for the long-term situation (1.38 and $1.54 \%$ for Ya and Ye, respectively; Table C3 in Appendix C) than the current situation (1.62\%), in which the $\mathrm{N}$ is accumulated due to the excessive supply of $\mathrm{N}$ fertiliser and limitation of other growing factors (Janssen et al., 1990).

For the Gansu region, the $\mathrm{N}$ fertiliser requirement was 113 and $198 \mathrm{~kg} \mathrm{ha}^{-1}$ for $\mathrm{Ya}$ and $\mathrm{Ye}$, respectively. Compared to the Current Situation I (2018), in the long-term situation the NUE increased from 49 to $84 \%$ for both $\mathrm{Ya}$ and $\mathrm{Ye}$, and $\mathrm{N}$ surplus declined from 151 to $21 \mathrm{~kg} \mathrm{ha}^{-1}$ for $\mathrm{Ya}$ and to $34 \mathrm{~kg} \mathrm{ha}^{-1}$ for Ye. The REF was 0.55 for Ya and 0.52 for $\mathrm{Ye}$; IE was $68 \mathrm{~kg} \mathrm{DM}$ $\mathrm{kg}^{-1} \mathrm{~N}$ for Ya and $55 \mathrm{~kg} \mathrm{DM} \mathrm{kg}^{-1} \mathrm{~N}$ for Ye (Table C3 in Appendix C).

For the Heilongjiang region, in the long-term, the $\mathrm{N}$ fertiliser requirement was 70 and $148 \mathrm{~kg}$ $\mathrm{ha}^{-1}$ for $\mathrm{Ya}$ and $\mathrm{Ye}$, respectively. Compared to the Current Situation I (2018), the NUE increased from 72 to $84 \%$ for both $\mathrm{Ya}$ and $\mathrm{Ye}$. N surplus decreased from 42 to $16 \mathrm{~kg} \mathrm{ha}^{-1}$ when targeting $\mathrm{Ya}$, and to $27 \mathrm{~kg} \mathrm{ha}^{-1}$ when targeting $\mathrm{Ye}$. The REF was 0.55 for $\mathrm{Ya}$ and 0.52 for $\mathrm{Ye}$; IE was 70 and $55 \mathrm{~kg} \mathrm{DM} \mathrm{kg}^{-1} \mathrm{~N}$ for Ya and Ye, respectively (Table C3 in Appendix C).

The results suggest that even when increasing yields to $\mathrm{Ye}, \mathrm{N}$ input can be reduced, NUE increased, and $\mathrm{N}$ surplus reduced in Inner Mongolia and Gansu, but in Heilongjiang larger $\mathrm{N}$ inputs may be needed for $\mathrm{Ye}$ (Table 4.3). Compared to $\mathrm{Ya}$, the yield target $\mathrm{Ye}$ is $13-29 \%$ higher across regions in the long-term situation, whereas the $\mathrm{N}$ surplus increased by $26-69 \%$, indicating a trade-off between yield and environmental effect. 


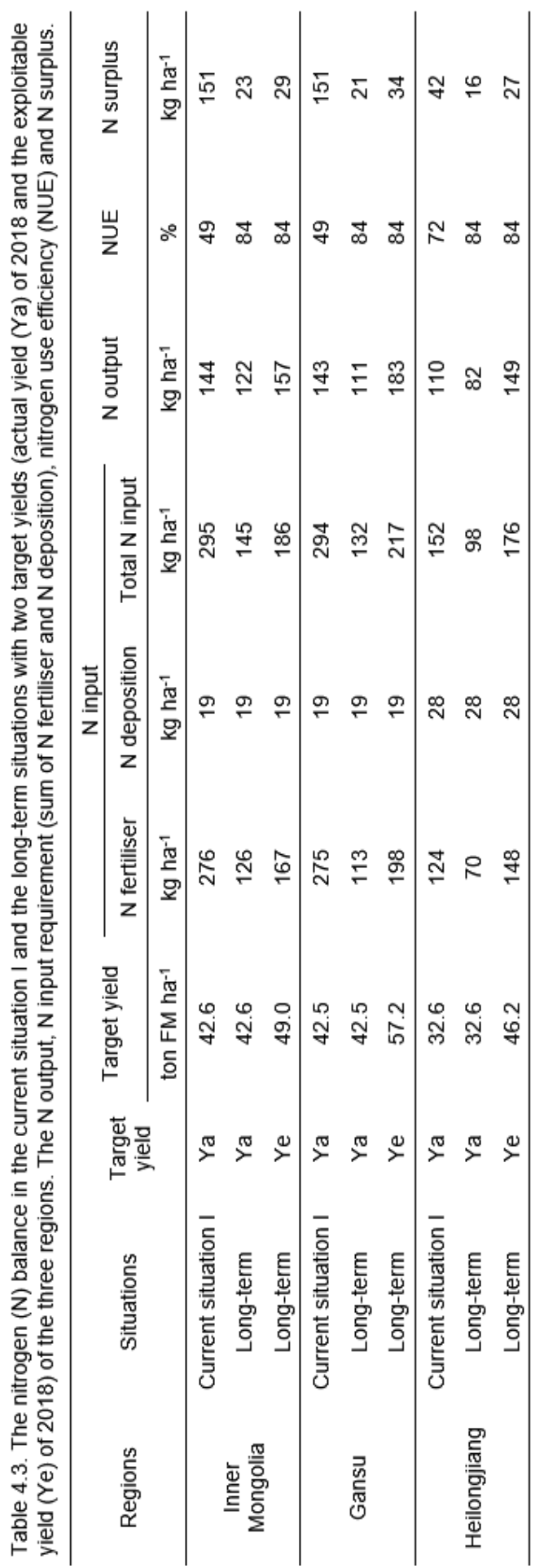




\subsection{Discussion}

\subsubsection{Yield}

The yield obtained by surveyed farmers ( 37.4 ton $\mathrm{FM} \mathrm{ha}^{-1}$ ) was much higher than the average value of the country (17 ton FM ha ${ }^{-1}$ in 2017; FAO, 2019). The seed tuber quality, technology, and mechanization level of the surveyed farms were superior to that of smallholder farmers in northern China. However, the Ya was still lower than the Ye estimated by the model. The major yield constraints for potato production in China are poor seed tuber quality (Inouye, 2018), limited availability of potato varieties for various production purposes (Jansky et al., 2009), and unbalanced nutrient supply (Duan et al., 2013). For the surveyed regions, poor soil conditions (compaction, shallow plough layer, lack of micronutrients), insufficient production inputs (machinery, labour, irrigation), and various pest and diseases problems (potato wilt, scab, late blight, early blight, etc.) were the major production constraints according to local agronomists and farmers (personal communications). In this study, a default DM percentage (20.8\%) was assumed for different varieties and various production purposes (French Fries, flakes, starch). The Yp, and the yield gap may be slightly different if different DM percentages for specific varieties were considered.

\subsubsection{Water use efficiency, water input and water surplus}

The ET (256-266 mm) and the WPe in Inner Mongolia (40 kg DM ha-1 $\mathrm{mm}^{-1}$ ) estimated in our study were close the values obtained by Jia et al. (2018; ET $=259 \mathrm{~mm}, \mathrm{WP}=37.4 \mathrm{~kg} \mathrm{DM} \mathrm{ha}^{-1}$ $\mathrm{mm}^{-1}$ ). The practice of covering land with plastic mulch is commonly applied in the surveyed farms in Gansu in order to reduce evaporation and maintain soil moisture. Despite this watersaving practice, water input and water surplus observed in Gansu was still high. With flooding irrigation, the total water input in the growing season is usually far above the ET requirement, whereas potato growth may still be limited due to water stress (Li et al., 2011). Sprinkler irrigation and drip irrigation consume much less water than flooding irrigation (Song et al., 2013). In Inner Mongolia, the total water input was higher than the ET in both years, yet water stress was observed by local farmers in some of the fields (based on farmers' interviews). This reflects the inefficient use of water (rainfall and irrigation) and loss of water resources (via runoff and deep drainage). Irrigation should be managed more efficiently tailored to the water requirements of the crops in specific growth stages. For Inner Mongolia and Gansu specifically, more efficient irrigation system (drip irrigation) is recommended to reduce irrigation water input and water surplus and to improve crop yield and water use efficiency. 


\subsubsection{Nitrogen use efficiency, nitrogen input and nitrogen surplus (short-term)}

For the Current Situation I (SNU was not considered as N input) the average NUE observed for potato production in northern China (47-68\% in different regions) was generally at a moderate level, whereas the $\mathrm{N}$ fertiliser input in the surveyed fields was $66-500 \mathrm{~kg} \mathrm{~N} \mathrm{ha}^{-1}$. A higher NUE (above 90\%) was observed in field experiments in the Netherlands with $\mathrm{N}$ fertiliser input of 100 to $250 \mathrm{~kg} \mathrm{~N} \mathrm{ha}^{-1}$ under fertigation conditions (SNU was also excluded; EU Nitrogen Expert Panel, 2015). Only in Heilongjiang region, a few fields with low $\mathrm{N}$ fertiliser input (less than $150 \mathrm{~kg} \mathrm{ha}^{-1}$ ) obtained a NUE above $90 \%$ (Figure 4.1e).

In the EU Nitrogen Expert Panel framework, soil mineral $\mathrm{N}$ supply was not considered as $\mathrm{N}$ input, which is defendable under the assumption that the soil mineral $\mathrm{N}$ supply can be considered stable over years. However, there is a lack of regulation on maximum $\mathrm{N}$ fertiliser input in crop land in China, and farmers tend to apply excessive amounts of $\mathrm{N}$ fertiliser to push the yield boundary (Liu et al., 2011; Xu et al., 2015b; Zhou et al., 2016). For instance, the N fertiliser input was as high as $700 \mathrm{~kg} \mathrm{~N} \mathrm{ha}^{-1}$ for large-scale commercial potato production in Inner Mongolia approximately 10 years ago and gradually reduced to the current level (200$300 \mathrm{~kg} \mathrm{~N} \mathrm{ha}^{-1}$; Wang, personal communication, 2018). In addition, soils in regions such as Heilongjiang have high SOM contents which will decline with long-term arable farming. Thus, it may be assumed that the soil mineral $\mathrm{N}$ supply is also currently in transition and will decline over the years. Under such conditions, the soil mineral $\mathrm{N}$ supply should be considered if the purpose of the analysis is to compare the production performance of different farms and monitor the change of a system over time. For comparative purpose, we have therefore included the SNU. However, for a fair comparison, the soil mineral $\mathrm{N}$ supply in the long-term equilibrium should be subtracted from the current soil mineral $\mathrm{N}$ supply. The resulting estimate provides the additional soil mineral $\mathrm{N}$ supply which is essentially related to the $\mathrm{N}$ losses. This long-term soil mineral $\mathrm{N}$ supply can be estimated by the model of Ten Berge et al. (2019) which we used, but depends on several assumptions, and was therefore not presented.

In addition, the target values (upper and lower targets of NUE and N surplus) should be changed accordingly when soil mineral $\mathrm{N}$ supply is considered. The target values that we used were tentatively set by the EU Nitrogen Expert Panel framework. Quemeda et al. (2020) suggested to use the first and third quartile of NUE to set lower and upper boundaries. These can be used to compare different farms and can be easily adopted. These are empirical values however, and do not necessarily relate to environmental effects.

For the Current Situation II, when SNU was added to the N input, the NUE was low and N surplus was high (Table 4.2). For the three surveyed regions, in the short-term, it was possible to improve NUE and reduce $\mathrm{N}$ surplus by reducing $\mathrm{N}$ fertiliser input and allowing soil mining. In Heilongjiang specifically, some fields have enough SNU to support the current average yield (Table 4.2). The scope to further reduce $\mathrm{N}$ fertiliser input depends on SNU, target yield, and the achievable recovery efficiency of $\mathrm{N}$ fertiliser. The short-term recommendations for $\mathrm{N}$ fertiliser input for specific fields should be based on reliable assessment of the SNU per field, 
which should thus be evaluated via on-farm field experiments, including control treatments without $\mathrm{N}$ fertiliser input.

The $\mathrm{N}$ surplus estimated in this study (on average $50-156 \mathrm{~kg} \mathrm{ha}^{-1}$ when SNU was not considered) is similar to that observed in farmers' fields for wheat $\left(89 \mathrm{~kg} \mathrm{ha}^{-1}\right)$ and maize (87 $\left.\mathrm{kg} \mathrm{ha}^{-1}\right)$, but much lower than that of vegetable (356 kg ha-1) and orchard fields (464 kg ha-1) in the North China Plain (Zhou et al., 2016). It was found that the major pathway of N losses in the arid and semi-arid area in northern China is through nitrate leaching and ammonia volatilization (Fan et al., 2010). The negative influence of $\mathrm{N}$ leaching on groundwater is limited in regions where the groundwater table is deep (Ju et al., 2006). However, due to the large $\mathrm{N}$ surplus, a substantial amount of nitrate enters the vadose zone (below the root zone and above the ground water surface), where denitrification is limited due to the high oxygen concentration, lack of carbon sources, and limited biological activity. The leached nitrate will gradually move downwards via intensive precipitation and irrigation (flood irrigation) and eventually threaten the groundwater quality (Fan et al., 2010; Ju et al., 2006; Zhou et al., 2016). Thus, a large N surplus is not only an economic loss to the growers but also a potential risk to the environment in the long term.

\subsubsection{Different situations based on the long-term soil nitrogen balance}

In the long-term, the estimated NUE was the same in both yield situations ( $\mathrm{Ya}$ and $\mathrm{Ye}$ ) in all regions (84\%; Table 4.3) because $\mathrm{N}$ input requirement was assumed equal to the crop $\mathrm{N}$ uptake for the target yield (Ten Berge et al., 2019). Therefore, NUE (the ratio between $\mathrm{N}$ output, i.e., $\mathrm{N}$ uptake in tubers, and $\mathrm{N}$ input) is equal to the $\mathrm{NHI}$ (the ratio between $\mathrm{N}$ uptake in tubers and $\mathrm{N}$ uptake in the whole crop, which is equal to the $\mathrm{N}$ input). The $\mathrm{NHI}$ was assumed to be the same for the two target yields (84\%; Janssen, 2017; Velthof and van Erp, 1999; see Materials and Methods section). However, it should be noted that the $\mathrm{NHI}$ may be different for different potato cultivars, and different values for $\mathrm{NHI}$ have been observed. High values of $88 \%$ (Vos, 1997) and 85\% (Biemond and Vos, 1992) have shown to be feasible, but current NHI in China ranges between 43 and $91 \%$, with an average of $64 \%$ (Xu et al., 2019), similar to what we found in our dataset.

Although NUEs above $90 \%$ are feasible in the short-term thanks to a high soil $\mathrm{N}$ supply, when considering long-term soil $\mathrm{N}$ dynamics and currently available technologies, our results suggest a maximum NUE of $84 \%$. To fulfill the long-term equilibrium conditions, the $\mathrm{N}$ resources (from fertiliser, soil, and crop residues) should be managed highly efficiently (REF was assumed $55 \%$ for Ya and 52\% for Ye; Table C3 in Appendix C; and RETE was estimated $86 \%$ for $\mathrm{Ya}$ and $88 \%$ for Ye; Table C3 in Appendix C). It should be noted, however, that a RETE of 86 to $88 \%$ may be difficult to achieve and maintain for the potato crop. Also, the REF obtained in experimental fields in Inner Mongolia ranged between 29 and $50 \%$ for potatoes in irrigated conditions (Duan et al., 2013), and only the maximum value (50\%) approached the value we assumed for the initial REF (55\%). Therefore, our estimations of NUE and N surplus are likely to be optimistic and must be verified experimentally, but they provide a benchmark based on literature and available empirical data, mostly for Dutch conditions. 
We assumed a monoculture in modelling $\mathrm{N}$; currently farmers do not employ a fixed rotation scheme. Yet, we recognize that for sustainable potato production, the crop should be rotated with cereal and non-cereal crops (maize, wheat, soybean, sunflower [Helianthus L.]) in a regular scheme. Proper rotation with such deep-rooting crops that can access the mineral $\mathrm{N}$ accumulated in deeper soil layers may improve RETE of the whole system. Ideally, the whole system must be considered when evaluating the system performance (in terms of yield, NUE, $\mathrm{N}$ surplus) by performing long-term field experiments and/or model simulations.

\subsubsection{Targets for sustainable intensification}

The EU Nitrogen Expert Panel set a lower target level for $\mathrm{N}$ yield of $80 \mathrm{~kg} \mathrm{~N} \mathrm{ha}^{-1}$. We adapted this lower target level to the economic breakeven yield, which was $91-118 \mathrm{~kg} \mathrm{~N} \mathrm{ha}^{-1}$ for potato in the three surveyed regions in China. The Ye can be used as an upper target for further intensification, corresponding to an average yield increase of $24 \%$ (relative Yge), to 37.6-57.2 ton FM ha-1 (127-193 $\mathrm{kg} \mathrm{N} \mathrm{ha}^{-1}$ ), depending on the year and region. The WPe was 29-44 kg $\mathrm{DM} \mathrm{ha} \mathrm{mm}^{-1} \mathrm{~mm}^{-1}$. The water surplus can be reduced, although temporal variability in water availability could still cause water stress, depending on initial soil water availability and weather variability. Many potato fields in northern China (Inner Mongolia and Gansu) performed below the lower NUE target of $50 \%$ (Figure $4.1 \mathrm{a}, \mathrm{c}$ ). In the short term, an NUE target (without considering SNU) of $90 \%$ or even higher is feasible on some farms in Heilongjiang, as soil mineral $\mathrm{N}$ supply is high due to the decomposition of SOM. The long-term situations showed that with currently available techniques, an NUE of $84 \%$ is a feasible target in the long term for both $\mathrm{Ya}$ and $\mathrm{Ye}$. A high REF (55\% for Ya and 52\% for Ye) and RETE (86\% for Ya and $88 \%$ for $\mathrm{Ye}$ ) are needed to make a NUE of $84 \%$ feasible in the long term. Our $\mathrm{N}$ surplus values of 27-34 $\mathrm{kg} \mathrm{N} \mathrm{ha}^{-1}$ in the long-term situation and Ye are much lower than the EU target of $80 \mathrm{~kg}$ $\mathrm{N}$ ha ${ }^{-1}$.

\subsection{Conclusion}

This study evaluated the current production performance in terms of yield, NUE, and WP and the scope to improve these simultaneously for potato production in northern China (Inner Mongolia, Gansu, and Heilongjiang). Farmers in Inner Mongolia and Gansu obtained higher yield than in Heilongjiang. Farmers in Inner Mongolia obtained highest $\mathrm{N}$ surplus, whereas those in Heilongjiang obtained lowest $\mathrm{N}$ surplus and water surplus due to the lower resource inputs. Farmers in Gansu obtained high water surplus due to the excessive irrigation water input. There was significant scope to improve yields, that is, from 37.6 to 57.2 ton $\mathrm{FM} \mathrm{ha}^{-1}$ in the different regions. The WP can be improved from $23-35$ to $29-44 \mathrm{~kg} \mathrm{DM} \mathrm{ha}^{-1} \mathrm{~mm}^{-1}$. Smarter irrigation systems (drip irrigation) are needed to improve WP and reduce water surplus. The current NUE was moderate and N surplus was high (when the SNU was excluded, NUE was $47-68 \%$ and $\mathrm{N}$ surplus was between $50-156 \mathrm{~kg} \mathrm{ha}^{-1}$; when SNU was added, NUE ${ }^{\text {avail }}$ was only $32-45 \%$ and $\mathrm{N}$ surplus ${ }^{\text {avail }}$ was $128-265 \mathrm{~kg} \mathrm{ha}^{-1}$ ) due to the high $\mathrm{N}$ fertiliser input and high SNU. In the short-term, NUE (without accounting for SNU) can be largely increased to above $90 \%$ due to a high $\mathrm{SNU}$, and $\mathrm{N}$ surplus can be reduced by improving the yield and/or reducing $\mathrm{N}$ 
fertiliser input. The evolution in soil $\mathrm{N}$ uptake should be considered for proper $\mathrm{N}$ fertilization. In the long term, with good agronomy including efficient nutrient management and avoidance of weeds, pests, and diseases, our results suggest it is possible to narrow the yield gaps and reduce the efficiency gaps and environmental effects at the same time. The upper target value of NUE (90\%) and $\mathrm{N}$ surplus ( $80 \mathrm{~kg} \mathrm{ha}^{-1}$ ) as applied by EU Nitrogen Expert Panel have been evaluated by considering long-term $\mathrm{N}$ dynamics and currently available technologies. For the potato crop in northern China, the estimated NUE in the long-term situation for the Ye under most efficient $\mathrm{N}$ management was $84 \%$, and $\mathrm{N}$ surplus was $27-34 \mathrm{~kg} \mathrm{ha}^{-1}$, which could be used as updated targets for the long term. These results must be verified experimentally with detailed measurements of nitrogen balances.

\subsection{Acknowledgements}

This work was supported by the China Scholarship Council (CSC) [grant number 201506610003]. We gratefully acknowledge input from Prof. Oene Oenema and Prof. Wim de Vries, Wageningen University \& Research (the Netherlands), on applying the EU NUE framework to potato production in northern China. We also thank Dr. Hein ten Berge, Wageningen University \& Research (the Netherlands), for his suggestions and careful revisions regarding the long-term scenarios. We would like to thank the three potato processing factories for coordinating the farm surveys and for sharing the data. We thank local farmers for their cooperation in farm interviews, and for providing information.

\subsection{Appendix C. Supplementary material}

Supplementary material related to this article can be found in the online version, and in Appendix $\mathrm{C}$ of this thesis. 



\section{Chapter 5}

\section{Enhancing sustainable potato production - a case study in northern China}

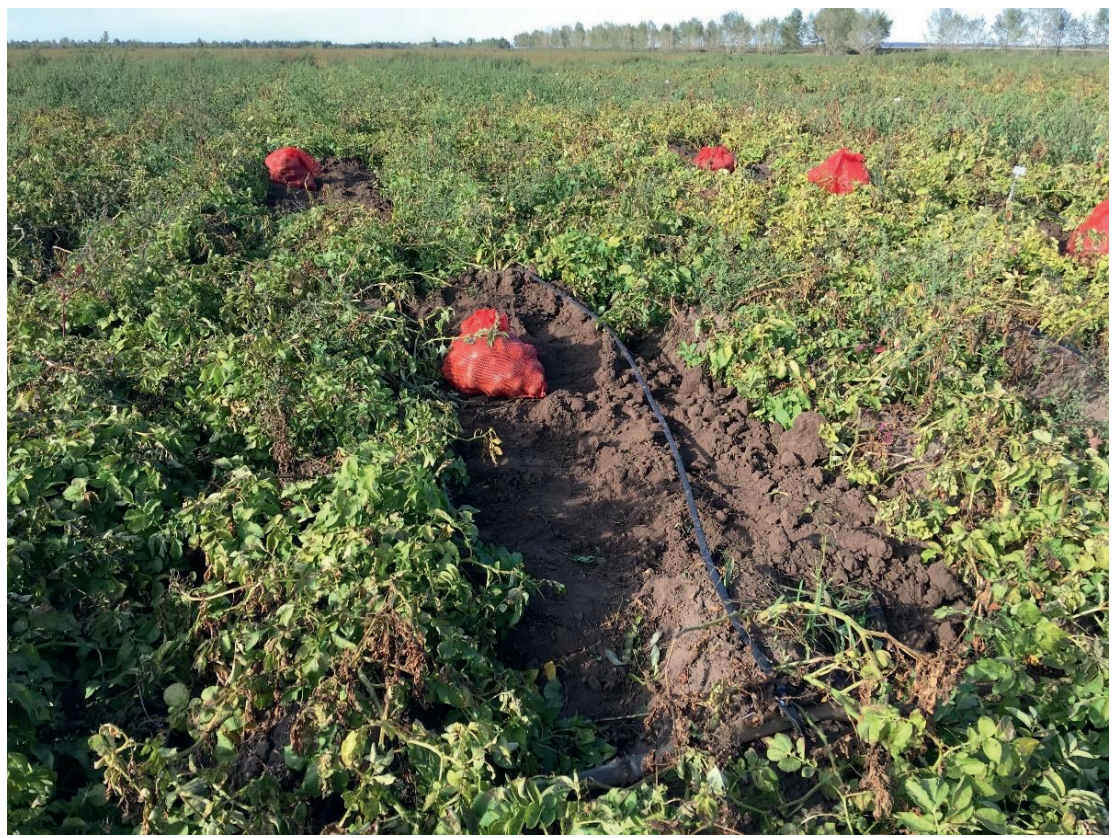

This chapter is in preparation as:

Wang N., Reidsma P., Wang Z.Q., Zhou X.H., Kempenaar, C., Lv D.Q., Van Ittersum M.K.. Enhancing sustainable potato production - a case study in northern China. 


\section{Abstract}

Potato is the fourth most important staple crop in China. To meet the increased demand and environmental objectives, potato production should be enhanced by sustainable practices that aim to maximize yield and resource use efficiencies and minimize environmental impacts. Most experiments so far have taken place on experimental stations, while on-farm experimentation is needed to demonstrate and scale more sustainable practices. On-farm field experiments were conducted in two years $(2017,2018)$ in northern China to investigate and demonstrate the effects of different nitrogen $(\mathrm{N})$ fertiliser and irrigation input levels on potato yield, quality, resource use efficiency and environmental impacts. The 2017 experimental results on one farmer's field showed that under irrigated conditions, adding $N$ fertiliser (from 0 to $267 \mathrm{~kg} \mathrm{ha}^{-1}$ ) did not increase yield, rather it reduced tuber quality. The 2018 experimental results, in which four additional farmers were involved, indicated that, under irrigated conditions, reducing $\mathrm{N}$ fertiliser from the current rates (189-252 kg ha-1) to lower levels (109-181 kg ha ${ }^{1}$ ) did not affect yield nor quality; while further reducing $N$ fertiliser inputs (to 9-117 kg ha-1) resulted in a yield reduction ( $18 \%$ on average) in some fields (with farmer-perceived good field conditions). In both years, irrigation improved potato yield and quality compared to that under rainfed conditions. The nitrogen use efficiency (the ratio between $\mathrm{N}$ output and $\mathrm{N}$ input) was improved and $\mathrm{N}$ surplus (the difference between $\mathrm{N}$ input and $\mathrm{N}$ output) was reduced by applying irrigation and reducing $\mathrm{N}$ fertiliser input. Farmers expressed they were willing to reduce $\mathrm{N}$ fertiliser input by $10-20 \%$, and indicated that a widespread adaptation to drip irrigation is hindered by the high costs and labor requirements. Sitespecific recommendations on optimum $\mathrm{N}$ fertiliser and irrigation management must be provided, which should preferably be based on regular quantitative monitoring of soil $\mathrm{N}$ supply and soil moisture content.

Keywords: Potato, yield, quality, nitrogen fertiliser, irrigation, resource use efficiency, sustainable intensification 


\subsection{Introduction}

China is the largest potato producing country in the world, both in terms of production area and quantity (FAO, 2019). Potato is critical for maintaining domestic food supply as a supplement to rice, maize and wheat (MOA, 2016). The scope for further increasing yield and production area for potatoes is large, which is reflected by the large yield gap (i.e., the difference between potential yield and actual farmers' yield) under both irrigated and rainfed conditions (Chapter 2; Van Ittersum et al., 2013).

Potato in northern China is mainly cultivated as a cash crop and often receives large amounts of nitrogen ( $N$ ) fertiliser input (USDA, 2018). Excessive $N$ fertiliser application has long been a common practice in China, which has caused low nitrogen use efficiency (NUE) and severe environmental problems (Li et al., 2013; Zhang et al., 2019). Excessive application of $\mathrm{N}$ fertiliser has little beneficial effect on yield due to the "diminishing marginal return principle" (de Wit, 1992), and has a negative effect on tuber quality (Storey and Davies, 1992). Many local studies have demonstrated the effects of various $\mathrm{N}$ fertiliser rates on potato yield, and provided recommendations on optimum $\mathrm{N}$ fertiliser rate for obtaining target yields and/or maximum profits (Duan et al., 2013; Li and Jin, 2012; Li et al., 2009). However, most of the studies were conducted in experimental fields where the soil conditions may be different from those of farmers' fields, while management practices used by farmers are much more diverse.

Irrigation is applied in some areas in the north to obtain high tuber yield and quality. Water resources are in severe limitation in northern China, and water should be used more efficiently to cope with the increasing water shortage (COWI, 2013; Jia et al., 2018; Tang et al., 2018). Improper water management, which may lead to both waterlogging and water stress, is one of the most important constraints limiting potato yield and quality (Li et al., 2011). Drip irrigation uses less water compared to the typical sprinkler irrigation system for obtaining the same yield, and thus uses water more efficiently (Li et al., 2011; Shock et al., 2013). Drip irrigation has become popular and is being demonstrated in some regions in northern China (Li et al., 2011). However, farmers schedule drip irrigation mainly based on experience and both over- or underirrigation is often observed in farmers' fields, which may lead to loss of both yield and quality. More efficient irrigation management is necessary, which should be based on regular quantitative monitoring of soil water content and estimation of daily crop water requirements (King and Stark, 1997).

Potato production requires sustainable practices that aim to use minimal resources to produce good tuber yields and tuber quality and low environmental impacts. A balanced management of $\mathrm{N}$ fertilization and irrigation is essential (Chapter 4). This should be investigated and demonstrated in farmers' fields, in order to account for diversity in farmers' conditions and to enhance their involvement and awareness. The latter is important to scale sustainable practices. Therefore, the main objective of this study was to understand and demonstrate (to farmers) the effects of different $\mathrm{N}$ fertiliser and irrigation levels on potato yield, tuber quality, resource use efficiencies, and environmental impacts with on-farm field experiments in 
northern China, and to understand the willingness and constraints of farmers to reduce $\mathrm{N}$ fertiliser inputs and adopt more efficient irrigation techniques (drip irrigation). The subobjectives were to identify (i) the impact of various $\mathrm{N}$ fertiliser and irrigation water input levels on potato yield and quality (agronomic objectives); (ii) the impacts of different $\mathrm{N}$ and water input levels on resource use efficiencies and environmental impacts (environmental objectives); and (iii) the possibilities and constraints of fulfilling agronomic and environmental objectives simultaneously from the perspective of farmers.

\subsection{Materials and methods}

\subsubsection{General description}

On-farm field experiments were conducted in Hulunbuir, Inner Mongolia, in northern China in 2017 and 2018. The farmers had a contract with a local French Fries processing company. The potato variety cultivated was Innovator. In 2017, the experiment was performed in a farmer's field to assess the influence of a combination of different $\mathrm{N}$ fertiliser and irrigation inputs on potato yield and quality. Instead of testing this another year on the same field, in 2018 we investigated the representativeness of the 2017 results on five farms in the same region, which had different soil conditions and management practices and therefore redesigned the treatments. The impacts of different $\mathrm{N}$ fertiliser and irrigation input on yield, quality, resource use efficiencies and environmental impacts were assessed. Finally, the farmers with whom the experiments were conducted (in 2018) were interviewed about their perspectives as to reducing $\mathrm{N}$ fertiliser input and adaptation to drip irrigation.

In this study, three quality aspects for French Fries processing were measured: (1) dry matter percentage of tubers (DM\%), (2) tuber size distribution (weight percentage (WP\%) of small (<60 mm), small-medium $(60-75 \mathrm{~mm})$, medium $(75-175 \mathrm{~mm})$, and extra-large tubers $(>175$ $\mathrm{mm})$ ), and (3) tuber sugar content (i.e., sucrose and glucose). For French Fries processing, a DM\% between $20.5-21.5 \%$ is most desired by the local factory (Chapter 3 ). The small and extra-large tubers are less desired than medium-sized tubers (Chapter 3 ). High reducing sugar (i.e., glucose and fructose) content is associated with browning of fried products (Beukema and Van der Zaag; Storey and Davies, 1992), and sucrose in tubers leads to the accumulation of reducing sugar during storage (Storey and Davies, 1992).

\subsubsection{Experimental design and data collection}

\section{The 2017 experiment}

In 2017, a randomized block split-plot design was laid out on a farmer's field with the combination of four $\mathrm{N}$ fertiliser and three irrigation treatments (Fig. D1 in Appendix D of this thesis). There were four blocks (used as four replications) and each consisted of three wholeplots which were randomly assigned to three irrigation treatments. In each whole-plot, four sub-plots were randomly assigned to four $\mathrm{N}$ fertiliser treatments. Drip irrigation was applied and the three irrigation treatments were (1) no-irrigation, (2) farmer's irrigation (i.e., the timing 
and amount per irrigation followed farmer's practice), and (3) full irrigation (i.e., the timing and amount per irrigation was set in order to maintain the soil moisture content above $80 \%$ of field capacity (FC)). During the growing season (from planting to harvesting), the total rainfall was $154 \mathrm{~mm}$, total irrigation of the farmer's irrigation treatment was $235 \mathrm{~mm}$ and $280 \mathrm{~mm}$ for the full irrigation treatment. A soil moisture sensor (Watermark, Spectrum Technologies, Inc.) was installed in each whole-plot (Fig. D1, Appendix D) to monitor the daily soil water moisture tension ( $\mathrm{kPa}$ ) (Fig. D3, Fig. D4, Appendix D). The daily rainfall and irrigation amount for the two irrigation treatments were measured from planting until harvesting (Fig. D5, Appendix D).

The four $\mathrm{N}$ treatments were (1) zero $\mathrm{N}$ fertiliser input (N0); (2) $\mathrm{N}$ fertiliser for a target yield of $60 \%$ of the potential yield (N1); (3) farmer's $N$ fertiliser input (N2); (4) N fertiliser for a target yield of $80 \%$ of the potential yield (N3) (Table 5.1). The potential yield of potato in the study region under irrigated conditions (Yp was 63 ton $\mathrm{FM} \mathrm{ha}^{-1}$ in Inner Mongolia, averaged over 10 years from 2005 to 2016) was estimated with the crop growth model WOFOST (Chapter 2). The target yields in our experiments were then 37.8 ton $\mathrm{FM} \mathrm{ha}^{-1}(60 \% \mathrm{Yp})$ and 50.4 ton $\mathrm{FM}^{-}$ ${ }^{1}$ ( $80 \% \mathrm{Yp}$ ), respectively. The $\mathrm{N}$ fertiliser input required to obtain the target yields was estimated based on the target yield, soil $\mathrm{N}$ supply, recovery efficiency of $\mathrm{N}$ fertiliser ( $50 \%$, representing highly efficient use of $\mathrm{N}$ fertiliser for the potato crop, Neeteson, 1989), tuber DM\% (20\%) and $\mathrm{N}$ concentration in tuber dry matter $(1.65 \%)$ (measured by the local agronomist). The soil $\mathrm{N}$ supply ( $66 \mathrm{~kg} \mathrm{~N} \mathrm{ha}^{-1}$ ) was estimated based on measurements in a different field on the same farm in 2015 and before potato planting. The estimation used an assumed soil bulk density $\left(1.6 \mathrm{~g} \mathrm{~cm}^{-3}\right)$ and the measured values of ammonium nitrogen $\left(\mathrm{NH}_{4}-\mathrm{N}, 5.9 \mathrm{mg} \mathrm{L}^{-1}\right)$ and nitrate nitrogen $\left(\mathrm{NO}_{3}-\mathrm{N}, 14.6 \mathrm{mg} \mathrm{L}^{-1}\right)$ using the colorimetric approach by Mosaic Crop Nutrition (https://www.cropnutrition.com/). It accounts for the mineral $\mathrm{N}$ in the $0-20 \mathrm{~cm}$ soil layer, while the mineralizable $\mathrm{N}$ from soil organic matter was not considered.

Tubers were planted on May 1 and harvested on September 15. $\mathrm{N}$ fertiliser (urea) was applied three times, at two, five, and 10 weeks after planting, respectively, at a rate of $65 \%, 20 \%$ and $15 \%$ of the total $\mathrm{N}$ fertiliser input. Phosphorus (calcium superphosphate) and potassium $\left(\mathrm{K}_{2} \mathrm{SO}_{4}\right)$ were applied at planting following farmer's practice (Table 5.1). Other management practices (tillage, weeding, pest and disease control, etc.) were performed by the farmer. At harvest, two "3-meter samples" (i.e., three meters in length along the ridge) were taken in each sub-plot in the middle two ridges respectively $\left(5.4 \mathrm{~m}^{2}\right.$ sample size per treatment) (Fig. D2, Appendix D). For each sample, tuber fresh matter production (kg FM) was measured (based on which the yield in $\mathrm{FM}$ ton ha-1 was calculated). The quality aspects were also measured (see Section 5.2.1). 


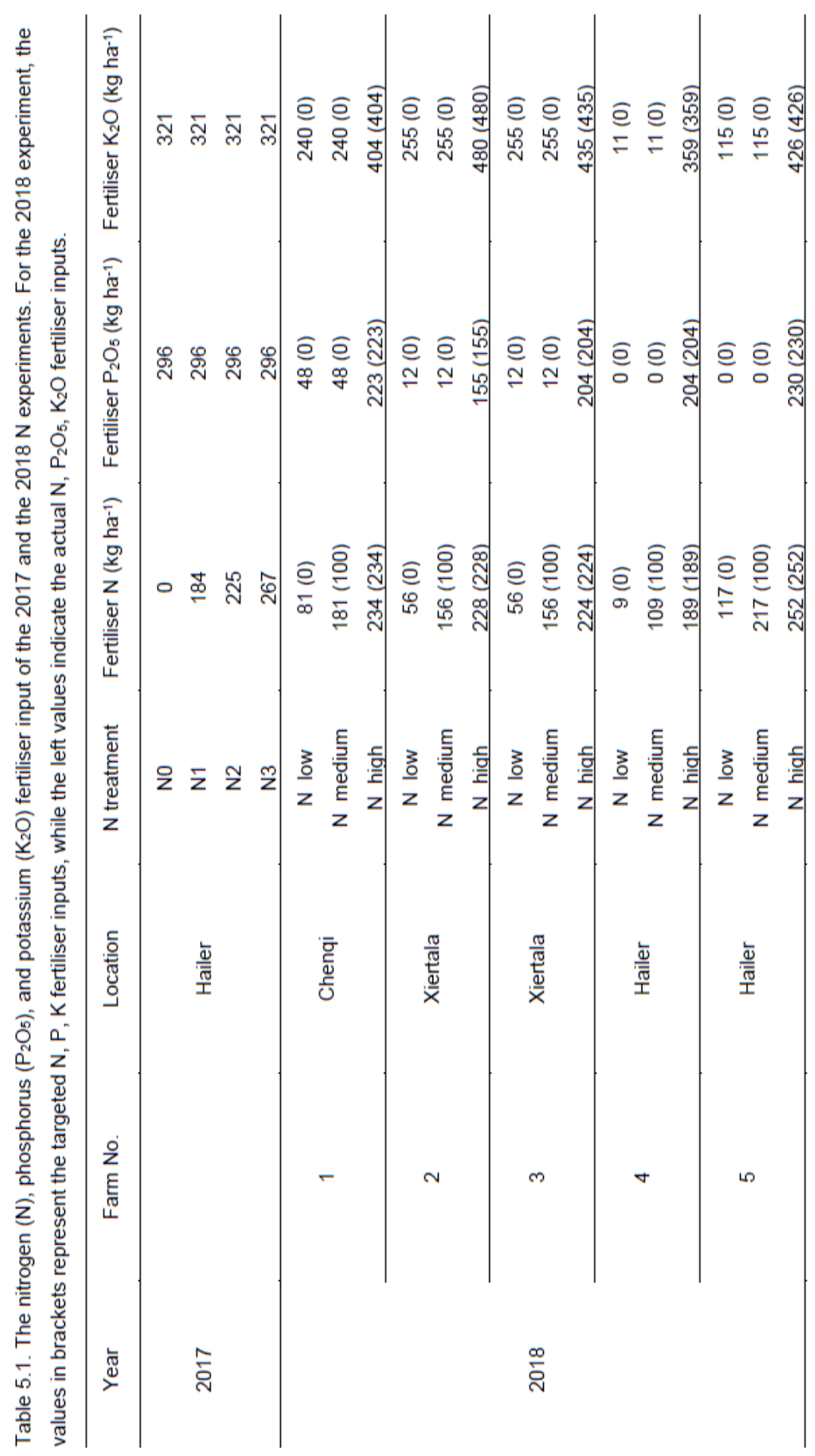




\section{The 2018 experiment}

The $2018 \mathrm{~N}$ experiments were conducted on five farms (used as five replications) (see Section 5.2.1). In each farm, two fields, with respectively farmer-perceived "good" and "poor" conditions, were selected as experimental fields. The variation in yield among the different fields of the same farm can be large (Fig. D8, Appendix D), which is mainly attributed to various biotic and abiotic growing conditions. Farmers perceived the conditions of the field based on the potato yield of previous years and a higher yield was associated with good field conditions. The three targeted $\mathrm{N}$ fertiliser input levels of the three $\mathrm{N}$ treatments were (1) zero $\mathrm{N}$ fertiliser input (N_low),

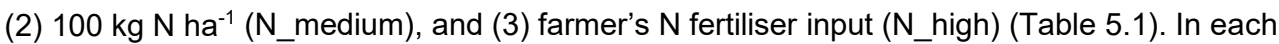
field, three adjacent plots were randomly assigned to the three $\mathrm{N}$ treatments, and each plot consisted of 8 ridges ( $0.9 \mathrm{~m}$ in width and $15 \mathrm{~m}$ in length). For the $\mathrm{N}$ llow treatment, no fertiliser was applied at planting. For the $\mathrm{N}$ _medium treatment, $\mathrm{N}$ fertiliser (urea) was applied manually at a rate of $100 \mathrm{~kg} \mathrm{~N} \mathrm{ha}^{-1}$ at 2-3 weeks after planting. Based on the soil test in 2017 and 2018 (Table 5.2), the phosphorus $(\mathrm{P})$ and potassium $(\mathrm{K})$ contents in the soil were deemed sufficient for obtaining Yp (i.e., 63 ton $\mathrm{FM} \mathrm{ha}^{-1}$, see The 2017 experiment), thus $\mathrm{P}$ and $\mathrm{K}$ fertiliser were not applied for the N_low and N_medium treatments in 2018 (targeted P, K fertiliser input, Table 5.1). For the farmer's $N$ fertiliser input ( $N$ high treatment), the application of $N, P, K$ fertiliser (type, time, amount) followed farmer's practice. In addition, all five farmers applied N, $\mathrm{P}, \mathrm{K}$ fertiliser via irrigation (Table D1, Appendix D). Thus, it was inevitable that the $\mathrm{N}$ _low and $\mathrm{N} \_$medium treatment plots in all five farms also received $\mathrm{N}, \mathrm{P}, \mathrm{K}$ fertiliser through irrigation, and hence the actual fertiliser input (see actual N, P, K fertiliser input, Table 5.1) was different from the targeted fertiliser input for all three $\mathrm{N}$ treatments.

The 2018 irrigation experiment was performed in a drip irrigation field. The three irrigation treatments were (1) no-irrigation, (2) irrigation to keep soil moisture content above $60 \%$ of FC $(60 \%$ FC), and (3) irrigation to keep soil moisture content above $80 \%$ of FC ( $80 \%$ FC). Each treatment consisted of four plots (used as four replications) and each plot consisted of 8 ridges of $0.9 \mathrm{~m}$ in width and $15 \mathrm{~m}$ in length. For each plot, a watermark was installed to monitor the daily soil water status (Fig. D6, Appendix D). For the two irrigation treatments, water was applied when the soil moisture content approached the critical levels (i.e., soil moisture tension was $33 \mathrm{kPa}$ for the $60 \%$ FC treatment, and $20 \mathrm{kPa}$ for $80 \%$ FC treatment) (Fig. D6, Appendix D). Daily rainfall and irrigation input (for the two irrigation treatments) was measured (Fig. D7, Appendix D). The total rainfall from planting until harvesting was $269 \mathrm{~mm}$, and irrigation amount was $136 \mathrm{~mm}$ and $74 \mathrm{~mm}$ for the $80 \% \mathrm{FC}$ and $60 \% \mathrm{FC}$ treatments, respectively. The compound $\mathrm{N}-\mathrm{P}-\mathrm{K}$ fertiliser was applied at planting at a rate of $101 \mathrm{~kg} \mathrm{~N} \mathrm{ha}^{-1}, 115 \mathrm{~kg} \mathrm{P}_{2} \mathrm{O}_{5} \mathrm{ha}^{-1}$ and $108 \mathrm{~kg}$ $\mathrm{K}_{2} \mathrm{O}$ ha $^{-1}$.

For the 2018 experiment, the planting date was between April 26 and May 3 and the harvesting date was between August 26 and September 4. The other management practices were performed by local farmers and were the same for the different experimental fields per farm. At harvest, three "3-meter samples" were taken in the middle three ridges of each treatment plot (8.1 $\mathrm{m}^{2}$ sample size per treatment). The samples were measured for yield and for quality aspects (see Section 5.2.1). 


\section{Soil characteristics}

In both years, soil samples $(30 \mathrm{~cm})$ of the experimental fields were taken in spring after ploughing (25- $30 \mathrm{~cm}$ ) and before planting. For the 2017 experimental field, a soil sample was taken for each sub-plot and analysed, and the average value across all sub-plots was used to indicate the soil condition of the field (Table 5.2). For the 10 experimental fields (five farms with two fields each) in the $2018 \mathrm{~N}$ experiment, one soil sample was collected from each $\mathrm{N}$ treatment plot, and the average value was calculated (Table 5.2). For the irrigation experimental field in 2018, one soil sample was taken from each irrigation plot and analysed and the average value across all plots was calculated (Table 5.2). For both years, the soil samples were tested for soil $\mathrm{pH}$, soil organic matter (\%), alkali-hydrolysable $\mathrm{N}\left(\mathrm{mg} \mathrm{kg}^{-1}\right)$, plant available phosphorus $\left(\mathrm{mg} \mathrm{P} \mathrm{kg}^{-1}\right)$, and available potassium $\left(\mathrm{mg} \mathrm{K} \mathrm{kg}^{-1}\right)$. Alkali-hydrolysable $\mathrm{N}$ includes mineral $\mathrm{N}\left(\mathrm{NH}_{4}-\mathrm{N}, \mathrm{NO}_{3}-\mathrm{N}\right)$ and easily hydrolysed organic $\mathrm{N}$ (i.e., amino acid, ammonium amide and easily hydrolysed protein) (see Appendix $D$ for the testing procedure). Alkali-hydrolysable $\mathrm{N}$ was calculated based on the assumed soil bulk density $\left(1.6 \mathrm{~g} \mathrm{~cm}^{-3}\right)$ and soil depth $(30 \mathrm{~cm})$. The plant available soil $P$ was tested based on the Olsen $P$ method, and plant available soil $\mathrm{K}$ was tested based on the ammonium acetate extraction method.

For the 2017 experimental field, the soil particle distribution was measured to identify the soil texture, and water holding capacity was also tested. The soil type was sandy loam, which was estimated based on the sand $(0.05-2 \mathrm{~mm}, 49 \%)$, silt $(0.002-0.05 \mathrm{~mm}, 45 \%)$, and clay $(<0.002$ $\mathrm{mm}, 3 \%$ ) content and the texture classification of USDA (USDA, 2019). The soil moisture content (volume, \%) at wilting point, field capacity, and saturation was $11 \%, 24 \%$ and $29 \%$ respectively. The soil water holding capacity of the 2018 irrigation experimental field was assumed to be the same as in the 2017 experimental field; the fields were on different farms but in the same area. 


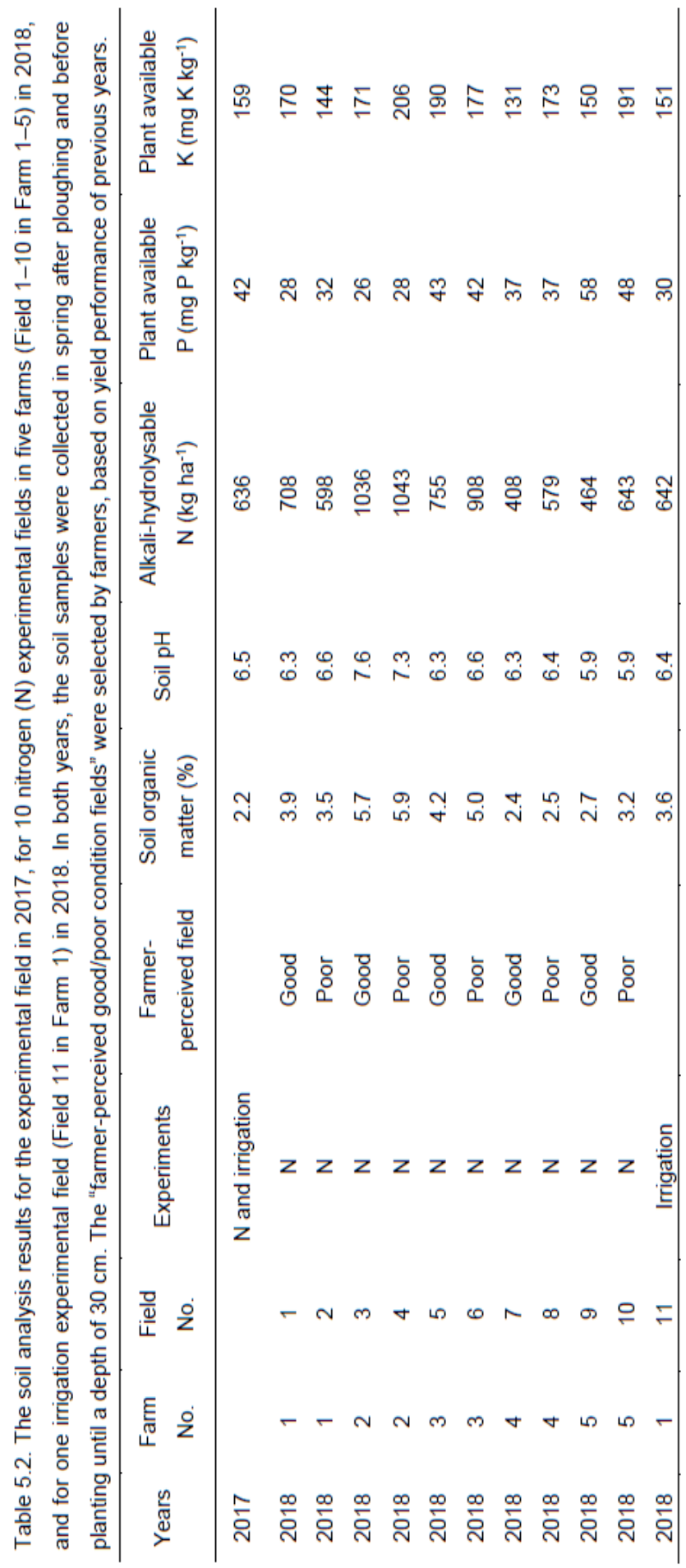




\subsubsection{Data analysis}

\section{Yield and quality}

For the 2017 experiment, a multilevel linear model (in R 3.6.0) was used to identify the significant main and interaction effects of $\mathrm{N}$ and irrigation on potato yield and quality, with $\mathrm{N}$ and irrigation as fixed factors, and block as random factor. If there was a significant interaction effect between $\mathrm{N}$ and irrigation ( $\mathrm{p}<0.05$ ), a multiple comparison was done by using a Post hoc analysis (Bonferroni test) to identify the significant differences between $\mathrm{N}$ treatments for each irrigation treatment. If there was no significant interaction effect, the difference between treatments of the main effects of $\mathrm{N}$ and/or irrigation were also assessed by the Bonferroni test. For the $2018 \mathrm{~N}$ experiment, the effects of different $\mathrm{N}$ treatments and field conditions on potato yield and quality were also assessed using a multilevel linear model. Here $\mathrm{N}$ and field condition were fixed factors, and farm was random factor. For the 2018 irrigation experiment, the effects of different irrigation treatments on potato yield and quality were assessed with a one-way ANOVA test and Post hoc analysis (Bonferroni test).

\section{Resource use efficiencies}

For the 2017 experiment and the $2018 \mathrm{~N}$ experiment, the nitrogen use efficiency (NUE) was estimated based on the input-output framework proposed by the EU Nitrogen Expert Panel (2015). The NUE was calculated as the ratio between $\mathrm{N}$ output and $\mathrm{N}$ input. $\mathrm{N}$ input included fertiliser $\mathrm{N}$ and atmospheric $\mathrm{N}$ deposition (19 kg ha-1, Xu et al., 2015a). $\mathrm{N}$ output was the $\mathrm{N}$ removed in tubers, and was calculated based on tuber FM yield (measured), DM\% (measured) and a default value of $\mathrm{N}$ concentration in dry tubers (1.62\%). The $\mathrm{N}$ surplus was the difference between $\mathrm{N}$ input and $\mathrm{N}$ output, and is an important indicator for potential $\mathrm{N}$ losses to the environment. The relationship between $\mathrm{N}$ input and $\mathrm{N}$ output was presented in a two dimensional diagram where the upper and lower target values for yield, NUE and $\mathrm{N}$ surplus threshold are presented. The lower target NUE (50\%) represents the NUE obtained for major crops under average management practice in the European countries (EU), and NUE below $50 \%$ indicates low use efficiency and high risk of $\mathrm{N}$ losses; the upper target NUE $(90 \%)$ is observed under highly efficient $\mathrm{N}$ management in the EU and an NUE above $90 \%$ indicates high risk of soil mining. $\mathrm{N}$ surplus of $80 \mathrm{~kg} \mathrm{ha}^{-1}$ was obtained under average management practice in the EU countries. The upper target yield was $80 \%$ of Yp which was estimated with the WOFOST crop growth model (i.e., 50 and 49 ton $\mathrm{FM} \mathrm{ha}^{-1}$ in 2017 and 2018 respectively). The lower target yield ( 37.5 ton FM ha-1) was the yield at "break-even point" at which farmers do not make profit nor suffer financial loss (Chapter 4).

Water use efficiency ( $\mathrm{kg} \mathrm{DM} \mathrm{ha}^{-1} \mathrm{~mm}^{-1}$ ) was estimated as the ratio between dry matter tuber weight ( $\left.\mathrm{kg} \mathrm{DM} \mathrm{ha}^{-1}\right)$ and total water input $(\mathrm{mm})$. The total water input included both rainfall and irrigation input. Water surplus was calculated as the difference between total water input and actual evapotranspiration (ET). For both years, the ET for the no-irrigation treatment was estimated based on the WOFOST model for crop production under water-limited conditions, with the rainfall of the experimental field as rainfall input. The ET for the irrigated treatment 
was also estimated under water-limited conditions, but now irrigation water was added as input to the rainfall.

\subsubsection{Farmer interviews}

In 2018, interviews were conducted with the five farmers with whom the experiments were performed. The interviews were conducted during the potato growing season, and farmers were not yet aware of the final yields of the different treatments. The perspectives of farmers on reducing $\mathrm{N}$ fertiliser input, and adapting irrigation type were surveyed. For $\mathrm{N}$ fertiliser, questions addressed the anticipated effect of reducing $\mathrm{N}$ fertiliser input on potato yield, quality, cost, labor and the environment; the main constraints and risks of reducing $\mathrm{N}$ fertiliser; and whether farmers would apply less $\mathrm{N}$ fertiliser if the experiment showed no effect of reducing $\mathrm{N}$ fertiliser on yield and quality. For irrigation, questions addressed the effect of over- and underirrigation on potato yield, quality, cost and labor, and the advantages and constraints of using drip irrigation.

\subsection{Results}

\subsubsection{Yield and quality in the 2017 experiment}

There was a significant interaction effect between $\mathrm{N}$ and irrigation on yield (Fig. 5.1a), dry matter percentage (DM\%) (Fig. 5.1b), and number of tubers per plant (Fig. 5.1c). Under irrigated conditions, adding $\mathrm{N}$ fertiliser (N1, N2, N3) did not contribute significantly to more yield compared to the zero $\mathrm{N}$ fertiliser treatment (N0) (Fig. 5.1a), while it reduced DM\% (Fig. 5.1b) and tended to increase the number of tubers per plant (Fig. 5.1c). Under the no-irrigation treatment, adding $\mathrm{N}$ fertiliser (N2) reduced yield compared to the N0 treatment (Fig. 5.1a). Irrigation (both farmer's irrigation and full irrigation) resulted in higher yield and better quality compared to rainfed conditions (Fig. 5.2). Compared to the no-irrigation treatment, farmer's irrigation also improved DM\% (Fig. 5.2b), number of tubers per plant (Fig. 5.2c), and reduced the weight percentage (WP\%) of small tubers (<60 mm) (Fig. 5.2d), sucrose content (Fig. 5.2e), and glucose content (Fig. 5.2f). On the other hand, the full irrigation treatment significantly reduced the DM\% (below the desirable range, i.e., 20.5-21.5\%, Fig. 5.2b), and increased the number of tubers per plant (Fig. 5.2c) compared to the farmer's irrigation treatment. Thus, more irrigation (full irrigation, $280 \mathrm{~mm}$ ) than farmer's irrigation input $(235 \mathrm{~mm})$ proved to be unnecessary or even undesirable. 

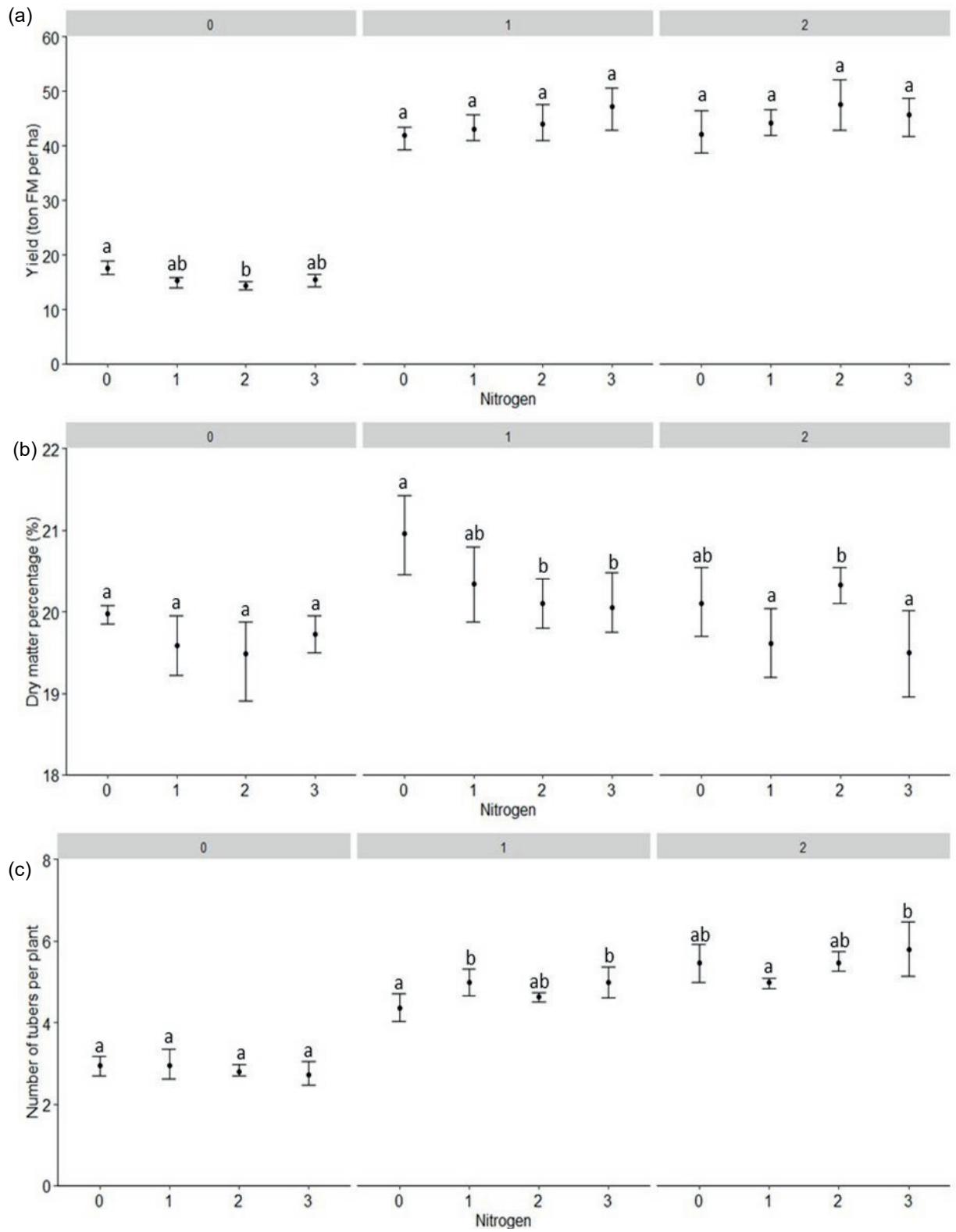

Figure 5.1. The interaction effect of nitrogen $(\mathrm{N})$ fertiliser (four levels) and irrigation (three levels) on (a) potato fresh matter yield (FM), (b) dry matter content (DM\%), and (c) number of tubers per plant in the 2017 experiment. The three irrigation treatments were (0) no-irrigation, (1) farmer's irrigation and (2) full irrigation, at the top of each figure. The four nitrogen treatments were (0) zero $\mathrm{N}$ fertiliser (N0), (1) $184 \mathrm{~kg} \mathrm{~N} \mathrm{ha}^{-1}$ (N1), (2) $225 \mathrm{~kg} \mathrm{~N} \mathrm{ha}^{-1}$ (N2), (3) $267 \mathrm{~kg} \mathrm{~N} \mathrm{ha}^{-1}$ (N3). The point indicates the mean of the observed values (four replications), and an error bar indicates the $95 \%$ confidence interval of the means of four replications. No shared letters between treatments refers to a statistically significant difference $(p<0.05)$. 

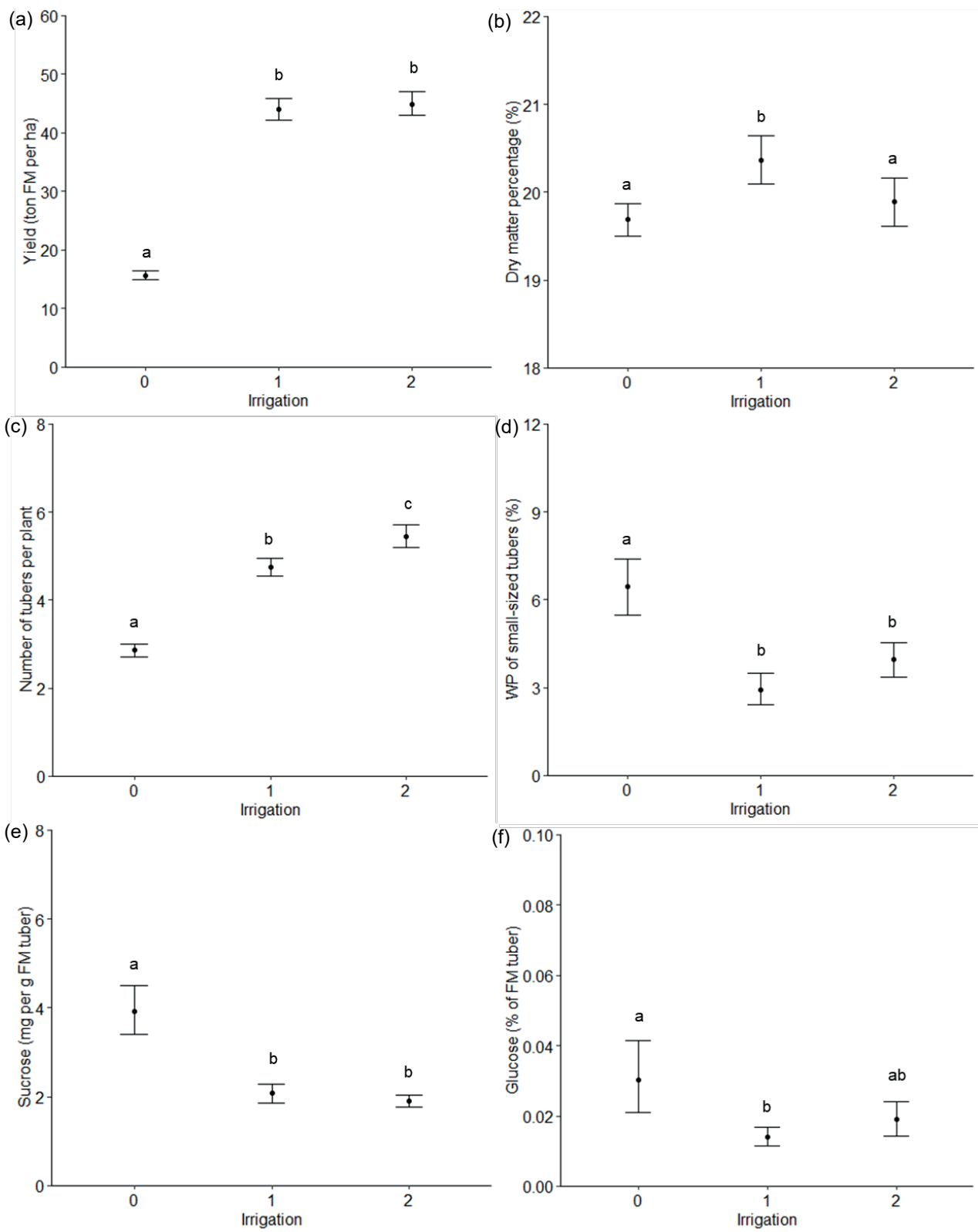

Figure 5.2. The main effect of irrigation on (a) potato fresh matter (FM) yield, (b) tuber dry matter content (DM\%),

(c) number of tubers per plant, (d) weight percentage (WP\%) of small tubers (<60 mm), (e) sucrose and (f) glucose content of tubers in the 2017 experiment. The three irrigation treatment were (0) no-irrigation, (1) farmer's irrigation and (2) full irrigation. The point indicates the mean of the observed values, and an error bar indicates the $95 \%$ confidence interval of the means. No overlap of letters between treatments refers to a statistically significant difference $(p<0.05)$. 


\subsubsection{Yield and quality in the 2018 experiment}

The effect of $\mathrm{N}$ fertiliser treatments on yield interacted with field conditions (Table 5.3). Applying a lower amount of $\mathrm{N}$ fertiliser ( $\mathrm{N} \_$low, 9-117 kg ha ${ }^{-1}$ ) than farmers' $\mathrm{N}$ fertiliser rate ( $\mathrm{N}$ high, 189-252 kg ha-1) did not affect yield significantly in the "farmer-perceived poor fields". However, in the "farmer-perceived good fields", reducing $\mathrm{N}$ fertiliser ( $\mathrm{N}_{-}$low) significantly reduced yield compared to the farmers $\mathrm{N}$ fertiliser input ( $\mathrm{N}$ high). In both field conditions, however, reducing $\mathrm{N}$ fertiliser to a medium level ( $N$ _medium, 109-181 kg ha-1) did not reduce yield significantly, though it tended to have a negative effect on some "farmer-perceived good fields" (Table 5.3). The effects of $\mathrm{N}$ fertiliser inputs and field conditions on quality aspects were not significant (data not shown).

Compared to the no-irrigation treatment, irrigation (60\% FC and $80 \%$ FC) significantly improved yield (Fig. 5.3a, Table 5.4) and quality, i.e., reduced sucrose content (Fig. 5.3d). Compared to $60 \%$ FC irrigation, 80\% FC irrigation increased yield (Fig. 5.3a, Table 5.4, relative yield improvement was 13\%). Compared to no-irrigation treatment, $80 \% \mathrm{FC}$ irrigation reduced WP\% of small tubers (Fig. 5.3c). On the other hand, the $80 \%$ FC treatment significantly reduced $\mathrm{DM} \%$ compared to the $60 \% \mathrm{FC}$ treatment, and the no-irrigation treatment (Fig. 5.3b). 

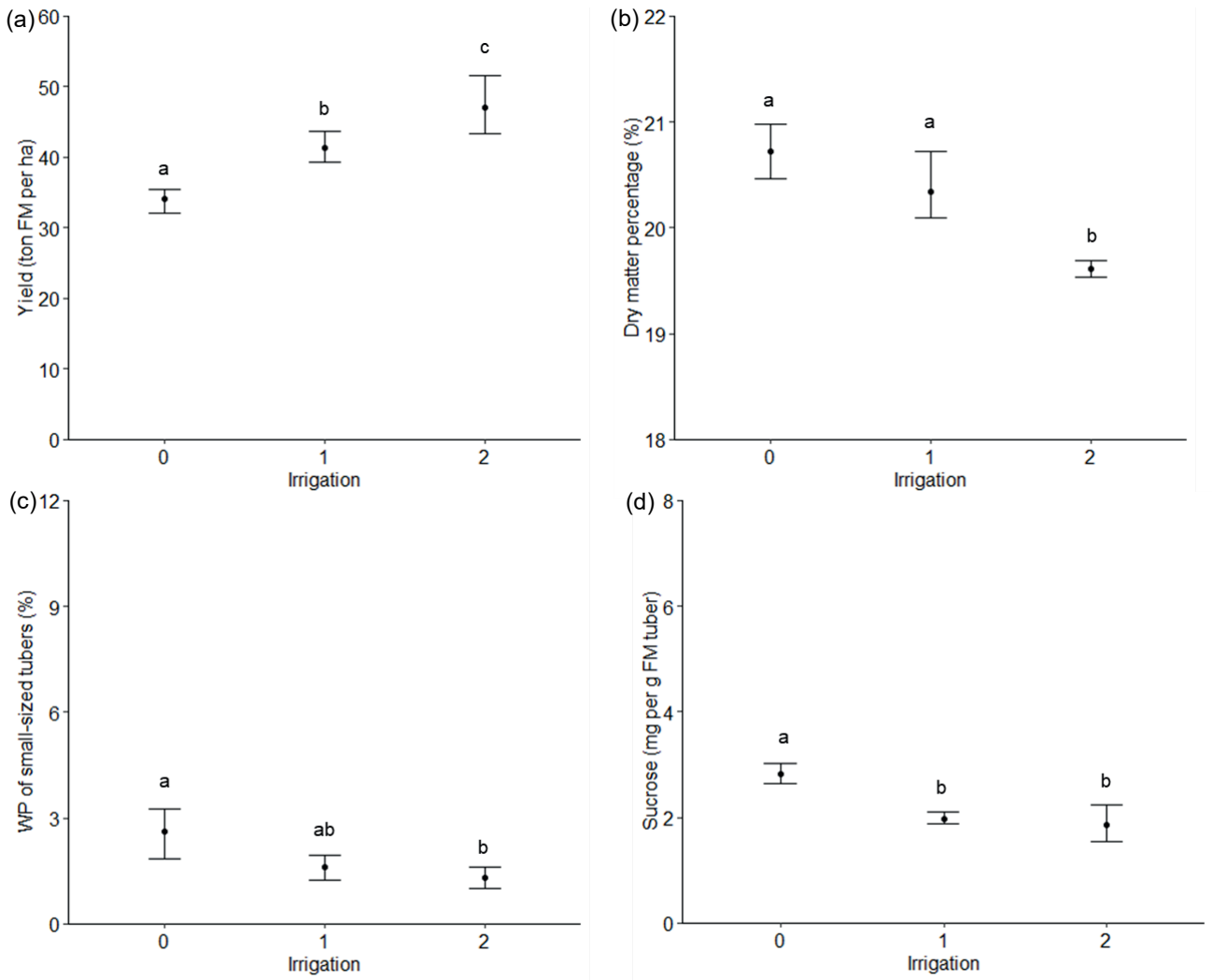

Figure 5.3. The effect of irrigation on (a) potato fresh matter (FM) yield, (b) dry matter content of tubers (DM\%),

(c) weight percentage (WP\%) of small tubers (<60 mm), and (d) sucrose content of FM tubers in the 2018 irrigation experiment. The three irrigation treatments were: (0) no-irrigation, (1) maintain soil moisture content at $60 \%$ field capacity ( $60 \% \mathrm{FC}$ ) and (2) maintain soil moisture content at $80 \%$ field capacity ( $80 \% \mathrm{FC})$. The point indicates the mean of the observed values, and an error bar indicates the $95 \%$ confidence interval of the means.

No overlap of letters between treatments refers to a statistically significant difference $(p<0.05)$. 


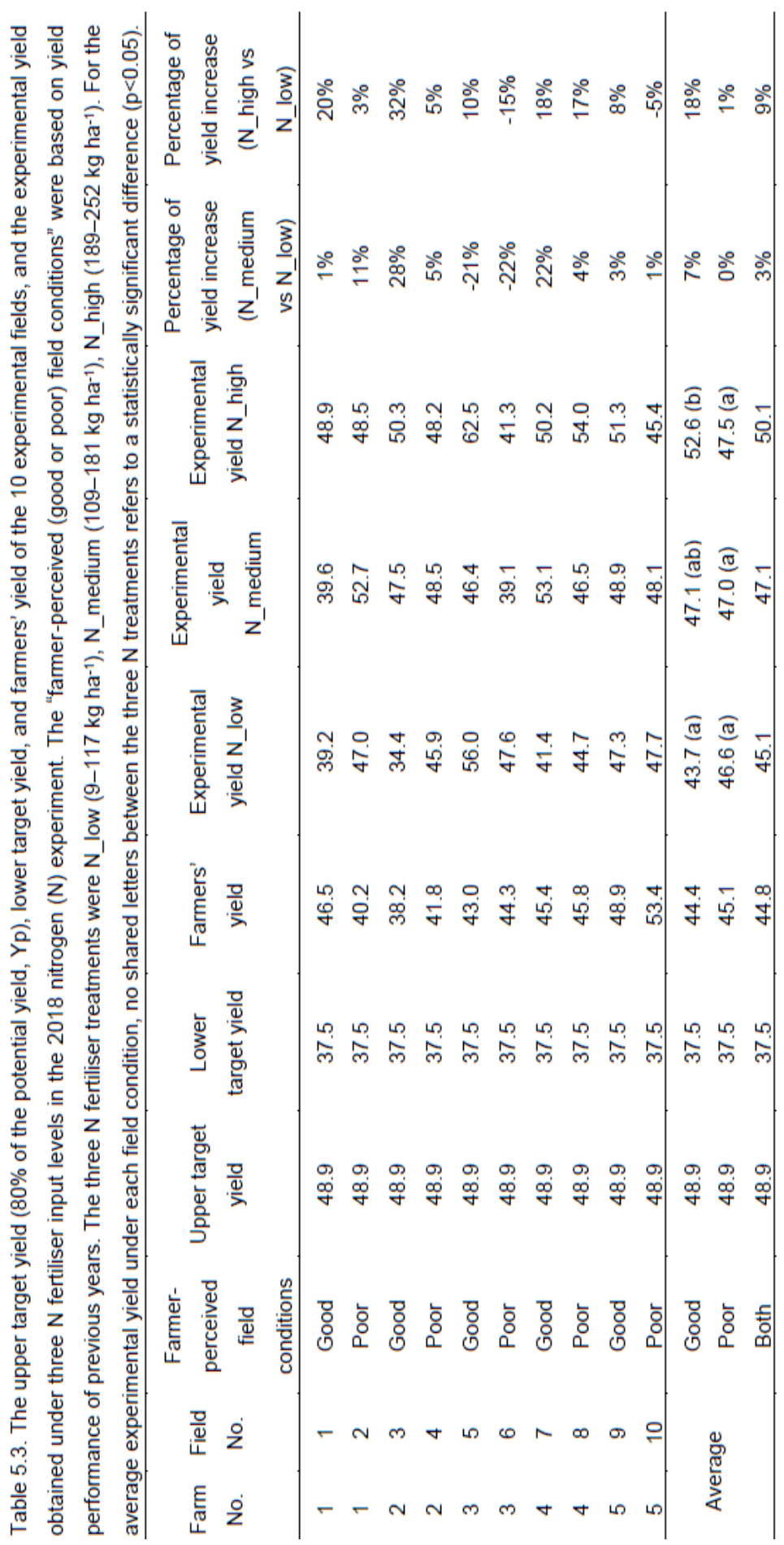




\subsubsection{Resource use efficiencies}

For the 2017 experiment, the average yields for the farmer's irrigation treatment (44.3 ton FM $\left.\mathrm{ha}^{-1}\right)$ and full irrigation treatment (45.0 ton FM ha-1) were higher than the lower target yield (37.5 ton FM ha-1) but lower than the upper target yield (i.e., 50.4 ton FM ha ${ }^{-1}$ ) (Fig. 5.4a, Table 5.4). This may due to the sub-optimum growing conditions in the experimental field (i.e., disease problems were observed in the experimental fields, such as Rhizoctonia solani, Alternaria solani, and a specific bacteria/fungi disease that leads to potato wilting). Irrigation increased yield, improved NUE and reduced $\mathrm{N}$ surplus compared to the no-irrigated condition (Fig. 5.4a). Under irrigated conditions, reducing $\mathrm{N}$ fertiliser improved NUE and reduced $\mathrm{N}$ surplus (i.e., the NUE was on average $727 \%$ (calculated based on $\mathrm{N}$ input, $\mathrm{N}$ deposition, 19 $\mathrm{kg} \mathrm{ha}^{-1}$, and $\mathrm{N}$ output, $\left.138 \mathrm{~kg} \mathrm{ha}^{-1}\right), 69 \%, 61 \%$, and $51 \%$, and $\mathrm{N}$ surplus was $-119,63,96$, and $139 \mathrm{~kg} \mathrm{ha}^{-1}$, for the N0, N1, N2 and N3 treatments, respectively).

For the $2018 \mathrm{~N}$ experiment, the average yield of all three $\mathrm{N}$ fertiliser treatments was higher than the lower target yield (Fig. 5.4b, Table 5.3). Yet, the average yield at N_low (45.1 ton FM ha $^{-1}$ ) and $\mathrm{N}$ _medium (47.1 ton $\mathrm{FM} \mathrm{ha}^{-1}$ ) treatment was lower than the upper target yield (i.e., 48.9 ton $\mathrm{FM} \mathrm{ha}^{-1}$ ) (Table 5.3). The average NUE across 10 fields was $237 \%, 89 \%$ and $67 \%$, and the $\mathrm{N}$ surplus was $-68,28$ and $81 \mathrm{~kg} \mathrm{ha}^{-1}$, under the $\mathrm{N} \_$low, N_medium, and N_high treatment, respectively (Fig. 5.4b). The NUE and $\mathrm{N}$ surplus of the $\mathrm{N}$ _medium treatment were within the "sustainable" range (i.e., NUE between $50-90 \%, \mathrm{~N}$ surplus $<80 \mathrm{~kg} \mathrm{ha}^{-1}$ ). For both years, reducing $\mathrm{N}$ fertiliser input (from high to medium and low) largely increased NUE and reduced $\mathrm{N}$ surplus.

In both years, the total water input under rainfed conditions (i.e., rainfall amount) was slightly lower than the model-based estimation of evapotranspiration (ET) under rainfed conditions (Table 5.4). This is likely due to the fact that the soil moisture content at planting was not added to the total water input. In both years, the water surplus was higher under the higher irrigation treatment than under the lower and no-irrigation treatments (Table 5.4). In 2017, the water use efficiency (WUE) of the no-irrigation treatment was the same as that of full irrigation treatment, while water surplus was higher under the full irrigation treatment (Table 5.4). In 2018, both yield and water surplus were higher under $80 \%$ FC compared to $60 \%$ and no-irrigation conditions, and WUE was lowest under the $80 \%$ FC treatment (Table 5.4). 

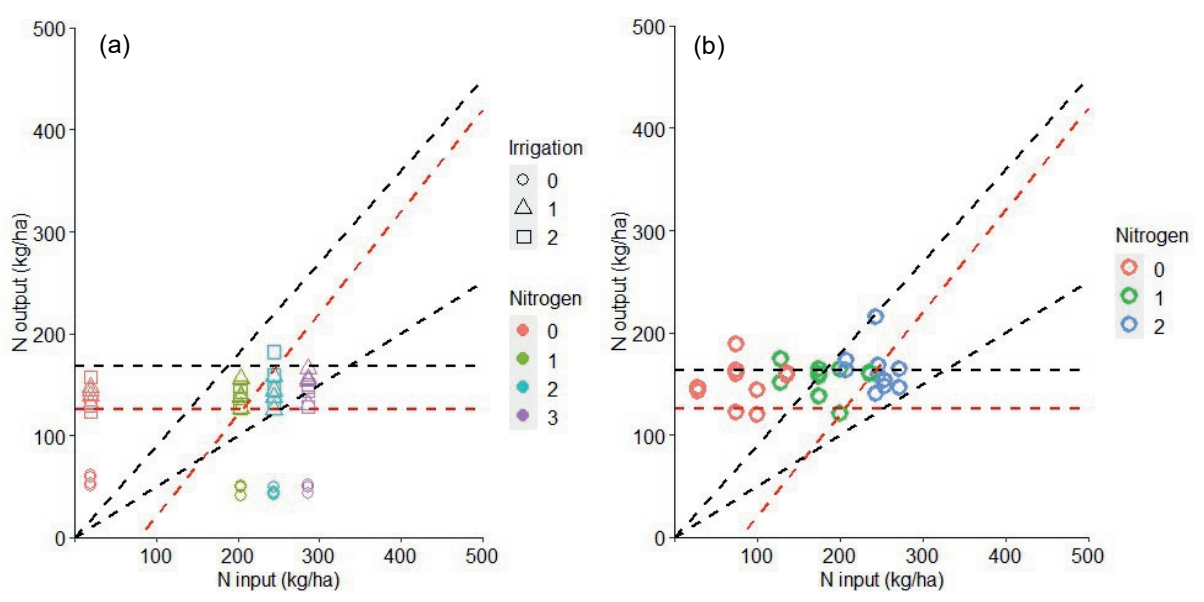

Figure 5.4. The effect of different nitrogen $(\mathrm{N})$ fertiliser and irrigation treatments on potato yield, nitrogen use efficiency (NUE) and environmental impacts as represented in the two dimensional $\mathrm{N}$ input-output diagram for the 2017 experiment (a) and the $2018 \mathrm{~N}$ experiment (b). In 2017, the three irrigation treatments were (0) no-irrigation, (1) farmer's irrigation and (2) full irrigation. The four $\mathrm{N}$ treatments were (0) zero $\mathrm{N}$ fertiliser (N0), (1) $184 \mathrm{~kg} \mathrm{~N} \mathrm{ha}^{-1}$ (N1), (2) $225 \mathrm{~kg} \mathrm{~N} \mathrm{ha}^{-1}$ (N2), (3) $267 \mathrm{~kg} \mathrm{~N} \mathrm{ha}^{-1}$ (N3). The dots indicate the different irrigation treatments (shape) and $\mathrm{N}$ treatments (color). In 2018, the three $\mathrm{N}$ fertiliser treatments were 0 ( $\mathrm{N} \_$low, 9-117 $\mathrm{kg} \mathrm{N} \mathrm{ha}^{-1}$ ), 1 (N_medium, 109-181 kg N ha-1), 2 (N_high, 189-252 kg N ha-1). The dots with three colors indicate the results of the three $\mathrm{N}$ treatments respectively with 10 samples per $\mathrm{N}$ treatment (i.e., two fields per farm $\mathrm{x}$ five farms). $\mathrm{N}$ input included both $\mathrm{N}$ fertiliser input and $\mathrm{N}$ deposition $\left(19 \mathrm{~kg} \mathrm{~N} \mathrm{ha}^{-1}\right)$. $\mathrm{N}$ output was the $\mathrm{N}$ removed by harvested product (tubers). The black horizontal line indicates the upper target yield (i.e., 50 and 49 ton FM ha-1 for 2017 and 2018, respectively), and the red horizontal line represents the lower target yield (i.e., 37.5 ton $\mathrm{FM} \mathrm{ha}^{-1}$ ). Yields are expressed in $\mathrm{N}$ uptake in tuber yield. The two diagonal black lines indicate the lower $(50 \%)$ and upper $(90 \%)$ target values for NUE. The diagonal red line indicates the upper boundary of $\mathrm{N}$ surplus ( $\mathrm{N}$ input minus $\mathrm{N}$ output) $\left(80 \mathrm{~kg} \mathrm{ha}^{-1}\right)$ for sustainable $\mathrm{N}$ management. 


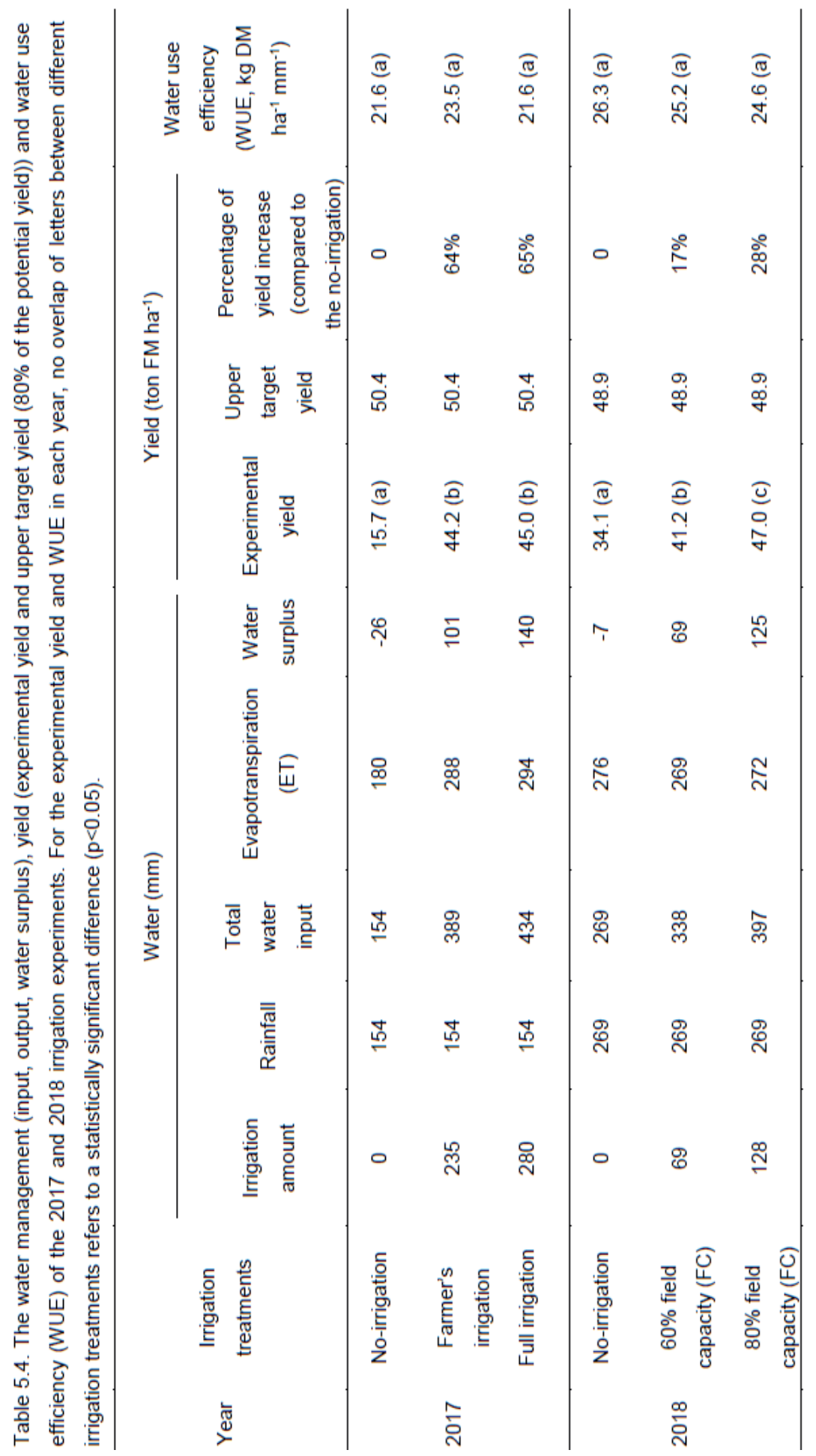




\subsubsection{Farmer interviews}

All five farmers stated that the current $\mathrm{N}$ fertiliser input (i.e., 189-252 kg ha-1, 2018) was not excessive. Four farmers (Farm 1, 2, 3, 4) commented that reducing $N$ fertiliser by $10-20 \%$ was acceptable, as it would not affect yield negatively, given that rainfall was not heavy (leading to substantial $\mathrm{N}$ leaching - interpretation of the authors). One farmer (Farm 5) perceived that less $\mathrm{N}$ fertiliser would reduce growth of plants, and thus reduce yield. Two farmers (Farm 1 and 5) thought that reducing $\mathrm{N}$ fertiliser has no impact on potato quality, while three farmers (Farm 2, 3 , and 4) believed that reducing $\mathrm{N}$ would improve quality (e.g., higher degree of maturity of tubers, higher DM\% and better storability). All farmers commented that reducing $\mathrm{N}$ fertiliser by 10-20\% would have limited effect on labor and cost (i.e., fertiliser costs accounted for approximately $11-13 \%$ of total costs, and $\mathrm{N}$ fertiliser was cheap). Four farmers (Farm 2, 3, 4, and 5) thought that the risk of omitting $\mathrm{N}$ fertiliser entirely would be very high, as it would largely reduce yield (i.e., the yield would be lower than the lower target yield, and farmers would suffer from financial losses). As to the environmental impact, two farmers (Farm 1 and 4) believed that applying excessive $\mathrm{N}$ fertiliser would not affect the environment, while the other three (Farm 2, 3, and 5) commented that excessive $\mathrm{N}$ fertiliser would damage the environment (e.g., groundwater pollution).

Overall, farmers believed that at the moment it would not be feasible to reduce $\mathrm{N}$ fertiliser input largely, as it might lead to yield reduction and has limited benefit on labor and cost, and thus does not contribute to higher profit. For most farmers (Farm 2, 3, 4, and 5), the driving force for reducing $\mathrm{N}$ fertiliser would be evidence that current $\mathrm{N}$ fertiliser input has negative effects on quality. Four farmers (Farm 2, 3, 4, and 5) were willing to reduce $\mathrm{N}$ fertiliser if the $2018 \mathrm{~N}$ experiment showed the reduced $\mathrm{N}$ input had no negative effect on yield and quality. None of the five farmers would accept to omit $\mathrm{N}$ fertiliser entirely. One farmer (Farm 1) believed that the $2018 \mathrm{~N}$ experiment was not a convincing demonstration as it was conducted in small plots; the experimental area should be at least 3 ha to demonstrate the effect.

Regarding the irrigation management, all five farmers believed that current irrigation input (i.e., 70-175 mm in 2018, Table D2, Appendix D) was not excessive. They acknowledged that improper irrigation, both excessive or deficient, would reduce yield. Each farmer has his own specific schedule as to when to apply and how much water to apply, which is based on experience. The farmer's aim of irrigation was to maintain soil moisture level at $40-80 \%$ FC, and adjustments were made at different stages of the potato crop (i.e., after planting, emergence, tuber initiation, tuber bulking, and towards harvesting), and depending on topography, daily temperature, and rainfall. Farmers judge the soil moisture level by feeling the soil in their hand and instruct labourers about the time of irrigation, duration (or irrigating depth), frequency, and rate of water flow. Improper irrigation often occurs due to the wrong judgment of the farmer, and failure to operate irrigation equipment properly by labourers (onfarm observation of the lead author). In addition, irrigation was often hindered due to defects of the irrigation equipment and lack of stable and sufficient electricity in the high irrigation demand period in summer. 
All farmers considered that drip irrigation outperformed sprinkler irrigation in terms of slow and even water supply, more efficient use of water and fertiliser (fertigation), and its suitability for most topographies and field dimensions. However, drip irrigation was considered to be expensive and very labor intensive because of the annual installation and removal of the tubes, and the maintenance of the irrigation system (especially filters and obstructed or leakages in the tubes). Farmers thus commented that drip irrigation is only suitable for the small-sized fields or part of the large-sized fields (for the so-called "dry corner" that pivot sprinkler irrigation cannot reach) but not for all farm land (e.g., 300 ha). On the other hand, if the groundwater level continues to decline and water is in limited supply in the future, all farmers would like to adopt drip irrigation.

\subsection{Discussion}

\subsubsection{Sustainable nitrogen management}

\section{Experimental results}

In the 2017 experiment, yield showed no significant response to the increasing $\mathrm{N}$ fertiliser input (from 0 to $267 \mathrm{~kg} \mathrm{ha}^{-1}$ ) under irrigated conditions (Fig. 5.1a), which indicates that the soil $\mathrm{N}$ supply was sufficient to support non-limited growth. The soil $\mathrm{N}$ uptake (i.e., the plant $\mathrm{N}$ uptake under zero $\mathrm{N}$ treatment) of the 2017 experimental field was between 189-193 $\mathrm{kg} \mathrm{ha}^{-1}$ (estimated based on the yield of the zero $\mathrm{N}$ treatment of $42.1-42.9$ ton $\mathrm{FM} \mathrm{ha}^{-1}$; a default DM\% of $20.8 \%$; a default $\mathrm{N}$ concentration in tuber dry matter of $1.62 \%$, and a default harvest index of dry matter of 0.75 ). The soil $\mathrm{N}$ uptake in 2017 was much higher than the soil $\mathrm{N}$ supply measured in 2015 ( $66 \mathrm{~kg} \mathrm{~N} \mathrm{ha}^{-1}$ which did not comprise the mineralizable $\mathrm{N}$ from soil organic matter that may become available as mineral $\mathrm{N}$ during the growing season; see Section 5.2.2, Soil characteristics). The soil samples taken in 2017 of the 2017 experimental field points at a

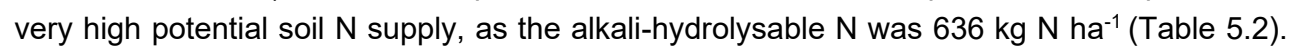
Note, that this value overestimates soil $\mathrm{N}$ supply, as the "easy hydrolysable organic N" measured in laboratory conditions is likely not fully released under field conditions. Li et al. (2009) found that the yield without $\mathrm{N}$ fertiliser input and under irrigated conditions in northwest China (including Inner Mongolia) varied between 7.5-54.6 ton FM ha-1, which indicates large variation in soil $\mathrm{N}$ supply across different potato production regions. Under no-irrigation conditions, the yield of the $225 \mathrm{~kg} \mathrm{~N}^{-1}$ treatment was significantly lower than that of the zero $\mathrm{N}$ treatment (Fig. 5.1a), which may be because the application of $\mathrm{N}$ fertiliser promoted crop growth in the early stages of the crop, which led to water stress during tuber bulking (Gregory and Simmonds, 1992).

In the 2018 experiment, reducing fertiliser (from N_high to N_low) did not affect yield significantly in the "farmer-perceived poor fields", while significant yield reduction was observed in the "farmer-perceived good fields" (Table 5.3). This is in accordance with "the law of optimum" (Liebscher, 1895) implying that a particular production factor can be used most efficiently if other production factors are at optimum levels (de Wit, 1992). The $\mathrm{N}$ fertiliser is used more efficiently under good growing conditions, and yield shows stronger response (from 
43.7 to 52.6 ton $\mathrm{FM} \mathrm{ha}{ }^{-1}$ ) to additional $\mathrm{N}$ fertiliser (from $\mathrm{N}$ low to $\mathrm{N}$ _high) than under suboptimum growing conditions (farmer-perceived poor fields; no significant yield effect). The actual $\mathrm{P}$ and $\mathrm{K}$ fertiliser inputs differed for different $\mathrm{N}$ fertiliser treatments in the same field and among different farms (Table 5.1; Table D1, Appendix D). We assumed that there was no interaction between $\mathrm{P}$ or $\mathrm{K}$ fertiliser inputs and the $\mathrm{N}$ fertiliser treatments due to the high measured values of soil $\mathrm{P}$ and $\mathrm{K}$ (Table 5.2; Section 5.2.2, The 2018 experiment).

Higher $\mathrm{N}$ fertiliser rate was associated with a decrease in DM\% (Fig. 5.1b), which is consistent with earlier studies (Harris, 1992; Perrenoud, 1983), as factors that encourage canopy growth reduce dry matter concentration (Beukema and Van der Zaag, 1990). The NUE was lower in no-irrigation conditions compared to that in irrigated conditions (Fig. 5.4a). This is also in accordance with the law of the optimum (Liebscher, 1895). Apparently, water was more limiting to potato growth than $\mathrm{N}$, and with higher water supply the crop used $\mathrm{N}$ more efficiently, produced more yield, and had lower $\mathrm{N}$ losses.

\section{Future nitrogen fertiliser management}

The actual $\mathrm{N}$ fertiliser input in the five farms in 2018 (189-252 kg ha-1) was within the range that is recommended for potato production in Inner Mongolia region under irrigated conditions (i.e., 45-307 kg ha-1 ${ }^{-1}$ Li et al., 2009; 104-307 kg ha-1 ${ }^{-1}$ Li and Jin, 2012). The actual $\mathrm{N}$ fertiliser input in the five farms was lower than the average $\mathrm{N}$ fertiliser input in Inner Mongolia region (i.e., $276 \mathrm{~kg} \mathrm{~N} \mathrm{ha}^{-1}$, based on farm surveys in 2018, Chapter 4). However, the results of 2017 and 2018 years indicated that it was, in the short term, possible to reduce the $\mathrm{N}$ fertiliser input to a lower level than the current rate while maintaining the yield and quality. In the 2018 experiment, compared to farmers' $\mathrm{N}$ fertiliser input (189-252 kg ha-1, $\mathrm{N} \_$high), reducing $\mathrm{N}$ fertiliser input to a lower level (109-181 kg ha-1, N_medium) did not significantly affect yield in the 10 experimental fields, and in some fields (i.e., "farmer-perceived poor fields") even further reducing $\mathrm{N}$ fertiliser (9-117 $\mathrm{kg} \mathrm{ha}^{-1}, \mathrm{~N} \_$low) did not affect yield significantly. This was most likely associated with the high soil $\mathrm{N}$ supply in the experimental fields, and hence $\mathrm{N}$ is not the yield limiting factor (Section 5.4.1, Experimental results).

The high $\mathrm{N}$ fertilization recommendation in Inner Mongolia is mainly based on field experiments performed in experimental stations of universities or research institutes rather than on farms. The site-specific soil conditions of farmers' fields (particularly the large variation in soil $\mathrm{N}$ supply) due to diversified management and land use types are not considered. The $\mathrm{N}$ fertiliser input in the studied farms was high in the previous years (i.e., up to $700 \mathrm{~kg} \mathrm{~N} \mathrm{ha}^{-1}$ was applied approximately 10 years ago and it was gradually reduced to the current level; personal communication). It is likely that a large amount of mineral $\mathrm{N}$ that was not taken up by crops was retained in the soil and became available during the experiment. $N$ fertiliser recommendation should be based on soil $\mathrm{N}$ supply, target yields, tuber quality requirements and the utilization efficiency of $\mathrm{N}$ fertiliser (agronomic efficiency). The agronomic $\mathrm{N}$ efficiency is associated with the conditions of other growing factors (de Wit, 1992) and the target yield (Ten Berge et al., 2019). For a defined $\mathrm{N}$ fertiliser input, agronomic $\mathrm{N}$ efficiency is lower under sub-optimum growing conditions than that under optimized conditions (de Wit, 1992), and for a defined growing condition, the agronomic $\mathrm{N}$ efficiency is lower for a higher target yield (de 
Wit, 1992). The soil $\mathrm{N}$ supply measured in the laboratory at the start of the growing season may not fully reflect the capacity of soil $\mathrm{N}$ supply for the entire growing season as the mineralization of soil organic matter during the growing season is difficult to estimate at the start of the season (i.e., it depends on total soil $\mathrm{N}, \mathrm{C} / \mathrm{N}$ ratio, $\mathrm{pH}$ and soil biological parameters and climate conditions). It is thus probably better to assess the soil $\mathrm{N}$ supply experimentally based on the $\mathrm{N}$ uptake by the crop in the $\mathrm{N}$-omitted plot in farmers' fields.

Based on the farmer interviews, it was evident that farmers were unwilling to "take the risk" to reduce $N$ fertiliser input by more than 10-20\%. Despite the efforts of researchers and government as to create awareness on environmental sustainability since 2015 (MOA, 2015b), so far not much has changed and the $\mathrm{N}$ fertiliser input is still high in the country. Substantial subsidies offered by the government to support the local fertiliser industry and fertiliser distribution makes fertiliser an easily affordable and accessible resource (Li et al., 2013), and it makes the overuse of fertiliser input economically viable. In the 2018 experiment, adding $\mathrm{N}$ fertiliser from N_low (9-117 $\mathrm{kg} \mathrm{ha}^{-1}$ ) to N_high (189-252 kg ha-1) improved yield, nonsignificantly, by 5 ton $\mathrm{FM} \mathrm{ha}^{-1}$ (average across the 10 fields) (Table 5.3). Based on the cost of $\mathrm{N}$ fertiliser (i.e., 0.59 USD per kg N (urea), Li et al., 2013, which equals 4 RMB per $\mathrm{kg} \mathrm{N}$ based on an exchange rate of $6.85 \mathrm{RMB} / \mathrm{USD}$ ), the total cost for $\mathrm{N}$ fertiliser at a rate of $250 \mathrm{~kg} \mathrm{~N}$ ha${ }^{1}$ was $1000 \mathrm{RMB} \mathrm{ha}^{-1}$ (the cost of fertiliser application is not considered), while the revenue per ton potato $\mathrm{FM}$ was $1380 \mathrm{RMB}^{-1}$ (based on interviews of farmers). Thus, the cost of fertiliser $\mathrm{N}$ relative to the revenues of potato yield crop was small. To reduce environmental impacts, legislation, norms and guidelines regarding environmental protection in agricultural production should be defined clearly, and implemented effectively and strictly.

\subsubsection{Sustainable water management}

\section{Experimental results}

Irrigation significantly improved potato yield in both years. Compared to no-irrigation conditions, yield increased by $65 \%$ in 2017 (full irrigation treatment) and $28 \%$ in 2018 ( $80 \%$ FC). The yield under no-irrigation conditions was higher in 2018 than in 2017, due to the higher rainfall in $2018(269 \mathrm{~mm})$ than in 2017 (154 mm). In 2017, the full irrigation $(280 \mathrm{~mm}$ ) did not outperform farmers' irrigation practice $(235 \mathrm{~mm}$ ) (Table 5.4). On the other hand, in 2018, the higher irrigation input ( $80 \%$ FC) significantly improved the yield compared to the lower irrigation treatment $(60 \%$ FC). This may due to the fact that in 2017 , under the full irrigation treatment the soil water moisture level was not maintained at $80 \%$ of $\mathrm{FC}$ which led to water-limited growth and a reduction in yield (Fig. D4, Appendix D). In addition, in 2017 the crop growth was reduced by disease infection and diseases like potato wilt can spread in irrigation water and high humidity in air and soil favors the disease development (Charkowski et al., 2020; Choudhary et al., 2018).

In general, irrigation significantly improved potato quality compared to rainfed conditions in both years, but not the DM\% in 2018 (Fig. 5.3b). The latter is different from our findings in Inner Mongolia when we analysed a larger number of farms (Chapter 3). Irrigation significantly 
increased the number of tubers per plant (Fig. 5.2c). Dry conditions around emergence (MacKerron and Jefferies, 1986) and at tuber initiation (Gregory and Simmonds, 1992; MacKerron, 1985; MacKerron and Jefferies, 1986; Storey and Davies, 1992; Van Loon, 1981) tend to reduce the number of tubers per plant. The share of small tubers was reduced under irrigated condition (Fig. 5.2d; Fig. 5.3c), which is in agreement with what MacKerrom and Jefferies (1988) found. Irrigation reduced both the glucose content (Fig. 5.2f) and sucrose content (Fig. 5.2e; Fig. 5.3d) in tubers, which matches what Moorby et al. (1975) already found. Overall, the results are in agreement with the finding that enhancing yield (to the maximum yield obtained by farmers in the case study, 55 ton $F M h^{-1}$ ) was associated with an improvement of various quality aspects (Chapter 3 ).

\section{Future irrigation management}

Both over-supply of water and drought conditions will lead to yield reduction (King and Stark, 1997). The commonly applied principle to guide the irrigation scheduling is that the plant available water in the soil should meet the daily evapotranspiration demand for unlimited growth (Gregory and Simmonds, 1992). The former can be estimated based on a soil water balance considering rainfall, irrigation, soil texture (determining field capacity and wilting point) and crop rooting depth; the latter depends on the crop and its environment. On the other hand, it has been argued that not all plant available water (calculated based on field capacity and wilting point for a particular root depth) can be accessed by the plants, and that plants experience water stress before the wilting point is reached (limiting deficit, $\mathrm{mm}$ ) (Gregory and Simmonds, 1992; Penman, 1970).

To ensure unlimited crop growth, more stable water supply and precise irrigation management is needed than currently applied. Drip irrigation is ideal for regular, uniform and frequent water supply and leads to more efficient use of water and other resources (e.g., energy, labor, fertiliser). The amount of irrigation water in drip irrigation (i.e., $128 \mathrm{~mm}$ in 2018, Table 5.4) is lower than that used in the traditional sprinkler irrigation system in the region (i.e., $275 \mathrm{~mm}$ in Inner Mongolia in 2018, Chapter 4), and the water surplus (between -7 and $125 \mathrm{~mm}$, Table $5.4)$ of the drip-irrigated fields was much lower than that under sprinkler irrigation $(285 \mathrm{~mm}$, Chapter 4). However, the current drip irrigation system is not suitable for large scale farms, due to the lack of experience and knowledge to operate drip irrigation systems, frequent defects of the system and large costs to install and maintain the system. Proper water management also requires farmers to base the irrigation on regular soil moisture monitoring rather than basing it on experience. Site-specific crop management aimed at targeting resource inputs (irrigation water, fertiliser, fungicides, pesticides, herbicides) to the spatial and temporal requirement of crops may provide a future for the large-scale potato farms in northern China.

\subsection{Conclusion}

Potato production in China should be enhanced with practices that aim to meet agronomic and environmental goals simultaneously. On-farm experiments in Inner Mongolia in northern China 
in 2017 and 2018 demonstrated the effect of different $\mathrm{N}$ fertiliser rates and irrigation variants on potato yield, quality, resource use efficiency (nitrogen and water) and environmental impacts (nitrogen and water surplus). The results indicated that the actual $\mathrm{N}$ fertiliser input (189-252 $\mathrm{kg} \mathrm{ha}^{-1}$ in 2018) is excessive due to the high soil $\mathrm{N}$ supply. By comparison, yield did not decrease significantly and quality was improved with medium $\mathrm{N}$ fertiliser inputs (109-181 $\mathrm{kg} \mathrm{ha}^{-1}$ ). However, further reducing $\mathrm{N}$ fertiliser (to $9-117 \mathrm{~kg} \mathrm{ha}^{-1}$ ) was found to reduce yield significantly in fields which were perceived by farmers as good. This suggests that the recommended $\mathrm{N}$ fertiliser input depends on the conditions of the field. Reducing $\mathrm{N}$ fertiliser input significantly improved NUE and reduced N surplus. However, farmers were unwilling to substantially reduce $\mathrm{N}$ fertiliser input due to the cheap fertiliser, and lack of legislation on $\mathrm{N}$ fertiliser input. Our results indicate that irrigation management should target maintenance of $80 \%$ of field capacity. Although desired, the adaptation to drip irrigation at large-scale is not practical at the moment due to the high investment in cost and labor. Precise nutrient and water management should be based on regular measurement of site-specific soil $\mathrm{N}$ supply and soil moisture conditions. A sustainable $\mathrm{N}$ and irrigation management also requires legislation with clear and strict regulations on $\mathrm{N}$ fertiliser and irrigation inputs, based on emissions to the environment and sustainable use of water resources.

\subsection{Acknowledgements}

This work was supported by the China Scholarship Council (CSC) [grant number 201506610003]. We would like to thank the local potato processing factory and the local agronomists for coordinating the onfarm experiments with the contract farmers. We thank local farmers for their cooperation in conducting the field experiments and performing farm interviews, and for their contribution to providing information.

\subsection{Appendix D. Supplementary material}

Supplementary material related to this article is provided in Appendix D. 



\section{Chapter 6}

\section{General Discussion}

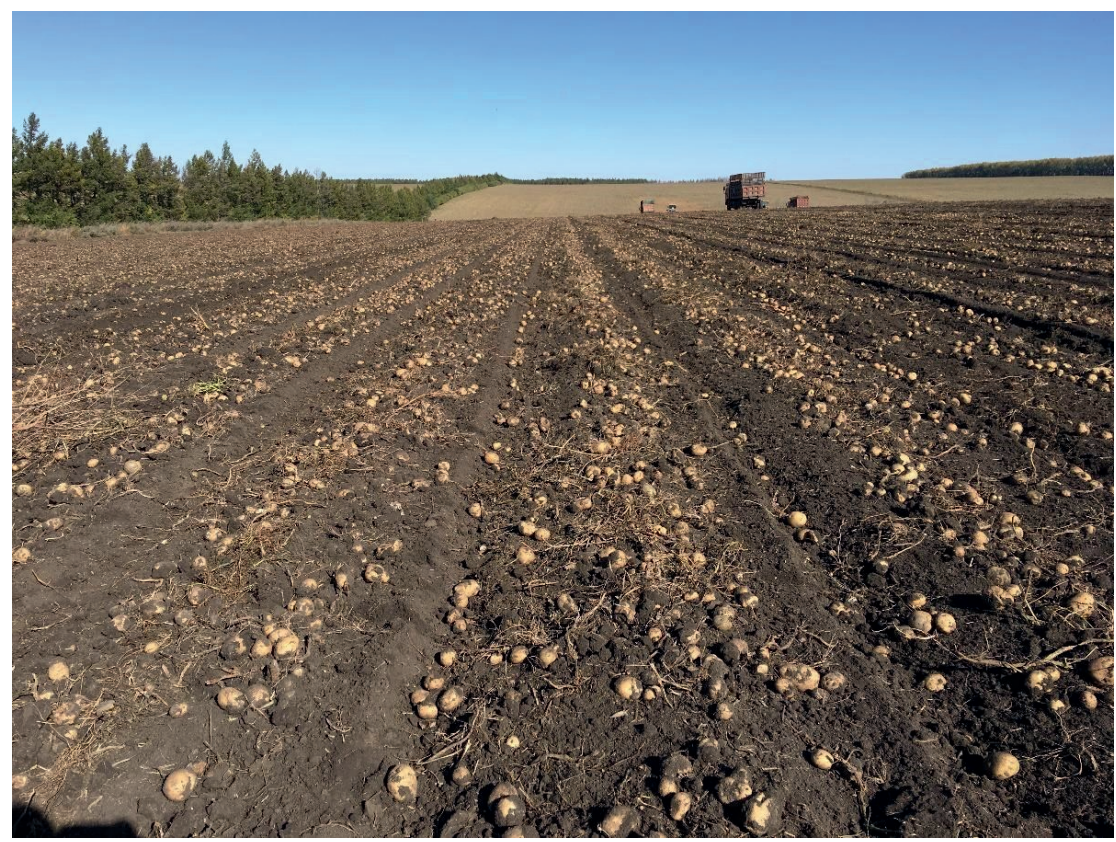




\subsection{Overview of the study}

China is facing the dual challenge to increase food production and maintain or enhance other sustainability objectives (i.e., agronomic, economic, and environmental objectives). As the largest potato producer in the world, China accounts for approximately $27 \%$ of the world potato area and $25 \%$ of global production (FAO, 2020). At the same time, the yield of potato is low and the production is associated with abundant resource inputs, low resource use efficiencies, and high environmental risks. China intends to enhance potato production in both area and quantity. The future intensification should rely on sustainable practices, aiming at balancing the multiple sustainable development goals. The pathways towards sustainable intensification should be site-specific, fitting the local context of biophysical and socio-economic conditions.

The general objective of this study was to explore the possibilities and demonstrate pathways of enhancing potato production sustainably through balancing the targeted outputs (yield, quality, and revenue) and non-targeted outputs (environmental impacts) of crop production (Fig. 6.1). The countrywide biophysical potential of the potato crop was identified under both irrigated and rainfed conditions (Chapter 2). The quantification of yield gaps and water input gaps provided spatially-explicit references for the scope to increase production. A thorough understanding of the yield, quality and economic performance of potato production in largescale commercial potato farms in northern China was achieved based on a framework that incorporates quality aspects into the yield gap notion (Chapter 3 ). The framework enabled quantifying the contribution of yield and quality to economic return through a direct link between production data (yield and quality) and the corresponding market price. An in-depth analysis of the current sustainability performance of potato production on large-scale commercial farms was performed for three major potato production regions in northern China (Inner Mongolia, Gansu and Heilongjiang) (Chapter 4). The findings provided insights into the feasible target values of yield, resource use efficiencies and environmental impacts in both the short-term and the long-term. These also stressed the need to recognize the local variability of biophysical (soil nitrogen supply) and socio-economic conditions to explore the optimum solutions. Finally, the management options for improving the sustainability performance of potato production were evaluated experimentally and demonstrated to farmers in Inner Mongolia (Chapter 5). The effects were tested of different nitrogen fertiliser and irrigation inputs (drip irrigation) on potato yield, quality, resource use efficiencies and environmental impacts. The socio-economic constraints of adapting to sustainable management practices were explored based on interviews of farmers.

At the national level, the actual yield (hereafter, Ya) of potatoes (i.e., 18.8 ton FM ha-1) is far below the biophysical potential (hereafter $Y p$ refers to the potential yield under irrigated conditions, and $Y w$ to water-limited potential yield under rainfed conditions; $Y w$ and $Y p$ were estimated to be 43.7 and 50.1 ton FM ha ${ }^{-1}$ for China, respectively) (Chapter 2). Potato yield could be substantially improved under both rainfed (yield gap is $61 \%$ ) and irrigated conditions (yield gap is $66 \%$ ). In a case study of potato production for French Fries processing in northern China, where yields are relatively high, we found that potato growers suffered a financial loss 
(due to a low market price) which was mainly driven by the poor quality (i.e., the product was rejected due to the low tuber dry matter percentage and the high weight percentage of smallsized tubers) (Chapter 3). Farmers could obtain higher revenue (i.e., the revenue gap between the revenue of best performing farmers (Ef) and the actual revenue (Ea) was $43 \%$ ) by enhancing yield (yield gap between the maximum yield obtained by farmers ( $\mathrm{Yf}$ ) and the actual yield (Ya) was $26 \%$ ) and improving potato quality simultaneously. The environmental impacts associated with potato production in the large-scale commercial farms were pronounced mainly due to the excessive inputs of nitrogen fertiliser and irrigation water (Chapter 4). From a theoretical perspective, reducing nitrogen fertiliser inputs could improve nitrogen use efficiency to more than $90 \%$ in the short-term, and in the long-term, the targets in yield (46-57 ton FM ha-1), nitrogen use efficiency (84\%) and $\mathrm{N}$ surplus (16-34 $\mathrm{kg} \mathrm{N}^{-1}$ ) could be balanced by adopting more efficient nutrient management practices. The findings were verified experimentally; it was shown that reducing nitrogen fertiliser input from the current rates (189$252 \mathrm{~kg} \mathrm{~N} \mathrm{ha}^{-1}$ ) to lower levels (109-181 $\mathrm{kg} \mathrm{N} \mathrm{ha}^{-1}$ ) did not affect yield (47 ton FM ha-1) nor quality, but improved NUE (89\%) and reduced $\mathrm{N}$ surplus $\left(28 \mathrm{~kg} \mathrm{~N} \mathrm{ha}^{-1}\right)$ (Chapter 5$)$. The results also stressed the benefit of efficient irrigation management with a drip irrigation system, which was critical to ensure good yield and quality, more efficient use of nitrogen fertiliser and water and low $\mathrm{N}$ surplus. Farmers indicated that they were willing to reduce nitrogen fertiliser use by $10-20 \%$ but not more, while the high cost and labor demand prevented farmers from adapting to drip irrigation at a broader scale.

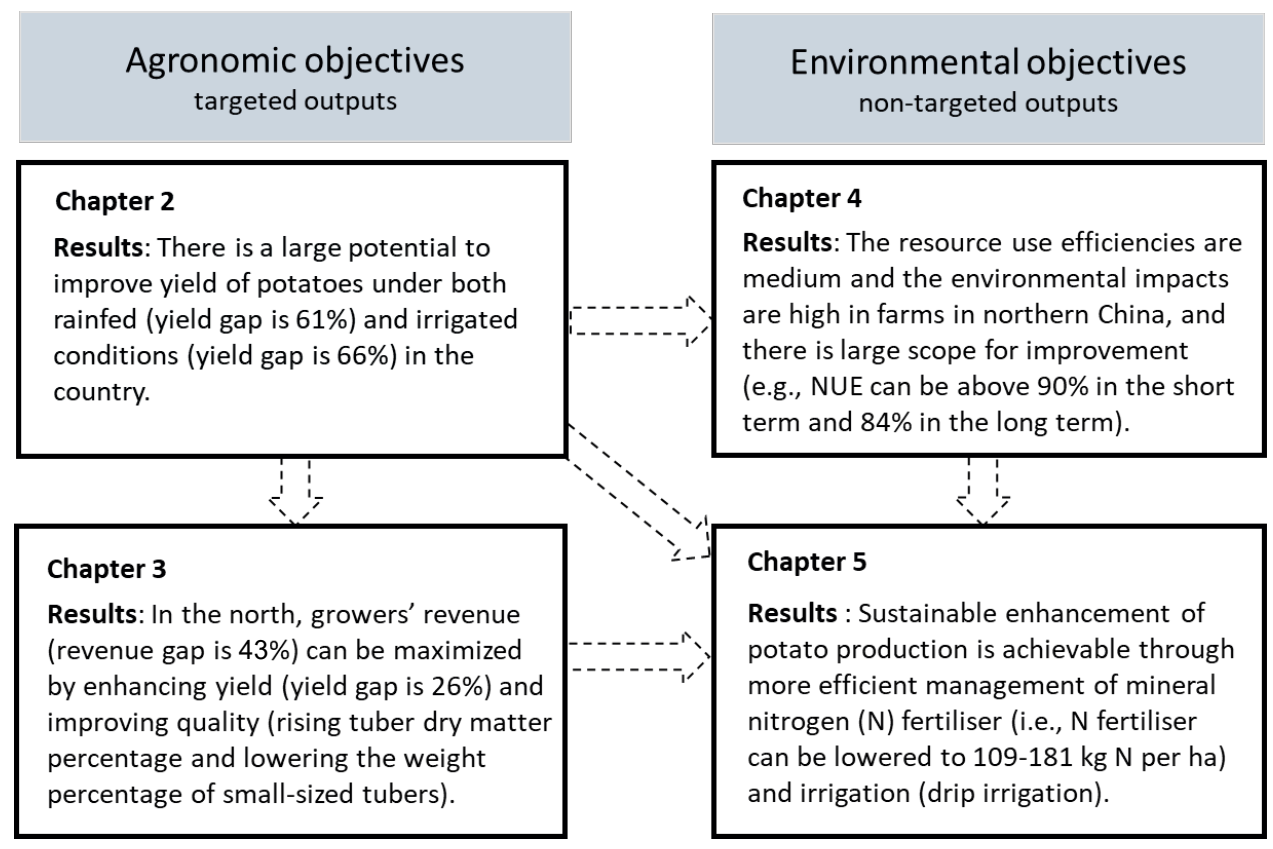

Figure 6.1. A summary overview of the results based on the research objectives of the four chapters as described in Figure 1.4 in Chapter 1. 


\subsection{Biophysical and socio-economic constraints of potato production}

The results clearly showed that it is possible to double or even triple potato yield in many regions in China (Chapter 2). The actual yield (Ya) at the provincial level in Inner Mongolia (14.1 ton FM ha-1), Gansu (16.4 ton FM ha-1) and Heilongjiang (21 ton FM ha-1) (averaged values for 2006-2015) from the national statistics (Chapter 2) was much lower than that observed during farm surveys in 2017 and 2018 (i.e., Ya was 40.5, 40.7 and 31.2 ton FM ha1 , respectively, in Inner Mongolia, Gansu, and Heilongjiang, Chapter 4). The surveyed farms in the three regions are representative of industrialized potato production with the widespread application of fertilisers, irrigation, and crop protection chemicals. I suppose that the national statistics mainly sampled small-scale farmers who have limited access to resources and apply partial or no irrigation, thus it has underreported the actual yield and resulted in an overestimation of the yield gap particularly for irrigated potatoes.

The crop production levels are defined by various growth-defining (climate conditions and crop characteristics, determining potential yield), growth-limiting (water and nutrients, determining water-limited and nutrient-limited yield, respectively) and growth-reducing factors (pest, diseases, and weeds, determining actual yield) (Van Ittersum and Rabbinge, 1997; Van Ittersum et al., 2013). Growers try to narrow the yield gaps through optimizing the growing conditions to avoid abiotic and biotic stresses. The implementation of optimum management activities is, however, often limited by socio-economic constraints. Incorporating the surveybased information, I tried to explore the major factors that drive the yield gaps (on average $24 \%$, difference between Ya and $85 \%$ of Yp under irrigated conditions) observed in the three surveyed regions in the north (i.e., Inner Mongolia, Gansu and Heilongjiang, Chapter 4).

\section{Growth-defining factors}

The potential yields $(Y p)$ of potatoes in the three surveyed regions were estimated based on the current biophysical conditions, common management practices, and for the Innovator variety. Yet, I think a further increase in $\mathrm{Yp}$ is possible through adapting management practices (e.g., mulching) that modify the microclimate conditions such that to extend the growing period. In addition, both yield and quality are expected to improve as new potato cultivars become available. In the north, the air temperature increases sharply at planting (end of April) (Fig. $6.2 \mathrm{a}, \mathrm{c}, \mathrm{e}$ ), while the rise in temperature in soil lags behind. The cool spring was perceived by farmers in Inner Mongolia and Heilongjiang regions as a major barrier to potato emergence. As an adaptation option, farmers in Inner Mongolia applied mulching at planting to improve the soil temperature and encourage earlier emergence (Fig. 6.3a). Another coping strategy applied by farmers was pre-sprouting (Fig. 6.3b), although the technique was not applied at a large scale in 2017-18, as it is time consuming (e.g., one month labour or more) and a successful application requires high financial investment (in terms of equipment and labor).

The number of varieties suitable for processing is limited. The most widely cultivated variety for French Fries processing is Innovator, which originates from the Netherlands. Potatoes have 
to be harvested before mid-September due to the early frost in Inner Mongolia. The fact that at harvesting, the haulm is still green and the haulm does not collapse, suggests that the growing season of Innovator ends prematurely (Fig. 6.3c). For starch processing in Heilongjiang, ca. 16 local varieties were cultivated in 2017-18, and farmers tended to grow a wide range of potato varieties (i.e., up to seven varieties were observed in the same field, in separate groups) as a strategy to reduce the risks of production and financial losses due to the variable performance in yield and quality. The popular cultivars were Xingjia 2 (cultivated by 13 farmers among the 21 farmers surveyed in 2017), Yanshu No.4 (eight farmers), Kenshu 1 (three farmers) and Holland 15 (three farmers). None of these varieties was bred specifically for starch processing. On the other hand, the starch content determines the price (i.e., a base price was given for potatoes with a starch content of $13 \%$ (based on fresh matter), farmers obtained a bonus when the starch content was above $13 \%$ and received a penalty when it was below the level). Many surveyed farmers complained that the actual price was lower than the base price because of the low starch concentration. There is a critical need to introduce new varieties that are more adaptive to the local climate conditions (i.e., cold-tolerant, droughtresistant and short-season varieties). Moreover, the quality aspects of potatoes (e.g., starch content and dry matter concentration) should be the primary consideration in future variety selection, particularly for processed potatoes. 

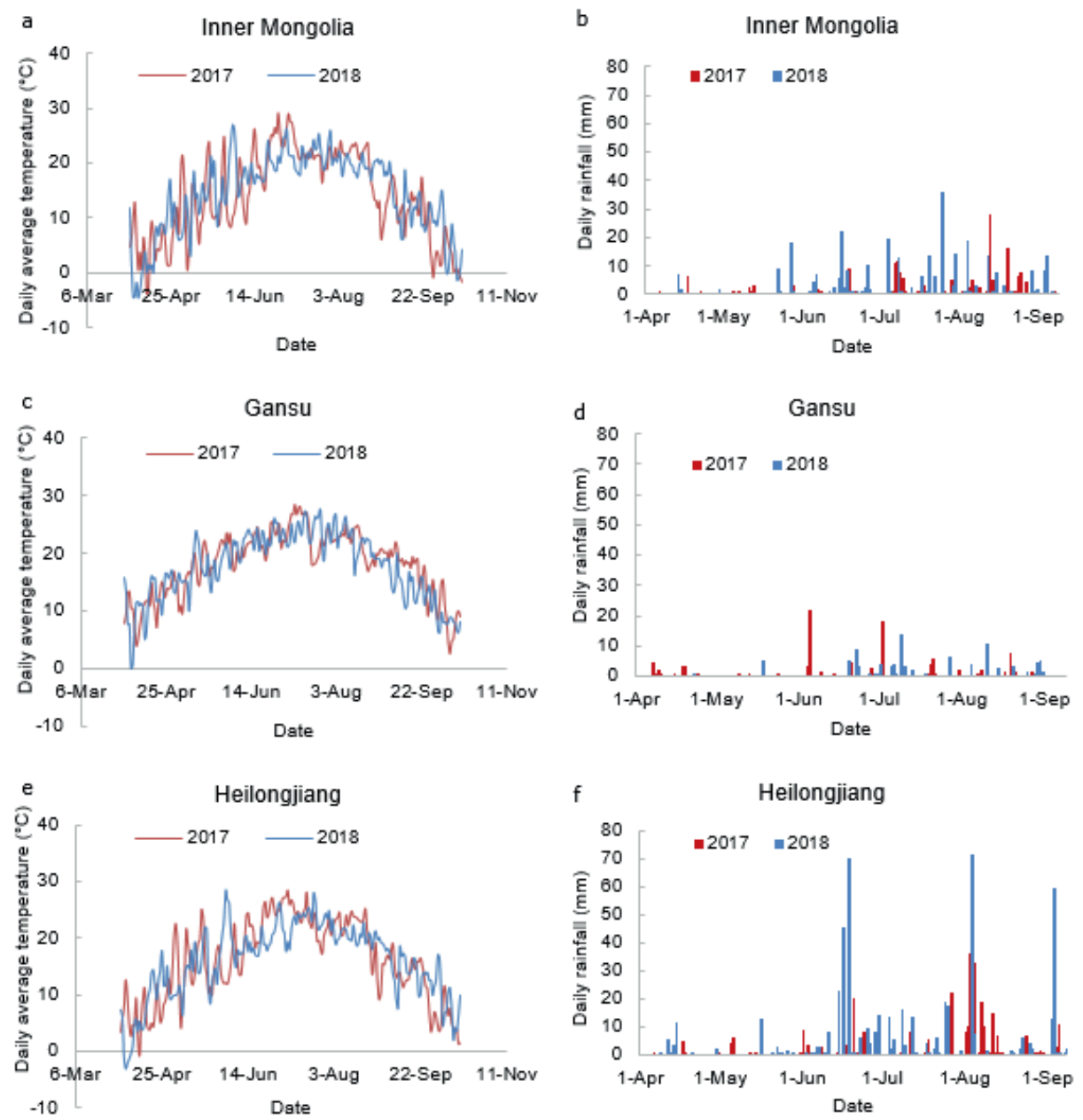

Figure 6.2. Daily average temperature and daily rainfall during the potato growing season in the three surveyed regions (Inner Mongolia, Gansu and Heilongjiang) in northern China in 2017 and 2018.

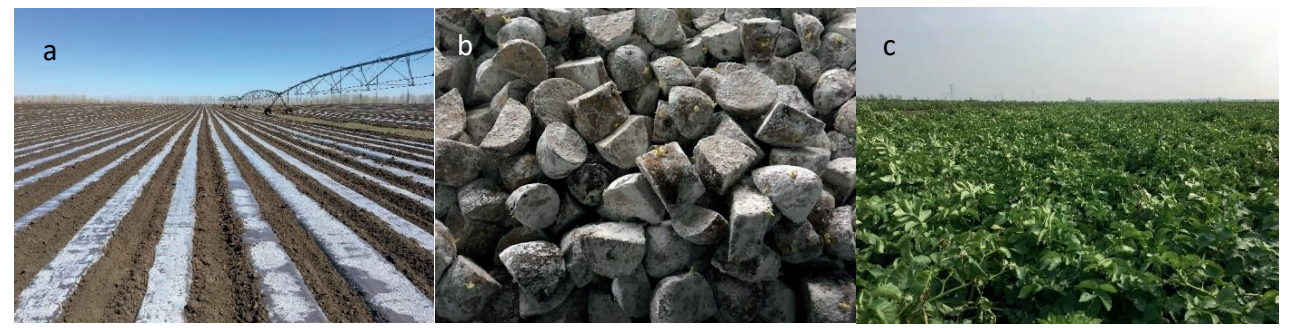

Figure 6.3. Potato cultivation in Inner Mongolia in northern China. Photo a was taken at potato planting in 2017. Photo b was taken before planting in 2018. Photo c was taken on 22 August in 2017. 


\section{Growth-limiting factors}

In the north, a water limitation is suggested by the large yield gap between $\mathrm{Yp}$ and $\mathrm{Yw}$ (i.e., between 4.6 and 19.7 ton FM ha ${ }^{-1}$ depending on different regions, Table 2.1, Chapter 2). Farmers of the surveyed regions described large variations in rainfall patterns across years. Water limitation was seen by farmers as one of the biggest challenges to potato production in all three surveyed regions. Potato production in Heilongjiang in the north is mainly under rainfed conditions, where the rainfall during the growing season (i.e., $316 \mathrm{~mm}$ in 2017 and 501 $\mathrm{mm}$ in 2018, Table 6.1) was more than the estimated evapotranspiration under non-waterlimited conditions (i.e., $271 \mathrm{~mm}$ in 2017 and $269 \mathrm{~mm}$ in 2018). Yet, I assume that potato suffered from water stress, particularly in 2017 , where a spring drought occurred due to the late onset of rain, and within-season drought happened in June and July (Fig. 6.2f). The lower survey-based yield in 2017 (29.7 ton FM ha-1) than in 2018 (32.6 ton FM ha-1) (Table 6.1) suggests the vulnerability of potatoes to rainfall variability. Despite the rainfall variability and the water limitation, I estimated a large scope for improving yield at current rainfall levels in Heilongjiang ( $\mathrm{Yw}$ is 51 ton $\mathrm{FM} \mathrm{ha}^{-1}$, yield gap between $\mathrm{Yw}$ and $\mathrm{Ya}$ is $59 \%$ ). Also the water input gap (39 mm) to achieve a higher yield (from Yw to Yp, 56 ton FM ha-1) is lower in Heilongjiang than in the other regions in the north (Chapter 2).

Inner Mongolia receives less rainfall than Heilongjiang, and rainfall in Gansu is even more sparse (Fig. 6.2b, d; Table 6.1). Potato yield in Inner Mongolia seems to be positively related to the growing-season rainfall in both years (Fig. 6.4a, b), and with total water input (irrigation and rainfall) in 2017 (Fig. 6.4c). The higher rainfall during the growing season in 2018 than in 2017 (266 mm versus $203 \mathrm{~mm}$ ) may, therefore, explain the higher farmers' yield in 2018 than in 2017 (42.6 versus 38.3 ton $\mathrm{FM} \mathrm{ha}^{-1}$ ) (Table 6.1). Farmers lack access to adequate irrigation water and related infrastructure, which limits their capacity to avoid water limitation. For instance, in Inner Mongolia, farmers complained that the electricity for sprinkler irrigation was insufficient to allow a good timing of irrigation for the entire farm. The electricity system was designed in the past when large-scale irrigated cropping was not prevalent. In Gansu, the irrigation water supply is governed by the local authority, who permits no more than three times irrigation over the entire growing season. Farmers regularly observe water stress, partially in the critical periods of potato growth (i.e., emergence, tuber bulking, etc.). To deal with such water scarcity, farmers tend to apply substantial amounts of water per irrigation during the growing season and after harvesting to enhance soil moisture (Table 6.1), which eventually results in enormous water surplus as shown in Chapter 4. For the two regions, a necessary step to empower farmers is to transfer the technical knowhow to deal with the expected drought. Besides, precise weather forecasts should be widely accessible to farmers, based on which they can better prepare for extreme climate events and plan irrigation appropriately. 

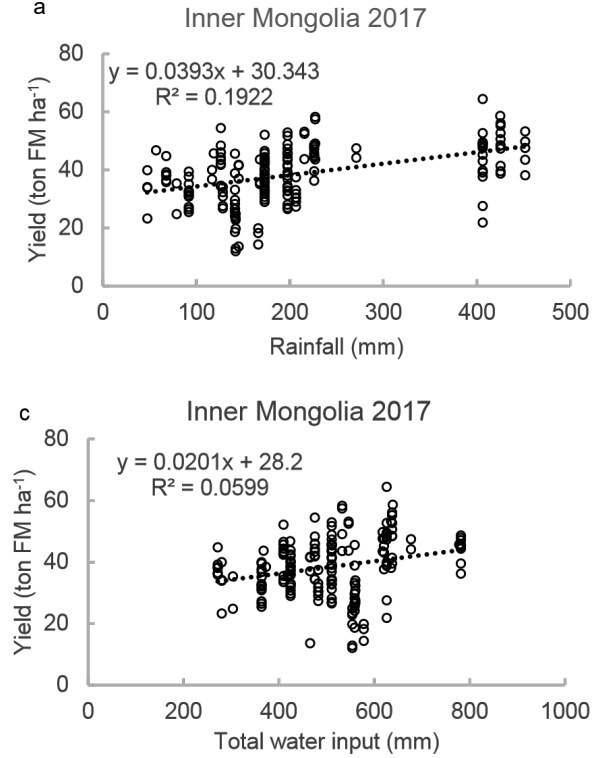
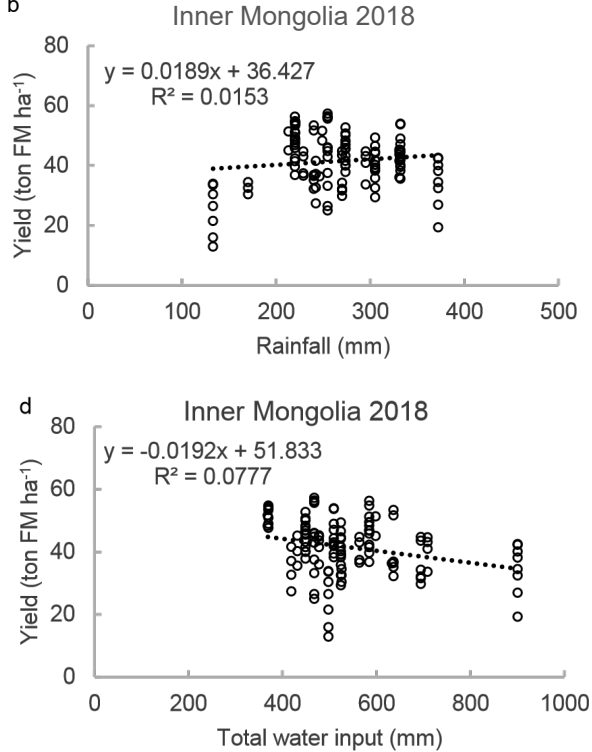

Figure 6.4. The relationships between potato yield and rainfall amount during the growing season in Inner Mongolia in 2017 (a) and 2018 (b); and between yield and total water input (rainfall and irrigation) in Inner Mongolia in 2017 (c) and 2018 (d). The rainfall amount was measured on-farm by the local agronomists in Inner Mongolia for 25 farms in 2017 and 23 farms in 2018. The yield was derived from 181 fields of the 25 farms in 2017 and 172 fields of the 23 farms in 2018 (each farm had multiple fields).

Table 6.1 The water input (rainfall and irrigation), the model-based evapotranspiration (ET) under nonwater-limited conditions, and actual yield of the three surveyed regions in northern China.

\begin{tabular}{lllllc}
\hline Years & Regions & Rainfall $(\mathrm{mm})$ & Irrigation $(\mathrm{mm})$ & ET $(\mathrm{mm})$ & Yield (ton FM ha-1) \\
\hline \multirow{2}{*}{2017} & Inner Mongolia & 203 & 302 & 266 & 38.3 \\
& Gansu & 91 & 767 & 288 & 38.8 \\
& Heilongjiang & 316 & 45 & 271 & 29.7 \\
\hline \multirow{2}{*}{2018} & Inner Mongolia & 266 & 275 & 256 & 42.6 \\
& Gansu & 95 & 588 & 269 & 42.5 \\
& Heilongjiang & 501 & 70 & 269 & 32.6 \\
\hline
\end{tabular}

\section{Growth-reducing factors}

Potato growth was reduced by various fungal, bacterial and virus diseases. Late blight (Phytophthora infestans), early blight (Alternaria solani) and common scab (Streptomyces species) were commonly observed diseases in the north in my survey. Virus diseases were observed in many fields during the farm surveys in Heilongjiang. In Inner Mongolia, Rhizoctonia solani was observed shortly after emergence, and severe wilting symptoms were found, especially in late in the growing season. Farmers commented that the wilted plants 
accounted for as many as $30-50 \%$ in a field. The symptom of wilting can be associated with many fungal and bacterial diseases such as bacterial wilt (Ralstonia solanacearum), fusarium wilt (various Fusarium species), verticillium wilt (Verticillium dahliae and Verticillium albo-atrum) and pink rot (Phytophthora erythroseptica) (Mulder and Turkensteen, 2005). In addition, black dot (Colletotrichum coccodes) and dry rot (Phoma foveata and Phoma exigua) were observed in some potato fields when visiting the farms.

I argue that the disease infestation is mainly due to the poor access of farmers to high-quality seed tubers. During the farmer interviews in 2017, I asked farmers to classify the quality of their seed tubers into three levels: good, average and poor. Farmers perceived whether the seed tuber quality was good or poor based mainly on the degree of disease infection observed during seed tuber preparation (cutting) and/or on the failure of emergence. In Heilongjiang (21 farmers were interviewed), 15 farmers purchased seed from the potato processing company with which they had a contract. Others obtained seed from other seed traders (six farmers), or used tubers they had grown themselves (seven farmers). Five farmers indicated poor seed quality, and four farmers thought the seed quality was average. Farmers tended to vary the origin of seed tubers and rely on large quantities of seed (i.e., between 3 and 4.5 ton $\mathrm{FM} \mathrm{ha}^{-1}$ ) to compensate for the losses from unsuccessful seed. In Inner Mongolia (eight farmers were interviewed), the seed tubers all originated from the same seed company. Three farmers commented that the seed quality was average, and the others thought it was good. For farmers in Gansu (12 farmers were interviewed), five farmers purchased seeds from two local traders, and six farmers relied on self-produced seeds. They believed that the seed obtained from the seed traders performed less well than the self-produced seeds. Overall, the poorer seed quality in Heilongjiang may explain the fact that the yield was lower than in Gansu and Inner Mongolia (Table 6.1).

\subsection{Synergies and trade-offs between crop production, resource use efficiency, and environmental impact}

\section{The synergy between yield, resource use efficiency, and environmental impact}

The potato yield production (expressed in the $\mathrm{N}$ content in tubers) in relation to $\mathrm{N}$ fertiliser inputs varied largely between the fields in each surveyed region (Fig. 4.1a, c, e in Chapter 4). Liebig's Law of the Minimum allows a good interpretation of the differences in yield (de Wit, 1992). The relatively lower yield in some fields than in others was more related to the deficiency of other growth factors (see Section 6.2) than $\mathrm{N}$ fertiliser, which induced sub-optimum growing conditions (Line 1 in Fig. 6.5). Furthermore, following the law of the optimum (Liebscher, 1895), de Wit (1992) states that "most resources are used more efficiently with an increased yield through optimizing growing conditions". In this way, for a given $\mathrm{N}$ input level, improving yield contributes to enhancing resource use efficiency and reducing environmental risks (synergy), which can be accomplished through better management practices (e.g., better pest and disease control) (from Line 1 to Line 2 in Fig. 6.5). This was demonstrated in the field experiments in Inner Mongolia where, compared to rainfed potatoes, applying irrigation led to a great improvement in yield, and significantly improved NUE and reduced $\mathrm{N}$ surplus at all $\mathrm{N}$ 
input levels (Fig. 5.4a in Chapter 5). Furthermore, a reduction in $\mathrm{N}$ fertiliser input from farmers' $\mathrm{N}$ rates (189-252 $\mathrm{kg} \mathrm{ha}^{1}$ ) to lower rates $\left(109-181 \mathrm{~kg} \mathrm{ha}^{-1}\right.$ ) did not affect yield (from II to III on Line 2) due to the high soil $\mathrm{N}$ supply; but a further decline in $\mathrm{N}$ fertiliser input (to 9-117 kg ha${ }^{1}$ ) induced $\mathrm{N}$ stress to plants (from III to IV on Line 2) (Table 5.3 in Chapter 5).

The trade-off between yield, resource use efficiency, and environmental impact

Under particular growing conditions, the response of yield in relation to $\mathrm{N}$ fertiliser input follows a diminishing return pattern (Line 1, 2, 3 in Fig. 6.5) (de Wit, 1992). Accordingly, for a given growing condition enhancing yield coincides with a decline in nitrogen use efficiency (the ratio between $\mathrm{N}$ output and $\mathrm{N}$ input), and an increase in $\mathrm{N}$ surplus (the difference between $\mathrm{N}$ output and $\mathrm{N}$ input), indicating the essence of a trade-off between yield, resource use efficiency and environmental impacts. The trade-off was observed in the potato production in the surveyed regions, where higher yield was associated with higher environmental impacts in terms of $\mathrm{N}$ surplus (Table 4.2 in Chapter 4). This type of trade-off was also identified in the hypothesized long-term situations assuming a more efficient $\mathrm{N}$ fertiliser management, i.e., compared to the lower target yield (Ya), a higher target yield (exploitable yield, $\mathrm{Ye}$ ) was associated with a higher $\mathrm{N}$ surplus (Table 4.3 in Chapter 4). Despite this, the environmental risk in terms of $\mathrm{N}$ surplus is low for a production aiming at high yield and following sustainable practices. In the 2018 field experiment in Inner Mongolia (Chapter 5), I found that a lower fertiliser input than farmers' inputs (109-181 kg ha-1) resulted in a reasonable yield (47 ton FM ha-1) and a low $\mathrm{N}$ surplus $\left(28 \mathrm{~kg} \mathrm{ha}^{-1}\right)$ due to the high soil $\mathrm{N}$ supply in the study region. The value was much below the upper target value ( $80 \mathrm{~kg} \mathrm{ha}^{-1}$ ) applied by the EU Nitrogen Expert Panel (Fig. 5.4b in Chapter 5). In the long-term, where I assumed a more efficient $\mathrm{N}$ management practice and an equilibrium soil $\mathrm{N}$ supply, the $\mathrm{N}$ surplus (between 27 and $34 \mathrm{~kg} \mathrm{ha}^{-1}$ ) in relation to a high target yield (i.e., the exploitable yield, Ye, was between 46.2 and 57.2 ton $\mathrm{FM} \mathrm{ha}^{-1}$, depending on the region) was also lower than the EU target (Table 4.3 in Chapter 4). 


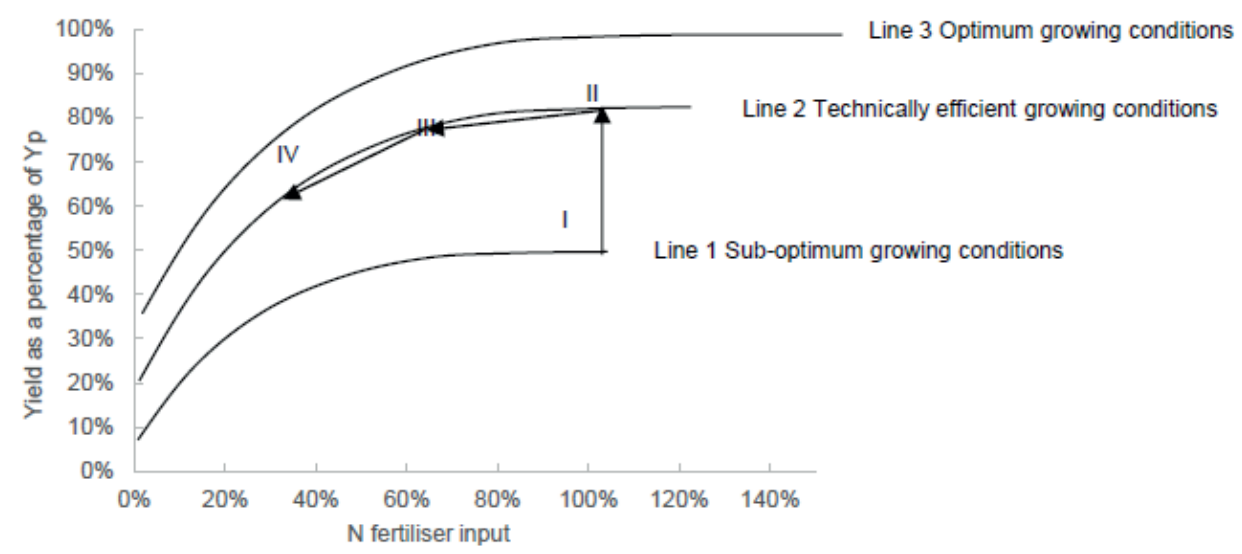

Figure 6.5. The illustration of the relationships between yield and $\mathrm{N}$ fertiliser inputs under different growing conditions: Line 1, sub-optimum growing conditions; Line 2, technically efficient growing conditions represented by the best performing farmers; and Line 3, optimum growing conditions for potential yield production. Adapted from de Wit (1992) and Silva et al. (2017). Points I-IV represent the production levels in relation to different $\mathrm{N}$ fertiliser inputs and different growing conditions.

\subsection{Intervention options for sustainable intensification of potato production in China}

Despite the government efforts to enhance potato production across the country (i.e., "Potato Staple Food Strategy", Chapter 1), a reduction in potato area was observed in 2018, which was mainly associated with the dropped market price (USDA, 2018). The abundant production in 2016 and 2017 resulted in a low price in 2018. In Heilongjiang, some potato farmers surveyed in 2017 switched to maize in 2018. Unlike the three main staples (i.e., rice, wheat, and maize), potato is not subsidized and the price of potato is sensitive to the market variability. The volatile market price reduced farmers' motivations to grow potatoes and to expand the existing production area (Zhang, 2016). If there is no effective intervention to enable a stable price over time, the aspiration of improving area (Chapter 1 ) may be hard to achieve.

The average potato yield of the country is low and shows stagnation in recent years (Fig. 2.1, Chapter 2). The low yield is associated with the widespread application of poor-quality seed tubers (Jansky et al., 2009; Kempenaar et al., 2015; USDA, 2016). The seed potato producers in China are not licensed (Xie et al., 2014). There is no technical distinction between the table and processing (ware) potato production and seed potato production (Xie et al., 2014). Farmers sell ware potatoes as seed potatoes and vice versa. As I observed in Heilongjiang, compared to the commercial potato cultivation, seed growers invested just a bit more in the pest and disease control. Furthermore, the practice of cutting tubers encouraged the spread of diseases. Regulating the seed sector through introducing legislation to promote the production of disease-free potato seed tubers is crucial to strengthen the seed system in China. Imports of new varieties offer an option to enrich domestic varieties, particularly for the 
processing sector. However, the import of seed potatoes is limited due to the high entry barriers. This has also to do with the great concern of the foreign seed suppliers on the legal use of variety licenses (i.e., breeders' rights) in the Chinese market. There is a pressing need to reinforce the national legislation in relation to potato variety protection to underpin the developments of new potato varieties that meet the requirement of the markets, producers and consumers.

Fertiliser is easily accessible and affordable to Chinese farmers due to the enormous subsidy supporting the fertiliser industry (Li et al., 2013). The cheap fertiliser motivates farmers to use excessive amounts of fertiliser to stimulate the production, rather than to invest in techniques that allow more efficient use of fertiliser. On the other hand, the policies and regulations regarding fertiliser management and environmental control are vague, guiding provisions. There exists no regulation on the maximum fertiliser input and sanctions are missing. Such regulations have existed for long in developed countries such as the Netherlands aiming to minimize the environmental impacts associated with agricultural production (Schröder and Neeteson, 2008). The laws, norms, and guidelines are urgently needed to reduce environmental impacts in agricultural production. They should be clearly defined and effectively and strictly implemented.

\subsection{Innovation and implications}

The present study matches the general goal by the Ministry of Agriculture in China (MOA, 2015) to enhance potato production and at the same time to pay attention to the efficient use of agricultural resources and the improvement of the environment to realize sustainable intensification. The environmental influences of potato production have been extensively studied at the country and global level (Franke, et al., 2011; Haverkort and Hillier, 2011; Haverkort et al., 2013a, 2014; Van Evert et al., 2013). The objective of the present study was to explore the critical aspects of sustainable potato production at the field and regional level based on farm surveys and on-farm field experiments.

Existing conceptual frameworks were applied to benchmark the sustainability performance of potato production in yield (yield gap analysis, Chapter 2) and nitrogen use efficiency (EU Nitrogen Expert Panel, 2015, Chapter 4). Building on these theories, I developed new frameworks to benchmark the production performance in terms of quality and revenue (Chapter 3) and use efficiency of water resources (Chapter 4). The concept of optimum quality (Qp) was introduced first in this study as the quality values that are most favoured by a specific market. In addition, the quality traits and their critical values in relation to the revenue were identified (i.e., acceptability, base and penalty price, and bonus price). In this way, the production performance in terms of yield (yield gaps), quality (quality gaps) and revenue (revenue gaps) could be assessed, and the scope of improvement in these aspects could be evaluated. The framework of the EU Nitrogen Expert Panel (2015) was adjusted to account for soil $\mathrm{N}$ supply and the soil $\mathrm{N}$ dynamics (Chapter 4 ). To address the environmental impacts caused by (over-) irrigation, water surplus was proposed first in this study as the difference between water input (rainfall and irrigation) and actual evapotranspiration per growing season. 
Based on these benchmarking approaches, the relationships between enhancing production and other sustainability objectives were assessed, and the scope for improvement was evaluated under site-specific conditions. As such it took up the challenge framed by de Wit (1992) and Van Noordwijk and Brussaard (2014) to investigate interrelationships of yield, resource use efficiency and environmental impact that are usually studied in isolation. In this way, the results provided advice to stakeholders, supporting farmers and politicians on how to promote potato production and at the same time to reduce environmental pollution and use natural resources more efficiently.

The generic framework developed in Chapter 3 provides a robust method to assess crop performance in relation to yield, quality and revenue of crop production. The yield gap analysis (Van Ittersum et al., 2013) points at how much yield can be increased by implementing better management practice. The evaluation on quality gaps enables a better understanding of the variation in price per unit harvested product which is often driven by particular quality traits. In this way, it enhances the yield gap notion and allows to explore the pathways of achieving economic growth of crop production. Performing such analysis will guide the industries to form specific requirements in relation to various quality traits and develop a better plan for the pricing structure. It also helps farmers to recognize the weak points of their production and implement better management strategies. The framework is generic and provides a starting point with a contextualized structure. It can be applied to other agricultural products (i.e., food crops, fodder crops and livestock products). The boundaries of the study area depend on the purpose of the study. For instance, if the aim is to evaluate the nutritional values of a specific crop, the framework can be up-scaled from field, to farm, regional and national levels. When the economic performance is concerned, the framework is better suited to be applied at field, farm and regional levels due to the high contextualized features of quality requirement and the corresponding market price.

\subsection{Limitations and research agenda}

For each chapter, data limitations and a research agenda can be defined. For Chapter 2, the data on irrigated areas and irrigation amount for potato was very limited. The National Statistics of China only shows the production area of the potato crop at provincial and national level, which includes both irrigated and rainfed area. Therefore, I estimated both Yp and Yw for all areas, and the resulted $Y w$ and $Y p$ apply to the whole country. In the southwest and south part of China (Zone II and IV, Fig. 1.2, Chapter 1), potato is cultivated mainly under rainfed conditions. For the north (Zone I, Fig. 1.2, Chapter 1) where rainfall is limited, farmers apply irrigation whenever they feel there is a need. Usually, the good irrigation facilities are available for processing companies and large-scale farmers as investigated in our study. For a more robust estimation, spatial-explicit information on the area and yield of irrigated and rainfed potato should be identified, and the yield data should be disaggregated better from the regional level to the farm/field level. The two farm types (smallholders and large-scale farms) are contrasting in resource inputs and production levels, and the pathways to improve the sustainability performance should be addressed taking such dissimilarity into account. 
The on-farm experiments should be conducted at broader scales to identify the viable options of enhancing potato cultivation sustainably, while considering the local variability in biophysical and socio-economic conditions. On the other hand, on-farm experiments with participation of farmers are challenging for researchers. In the field experiment in Inner Mongolia, some discrepancies between the designed and actual experimental treatments had to be accepted (i.e., $\mathrm{N}$ fertiliser was added by sprinkler irrigation which was not intended by the researchers). Consequently, it was not possible to test the treatments as planned (2018) and I could not demonstrate the effect of the originally designed fertiliser treatments (i.e., $100 \mathrm{~kg} \mathrm{~N} \mathrm{ha}^{-1}$, zero $\mathrm{P}$ and $\mathrm{K}$ fertiliser) on potato production. I suspect that further reducing fertiliser input (to 100 $\mathrm{kg} \mathrm{N} \mathrm{ha}^{-1}$ ) of the surveyed farms is feasible, which should be tested experimentally in the future. For other farms (fields), the feasibility of reducing fertiliser inputs depends on field conditions (i.e., the capacity of a field to produce high yield, and soil $\mathrm{N}$ supply capacity). The "easy hydrolysable organic N" (alkali-hydrolysable N, Table 5.2 in Chapter 5) as measured in the local laboratory give an indication of the mineral soil $\mathrm{N}$ that is available for a crop during the growing season. A more reliable information on soil $\mathrm{N}$ supply is needed, which should reveal the mineral $\mathrm{N}$ measured at planting and the mineralized $\mathrm{N}$ that is released during the growing season. Based on the experiments, we recommended that in the short-term, the $\mathrm{N}$ fertiliser input can be reduced to $109-181 \mathrm{~kg} \mathrm{~N} \mathrm{ha}^{-1}$ in Inner Mongolia without yield penalty (Chapter 5). The values are close to the $\mathrm{N}$ fertiliser input of $167 \mathrm{~kg} \mathrm{~N}$ ha-1 $^{-1}$ estimated in the long-term scenario to obtain the exploitable yield (Table 4.3 in Chapter 4). This estimation was however based on potato monoculture and did not consider potatoes in rotation with other crops. The proper $\mathrm{N}$ fertiliser inputs to combine high yields with low $\mathrm{N}$ losses should be verified in consecutive years considering a proper rotation with other crops.

\subsection{Conclusion}

China is currently aiming to boost potato production to transform the crop into the country's fourth staple food after rice, wheat, and maize. While it is difficult to improve the yields of main cereal staples considering their already high productivity, it is relatively easy to improve the yield of potato due to its large yield gaps. Improving potato production is of high importance to safeguard the country's food supply. China's agriculture developed steeply over the past decades at tremendous resource and environmental costs. Resource use inefficiency and ecological and environmental pressures are threatening environmental sustainability. Therefore, identifying the biophysical potential of potato yield improvement, the current and "desirable" sustainability performance, and the feasible options of sustainable practices are urgently needed.

The present study applied a quantitative approach to assess the scope and pathways of sustainable intensification of potato production in China. The aim was to enhance potato production with sustainable practices that balance the targeted outputs (agronomic and economic goals) and non-targeted outputs (environmental impacts). The findings indicated that the biophysical potential of potatoes is high and the scope for improving yield is large for both rainfed (yield gap is 61\%) and irrigated (yield gap is 66\%) potato production in the country (Chapter 2). Synergy in maximizing the targeted outputs (yield, quality, and revenue) was 
identified in a case study for potato produced for French Fries processing in Inner Mongolia (Chapter 3). Enhancing yield contributed to an improved quality and increased revenue. The revenue gap (43\%) could be narrowed by closing the yield gap $(26 \%)$ along with improving quality (i.e., improved tuber dry matter percentage and reduced weight percentage of smallsized tubers). The current production was characterised by high resource inputs (nitrogen fertiliser and water), medium output, medium resource use efficiencies and high environmental influences, and there was a trade-off between yield and environmental risks (Chapter 4). However, it was estimated that in the long-term, with more efficient nitrogen management practices, a good compromise between the targeted and non-targeted objectives can be achieved. This estimation was verified experimentally, i.e. better irrigation management alongside with reduced $\mathrm{N}$ fertiliser inputs were demonstrated pathways to enhance yield, improve resource use efficiencies, and reduce environmental impacts simultaneously (Chapter 5). Meanwhile, the introduction of sustainable practices is limited by the socioeconomic concerns (i.e., limited economic advantage of reducing $\mathrm{N}$ fertiliser inputs, high cost and labor demand of adapting to more efficient irrigation system), which called for appropriate political and institutional arrangements to ensure the successful operation of sustainable intensification. In this way, the present study provided crucial knowledge and contextualized suggestions to underpin sustainable intensification of potato production in China. 

References 
Ahmed, S., Stepp, J.R., 2016. Beyond yields: Climate effects on specialty crop quality and agroecological management. Elementa: Science of the Anthropocene 4, 92.

Asseng, S., Ewert, F., Rosenzweig, C., Jones, J.W., Hatfield, J.L., Ruane, A.C., Boote, K.J., Thorburn, P.J., Rötter, R.P., Cammarano, D., Brisson, N., 2013. Uncertainty in simulating wheat yields under climate change. Nature Climate Change 3 (9), 827-832.

Beukema, H.P., Van der Zaag, D.E., 1990. Introduction to Potato Production. Centre for Agricultural Publishing and Documentation (Pudoc), Wageningen, the Netherlands.

Boogaard, H.L., de Wit, A.J.W., te Roller, J.A., Van Diepen, C.A., 2014. WOFOST CONTROL CENTRE 2.1, User's Guide for the WOFOST CONTROL CENTRE 2.1 and the Crop Growth Simulation Model WOFOST 7.1.7. Wageningen University and Research Centre, Alterra, Wageningen, the Netherlands.

Brolsma, K., 2019. Personal communication with expert from the Eurofins. https://www.eurofins.nl/en/.

Brouwer, C., Prins, K., Heibloem, M., 1989. Irrigation Water Management: Irrigation Scheduling. Training Manual.

Cai, G.X., 1997. Ammonia volatilization. In: Nitrogen in soils of China. Springer, Dordrecht. 193-213.

Cassman, K.G., 1999. Ecological intensification of cereal production systems: yield potential, soil quality, and precision agriculture. Proceedings of the National Academy of Sciences 96 (11), 5952-5959.

Cassman, K.G., Dobermann, A.D., Walters, D., Yang, H., 2003. Meeting cereal demand while protecting natural resources and improving environmental quality. Annual Review of Environment and Resources 28, 315-358.

Chapman, H.W., Loomis, W.E., 1953. Photosynthesis in the potato under field conditions. Plant Physiology 28 (4), 703-716.

Charkowski, A., Sharma, K., Parker, M.L., Secor, G.A., Elphinstone, J., 2020. Bacterial Diseases of Potato. In: The Potato Crop. Springer, Cham, 351-388.

Chen, X.P., Cui, Z.L., Vitousek, P.M., Cassman, K.G., Matson, P.A., Bai, J.S., Meng, Q.F., Hou, P., Yue, S.C., Römheld, V., Zhang, F.S., 2011. Integrated soil-crop system management for food security. Proceedings of the National Academy of Sciences 108 (16), 6399-6404.

Cheng, J.S., Zhang, X.X., 2000. Study on the ecological effects of plastic mulching on potato in cool and humid highland of Wei'nan county in Gansu province. Chinese Potato. 14 (2), 83-84. In Chinese with English Abstract.

China Potato Website, accessed in 2017. Available at: http://www.potato.agri.cn/. In Chinese. Choudhary, D.K., Nabi, S.U., Dar, M.S., Khan, K.A., 2018. Ralstonia solanacearum: A wide spread and global bacterial plant wilt pathogen. Journal of Pharmacognosy and Phytochemistry 7(2), 85-90.

CMDC, 2016. China Meteorological Data Service Center (CMDC), accessed in 2016. Available at: http://data.cma.cn/en.

CMDC, 2018. China Meteorological Data Service Center (CMDC), accessed in 2018. Available at: http://data.cma.cn/en. 
CMDC, 2019. China Meteorological Data Service Center (CMDC), accessed in 2019. Available at: http://data.cma.cn/en.

Conant, R.T., Berdanier, A.B., Grace, P.R., 2013. Patterns and trends in nitrogen use and nitrogen recovery efficiency in world agriculture. Global Biogeochemical Cycles 27 (2), 558566.

COWI, 2013. Nature Agency, Ministry of the Environment. Groundwater in China. Part 1 Occurrence and Use. Available at: https://ecoinnovation.dk/media/mst/94641/130618\%20Groundwater\%20in\%20China_Part $\% 201 \_O c c u r r e n c e \%$ 20and\%20Use.pdf.

Cui, Z., Chen, X., Miao, Y., Zhang, F., Sun, Q., Schroder, J., Zhang, H., Li, J., Shi, L., Xu, J., Ye, Y., Liu, C., Yang, Z., Zhang, Q., Huang, S., Bao, D., 2008. On-farm evaluation of the improved soil $\mathrm{N}$ min-based nitrogen management for summer maize in North China plain. Agronomy Journal 100 (3), 517-525.

Dai, Y., Wei, S., Duan, Q., Liu, B., Fu, S., Niu, G., 2013. Development of a China dataset of soil hydraulic parameters using pedotransfer functions for land surface modeling. Journal of Hydrometeorology 14 (3), 869-887.

De Koning, G., Van Diepen, C.A., Reinds, G.J., 1995. Crop growth model WOFOST applied to potatoes. In: Modelling and Parameterization of the Soil-Plant-Atmosphere System, 275297.

de Wit, A., Boogaard, H., Fumagalli, D., Janssen, S., Knapen, R., van Kraalingen, D., Supit, I., van der Wijngaart, R., van Diepen, K., 2018. 25 years of the WOFOST cropping systems model. Agricultural Systems 168, 154-167.

de Wit, C.D., 1992. Resource use efficiency in agriculture. Agricultural Systems 40 (1-3), 125151.

DeFauw, S.L., He, Z., Larkin, R.P., Mansour, S.A., 2012. Sustainable potato production and global food security. In: Sustainable potato production: global case studies. Springer Netherlands, 3-19.

Deng, N., Grassini, P., Yang, H., Huang, J., Cassman, K.G., Peng, S., 2019. Closing yield gaps for rice selfsufficiency in China. Nature Communications 10 (1), 1725.

Deng, X.P., Shan, L., Zhang, H., and Turner, N.C. 2006. Improving agricultural water use efficiency in arid and semiarid areas of China. Agricultural Water Management 80 (1-3), 23-40.

Diepen, C.V., Wolf, J., Keulen, H.V., Rappoldt, C., 1989. WOFOST: a simulation model of crop production. Soil Use Manage 5 (1), 16-24.

Dua, V.K., Govindakrishnan, P.M., Singh, B.P., 2014. Calibration of WOFOST model for potato in India. Potato Journal 41 (2), 105-110.

Duan, Y., Tuo, D.B., Zhao, P.Y., Li, H.C., Li, S., 2013. Response of potato to fertiliser application and nutrient use efficiency in Inner Mongolia. Better Crops 97 (3), 24-26.

Duan, Y., Zhang, J., Li, H.C., Zhao, P.Y., Tuo, D.B., Yao, J.Q., An, H., Jia, Y.Y., 2014. Fertilization effect and nutrition use efficiency of potato in Inner Mongolia. Soils 46 (2), 212 217. In Chinese with English Abstract.

ECPD, 2016. The European Cultivated Potato Database (ECPD), accessed in 2016. Available at: https://www.europotato.org/menu.php. 
EU Nitrogen Expert Panel, 2015. Nitrogen Use Efficiency (NUE) an indicator for the utilization of nitrogen in food systems. Wageningen University, Alterra, Wageningen, Netherlands. Available at: http://www.eunep.com/wpcontent/uploads/2017/03/Report-NUE-IndicatorNitrogen-Expert-Panel-18-12-2015.pdf.

Fan, J., Hao, M., Malhi, S.S. 2010. Accumulation of nitrate $\mathrm{N}$ in the soil profile and its implications for the environment under dryland agriculture in northern China: A review. Canadian Journal of Soil Science 90 (3), 429-440.

FAO, 2016a. Food and Agriculture Organization of the United Nations (FAO). FAOSTAT, Production Database, accessed in 2016. Available at: http://faostat3.fao.org/home/E.

FAO, 2016b. Food and Agriculture Organization of the United Nations (FAO). International Year of the Potato, 2008, accessed in 2016. Available at: http://www.fao.org/potato2008/en/.

FAO, 2019. Food and Agriculture Organization of the United Nations (FAO). FAOSTAT, Production Database, accessed in 2019. Available at: http://faostat3.fao.org/home/E.

FAO, 2020. Food and Agriculture Organization of the United Nations (FAO). FAOSTAT, Production Database, accessed in 2020. Available at: http://www.fao.org/faostat/en/.

Fernie, A.R., Tadmor, Y., Zamir, D., 2006. Natural genetic variation for improving crop quality. Current opinion in plant biology 9 (2), 196-202.

Fleisher, D.H., Condori, B., Quiroz, R., Alva, A., Asseng, S., Barreda, C., Bindi, M., Boote, K.J., Ferrise, R., Franke, A.C., Govindakrishnan, P.M., 2017. A potato model intercomparison across varying climates and productivity levels. Global Change Biology 23 (3), 1258-1281.

Foley, J.A., Ramankutty, N., Brauman, K.A., Cassidy, E.S., Gerber, J.S., Johnston, M., Mueller, N.D., Connell, C.O., Ray, D.K., West, P.C., Balzer, C., Bennett, E.M., Carpenter, S.R., Hill, J., Monfreda, C., Polasky, S., Rockström, J., Sheehan, J., Siebert, S., Tilman, D., Zaks, D.P.M, 2011. Solutions for a cultivated planet. Nature 478 (7369), 337.

Franke, A.C., Steyn, J.M., Ranger, K.S., Haverkort, A.J., 2011. Developing environmental principles, criteria, indicators and norms for potato production through field surveys and modelling. Agricultural Systems 104 (4), 297-306.

Gaastra, P., 1959. Photosynthesis of crop plants as influenced by light, carbon dioxide, temperature, and stomatal diffusion resistance. Wageningen, Veenman, 1-68.

Ghose, B., 2015. Food security and food self-sufficiency in China: from past to 2050 . Food \& Energy Security 3 (2), 86-95.

GYGA, 2016. Global Yield Gap Atlas (GYGA), accessed in 2016.

Available at: http://www.yieldgap.org/.

GYGA, 2017a. Global Yield Gap Atlas (GYGA), accessed in 2017.

Available at: http://www.yieldgap.org/.

GYGA, 2017b. Global Yield Gap Atlas (GYGA), accessed in 2017. Model Calibration, Appendix III- Guidelines for Model Calibration.

Available at: http://www.yieldgap.org/methods-modelcalibration.

GYGA, 2019. Global Yield Gap Atlas (GYGA), accessed in 2019.

Available at: http://www.yieldgap.org/.

GYGA, 2020. Global Yield Gap Atlas (GYGA), accessed in 2020.

Available at: http://www.yieldgap.org/. 
Godfray, H.C.J., Beddington, J.R., Crute, I.R., Haddad, L., Lawrence, D., Muir, J.F., Pretty, J., Robinson, S., Thomas, S.M., Toulmin, C., 2010. Food security: the challenge of feeding 9 billion people. Science 327 (5967), 812-818.

Goudriaan, J., Van Laar H.H., 1978. Calculation of daily totals of the gross assimilation of leaf canopies. Netherlands Journal of Agricultural Science 26, 373-382.

Grassini, P., Van Bussel, L.G., Van Wart, J., Wolf, J., Claessens, L., Yang, H., Boogaard, H., Groot, H., Van Ittersum, M.K., Cassman, K.G., 2015. How good is good enough? Data requirements for reliable crop yield simulations and yield-gap analysis. Field Crops Research 177, 49-63.

Grassini, P., Yang, H., Irmak, S., Thorburn, J., Burr, C., Cassman, K.G., 2011. High-yield irrigated maize in the Western U.S. Corn Belt: II. Irrigation management and crop water productivity. Field Crops Research 120 (1), 133-141.

Gregory, P.J., Simmonds, L.P., 1992. Water relations and growth of potatoes. In: The Potato Crop. Springer, Dordrecht. 214-246.

Guardia, G., Sanz-Cobena, A., Sanchez-Martín, L., Fuertes-Mendizábal, T., González-Murua, C., Álvarez, J.M., Chadwick, D., Vallejo, A., 2018. Urea-based fertilization strategies to reduce yield-scaled $\mathrm{N}$ oxides and enhance bread-making quality in a rainfed Mediterranean wheat crop. Agriculture, Ecosystems \& Environment 265, 421-431.

Hao, T., Zhu, Q., Zeng, M., Shen, J., Shi, X., Liu, X., Zhang, F., de Vries, W., 2019. Quantification of the contribution of nitrogen fertilization and crop harvesting to soil acidification in a wheat-maize double cropping system. Plant and Soil 434 (1-2), 167-184.

Harris, P.M., 1992. Mineral nutrition. In: The Potato Crop. Springer, Dordrecht. 162-213.

Haverkort, A.J., 1985. Relationships Between Intercepted Radiation and Yield of Potato Crops Under the Tropical Highland Conditions of Central Africa. Ph.D.Thesis, University of Reading, U.K..

Haverkort, A.J., De Ruijter, F.J., Van Evert, F.K., Conijn, J.G., Rutgers, B., 2013a. Worldwide sustainability hotspots in potato cultivation. 1. Identification and mapping. Potato Research 56 (4), 343-353.

Haverkort, A.J., Franke, A.C., Engelbrecht, F.A., Steyn, J.M., 2013b. Climate change and potato production in contrasting South African agro-ecosystems 1. Effects on land and water use efficiencies. Potato Research 56 (1), 31-50.

Haverkort, A.J., Franke, A.C., Steyn, J.M., Pronk, A.A., Caldiz, D.O., Kooman, P.L., 2015. A Robust Potato Model: LINTUL-POTATO-DSS. Potato Research 58 (4), 313-327.

Haverkort, A.J., Grashoff, C., 2004. 13. IDEOTYPING-POTATO a modelling approach to genotype performance. In: Decision Support Systems in Potato Production: Bringing Models to Practice. Wageningen Academic Publishers, Wageningen,199-212.

Haverkort, A.J., Hillier, J.G., 2011. Cool farm tool-potato: model description and performance of four production systems. Potato Research 54 (4), 355-369.

Haverkort, A.J., Sandaña, P., Kalazich, J., 2014. Yield gaps and ecological footprints of potato production systems in Chile. Potato Research 57 (1), 13-31.

Haverkort, A.J., Struik, P.C., 2015. Yield levels of potato crops: recent achievements and future prospects. Field Crops Research 182, 76-85. 
Haverkort, A.J., Verhagen, A., Grashoff, A.C., Uithol, P.W.J., 2004. Potato-zoning: a decision support system on expanding the potato industry through agro-ecological zoning using the LINTUL simulation approach. In: Decision Support Systems in Potato Production: Bringing Models to Practice. Wageningen Academic Publishers, Wageningen, 29-44.

He, Z., Larkin, R.P., Honeycutt, W. (Eds.), 2012. Sustainable Potato Production: Global Case Studies. Springer Science \& Business Media.

Hijmans, R.J., Spooner, D.M., 2001. Geographic distribution of wild potato species. American Journal of Botany 88 (11), 2101-2112.

Huber, R., 2010. Yield Gap Analysis of Potato Yield in Poland. M.Sc. Thesis. Wageningen University, the Netherlands.

HZPC, 2018, accessed in 2018. Available at: https://www.hzpc.nl/nl/aardappelen/rassen/ innovator?variety_id=160.

Ingram, K.T., McCloud, D.E., 1984. Simulation of potato crop growth and development. Crop Science 24 (1), 21-27.

Jansky, S.H., Jin, L.P., Xie, K.Y., Xie, C.H., Spooner, D.M., 2009. Potato production and breeding in China. Potato Research 52 (1), 57.

Janssen, B.H., 2017. Crop yields and NPK use efficiency of a long-term experiment on a former sea bottom in the Netherlands. Wageningen University, Plant Production Systems.

Janssen, B.H., Guiking, F.C.T., Van der Eijk, D., Smaling, E.M.A., Wolf, J., Van Reuler, H., 1990. A system for quantitative evaluation of the fertility of tropical soils (QUEFTS). Geoderma 46 (4), 299-318.

Jia, L., Qin, Y., Chen, Y., Fan, M., 2018. Fertigation improves potato production in Inner Mongolia (China). Journal of Crop Improvement 32 (5), 648-656.

Jin, J., 2012. Changes in the efficiency of fertiliser use in China. Journal of the Science of Food and Agriculture 92 (5), 1006-1009.

Ju, X.T., Kou, C.L., Zhang, F.S., Christie, P., 2006. Nitrogen balance and groundwater nitrate contamination: comparison among three intensive cropping systems on the North China Plain. Environmental Pollution 143 (1), 117-125.

Kar, G., Kumar, A., 2007. Effects of irrigation and straw mulch on water use and tuber yield of potato in eastern India. Agricultural Water Management 94 (1), 109-116.

Keating, B.A., Carberry, P.S., Bindraban, P.S., Asseng, S., Meinke, H., Dixon, J., 2010. Ecoefficient agriculture: concepts, challenges, and opportunities. Crop Science 50 (1), S-109.

Kempenaar, C., Kessel, G.J.T., Wustman, R., Pronk, A.A., Haverkort, A.J., de Ruijter, F.J., Lv, D.Q., Wan, S.M., Fan, G.Q., Bai, Y.J., Min, F.X., Guo, M., Zhang, S., Yang, S., Gao, Y.F., 2015. Progress Report China Potato GAP Project: Late Blight Control, Seed Quality, Storage Facilities and Sustainability Studies in Heilongjiang Province and Communications. Applied Plant Research \& Plant Research International, Wageningen University \& Research, the Netherlands.

King, B.A., Stark, J.C., 1997. Potato irrigation management (No. 789). University of Idaho, Cooperative Extension System, College of Agriculture.

Kooman, P.L., 1995. Yielding Ability of Potato Crops as Influenced by Temperature and DayLength. Ph.D. Thesis, Wageningen University, the Netherlands. 
Kooman, P.L., Haverkort, A.J., 1995. Modelling development and growth of the potato crop influenced by temperature and daylength: LINTUL-POTATO. In: Ecology and Modeling of Potato Crops Under Conditions Limiting Growth. Kluwer Academic Publishers, Dordrecht, 41-60.

Kroes, J.G., Van Dam, J.C., Groenendijk, P., Hendriks, R.F.A., Jacobs, C.J., 2008. SWAP version 3.2.

Kumari, M., Kumar, M., Solankey, S.S., 2018. Breeding potato for quality improvement. In: Potato: From Incas to All Over the World. IntechOpen.

Kunkel, R., Campbell, G.S., 1987. Maximum potential potato yield in the Columbia Basin, USA: model and measured values. American Potato Journal 64 (7), 355-366.

Le, C., Zha, Y., Li, Y., Sun, D., Lu, H., Yin, B., 2010. Eutrophication of lake waters in China: cost, causes, and control. Environmental Management 45 (4), 662-668.

Li, K., Yang, X., Liu, Z., Zhang, T., Lu, S., Liu, Y., 2014a. Low yield gap of winter wheat in the North China Plain. European Journal of Agronomy 59, 1-12.

Li, S., Duan, Y., Chen, Z., Guo, T., Li, Y., 2014b. Yield response and economic benefit of fertiliser application on potato in Northwest China. Soil Fertility Science 04, 42-47. In Chinese with English Abstract.

Li, S., Duan, Y., Guo, T., Zhang, T., 2011. Demonstrating a link between nutrient use and water management to improve crop yields and nutrient use efficiency in arid Northwest China. International Plant Nutrition Institute (IPNI), Better Crops with Plant Food 95, 20-22.

Li, S., He, P., Duan, Y., Sui, D., 2015. 4R Nutrient Management Practices for Potato Production in China. Available at: http://china-zh.ipni.net/. In Chinese.

Li, S., Jin, J., 2012. 4R Nutrient Management Practices for Potato Production in China. Better Crops 96 (1). Available at: http://china.ipni.net/article/CNP-3031.

Li, S., Jin, J., Duan, Y., Chen, Z., Guo, T., Li, Y., Tong, Y. A., 2009. Agronomic evaluation of nutrient management for potato in Northwest China.

Available at: http://china.ipni.net/article/CNP-3021.

Li, S., Zhou, Y., Wang, S., Shang, M., Yang, B., 2019. Spatial-temporal variation of NDVI and its responses to precipitation and temperature in Inner Mongolia from 2001 to 2015. Journal of University of Chinese Academy of Sciences 36 (1), 48-55.

Li, Y., Zhang, W., Ma, L., Huang, G., Oenema, O., Zhang, F., Dou, Z., 2013. An analysis of China's fertiliser policies: impacts on the industry, food security, and the environment. Journal of Environmental Quality 42 (4), 972-981.

Liang, D.C., Li, W.G., Gong, X.F., 1998. Effects of plastic mulching on potato production. Inner Mongolia Agricultural Science and Technology, 67-68. In Chinese with English Abstract.

Liebscher, G., 1895. Untersuchungen über die Bestimmung des Düngerbedürfnisses der Ackerböden und Kulturpflanzen. Journal für Landwirtschaft 43, 49-125.

Lisinska, G., Peksa, A., Kita, A., Rytel, E., Tajner-Czopek, A., 2009. The quality of potato for processing and consumption. Food 3, 99-104.

Liu, C.M., Yu, J.J., Eloise, K., 2001. Groundwater exploitation and its impact on the environment in the North China Plain. Water International 26 (2), 265-272. 
Liu, J., You, L., Amini, M., Obersteiner, M., Herrero, M., Zehnder, A. J., Yang, H., 2010. A highresolution assessment on global nitrogen flows in cropland. Proceedings of the National Academy of Sciences 107 (17), 8035-8040.

Liu, X., He, P., Jin, J., Zhou, W., Sulewski, G., Phillips, S., 2011. Yield gaps, indigenous nutrient supply, and nutrient use efficiency of wheat in China. Agronomy Journal 103 (5), 14521463.

Liu, X., Zhang, Y., Han, W., Tang, A., Shen, J., Cui, Z., Vitousek, P., Erisman, J.W., Goulding, K., Christie, P., Fangmeier, A., Zhang, F., 2013. Enhanced nitrogen deposition over China. Nature 494 (7438), 459.

Lobell, D.B., Cassman, K.G., Field, C.B., 2009. Crop yield gaps: their importance, magnitudes, and causes. Annual Review of Environment and Resources 34, 179-204.

Lu, C.H., Fan, L., 2013. Winter wheat yield potentials and yield gaps in the North China Plain. Field Crops Research 143, 98-105.

Mackay, I., Horwell, A., Garner, J., White, J., McKee, J., Philpott, H., 2011. Reanalyses of the historical series of UK variety trials to quantify the contributions of genetic and environmental factors to trends and variability in yield over time. Theoretical and Applied Genetics 122 (1), 225-238.

MacKerron, D.K.L., 1985. Timing of irrigation in relation to yield and quality of potatoes. In: Irrigating Potatoes. UK Irrigation Association Technical Monograph 2, Cranfield Press, Silsoe, 54-60.

MacKerron, D.K.L., Jefferies, R.A., 1986. The influence of early soil moisture stress on tuber numbers in potato. Potato Research 29, 299-312.

MacKerron, D.K.L., Jefferies, R.A., 1988. The distributions of tuber sizes in droughted and irrigated crops of potato. I. Observations on the effect of water stress on graded yields from differing cultivars. Potato Research 31, 269-278.

Manrique, L.A., Hodges, T., 1989. Estimation of tuber initiation in potatoes grown in tropical environments based on different methods of computing thermal time. American Potato Journal 66 (7), 425-436.

Meng, Q., Hou, P., Wu, L., Chen, X., Cui, Z., Zhang, F., 2013. Understanding production potentials and yield gaps in intensive maize production in China. Field Crops Research 143, 91-97.

MOA, 2008. Ministry of Agriculture and Rural Affairs of The People's Republic of China (MOA). Mapping of Superior Potato Production Areas in China (2008-2015). Available at: https://wenku.baidu.com/view/ db20a4ea172ded630b1cb6ed.html. In Chinese.

MOA, 2015a. Ministry of Agriculture and Rural Affairs of The People's Republic of China (MOA). Potato as the Fourth Staple Food in China, accessed in 2015. Available at: http://www.moa.gov.cn/xw/zwdt/201501/t20150107_4324333.htm. In Chinese.

MOA, 2015b. Ministry of Agriculture and Rural Affairs of The People's Republic of China (MOA) National Agricultural Sustainable Development Plan (2015-2030), accessed in 2015. In Chinese.

MOA, 2016, Ministry of Agriculture and Rural Affairs of The People's Republic of China (MOA). Suggestions for Promoting the Development of the Potato Industry. Available at: http://www.moa.gov.cn/nybgb/2016/disanqi/201711/t20171126_5919565.htm. In Chinese. 
MOA, 2017. Ministry of Agriculture and Rural Affairs of The People's Republic of China (MOA). Key Technologies to Produce High Efficient and High Yield Potatoes. In Chinese.

Monfreda, C., Ramankutty, N., Foley, J.A., 2008. Farming the planet: 2. Geographic distribution of crop areas, yields, physiological types, and net primary production in the year 2000. Global Biogeochemical Cycles 22 (1).

Moorby, J., Munns, R., Walcott, J.,1975. Effect of water deficit on photosynthesis and tuber metabolism in potatoes. Functional Plant Biology 2, 323-333.

Mueller, N.D., Gerber, J.S., Johnston, M., Ray, D.K., Ramankutty, N., Foley, J.A., 2012. Closing yield gaps through nutrient and water management. Nature 490 (7419), 254.

Mulder, A., Turkensteen, L.J., 2005. Potato diseases. Diseases, pests, and defects. NIVAP, Holland, 280.

NASA, 2019. NASA Prediction of Worldwide Energy Resource, accessed in 2019. Available at: https://power.larc.nasa.gov/data-access-viewer/.

MWR, 2016. The Ministry of Water Resources of the People's Republic of China (MWR), accessed in 2016.

Available at: http://www.gov.cn/xinwen/2017-07/11/content_5209533.htm. In Chinese.

NBSC, 2016. National Bureau of Statistics of China (NBSC), accessed in 2016. Available at: http://data.stats.gov.cn/search.htm?s=\%E9\%A9\%AC\%E9\%93\%83\%E8\%96\%AF.

Neeteson, J. J., 1989. Effect of reduced fertilizer nitrogen application rates on yield and nitrogen recovery of sugar beet and potatoes. NJAS Wageningen Journal of Life Sciences, 37(3), 227-236.

$\mathrm{Ng}$, E., Loomis, R.S.,1984. Simulation of growth and yield the potato crop. Series Simulation Monographs, Pudoc, Wageningen, the Netherlands.

Peng, S., Buresh, R.J., Huang, J., Zhong, X., Zou, Y., Yang, J., Wang, G., Liu, Y., Hu, R., Tang, Q., Cui, K., Zhang, F., Dobermann, A., 2010. Improving nitrogen fertilization in rice by site specific N management. A review. Agronomy for Sustainable Development 30 (3), 649-656.

Penman, H.L., 1956. Evaporation: an introductory survey. Netherlands Journal of Agricultural Sciences 4 (1), 9-29.

Perrenoud, S., 1983. Potato: fertilisers for yield and quality. International Potash Institute Bulletin, (8) 84.

Qin, J.H., 2013. Potato Response to Water and Yield-Increasing Mechanism of Drip Irrigation Under Mulch. Ph.D. Thesis, Inner Mongolian Agricultural University, China. In Chinese with English Abstract.

Qu, D.Y., Jin, L.P., Xie, K.Y., Bian, C.S., 2001. The current development, problems and trend of potato industry in China. Crop Science Society of China. Proceedings of the annual conference 2011. Available at: http://cpfd.cnki.com.cn/Article/CPFDTOTALZMLS200107001003.htm. In Chinese.

Qu, D.Y., Xie, K.Y., Jin, L.P., Pang, W.F., Bian, C.S., Duan S.G., 2005. Development of Potato Industry and Food Security in China. Agricultural Sciences in China 38 (2), 358-362. In Chinese with English Abstract.

Quemada, M., Lassaletta, L., Jensen, L.S., Godinot, O., Brentrup, F., Buckley, C., Foray, S., Hvid, S.K., Oenema, J., Richards, K.G., Oenema, O., 2020. Exploring nitrogen indicators of 
farm performance among farm types across several European case studies. Agricultural Systems 177, 102689.

Rijk, B., Van Ittersum, M.K., Withagen, J., 2013. Genetic progress in Dutch crop yields. Field Crops Research 149, 262-268.

Sale, P.J.M., 1979. Growth of potatoes (Solanum tuberosum L.) to the small tuber stage as related to soil temperature. Crop and Pasture Science 30 (4), 667-675.

Schröder, J.J., Neeteson, J.J., 2008. Nutrient management regulations in The Netherlands. Geoderma 144 (3-4), 418-425.

Shang, X.N., Song, P.S., Li, S.B., He, L.R., Zhao, J.B., Ding, Y.H., Jin, X.J., 2012. The Correlation Analysis and Gray Correlation Analysis Between Banlangen Active Ingredient Content and Soil Factors. Chinese Agricultural Science Bulletin 2012, 28 (30), 151-154. In Chinese with English Abstract.

Shen, J., Cui, Z., Miao, Y., Mi, G., Zhang, H., Fan, M., Zhang, C., Jiang, R., Zhang, W., Li, H., Chen, X., Li, X., Zhang, F., Chen, X., 2013. Transforming agriculture in China: From solely high yield to both high yield and high resource use efficiency. Global Food Security 2 (1), 1-8.

Shock, C.C., Wang, F., Flock, R., Eldredge, E., Pereira, A., Klauzer, J., 2013. Drip irrigation guide for potatoes. Sustainable Agriculture Techniques EM8912. Oregon State University Extension Service.

Silva, J.V., Reidsma, P., Laborte, A.G., Van Ittersum, M.K., 2017. Explaining rice yields and yield gaps in Central Luzon, Philippines: An application of stochastic frontier analysis and crop modelling. European Journal of Agronomy 82, 223-241.

Smelt, G.J., 2016. Simulation of Potato Leaf Area Growth in the Netherlands. M.Sc. Internship Report. Wageningen University, the Netherlands.

Song, N., Wang, F., Yang, C., Yang, K., 2013. Coupling effects of water and nitrogen on yield, quality and water use of potato with drip irrigation under plastic film mulch. Transactions of the Chinese Society of Agricultural Engineering 29 (13), 98-105.

Spitters, C.J.T., Van Keulen, H., Van Kraalingen, D.W.G., 1989. A simple and universal crop growth simulator: SUCROS87. Simulation and Systems Management in Crop Protection. Pudoc, 147-181.

Storey, R.M.J., Davies, H.V., 1992. Tuber quality. In: The Potato Crop. Springer, Dordrecht, 507-569.

Supit, I., Van der Goot, E., 2003. Updated System Description of the WOFOST Crop Growth Simulation Model as Implemented in the Crop Growth Monitoring System by the European Commission. Available at: http:// www.supit.net.

Tang, J., Wang, J., Fang, Q., Wang, E., Yin, H., Pan, X., 2018. Optimizing planting date and supplemental irrigation for potato across the agro-pastoral ecotone in North China. European Journal of Agronomy 98, 82-94.

Ten Berge, H.F.M., Hijbeek, R., Van Loon, M.P., Rurinda, J., Tesfaye, K., Zingore, S., Craufurd, P., Van Heerwaarden, J., Brentrup, F., Schröder, J.J., Boogaard, H.L., de Groot, H.L.E., Van Ittersum, M.K., 2019. Maize crop nutrient input requirements for food security in subSaharan Africa. Global Food Security 23, 9-21. 
Tian, Y., Su, D., Li, F., Li, X., 2003. Effect of rainwater harvesting with ridge and furrow on yield of potato in semiarid areas. Field Crops Research 84 (3), 385-391.

Tilman, D., Balzer, C., Hill, J., Befort, B.L., 2011. Global food demand and the sustainable intensification of agriculture. Proceedings of the National Academy of Sciences, 108 (50), 20260-20264.

USDA, 2016. United States Department of Agriculture (USDA), accessed in 2016. China's Potato Production to Rise in MY2016/17, Potatoes and Potato Products Annual, ChinaPeople's Republic of China, GAIN Report, USDA Foreign Agricultural Service.

USDA, 2017. United States Department of Agriculture (USDA), accessed in 2017. Available at: https://ndb.nal.usda.gov/ndb/.

USDA, 2018. United States Department of Agriculture (USDA), accessed in 2018. Potato and Potato Productions Annual Report. The People's Republic of China. GAIN Report. USDA Foreign Agricultural Service.

USDA, 2019. United States Department of Agriculture (USDA), accessed in 2019. Natural Resources Conservation Service Soils. Available at:

https://www.nrcs.usda.gov/wps/portal/nrcs/detail/soils/survey/?cid=nrcs142p2_054167.

Van Bussel, L.G., Grassini, P., Van Wart, J., Wolf, J., Claessens, L., Yang, H., Boogaard, H., de Groot, H., Saito, K., Cassman, K.G., Van Ittersum, M.K., 2015. From field to atlas: upscaling of location-specific yield gap estimates. Field Crops Research 177, 98-108.

Van Delden, A., Pecio, A., Haverkort, A.J., 2000. Temperature response of early foliar expansion of potato and wheat. Annals of Botany 86 (2), 355-369.

Van Evert, F.K., De Ruijter, F.J., Conijn, J.G., Rutgers, B., Haverkort, A.J., 2013. Worldwide Sustainability Hotspots in Potato Cultivation. 2. Areas with Improvement Opportunities. Potato Research 56 (4), 355-368.

Van Halsema, G.E., Vincent, L. 2012. Efficiency and productivity terms for water management: A matter of contextual relativism versus general absolutism. Agricultural Water Management 108, 9-15.

Van Heemst, H.D.J., 1986. The distribution of dry matter during growth of a potato crop. Potato Research 29 (1), 55-66.

Van Ittersum, M.K., Cassman, K.G., Grassini, P., Wolf, J., Tittonell, P., Hochman, Z., 2013. Yield gap analysis with local to global relevance - a review. Field Crops Research 143, 417.

Van Ittersum, M.K., Rabbinge, R., 1997. Concepts in production ecology for analysis and quantification of agricultural input-output combinations. Field Crops Research 52 (3), 197208.

Van Keulen, H., Van Diepen, C.A., 1990. Crop growth models and agro-ecological characterization. In: Proceedings of the First Congress of the European Society of Agronomy, Paris. CEC, ESA, INRA. Session 2, 1-16.

Van Loon, C.D., 1981. Effect of water stress on potato growth, development and yield. American Journal of Potato Research 58, 51-69.

Van Loon, W.A.M., 2005. Process Innovation and Quality Aspects of French Fries. Ph.D. Thesis, Wageningen University. 
Van Noordwijk, M., Brussaard, L., 2014. Minimizing the ecological footprint of food: closing yield and efficiency gaps simultaneously? Current Opinion in Environmental Sustainability 8, 62-70.

Van Wart, J., Kersebaum, K.C., Peng, S., Milner, M., Cassman, K.G., 2013. Estimating crop yield potential at regional to national scales. Field Crops Research 143, 34-43.

Velthof, G.L., Van Erp, P.J., 1999. Fertiliser recommendations for ware potatoes according to QUEFTS. Verslag 216.98. Wageningen Nutriënten Management Instituut NMI. 59. In Dutch.

Verhagen, A., Grashoff, C., Uithol, P.W., Haverkort, A.J., 2000. Agro-Ecological Zoning of Potato. Plant Research International, Wageningen, the Netherlands.

Versteeg, M.N., Van Keulen, H., 1986. Potential crop production prediction by some simple calculation methods, as compared with computer simulations. Agricultural Systems 19 (4), 249-272.

Vos, J. 1997. The nitrogen response of potato (Solanum tuberosum L.) in the field: nitrogen uptake and yield, harvest index and nitrogen concentration. Potato Research 40 (2), 237248.

Vos, J. 2009. Nitrogen responses and nitrogen management in potato. Potato Research 52 (4), 305-317.

Vos, J., Van der Putten, P.E.L., 1998. Effect of nitrogen supply on leaf growth, leaf nitrogen economy and photosynthetic capacity in potato. Field Crops Research 59 (1), 63-72.

Wang, F.X., Feng, S.Y., Hou, X.Y., Kang, S.Z., Han, J.J., 2009. Potato growth with and without plastic mulch in two typical regions of Northern China. Field Crops Research 110 (2), 123 129.

Wang, H., Zhang, D., Zhang, Y., Zhai, L., Yin, B., Zhou, F., Geng, Y., Pan, J., Luo, J., Gu, B., Liu, H., 2018a. Ammonia emissions from paddy fields are underestimated in China. Environmental Pollution 235, 482-488.

Wang, H., Zhao, W. Z., Wu, L. Y., 2010. Change of soil physical properties with precipitation gradient in desert region of Hexi corridor. Bulletin of Soil and Water Conservation 30, 4651.

Wang, H.Y., Qin, J.H., Liu, Y., Hu, X., Maurer, A., 2018b. Potential Opportunities for Potato Industry's Development in China based on Selected Companies. CIP-China Center for Asia Pacific (CCCAP).

Wang, Q., Zhang, W., 2004. China's potato industry and potential impacts on the global market. American Journal of Potato Research 81 (2), 101-109.

Wang, X.F., Yang, Y.Z., You, F., 2011. Analysis on Characteristics of Climate Change in Recent 30 Years in Heilongjiang Province. Chinese Journal of Agrometeorology S1.

Wang, X.L., Li, F.M., Jia, Y., Shi, W.Q., 2005. Increasing potato yields with additional water and increased soil temperature. Agricultural Water Management 78 (3), 181-194.

Wang, Z.Q., 2014. Effects of Nitrogen Rate on Yield and Quality of French Fries Potato and Nitrogen Nutrition Diagnosis. Northeast Agricultural University, China, Ph.D. Thesis. In Chinese with English Abstract.

Wang, Z.Q., 2018. Personal communication with the agronomist of the local potato processing company. 
Wolf, J., de Wit, A., 2003. Calibration of WOFOST Crop Growth Simulation Model for Use Within CGMS Report. RIZa, SC. DLO, Wageningen, the Netherlands.

Xie, K., Li, W., Qin, J., Bai, Y., Liu, J., He, W., 2014. Seed potato production system and technology transformation. In: Potato Industry and Sustainable Agriculture (22), 10-12. In Chinese.

Xie, K., Wang, X., Zhang, R., Gong, X., Zhang, S., Mares, V., Gavilan, C., Posadas, A., Quiroz, R., 2012. Effect of partial root-zone drying on potato water utilization on semi-arid conditions in China. Chinese Potato Journal 26 (1), 5-10. In Chinese.

Xu, W., Luo, X.S., Pan, Y.P., Zhang, L., Tang, A.H., Shen, J.L., Zhang, Y., Li, K.H., Wu, Q.H., Yang, D.W., Zhang, Y.Y., Xue, J., Li, W.Q., Li, Q.Q., Tang, L., Lu, S.H., Liang, T., Tong, Y.A., Liu, P., Zhang, Q., Xiong, Z.Q., Shi, X.J., Wu, L.H., Shi, W.Q., Tian, K., Zhong, X.H., Shi, K., Tang, Q.Y., Zhang, L.J., Huang, L.J., He, C.E., Kuang, F.H., Zhu, B., Liu, H., Jin, X., Xin, Y.J., Shi, X.K., Du, E.Z., Dore, A.J., Tang, S., Collett Jr., J.L., Goulding, K., Sun, Y.X., Ren, J., Zhang, F.S., Liu, X.J., 2015a. Quantifying atmospheric nitrogen deposition through a nationwide monitoring network across China. Atmospheric Chemistry and Physics 15 (21), 12345-12360.

Xu, X., Liu, X., He, P., Johnston, A.M., Zhao, S., Qiu, S., Zhou, W., 2015b. Yield gap, indigenous nutrient supply and nutrient use efficiency for maize in China. PLoS One 10 (10).

Xu, Y., He, P., Xu, X., Qu, S., Ullah, S., Gao, Q., Zhou, W., 2019. Estimating Nutrient Uptake Requirements for Potatoes Based on QUEFTS Analysis in China. Agronomy Journal 111 (5), 2387-2394.

Yan, Y., 2015. Application of SWAP-WOFOST to Evaluate the Influence of Water and Oxygen Stress on Potato Yield in a Dutch Farm. M.Sc. Thesis. Wageningen University, the Netherlands.

Yang, X.G., Li, H.Y., Fu, Z., Ma, P.L., Wang, R.Y., Yang, Q.G., 2004. Characteristics of Water Requirement and Supply of Main Crops in Gansu Province. Plateau Meteorology 23 (6): 821-827. In Chinese with English Abstract.

You, L., Wood-Sichra, U., Fritz, S., Guo, Z., See, L., Koo, J., 2014. Spatial Production Allocation Model (SPAM) 2005 v2.0. Available at: http://mapspam.info.

Yu, C., Huang, X., Chen, H., Godfray, H.C.J., Wright, J. S., Hall, J.W., Gong, P., Ni, S., Qiao, S., Huang, G., Xiao, Y., Zhang, J., Feng, Z., Ju, X., Ciais, P., Stenseth, N.C., Hessen, D., Sun, Z., Yu, L., Cai, W., Fu, H., Huang, X., Zhang, C., Liu, H., Taylor, J., 2019. Managing nitrogen to restore water quality in China. Nature 567 (7749), 516-520.

Yuan, S., Peng, S., 2017. Exploring the trends in nitrogen input and nitrogen use efficiency for agricultural sustainability. Sustainability 9 (10), 1905.

Zhang, C., Ju, X., Powlson, D.S., Oenema, O., Smith, P., 2019. Nitrogen surplus benchmarks for controlling $\mathrm{N}$ pollution in the main cropping systems of China. Environmental science \& technology 53 (12), 6678-6687.

Zhang, Q.Y., 2016. Strategy of Enhancing Potato as Staple Food in China. China Agriculture Press Co., LTD. In Chinese.

Zhang, T., Yang, X., Wang, H., Li, Y., Ye, Q., 2014. Climatic and technological ceilings for Chinese rice stagnation based on yield gaps and yield trend pattern analysis. Global Change Biology 20 (4), 1289-1298. 
Zhao, H., Xiong, Y.C., Li, F.M., Wang, R.Y., Qiang, S.C., Yao, T.F., Mo, F., 2012. Plastic film mulch for half growingseason maximized WUE and yield of potato via moisture temperature improvement in a semi-arid agroecosystem. Agricultural Water Management 104, 68-78.

Zhou, J., Gu, B., Schlesinger, W.H., Ju, X., 2016. Significant accumulation of nitrate in Chinese semi-humid croplands. Scientific Reports 6, 25088.

Zhu, Z.L., Chen, D.L., 2002. Nitrogen fertiliser use in China - Contributions to food production, impacts on the environment and best management strategies. Nutrient Cycling in Agroecosystems 63 (2-3), 117-127. 
Appendix A Calibration and validation of two crop models for potato in China (Chapter 2) 


\section{Abstract}

Two crop growth models WOFOST and LINTUL POTATO DSS were calibrated and validated for potential production of potato in northern China. For WOFOST, the important parameters calibrated were: daily increase in temperature sum as a function of average temperature (DTSMTB); temperature sum from emergence to tuber initiation (TSUM1) and from tuber initiation till maturity (TSUM2); specific leaf area as a function of development stage (SLATB); life span of leaves at $35{ }^{\circ} \mathrm{C}$ (SPAN), partitioning factor to tuber and stem as a function of development stage (FOTB, FSTB), and maximum photosynthesis rate as a function of development stage (AMAXTB). The major parameters calibrated in LINTUL POTATO DSS were sprout growth rate, and maximum average temperature for photosynthesis. Both models were validated to be able to estimate the potential yield of potatoes in China. The crop phenology was simulated well and the differences in modeled and actual biomass production were in the acceptable range.

\section{Introduction}

Potato is the fourth most important crop in the world and is increasingly important for maintaining food security and stability, particularly in developing countries (DeFauw et al., 2012). China is enhancing the potato production to boost potato as the fourth most important staple crop in the country (MOA, 2016). Despite its large growing area, the yield of potatoes remains low compared to the world average (Jansky et al., 2009).

Estimating the potential yields for major potato production regions is important for understanding the scope for yield increase and the required water inputs, and to identify the regions where increasing yield is feasible considering the limited water availability in the country. There is little documentation on estimating potential yield of potatoes in China with a model approach. Therefore, this report aims to introduce and validate two crop models for potato in China: WOFOST (De Koning et al., 1995) and LINTUL POTATO DSS (Haverkort et al., 2015).

To apply both models for specific potato varieties in China, there is a need to calibrate and validate the models under particular climate and soil conditions in major potato production regions (De Koning et al., 1995; Van Ittersum et al., 2013; Wolf and De Wit, 2003). To conduct an elaborate calibration, robust experiments are required where crops are cultivated under optimum management with no biotic and abiotic constraints (GYGA, 2016; Wolf and De Wit, 2003). Specific crop growth and development data are required for both models (e.g., planting and harvesting date, planting depth, phenological stages, leaf area index, aboveground biomass, and tuber yield). Preferably a local climate station exists within limited distance from the location of the field experiments (i.e., in the same climate zone) to allow a siteyear specific simulation. 
With a selection procedure, the field experiments were selected to calibrate and validate the two models for potato production in China. The models were calibrated using the results of potato experiments in Heilongjiang, China in 2010 under potential conditions. With the calibrated models, the potato growth and development in 2011 experiments in the same location was simulated to validate the calibrated parameters.

\section{Methodology}

\subsection{Model description}

WOFOST Control Centre (WCC) version 2.1 was applied to model the potential yield of potato in China using daily weather data (i.e., maximum and minimum daily temperature, daily radiation, wind speed, precipitation and evapotranspiration) and cultivation data (i.e., planting or emergence date and maturity or harvesting date). In command of WOFOST (most updated version 7.1.7), WCC 2.1 is a user interface based on graphics that allows the user to interact with the system. The "Rerun" function in WCC allows modelers to calibrate the model by running the model for several times with different values for a particular parameter. A user guide is available for detailed explanation of files of crop, soil, climate, inputs and outputs in WOFOST Control Centre 2.1 and WOFOST 7.1.7 (Boogaard et al., 2014).

LINTUL POTATO DSS is a simplified version of LINTUL POTATO that allows the prediction of potato yield and quality in commercial production (Haverkort et al., 2015). Compared to LINTUL POTATO, LINTUL POTATO DSS has less model parameters and requires less input data. The simplification of LINTUL POTATO DSS is replaced in a number of model processes. In LINTUL POTATO DSS, the canopy closure is reached when temperature sum is equal to $650 \mathrm{Cd}$ and $100 \%$ ground cover remains until harvest. The dry matter yield of tubers is calculated based on the assumption that approximately $75 \%$ of accumulated dry matter is allocated to tubers at harvest. Unlike LINTUL POTATO where leaf senescence starts due to temperature, mutual shading and/or dry matter partitioning, in LINTUL POTATO DSS, the end of crop growth is one of the input data, which depends on maturity features of potato and climate conditions that regulate the crop growing season.

\subsection{Description of data}

\subsubsection{Experiments used for model calibration and validation}

The models were calibrated using results of two field experiments that were performed in Harbin, Heilongjiang province, China in two consecutive years (2010 and 2011) (Wang, 2014). In the experiments, nitrogen $(\mathrm{N})$ fertiliser was applied at various rates (i.e., 0, 75, 150, 225, $300,375 \mathrm{~kg} \mathrm{ha}^{-1}$ ) to identify the effect of different $\mathrm{N}$ inputs on the quantity and quality of tuber yield of potato variety Innovator. Irrigation was applied to minimize water limitation (i.e., rainfall amount and irrigation water inputs were respectively $521 \mathrm{~mm}$ and $134 \mathrm{~mm}$ in 2010, and 384 $\mathrm{mm}$ and $126 \mathrm{~mm}$ in 2011, which were sufficient to ensure potential yield). Pests and diseases were properly controlled. Fertiliser $\mathrm{P}$ and $\mathrm{K}$ were applied sufficiently. The highest tuber yield 
was obtained when $\mathrm{N}$ was applied at a rate of $225 \mathrm{~kg} \mathrm{ha}^{-1}$; therefore this treatment and results were used for model calibration.

For both years, tuber fresh weight and dry matter concentration were measured at final harvest. Leaf area index $\left(\mathrm{LAl}, \mathrm{m}^{2} \mathrm{~m}^{-2}\right)$ and total dry matter (TDM, g plant $\left.{ }^{-1}\right)$ were measured at 9 harvests, $10,20,30,40,50,60,70,80$ and 90 days after emergence in 2010 experiment. In 2011, only the tuber fresh weight at final harvest was measured. For each harvest, three plant samples in each of the four replication plots $\left(43.2 \mathrm{~m}^{2}\right)$ were collected. Crop phenological development stage was recorded when more than $50 \%$ of total plant population reached the particular stage.

\subsubsection{Climate data}

Climate data was derived from the China Meteorological Data Service Centre (CMDC, 2016). The database describes climate data on a daily basis. The database consists of eight climate elements (i.e., atmospheric pressure, air temperature, relative humidity, precipitation, evaporation, wind speed and direction, radiation hours, and soil temperature). The climate station that is most adjacent to the experimental location was identified. The climate elements used in model calibration consisted of (1) daily maximum temperature $\left({ }^{\circ} \mathrm{C}\right),(2)$ daily minimum temperature $\left({ }^{\circ} \mathrm{C}\right)$, (3) wind speed $\left(10\right.$ meters above the ground, $\left.\mathrm{m} \mathrm{s}^{-1}\right)$, and (4) daily precipitation (from 20.00 p.m. to 20.00 p.m., mm). The daily irradiation data was obtained from the NASA-POWER project (http://power.larc.nasa.gov/), by searching for SRAD (daily insolation incident on a horizontal surface) at the experimental location. Climate data was compiled into CABO format that is currently used in WCC.

\subsubsection{Original crop file}

The starting point of model calibration was the standard WOFOST crop parameter set for potato "POT701.CAB". The parameters were calibrated in 1992 for estimating growth of potato with WOFOST Version 5.4 under European conditions (i.e., Germany, France, The Netherlands, Belgium, Luxembourg, United Kingdom, Ireland, and Denmark). The parameter set in "POT701.CAB" was originally derived from a dataset in the crop growth model "SUCROS87" (Simple and Universal Crop Growth Simulator, version 1987) (Spitters et al., 1989) for the potato variety "Bintje" (De Koning et al., 1995). Bintje is an early-medium maturity potato variety bred in the Netherlands (ECPD, 2016).

\subsection{Calibration and validation of the crop models for potato yield under potential conditions in China}

\subsubsection{Calibration procedure of WOFOST}

The actual emergence and maturity date of the 2010 experiment (i.e., Julian Day 160 and 253, respectively) were used as timer inputs to estimate the potential yield of Innovator potato in the 2010 experiment. The model was first run using the original crop file. The crop related 
parameters were calibrated by using the "Rerun" function in the WCC and by editing the crop file. With the "Rerun" function, the values of each variable are restricted to a limited range.

The calibration followed the procedure described in "Calibration of WOFOST crop growth simulation model for use within CGMs" by Wolf and De Wit (2003), with an adaption in calibration order following the description in the GYGA protocol (GYGA, 2016). The starting point of calibration was the phenological development of the crop, and then leaf area related parameters, which was followed by the partitioning factors of different plant organs, and finally the photosynthesis parameters. The adapted model parameters, their description, default value, and plausible range are given in Table A1, in the order that the calibration was actually performed.

Temperature sum from emergence to tuber initiation (TSUM1) and from tuber initiation to harvest (TSUM2) were calibrated based on the observed emergence, tuber initiation and harvest date and daily average temperature during the growing season. Leaf area related parameters (SLATB, SPAN) were changed to obtain a close correspondence between the modeled and observed development of LAI (thus light interception). The partitioning factors to tuber (FOTB) and stems (FSTB) were adapted in order to match the modeled yield level and harvest index to the observation. The coefficient of determination $\left(R^{2}\right)$ was calculated to test how well the observed outcomes were replicated by the model.

A new DTSMTB table (daily increase in temperature sum as function of average temperature) was generated taking into account the effects of average daily temperatures on the rate of tuber initiation and maturation. The maximum and minimum temperatures for potato growth (i.e., 30 and $2{ }^{\circ} \mathrm{C}$ respectively) were not changed. The lower and upper boundary of the optimum temperature range were calibrated in the physiological range between 10 and $25^{\circ} \mathrm{C}$ (Dua et al., 2014; Kooman, 1995; Kooman and Haverkort, 1995; Manrique and Hodges, 1989; Sale, 1979). The optimum temperature range was determined based on two criteria. With the calibrated DTSMTB table, the calculated TSUM 1 and TSUM2 should be within the plausible range (Table A1). Besides, the calculated TSUM1 and TSUM2 of the 2010 experiment should be as close as possible to those observed in the 2011 experiment.

When estimating potato yield with the POTATO model, $\mathrm{Ng}$ and Loomis (1984) considered the mobilization of dry matter from dead leaves (and stems) to tuber. The redistribution of dry matter from leaves and stems to tuber was a large contribution of tuber dry matter accumulation at the late stage of crop growth (i.e., $50 \%$ of leave dry matter goes to the assimilation pool) ( $\mathrm{Ng}$ and Loomis, 1984). In our calibration, when the modeled tuber dry matter and harvest index were lower than the observed value, the fraction that allocated to tubers at early stage (i.e., DVS (development stage) 1.27 when FOTB is 0.75 ) was increased. This was assumed to be able to compensate for tuber weight increase near maturity caused by the redistribution of dry matter to tubers.

The plausible range and the calibration of DTSMTB, TSUM1 and TSUM2 and AMAXTB will be discussed further in the Discussion Section. 


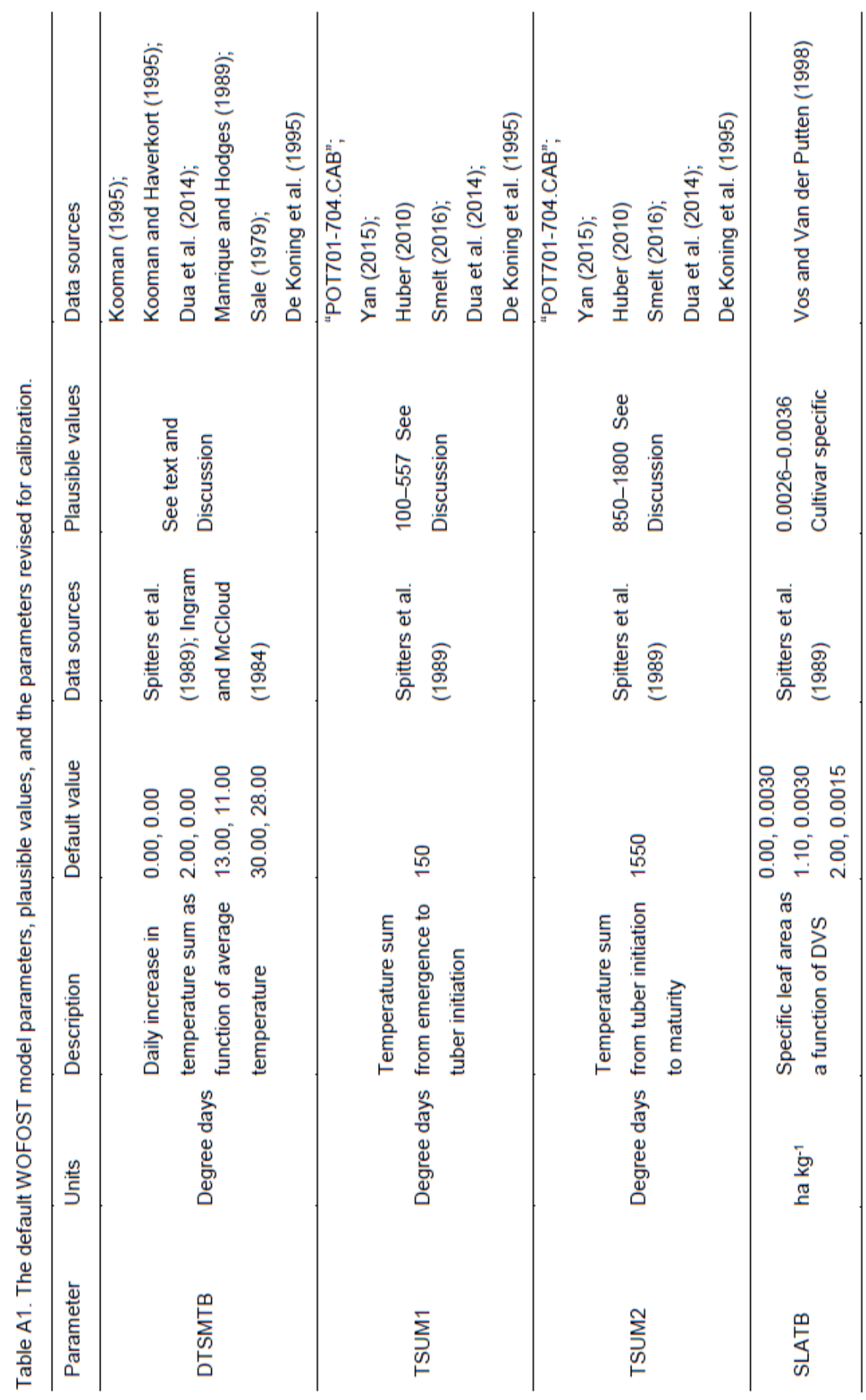




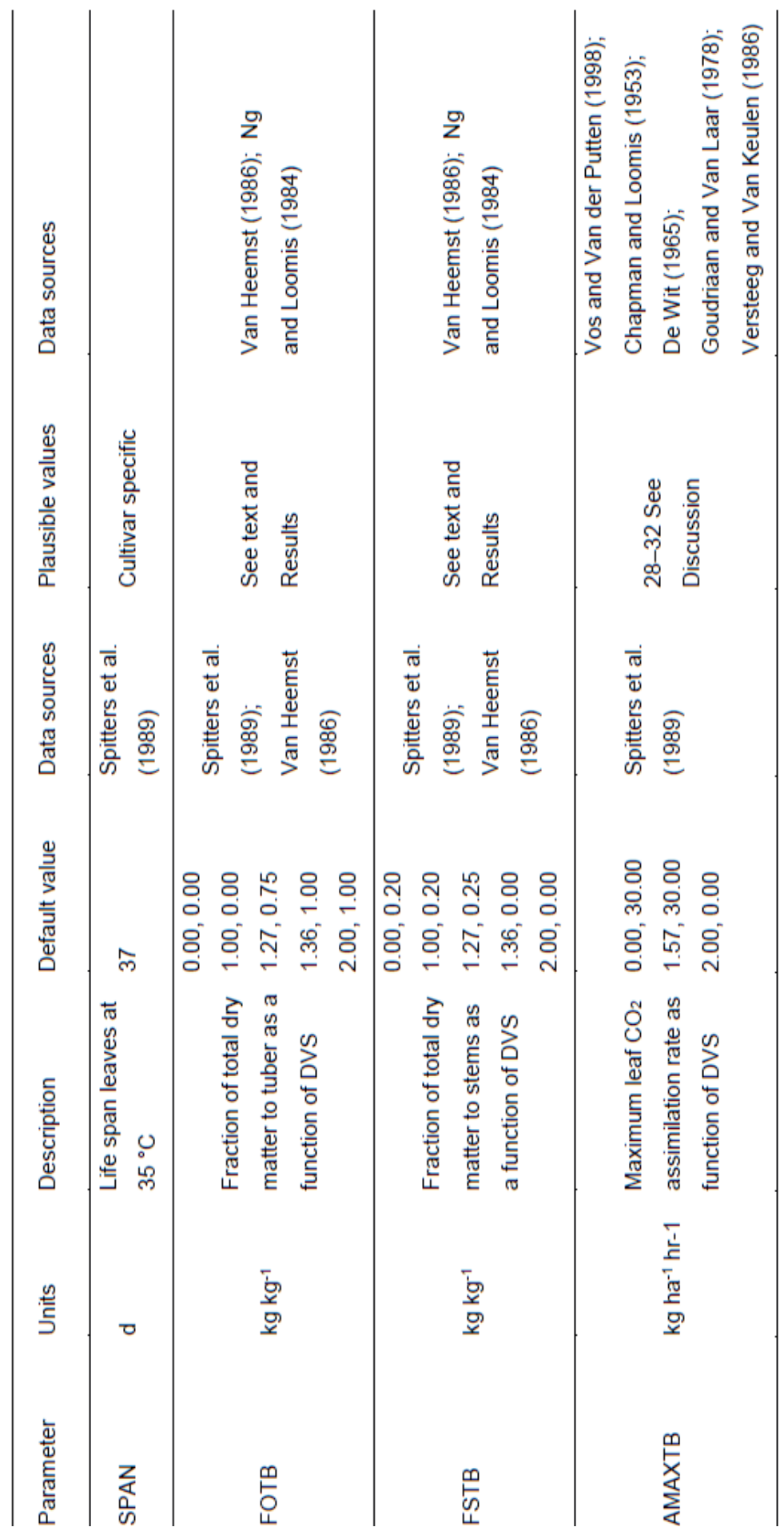




\subsubsection{Calibration procedure of LINTUL POTATO DSS}

For modeling potato yield under potential conditions, the important crop parameters in LINTUL POTATO DSS are listed in Table A2. The same calibration procedure as applied for WOFOST was used for LINTUL POTATO DSS, i.e., the phenological development, leaf area and light interception, dry matter distribution and harvest index and finally, photosynthesis.

The temperature before sowing was extremely low in the 2010 field experiment, thus the planting date in the 2010 experiment was a few days later than usual (personal communication with the author). The low temperature before planting might have constrained the growth of sprouts and thus delayed the emergence in 2010. Therefore, the sprout growth rate was calibrated using the 2011 experiment. The dry matter concentration of tubers was calibrated according to the measured value of 2010 and 2011 experiments.

Table A2. LINTUL POTATO DSS model parameters before calibration.

\begin{tabular}{|c|c|c|c|}
\hline Parameters & Units & Default value & Data sources \\
\hline \multirow[t]{2}{*}{ Harvest index } & & 0.75 & Haverkort et al. (2015) \\
\hline & & & Haverkort et al. (2015) \\
\hline \multirow[t]{2}{*}{ Sprout growth rate } & $\begin{array}{l}\mathrm{mm} \text { per degree } \\
\text { day }\end{array}$ & 0.7 & $\begin{array}{l}\text { Van Delden et al. } \\
(2000)\end{array}$ \\
\hline & & & Haverkort et al. (2015) \\
\hline \multirow{2}{*}{$\begin{array}{l}\text { Degree days emergence to } 100 \% \\
\text { crop cover }\end{array}$} & Degree days & 650 & Haverkort (1985) \\
\hline & & & Kooman (1995) \\
\hline LUE (all radiation) & $\begin{array}{l}\mathrm{g} \mathrm{MJ}^{-1} \text { light } \\
\text { intercepted }\end{array}$ & 1.25 & Haverkort et al. (2015) \\
\hline $\begin{array}{l}\text { Min. temp. photosynthesis } \\
\text { (Daily average temperature) }\end{array}$ & Degree & 3 & Haverkort et al. (2015) \\
\hline $\begin{array}{l}\text { Min. temp. optimal photosynthesis } \\
\text { (Daily average temperature) }\end{array}$ & Degree & 15 & Haverkort et al. (2015) \\
\hline $\begin{array}{l}\text { Max. temp. optimal photosynthesis } \\
\text { (Daily average temperature) }\end{array}$ & Degree & 20 & Haverkort et al. (2015) \\
\hline $\begin{array}{l}\text { Max. temp. photosynthesis } \\
\text { (Daily average temperature) }\end{array}$ & Degree & 28 & Haverkort et al. (2015) \\
\hline Dry matter concentration of tuber & $\%$ & 21 & Haverkort et al. (2015) \\
\hline
\end{tabular}

\subsubsection{Validation procedure}

The calibrated parameter sets of the two models were validated using the independent data set derived from the 2011 experiment. The actual emergence and ending date (Julian day 155 and 248) were used as timer inputs. The measured total crop growth period, tuber fresh matter 
weight and tuber dry matter concentration at final harvest were the benchmarks for validation of the calibrated model (i.e., the development of LAI and total dry matter weight were not measured in the 2011 experiment). When the simulated potato growing period and tuber dry matter was within $+/-15 \%$ range of the actual value (i.e., actual tuber dry matter weight was derived from the measured tuber fresh matter and tuber dry matter concentration), the calibrated model was considered to be validated (GYGA, 2016).

\subsubsection{Performance of the calibrated model for potato variety KeXin No.1}

KeXin No.1 is a dominant local variety in China that is grown widely in northern China for table consumption. The growing period and maximum yield of KeXin No.1 is similar to that of Innovator. Therefore, it is assumed that the calibrated model based on Innovator can also be used for estimating potential yield of KeXin No.1.

The two models were run to estimate the potential yield of KeXin No.1 for a field experiment conducted in Inner Mongolia, China. The field experiments were conducted in Wuchuan county in Inner Mongolia in two consecutive years 2010 and 2011 (Qin, 2013). Potato was grown from May 17 to September 20 in 2010 and from May 17 to September 13 in 2011. For both years, the dry matter of tubers (per plant) were measured. For WOFOST, the actual emergence and ending date were used as time inputs (i.e., emergence date, if not reported, was assumed to be 30 days after planting). For LINTUL POTATO DSS, the sprout growth rate was determined when the modeled emergence date matched the observed value. The dry matter concentration of tubers was not measured for variety KeXin No.1; therefore this was assumed to be the same as that of Innovator.

\section{Results}

\subsection{Calibration and validation results of WOFOST}

\subsubsection{Original parameter file}

WOFOST was first run using the original crop file. The modeled LAl and total dry matter (TDM) over 9 harvests are given in Fig. A1a, b. The modeled growing period was 79 days, much shorter than the actual growing time (i.e., 93 days). There was a poor agreement between the modeled and measured LAI and TDM $\left(R^{2}=0.26\right.$ and 0.027 for LAl and TDM, respectively). The modeled LAI and TDM were clearly lower than the observation.

\subsubsection{Calibrated parameters}

The calibrated parameter set is listed in Table A3, including values before and after calibration. The new DTSMTB table indicates that the optimum temperature for the development rate of tuber initiation and maturity is between $19{ }^{\circ} \mathrm{C}$ and $25^{\circ} \mathrm{C}$. With the new DTSMTB table, the TSUM 1 (250 Cd) and TSUM 2 (1165 Cd) were calculated from the daily average temperature of the growing period. The SLATB at late growing stage (DVS 2) increased from 0.0015 to 
$0.0028 \mathrm{ha} \mathrm{kg}^{-1}$. The SPAN was slightly increased from $37 \mathrm{~d}$ to $38 \mathrm{~d}$. The allocation of biomass production to tubers at early development stage (DVS 1.27) increased from 0.75 to 0.80 . Accordingly, the distribution of biomass to stems reduced from 0.25 to 0.20 for the same development stage. Finally, the AMAXTB was enhanced from 30 to $35 \mathrm{~kg} \mathrm{ha}^{-1} \mathrm{hr}^{-1}$ at early development stages (DVS increased from 1.57 to 1.8), and from 0 to $20 \mathrm{~kg} \mathrm{ha}^{-1} \mathrm{hr}^{-1}$ at harvest (DVS 2).
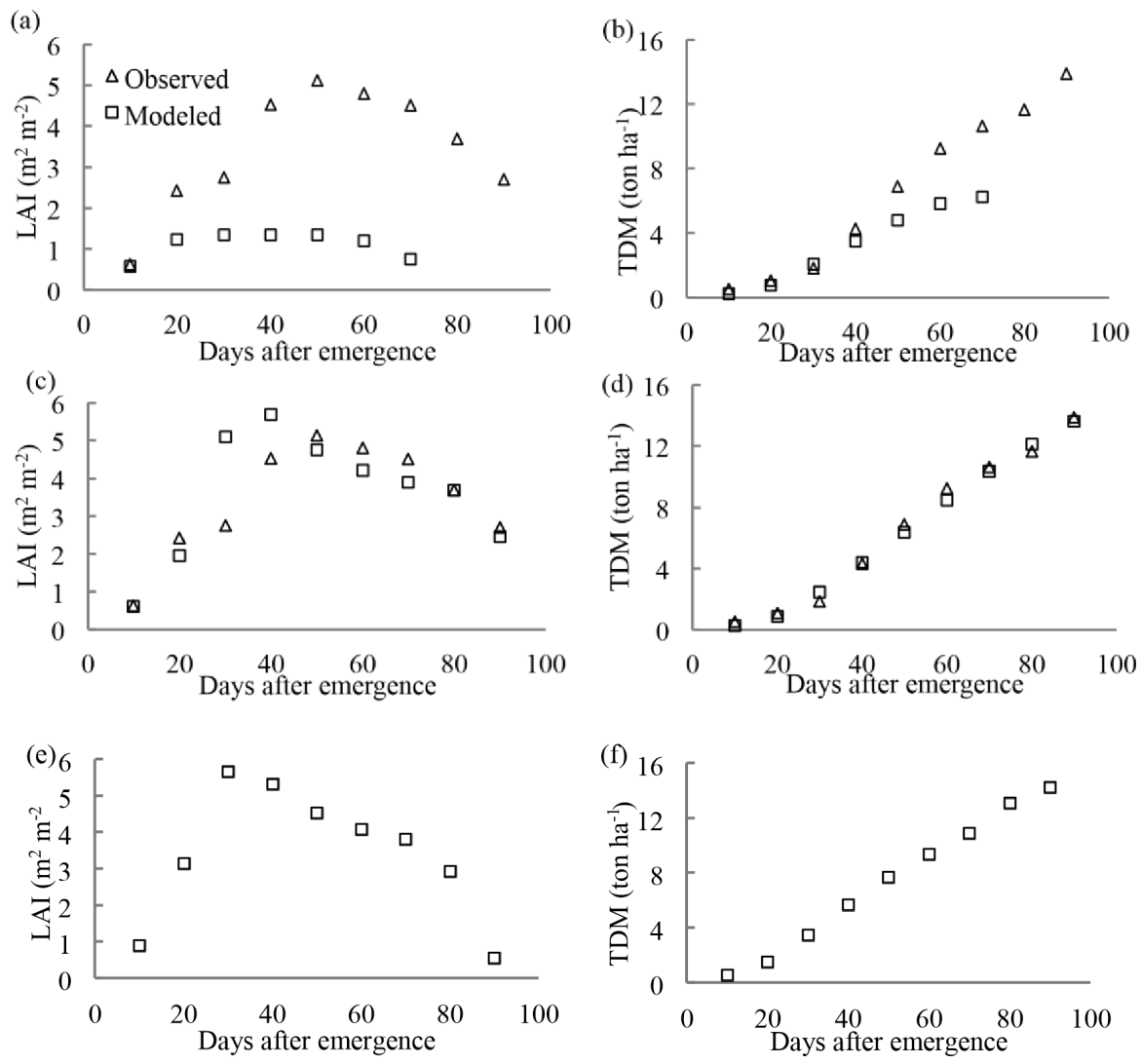

Figure A1. Observed and simulated leaf area index ( $\mathrm{LAI}$ ) and total plant dry matter (TDM) in different simulations and years, including: the observed LAI (a) and TDM (b) over 9 harvests in 2010, and modeled values by WOFOST with the original model parameters; the observed and modeled LAI (c) and TDM (d) over 9 harvests in 2010 by WOFOST with the adapted model parameters $\left(\mathrm{LAl}\left(\mathrm{R}^{2}=0.63\right)\right.$ and TDM $\left(\mathrm{R}^{2}=0.99\right)$ ); the modeled LAI (e) and TDM (TDM) (f) over 9 harvests in 2011 by WOFOST with the adapted model parameters.

The model was run with the adapted parameter set (Table A3) for the 2010 experiment (Fig. A1c, d). The modeled period from emergence to tuber initiation (i.e., 23 days) and the modeled total growing period (i.e., 93 days) matched the observation completely. The correlation coefficient between the modeled and the observed value was 0.63 for LAI and 0.99 for TDM. At final harvest, the total dry matter modeled $\left(14.0\right.$ ton ha $\left.{ }^{-1}\right)$ was slightly higher than the observed value (13.9 ton ha ${ }^{-1}$ ) with a difference of $0.86 \%$. The modeled tuber dry matter weight 
was 10.5 ton $\mathrm{ha}^{-1}$, which was $3.3 \%$ higher than the actual value (i.e., 10.4 ton $\mathrm{ha}^{-1}$ ). The variation between the simulated and measured total dry matter and tuber yield were within the acceptable limits (i.e., $+/ 15 \%$ ).

Table A3. WOFOST model parameters before and after calibration (see Table A1 for units and descriptions).

\begin{tabular}{|c|c|c|c|}
\hline Parameters & Units & Default value & After calibration \\
\hline \multirow[t]{5}{*}{ DTSMTB } & Degree days & $0.00,0.00$ & $0.00,0.00$ \\
\hline & & $2.00,0.00$ & $2.00,0.00$ \\
\hline & & $13.00,11.00$ & $19.00,17.00$ \\
\hline & & $30.00,28.00$ & $25.00,17.00$ \\
\hline & & & $30.00,0.00$ \\
\hline TSUM1 & Degree days & 150 & 250 \\
\hline TSUM2 & Degree days & 1550 & 1165 \\
\hline \multirow[t]{3}{*}{ SLATB } & ha $\mathrm{kg}^{-1}$ & $0.00,0.0030$ & $0.00,0.0030$ \\
\hline & & $1.10,0.0030$ & $1.10,0.0030$ \\
\hline & & $2.00,0.0015$ & $2.00,0.0028$ \\
\hline SPAN & $d$ & 37 & 38 \\
\hline \multirow[t]{5}{*}{ FOTB } & $\mathrm{kg} \mathrm{kg}^{-1}$ & $0.00,0.00$ & $0.00,0.00$ \\
\hline & & $1.00,0.00$ & $1.00,0.00$ \\
\hline & & $1.27,0.75$ & $1.27,0.80$ \\
\hline & & $1.36,1.00$ & $1.36,1.00$ \\
\hline & & $2.00,1.00$ & $2.00,1.00$ \\
\hline \multirow[t]{5}{*}{ FSTB } & $\mathrm{kg} \mathrm{kg}^{-1}$ & $0.00,0.20$ & $0.00,0.20$ \\
\hline & & $1.00,0.20$ & $1.00,0.20$ \\
\hline & & $1.27,0.25$ & $1.27,0.20$ \\
\hline & & $1.36,0.00$ & $1.36,0.00$ \\
\hline & & $2.00,0.00$ & $2.00,0.00$ \\
\hline \multirow[t]{3}{*}{ AMAXTB } & $\mathrm{kg} \mathrm{ha}^{-1} \mathrm{hr}^{-1}$ & $0.00,30.00$ & $0.00,35.00$ \\
\hline & & $1.57,30.00$ & $1.80,35.00$ \\
\hline & & $2.00,0.00$ & $2.00,20.00$ \\
\hline
\end{tabular}

\subsubsection{Validation}

With the adapted parameters (Table A3), the simulated results for the potential yield in the 2011 experiment are shown in Fig. A1e, f and Table A4. The differences between the modeled and observed date of crop phenology were 5 days and 1 day for period from emergence to tuber initiation and from emergence to maturity respectively. The modeled TDM (14.3 ton ha${ }^{1}$ ) was in agreement with the observed value $\left(14.8\right.$ ton $^{-1}$ ) with a difference of $3.7 \%$. Tuber dry matter at maturity was also well simulated $\left(10.7\right.$ ton ha $\left.{ }^{-1}\right)$ with a difference of $4.2 \%$ 
compared to the observation (11.1 ton ha ${ }^{-1}$ ). The modeled harvest index was the same as the observed value of 0.75 . The difference between modeled and observed dry matter production were within the acceptable range $(+/-15 \%)$.

Table A4. Modeling results of WOFOST compared to observed values for the 2011 experiment.

\begin{tabular}{|c|c|c|c|c|c|}
\hline & $\begin{array}{l}\text { Total dry matter } \\
\text { (ton ha-1) }\end{array}$ & $\begin{array}{l}\text { Tuber dry matter } \\
(\text { ton ha-1) }\end{array}$ & $\begin{array}{l}\text { Harvest } \\
\text { index }\end{array}$ & $\begin{array}{l}\text { Days from } \\
\text { emergence till } \\
\text { tuber initiation }\end{array}$ & $\begin{array}{l}\text { Days from } \\
\text { emergence till } \\
\text { maturity }\end{array}$ \\
\hline Modeled & 14.3 & 10.7 & 0.75 & 17 & 92 \\
\hline Actual & 14.8 & 11.1 & 0.75 & 22 & 93 \\
\hline
\end{tabular}

\subsection{Calibration and validation results of LINTUL POTATO DSS}

\subsubsection{Original parameter file}

The observed and model results for the 2010 experiment with the original crop parameters (Table A2) are shown in Fig. A2a, b. The modeled time from planting to emergence was 13 days, while the observed period was much longer (i.e., 30 days). At final harvest, the modeled TDM (12.7 ton ha ${ }^{-1}$ ) was lower than the actual value (i.e., 13.9 ton $^{-1} \mathrm{a}^{-1}$ ) with a difference of $8.4 \%$. At final harvest, the modeled tuber dry matter $(9.5$ ton ha-1 $)$ and fresh matter ( 45.4 ton $\mathrm{ha}^{-1}$ ) were lower than the observed value (i.e., 10.4 ton ha ${ }^{-1}$ and 50.4 ton ha ${ }^{-1}$, respectively) with difference of $8.6 \%$ and $9.9 \%$ respectively. 

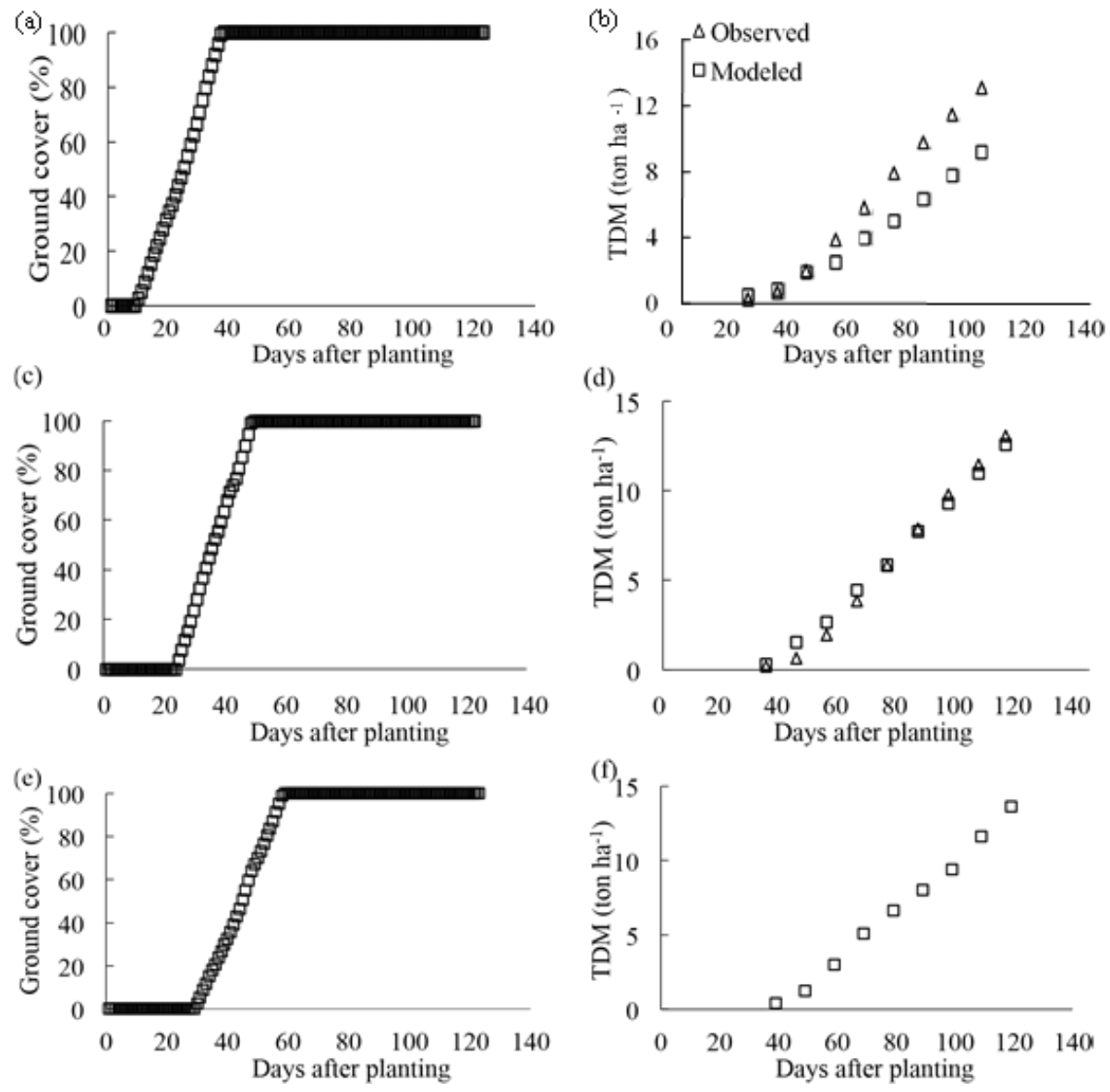

Figure A2. Observed and simulated ground cover development and total plant dry matter (TDM) in different simulations and years, including: the modeled ground cover development (a), and the observed and modeled TDM (b) over 9 harvests in 2010, by LINTUL POTATO DSS with the original model parameters. The modeled ground cover development (c), and the observed and modeled TDM (d) over 9 harvests in 2010, by LINTUL POTATO DSS with the adapted model parameters. The modeled ground cover development (e), and modeled TDM (f) over 9 harvests in 2011, by LINTUL POTATO DSS with the adapted model parameters.

\subsubsection{Calibrated parameters}

The default and adapted parameters of LINTUL POTATO DSS model are indicated in Table A5. The maximum temperature for photosynthesis was increased from 28 to 33 degrees. The dry matter concentration of tubers was slightly adapted from $21 \%$ to $20.8 \%$ according to the average measured value in 2010 and 2011 experiments. 
Table A5. LINTUL POTATO DSS model parameters before and after calibration of the 2010 experiment.

\begin{tabular}{|c|c|c|c|}
\hline Parameters & Units & Before calibration & After calibration \\
\hline \multirow[t]{2}{*}{ Harvest index } & - & 0.75 & 0.75 \\
\hline & & & Values depends \\
\hline Sprout growth rate & $\mathrm{mm}$ per degree day & 0.7 & $\begin{array}{l}\text { on location, see } \\
\text { text. }\end{array}$ \\
\hline $\begin{array}{l}\text { Degree days emergence to } 100 \% \\
\text { crop cover }\end{array}$ & Degree days & 650 & 650 \\
\hline LUE (all radiation) & $\begin{array}{l}\mathrm{g} \mathrm{MJ}^{-1} \text { light } \\
\text { intercepted }\end{array}$ & 1.25 & 1.25 \\
\hline $\begin{array}{l}\text { Min. temp. photosynthesis } \\
\text { (T. Average) }\end{array}$ & Degree & 3 & 3 \\
\hline $\begin{array}{l}\text { Min. temp. optimal photosynthesis } \\
\text { (T. Average) }\end{array}$ & Degree & 15 & 15 \\
\hline $\begin{array}{l}\text { Max. temp. optimal photosynthesis } \\
\text { (T. Average) }\end{array}$ & Degree & 20 & 20 \\
\hline $\begin{array}{l}\text { Max. temp. photosynthesis } \\
\text { (T. Average) }\end{array}$ & Degree & 28 & 33 \\
\hline Dry matter concentration of tubers & $\%$ & 21 & 20.8 \\
\hline
\end{tabular}

Modeling results with calibrated parameters (Table A4) for the 2010 experiment are shown in Fig. A2c, d and Table A6. The difference between the simulated and observed values were smaller compared to those derived from the original parameters. The modeled days between planting and emergence (i.e., 24 days) was 6 days earlier than the observed 30 days. The development of TDM was closely simulated by the model (Fig. A2d, $\left.R^{2}=0.995\right)$. At final harvest, the TDM modeled was 14.6 ton $\mathrm{ha}^{-1}$, which was slightly higher than the observed value (13.9 ton ha ${ }^{-1}$ ) with $5 \%$ difference (Table A6). At the final harvest, the modeled tuber dry matter modeled was 11 ton ha ${ }^{-1}$ and fresh matter was 52.7 ton ha-1; both were closer to the observed value (i.e., 10.4 and 50.4 ton ha ${ }^{-1}$ respectively) with difference of $5 \%$ and $4.5 \%$ respectively (Table A6).

Table A6. Modeling results with calibrated parameters with LINTUL POTATO DSS for the 2010 experiment.

\begin{tabular}{|c|c|c|c|c|c|c|c|}
\hline & $\begin{array}{l}\text { Total dry } \\
\text { matter } \\
(\text { ton ha-1) }\end{array}$ & $\begin{array}{l}\text { Tuber dry } \\
\text { matter (ton } \\
\text { ha- }^{-1} \text { ) }\end{array}$ & $\begin{array}{l}\text { Tuber fresh } \\
\text { matter (ton } \\
\text { ha-1) }^{-1}\end{array}$ & $\begin{array}{l}\text { Harvest } \\
\text { index }\end{array}$ & $\begin{array}{l}\text { Days from } \\
\text { planting till } \\
\text { emergence }\end{array}$ & $\begin{array}{l}\text { Days from } \\
\text { emergence } \\
\text { till } 100 \% \\
\text { ground cover }\end{array}$ & $\begin{array}{l}\text { Days from } \\
\text { planting } \\
\text { till } \\
\text { maturity }\end{array}$ \\
\hline Modeled & 14.6 & 11.0 & 52.8 & 0.75 & 24 & 25 & 123 \\
\hline Observed & 13.9 & 10.4 & 50.4 & 0.75 & 30 & 28 & 123 \\
\hline
\end{tabular}




\subsubsection{Validation}

The modeled results for the 2011 experiment, with calibrated parameters, are shown in Fig. A2e, f and Table A7. The modeled period from planting to emergence ( 29 days) matches the observed days (i.e., 28 days). The total dry matter, tuber dry matter and tuber fresh matter were all well simulated with differences less than $1 \%$ (i.e., $0.8 \%, 0.9 \%$, and $0.5 \%$ respectively).

Table A7. Modeling results with calibrated parameters with LINTUL POTATO DSS for the 2011 experiment.

\begin{tabular}{|c|c|c|c|c|c|c|c|}
\hline & $\begin{array}{l}\text { Total dry } \\
\text { matter } \\
(\text { ton ha-1) }\end{array}$ & $\begin{array}{l}\text { Tuber dry } \\
\text { matter } \\
(\text { ton ha-1) }\end{array}$ & $\begin{array}{l}\text { Tuber } \\
\text { fresh } \\
\text { matter } \\
(\text { ton ha-1) }\end{array}$ & $\begin{array}{l}\text { Harvest } \\
\text { index }\end{array}$ & $\begin{array}{l}\text { Days from } \\
\text { planting till } \\
\text { emergence }\end{array}$ & $\begin{array}{l}\text { Days from } \\
\text { emergence till } \\
100 \% \text { ground } \\
\text { cover }\end{array}$ & $\begin{array}{l}\text { Days from } \\
\text { planting till } \\
\text { maturity }\end{array}$ \\
\hline Modeled & 14.7 & 11.0 & 53.0 & 0.75 & 29 & 29 & 123 \\
\hline Observed & 14.8 & 11.1 & 52.7 & 0.75 & 28 & - & 123 \\
\hline
\end{tabular}

\subsection{Performance of the calibrated model for potato variety KeXin No.1}

The modeled results for KeXin No.1 in Inner Mongolia with the calibrated models WOFOST and LINTUL POTATO DSS are presented in Table A8. For LINTUL POTATO DSS, the sprout growth rate for Inner Mongolia region was calibrated to be $0.17 \mathrm{~mm}$ per degree days. For WOFOST, the difference between the modeled and observed tuber dry matter value were in the acceptable range (i.e. 15\%) (Table A8). The modeled tuber dry matter by LINTUL POTATO DSS were much higher than the observed values in both years (Table A8). For both years, the modeled TDM and tuber dry matter by LINTUL POTATO DSS were higher than those modeled by WOFOST. Both models estimate the total planting period correctly (Table A8). 
Table A8. Modeling results and observed yield and development for KeXin No.1 potato variety in Inner Mongolia with the calibrated models WOFOST and LINTUL POTATO DSS.

\begin{tabular}{|c|c|c|c|c|c|c|}
\hline & $\begin{array}{l}\text { Total dry } \\
\text { matter } \\
(\text { ton ha-1) }\end{array}$ & $\begin{array}{l}\text { Tuber dry } \\
\text { matter } \\
(\text { ton ha-1) }\end{array}$ & $\begin{array}{l}\text { Difference } \\
\text { between } \\
\text { modeled and } \\
\text { observed } \\
\text { value in tuber } \\
\text { dry matter (\%) }\end{array}$ & $\begin{array}{l}\text { Harvest } \\
\text { index }\end{array}$ & $\begin{array}{l}\text { Days from } \\
\text { emergence } \\
\text { till tuber initiation in } \\
\text { WOFOST (till 100\% } \\
\text { ground cover in } \\
\text { LINTUL) }\end{array}$ & $\begin{array}{l}\text { Days from } \\
\text { emergence till } \\
\text { maturity } \\
\text { (days) }\end{array}$ \\
\hline Actual 2010 & - & 10.1 & - & - & - & 97 \\
\hline WOFOST & 13.2 & 10.1 & 0 & 0.77 & 16 & 97 \\
\hline LINTUL DSS & 16.4 & 12.3 & 21.5 & 0.75 & 25 & 97 \\
\hline Actual 2011 & - & 9.1 & - & - & - & 90 \\
\hline WOFOST & 13.9 & 10.3 & 13.6 & 0.74 & 15 & 89 \\
\hline LINTUL DSS & 15.3 & 11.5 & 26.8 & 0.75 & 27 & 89 \\
\hline
\end{tabular}

\section{Discussion}

\subsection{Field experiments for model calibration and validation}

In seeking for qualified field experiments for model calibration and validation, we found that many potentially relevant studies (i.e., having experiments on potato production under potential conditions) only provide results of tuber yield, and miss detailed information regarding management practices, measured data (e.g., for LAI), the daily weather conditions, pests, disease and weeds problems and short-term nutrient and water stress during the crop growing period. This information is, however, important for model calibration and validation.

In addition, caution has to be taken when using the observations of crop phenology. For instance, the observation criteria for tuber initiation applied by local researchers (e.g., occurrence of floral bud) might be different from the standard criteria used in European countries (i.e., the diameter of tuber is twice the size of stolon). For potato specifically, harvesting (or haulm killing) can take place before or after the physiological maturity. The actual date of physiological maturity should be identified for model calibration. Details on those issues may not be available in research reports, but are important for conducting an elaborate model calibration. In this study, the experimenter was approached to discuss those specific issues, which gives confidence in evaluating the quality of the experimental data.

\subsection{Evaluation of calibrated parameters}

\subsubsection{Calibration of the phenology in WOFOST (DTSMTB, TSUM1, TSUM2)}

The phenological development of many crops is temperature dependent. Temperature sum has been used as a generic method for expressing specific crop growth periods in many crop 
growth models based on daily accumulation of effective air temperature (Manrique and Hodges, 1989). In WOFOST, the daily increase in temperature sum (DTSMTB) is calculated as the average daily temperature (i.e., average of maximum and minimum $\mathrm{T}$ ) minus the base temperature (i.e., $2{ }^{\circ} \mathrm{C}$ for potato crop) (Wolf and De Wit, 2003). Although this temperature sum function gives a good estimation of the crop growth period in temperate regions, it is not validated for regions with warmer climates, as it does not consider the effect of temperature on crop growth when temperature is beyond the optimum value (Manrique and Hodges, 1989).

Literature reports show that the optimum temperature for tuber initiation ranges between 10 and $21^{\circ} \mathrm{C}$ or between 10 and $24^{\circ} \mathrm{C}$ for tuber growth (Kooman, 1995; Kooman and Haverkort, 1995). However, these values were mostly derived from temperate regions where the average daily temperature during the tuber initiation period is rarely above $25^{\circ} \mathrm{C}$. The documentation on the effect of high temperatures (e.g., above $25^{\circ} \mathrm{C}$ ) on tuber growth rate in warm areas is limited. Manrique and Hodges (1989) studied potato growth in tropical environments and identified that the tuber initiation was delayed when temperature raised above $25^{\circ} \mathrm{C}$. The tuber initiation rate was constant when the mean soil temperature ranged between $18^{\circ} \mathrm{C}$ and $24^{\circ} \mathrm{C}$ (Sale, 1979). In this study, the optimum temperature range for potatoes in northern China was calibrated between 19 and $25^{\circ} \mathrm{C}$. However, more research and measurements are needed to identify the relationship between temperature and the initiation and growth of tubers in regions with high temperature.

With the default DTSMTB, the calibrated TSUM1 in this study varied largely between the two experimental years for the same variety in the same region. The rather large variation in TSUM1 made it difficult to select a constant value for the parameter. With the adapted DTSMTB table, the calibrated TSUM $1(260 \mathrm{Cd})$ and TSUM 2 (1165 Cd) were within the plausible range of TSUM1 (100-380 Cd) and TSUM2 (1100-1800 Cd) for potatoes with different maturity features (Huber, 2010; Smelt, 2016). The crop phenology was well simulated for both years with constant TSUM1 and TSUM2 values.

When calibrating the WOFOST model for potato production in the Netherlands, Yan (2015) identified that a TSUM1 of $420 \mathrm{Cd}$ and TSUM2 of $1450 \mathrm{Cd}$ could best match the observed dates for tuber initiation and maturity. With the default DTSMTB table, Smelt (2016) calibrated the WOFOST model for potato grown in the Netherlands and found a TSUM1 of $470 \mathrm{Cd}$. A higher value for TSUM1 $(525 \mathrm{Cd}$ ) has been identified in previous research in the country (Smelt 2016). The default value for TSUM1 (150 Cd) is apparently too low even for potatoes cultivating under European conditions where the value was originally derived. A possible explanation for this may be that high temperatures occasionally occurred during the early growing period, delaying tuber initiation, and this is not accounted by the old DTSMTB table.

\subsubsection{Calibration of the photosynthesis in WOFOST (AMAXTB)}

When parameterizing the maximum leaf $\mathrm{CO}_{2}$ assimilation rate as function of development stage (AMAXTB), Smelt (2016) referred to values reported by Kroes et al. (2008) and Vos and Van der Putten (1998) and found best values of $35 \mathrm{~kg} \mathrm{CO}_{2} \mathrm{ha}^{-1} \mathrm{hr}^{-1}$ at DVS 0 and 1 and $11 \mathrm{~kg}$ 
$\mathrm{CO}_{2} \mathrm{ha}^{-1} \mathrm{hr}^{-1}$ at DVS 2, which is in agreement with our study that there is a need to increase the AMAX in order to estimate the potential biomass production correctly.

The default value for AMAX $\left(30 \mathrm{~kg} \mathrm{CO}_{2} \mathrm{ha}^{-1} \mathrm{hr}^{-1}\right)$ was derived from experiments of more than 60 years ago. To adapt this value, it is important to understand how the original value was derived and why it can or cannot be adapted. As mentioned before, the potato crop file in WCC referred mainly to the data of "SUCROS87" (Spitters et al., 1989) for potato. Spitters et al. (1989) referred to the work of Versteeg and Van Keulen (1986) when defining AMAX for C3 crops in temperature regions (including potato). Versteeg and Van Keulen (1986) compared different calculation methods for potential production of crops and referred to the work of Goudriaan and Van Laar (1978), who adapted the calculation of biomass assimilation based on the results of De Wit (1965) on photosynthesis of leaf canopies, and used the same AMAX (30 kg CO $2 \mathrm{ha}^{-1} \mathrm{hr}^{-1}$ ) for C3 plants. De Wit (1965) referred to the results of Gaastra (1959) who studied the effect of light, $\mathrm{CO}_{2}$ and temperature on crop photosynthesis for tomato, spinach, turnip, cucumber and sugar beet, and used Gaastra's data for sugar beet for AMAX (i.e., 30 $\mathrm{kg} \mathrm{CO} 2 \mathrm{ha}^{1} \mathrm{hr}^{-1}$ with normal $\mathrm{CO}_{2}$ concentration (0.03\%) at leaf surface), which is likely to be the original source for AMAX in WOFOST for potato.

For potato specifically, the study of Chapman and Loomis (1953) illustrated potato photosynthesis under field conditions and found that the AMAX under normal $\mathrm{CO}_{2}$ concentrations (i.e., $0.025-0.03 \%$ in experimental year 1951) was $18 \mathrm{~kg} \mathrm{CO}_{2} \mathrm{ha}^{-1} \mathrm{hr}^{-1}$ and that the relationship between $\mathrm{CO}_{2}$ concentration and maximum $\mathrm{CO}_{2}$ absorption was linear (i.e., the AMAX was $32 \mathrm{~kg} \mathrm{CO}_{2} \mathrm{ha}^{-1} \mathrm{hr}^{-1}$ at $\mathrm{CO}_{2}$ concentration $0.06 \%$, and increased up to $50 \mathrm{~kg} \mathrm{CO}_{2}$ $\mathrm{ha}^{-1} \mathrm{hr}^{-1}$ at the high $\mathrm{CO}_{2}$ concentration of $0.15 \%$ ) (Chapman and Loomis, 1953). Vos and Van der Putten (1998) found a maximum $P_{\max }\left(\right.$ AMAX) for potato of $32 \mathrm{~kg} \mathrm{ha}^{-1} \mathrm{hr}^{-1}$ and that $\mathrm{P}_{\max }$ decreased with the aging of leaves (e.g., $P_{\max }$ at age 30 days was about $25 \mathrm{~kg} \mathrm{ha}^{-1} \mathrm{hr}^{-1}, \mathrm{P}_{\max }$ at age of 50 days was about $18 \mathrm{~kg} \mathrm{ha}^{-1} \mathrm{hr}^{-1}$ ). Thus, the AMAX of young leaves is expected to be higher than $32 \mathrm{~kg} \mathrm{CO}_{2} \mathrm{ha}^{-1} \mathrm{hr}^{-1}$, as the current $\mathrm{CO}_{2}$ level is higher than in 1998. An AMAX of $35 \mathrm{~kg} \mathrm{CO}_{2} \mathrm{ha}^{-1} \mathrm{hr}^{-1}$ can be assumed.

WOFOST assumes that the crop is dead at maturity (DVS 2) and all the leaves die and do not function anymore. Therefore, the AMAX at DVS 2 in the original parameter set is zero. However, the visual criteria used by local agronomist for potato maturity ("harvestable") is that approximately $30-50 \%$ of aboveground canopy is yellow (personal communication with the experimenter), which explains why the observed LAl was still higher than $3 \mathrm{~m}^{2} \mathrm{~m}^{-2}$ toward "harvested date". Therefore, it is reasonable that at "harvested date" the remaining green leaves still function for photosynthesis but have a lower AMAX due to ageing. Therefore, it is reasonable that the maximum AMAX lasted longer (DVS 1.8 instead of DVS 1.57) and that AMAX is $20 \mathrm{~kg} \mathrm{CO}_{2} \mathrm{ha}^{-1} \mathrm{hr}^{-1}$ for the latest generated leaves of 30-50 days age at DVS 2 .

\subsubsection{Calibration of the sprout growth rate in LINTUL POTATO DSS}

The original value of the sprout growth rate (i.e., $0.7 \mathrm{~mm}$ per degree day) was derived from regions in a temperate maritime climate where temperature increases gradually in spring 
(Haverkort et al., 2015). However, the rate of sprout growth should be lower in regions where air temperature increases sharply in spring and the rise of soil temperature lags behind. We found that the estimation of tuber yield is very sensitive to the value of sprout growth rate, as it determines the period of $100 \%$ ground cover and thus the period of light interception. Therefore we assume that the sprout growth rate is site-specific and should be calibrated for each specific growing region with particular weather conditions during the sowing period. It can be seen as an input value that is different in each model run, instead of a constant parameter.

\subsection{Calibration processes and adapted parameters compared to other calibration studies}

The number of parameters that can be adapted in model calibration is enormous and the value for an individual parameter is diverse (De Koning et al., 1995). The number of calibrated parameters in our calibration procedure was smaller (i.e., 8 parameters were calibrated) compared to other calibration studies of WOFOST (De Koning et al., 1995; Dua et al., 2014; Smelt, 2016; Yan, 2015). By minimizing the number of calibrated parameters, the calibrated model is assumed to properly represent the reality with the least errors. The parameter set can be adapted to make the estimation fit the observation almost perfectly. However, it is important that the parameters are calibrated within a plausible range and to prove that the change of a particular parameter is physiologically possible.

Yan (2015) parameterized the AMAX (i.e., maximum photosynthesis rate) by testing various values (i.e., 30, 47, 65, 200) and identified the best fitted value for AXAMTB (i.e., 47, 47, 0 at DVS 0, 1, 2 respectively). When calibrating WOFOST for potato under Indian conditions, Dua et al. (2014) also obtained a rather high AMAX value (i.e., 35, 35, 0; 40, 40, 0 and 45, 45, 0 respectively for three potato varieties). However, the AMAX values used for testing, and the calibrated AMAX values, were out of the physiological range for the maximum photosynthesis rate of potatoes (i.e., $35 \mathrm{~kg} \mathrm{CO}_{2} \mathrm{ha}^{-1} \mathrm{hr}^{-1}$ ).

In this study, the parameters were only calibrated when the relevant observation data were available, and/or the adaptation could be explained. For instance, the biomass allocation to leaves and roots were not parameterized in our calibration procedure, while it is a common practice in other studies to change the allocation factor in order to get a good correspondence between the modeled results and the measured values. The parameters SLATB and SPAN are highly cultivar specific and diverse and thus were calibrated without the back up of measured data. In addition to AMAXTB, other photosynthesisrelated parameters were not calibrated as it was assumed that the original value derived from previous experiments are accurate to be applied in the current situation.

\subsection{Comparison and application of two models}

Compared to WOFOST, LINTUL POTATO DSS requires less calibration and uses less parameter inputs. As explained above, the temperature sum inputs (TSUM1 and TSUM2) in WOFOST have a great influence on the modeled total dry matter and tuber yield and a new 
DTSMTB table had to be generated to model the crop phenology correctly. LINTUL POTATO DSS does not estimate the crop phenology in such a way. Rather, the model assumes that the temperature sum from emergence to $100 \%$ ground cover $\left(\mathrm{LAl}>3 \mathrm{~m}^{2} \mathrm{~m}^{-2}\right.$ ) is a constant value of $650 \mathrm{Cd}$, and the $100 \%$ ground cover remains until reaching crop maturing. Therefore, in LINTUL POTATO DSS, leaf senescence is not simulated, and thus reduction of photosynthesis capacity as a function of the development stage (AMAXTB) is not considered. Moreover, the biomass distribution to different organs is not considered in LINTUL POTATO DSS, as the model assumes a constant harvest index of 0.75 at maturity and does not include the partitioning of assimilation to other plant organs.

However, LINTUL POTATO DSS has less explainable power than WOFOST. For instance, WOFOST estimates the development of different plant organs by assuming partitioning factors to leaves, stems, roots and tubers as a function of different development stages. With the assumed value of SLATB (specific leaf area), the development of LAI can be modeled. LINTUL POTATO DSS, on the other hand, only estimates the starting and the length of canopy closure.

The results demonstrated that both models can be used for estimating potato yield under potential conditions in China. The experiments that fulfill the requirements for model calibration are limited for potatoes in northern China and even rare in southern China where potatoes are mainly grown in small plots. Considering the limited data sources, the calibration can be done with the "simple calibration approach" that parameterizes only the important phenological features (i.e., adapt the TSUM1 and TSUM2 in WOFOST and sprout growth rate in LINTUL POTATO DSS so that the modeled phenology date matches the date that reported in literature or by local agronomists) (GYGA, 2016). 
Appendix B Yield gap analysis of the potato crop in different regions in China (Chapter 2) 


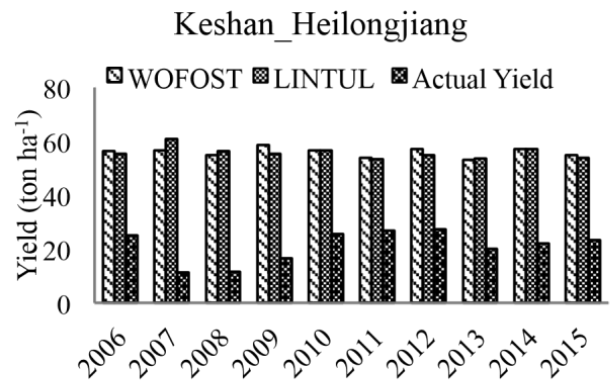

Huhehaote_Inner Mongolia

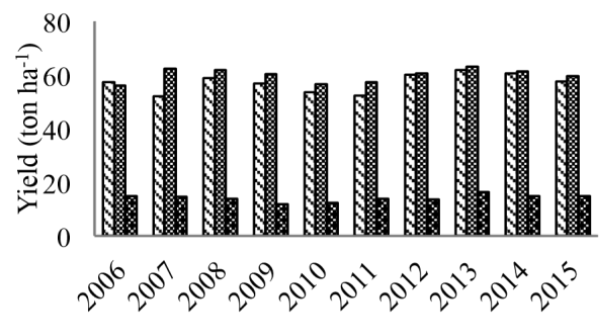

Gaolan_Gansu

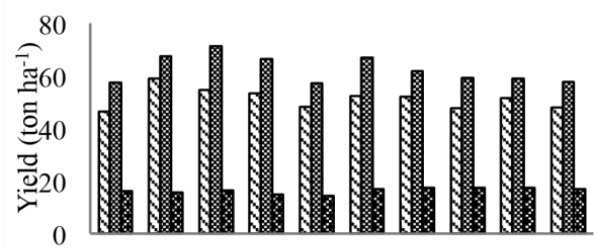

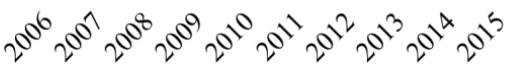

Hailun_Heilongjiang

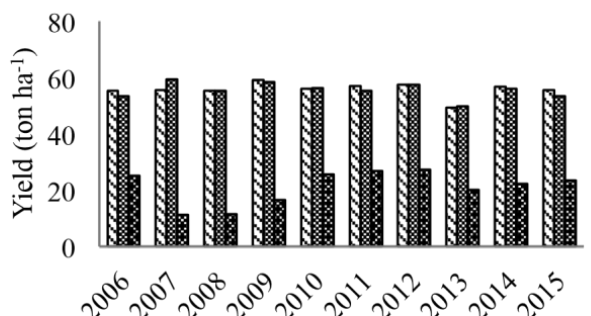

Huade_Inner Mongolia

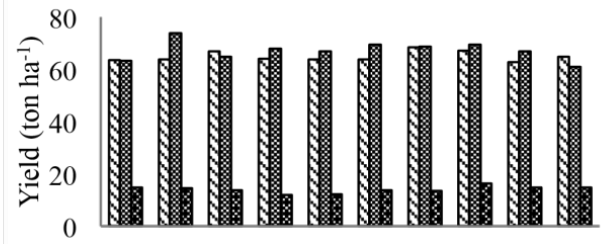

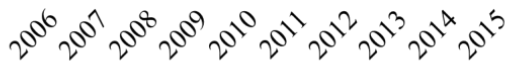

Kongtong_Gansu

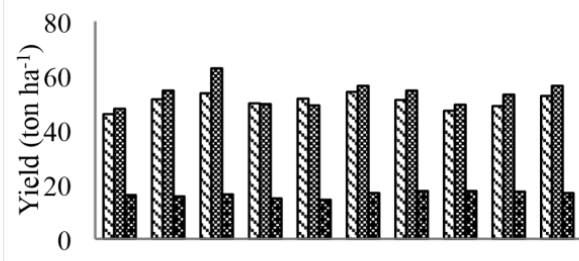

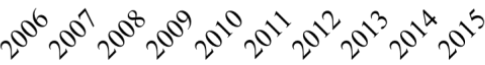

Wushaoling_Gansu

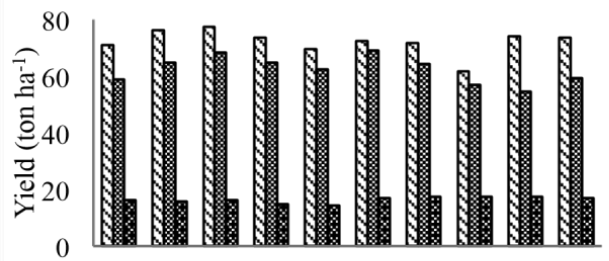

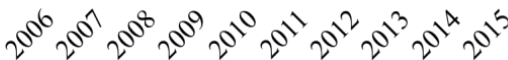

Xining_Qinghai

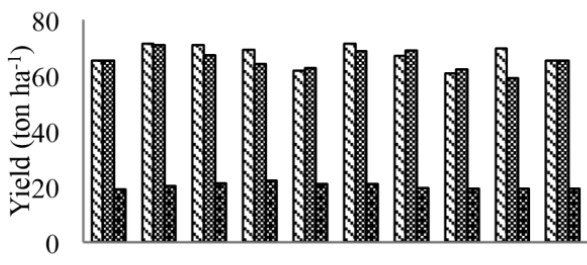

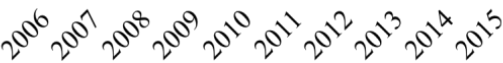

Figure B1 (part 1 of 2). Potential yield (Yp) of potatoes estimated by the two models (i.e., WOFOST and LINTUL POTATO DSS) and actual yield (Ya) for the selected RWSs over 10 years $(2006-2015)$. 

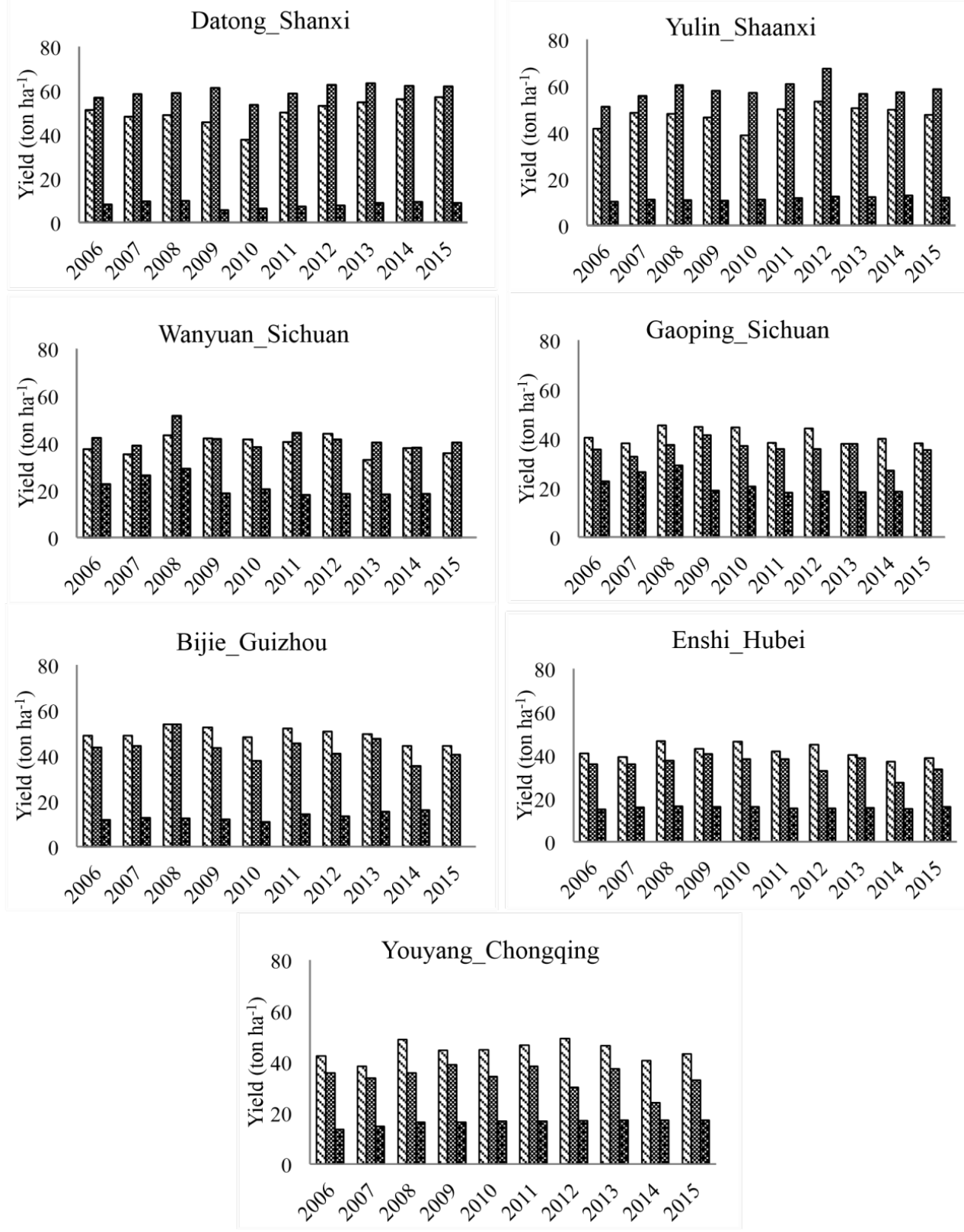

Figure B1 (part 2 of 2). Potential yield (Yp) of potatoes estimated by the two models (i.e., WOFOST and LINTUL POTATO DSS) and actual yield (Ya) for the selected RWSs over 10 years $(2006-2015)$. 

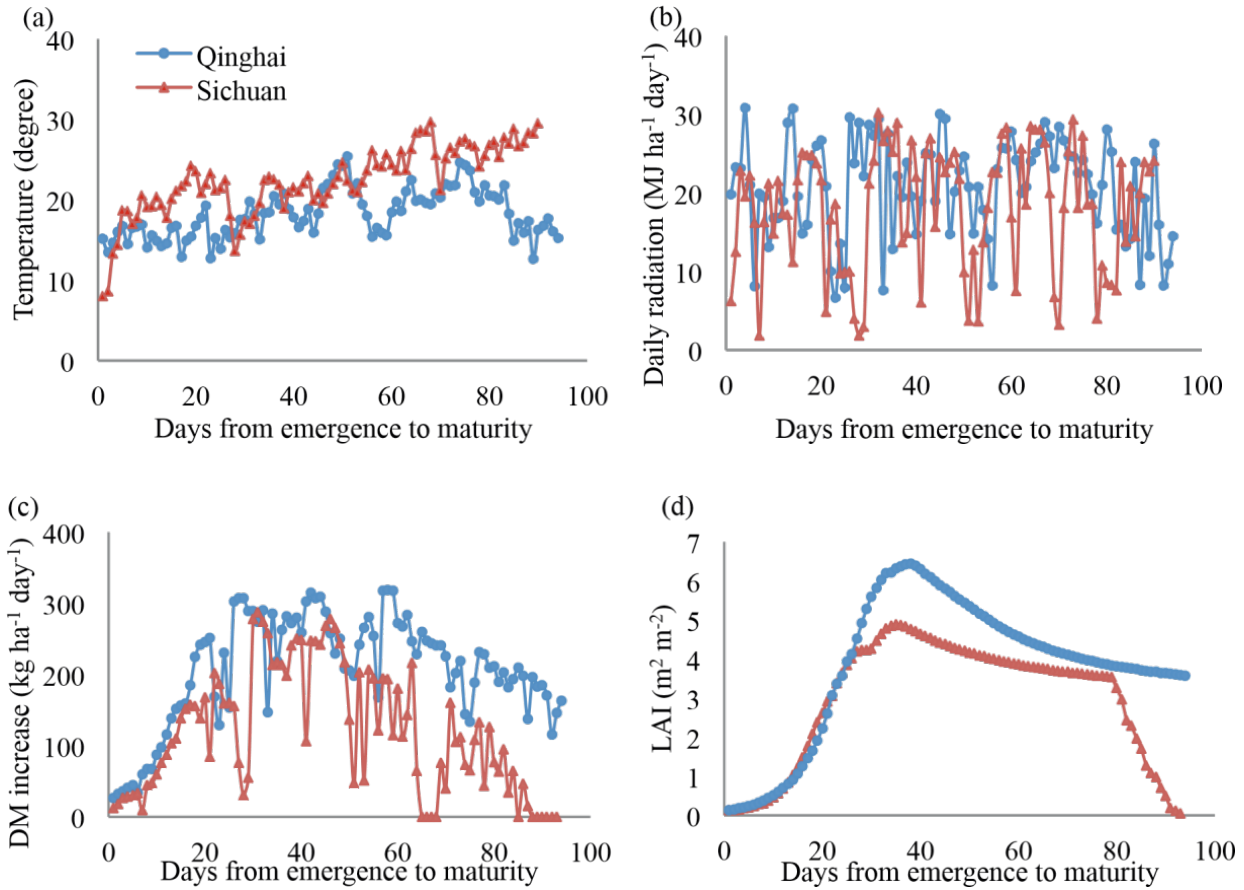

Figure B2. Average daily temperature (a), daily radiation level (b), daily dry matter accumulation (c) and leaf area index (LAI) development (d) in Sichuan Wanyuan and Qinghai Xining in 2006. 
Kenshan Heilongjiang

ه Potential yield $\mathrm{a}$ Water limited yield $\mathbf{0}$ Actual yield

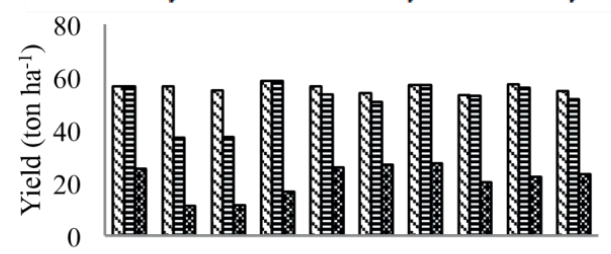

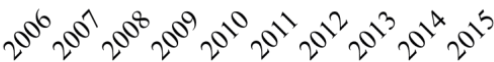

Huade_Inner Mongolia

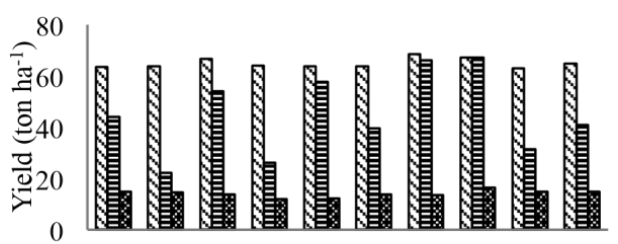

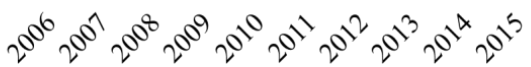

Gaolan_Gansu

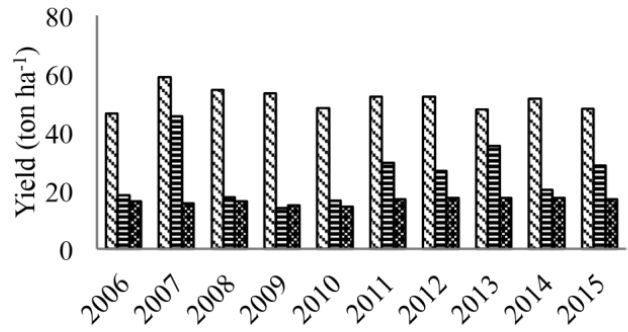

Wushaoling_Gansu

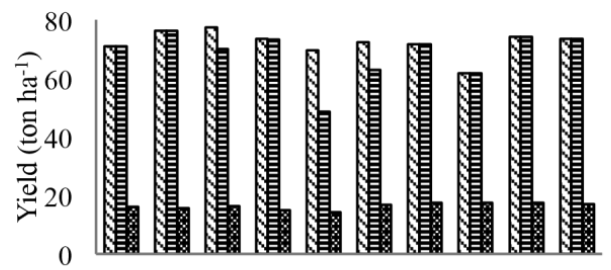

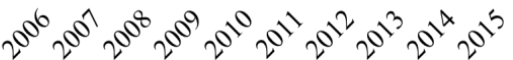

Hailun Heilongjiang
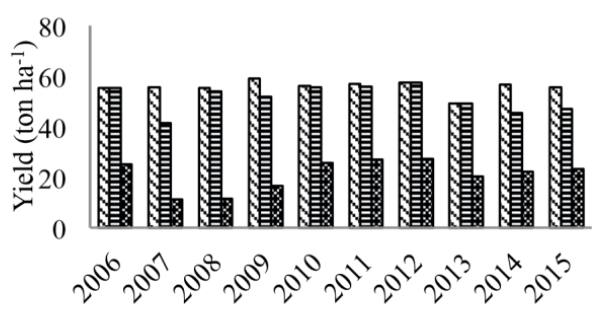

Huhehaote_Inner Mongolia

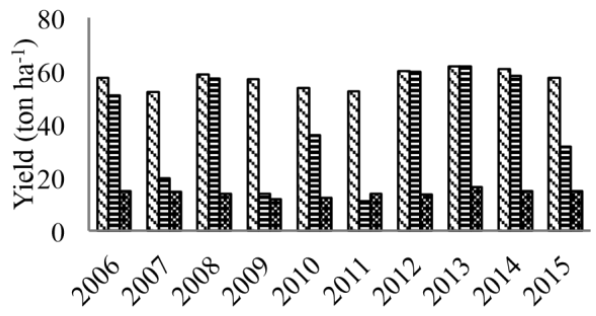

Kongtong_Gansu

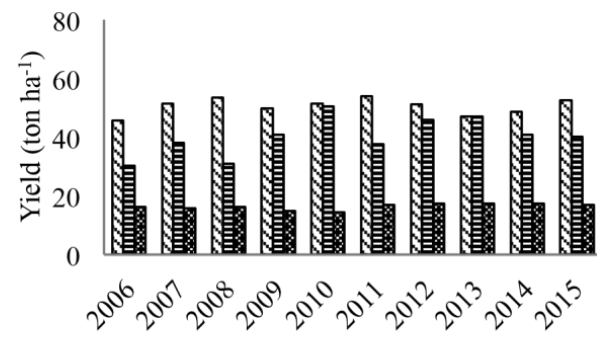

Xining_Qinghai
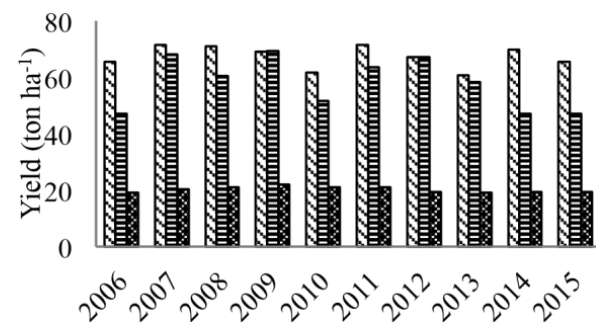

Figure B3 (part 1 of 2). The potential yield (Yp), water limited yield ( $Y w)$ and actual yield (Ya) of potatoes for the selected RWSs over 10 years from 2006 to 2015. Both Yp and Yw were estimated by WOFOST only. 
Datong_Shanxi

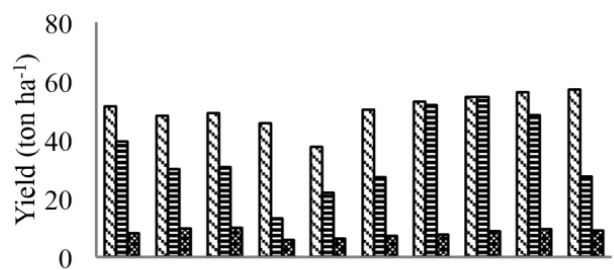

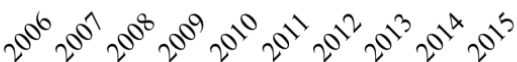

Wanyuan_Sichuan
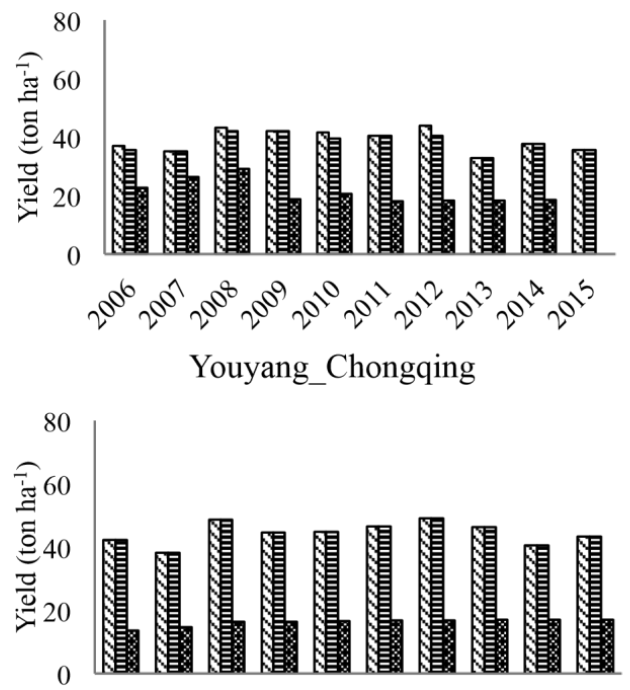

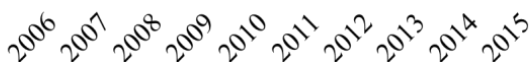

Yulin Shaanxi
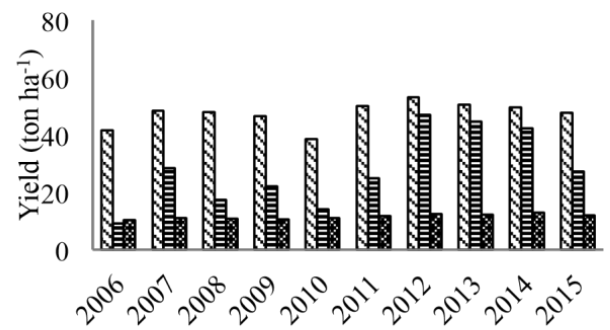

Gaoping_Sichuan

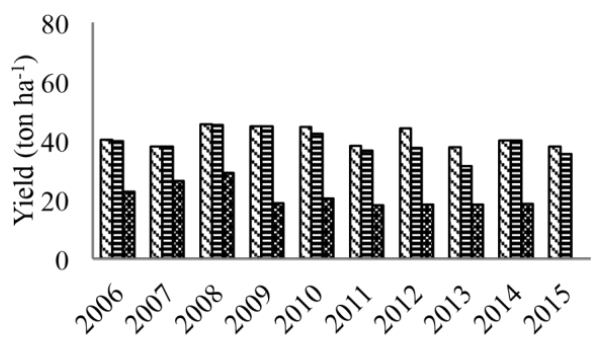

Enshi Hubei

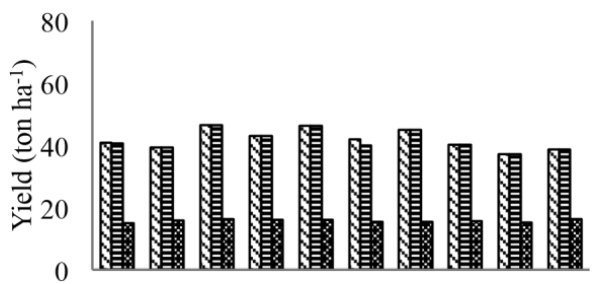

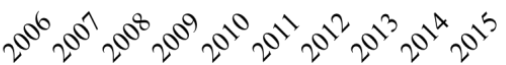

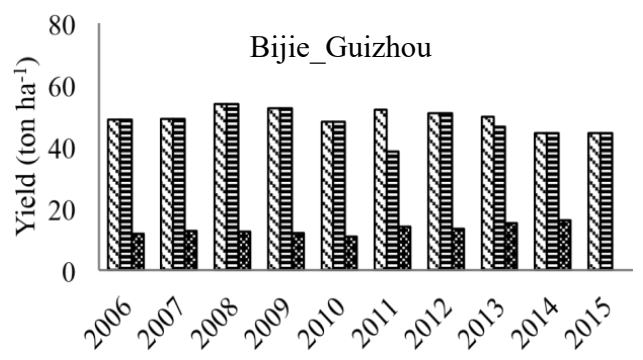

Figure B3 (part 2 of 2). The potential yield (Yp), water limited yield ( $Y w)$ and actual yield $(Y a)$ of potatoes for the selected RWSs over 10 years from 2006 to 2015. Both Yp and Yw were estimated by WOFOST only. 


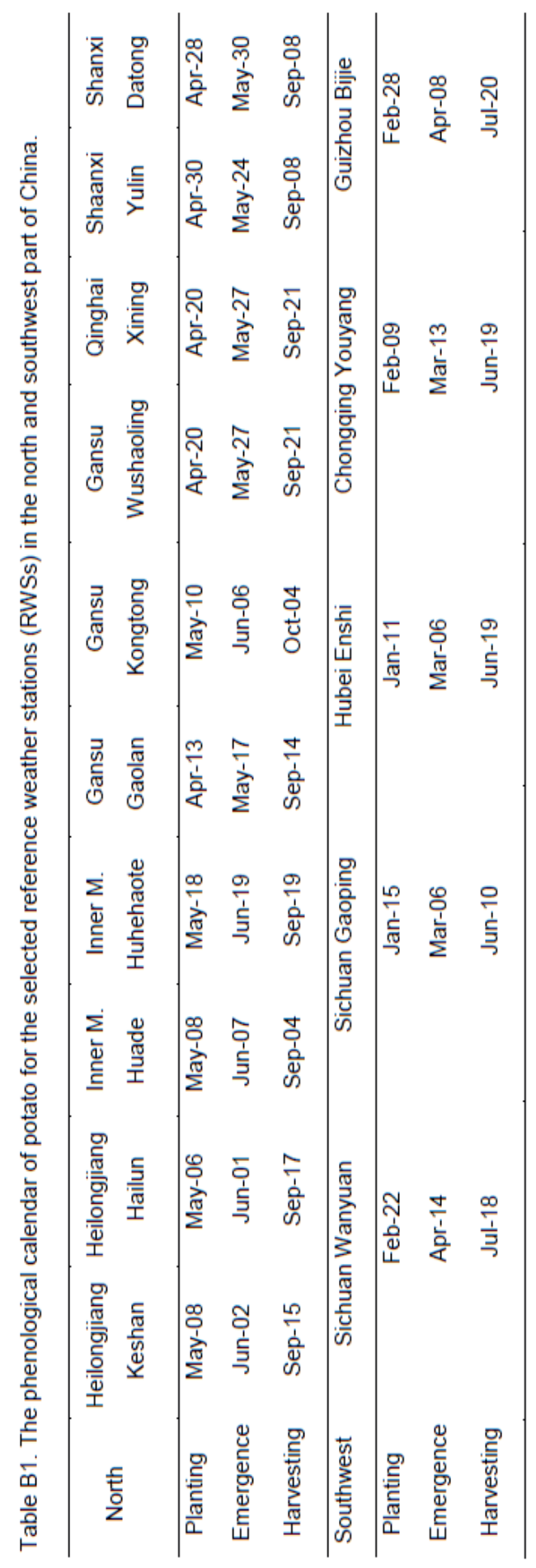




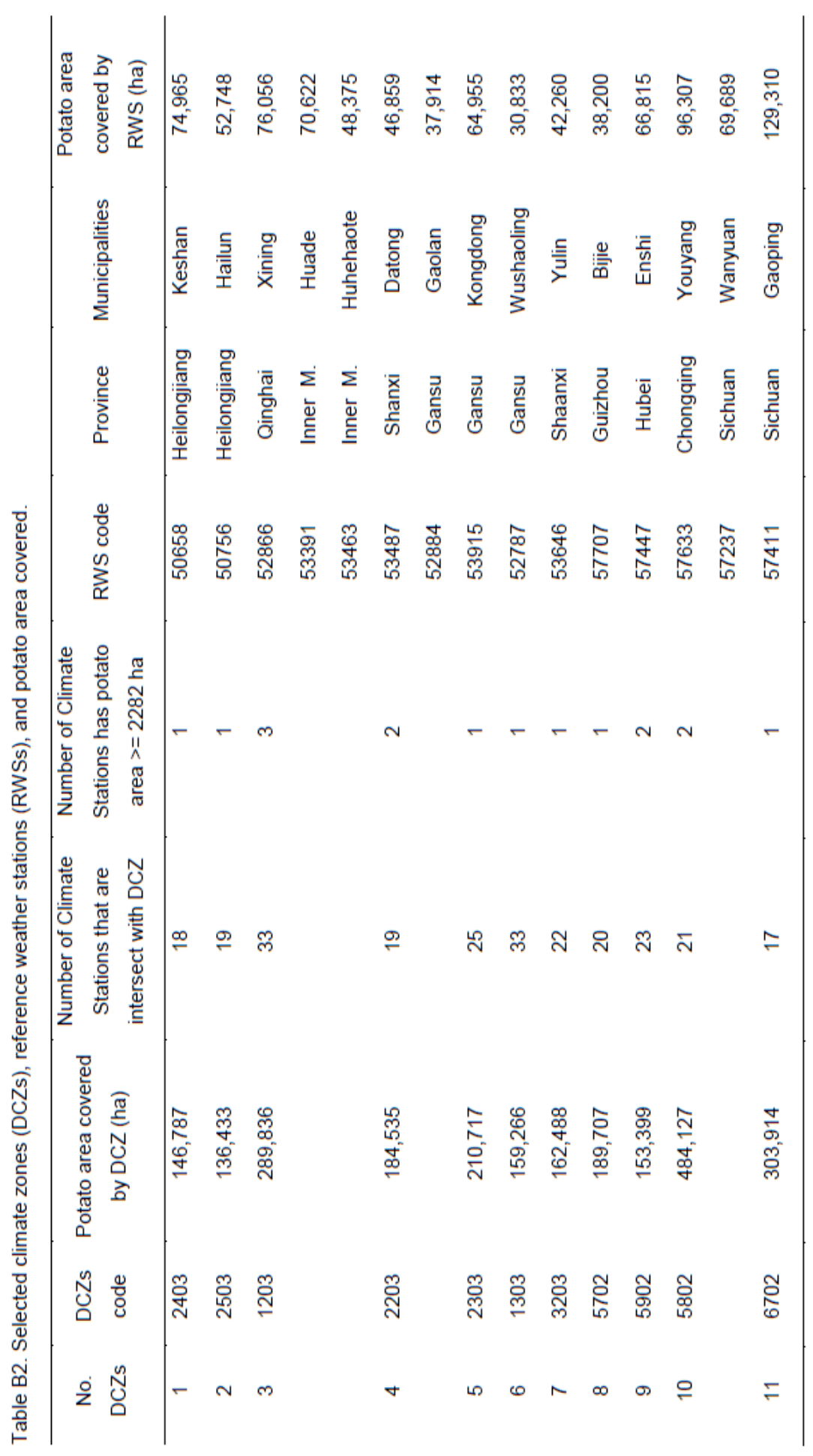




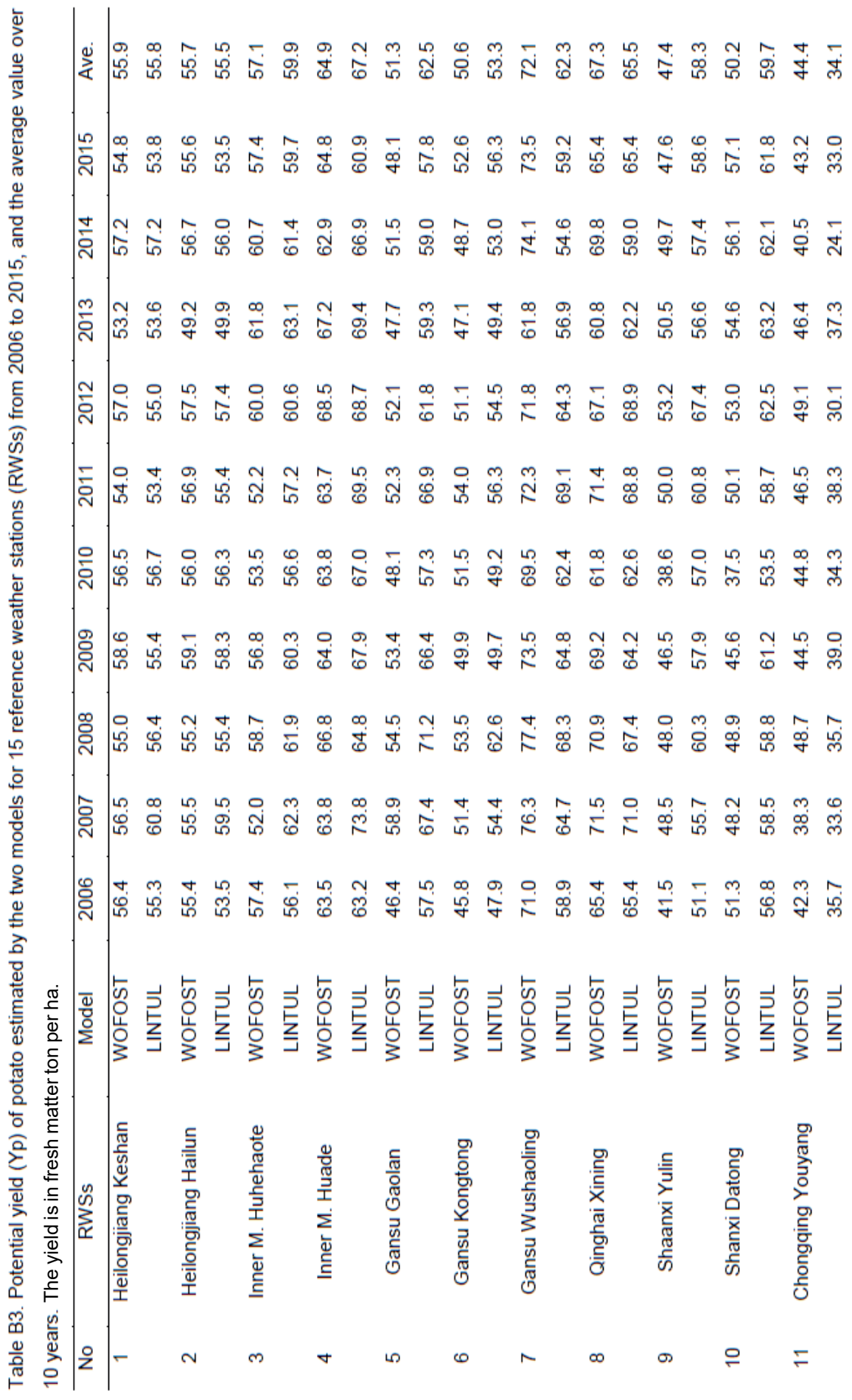




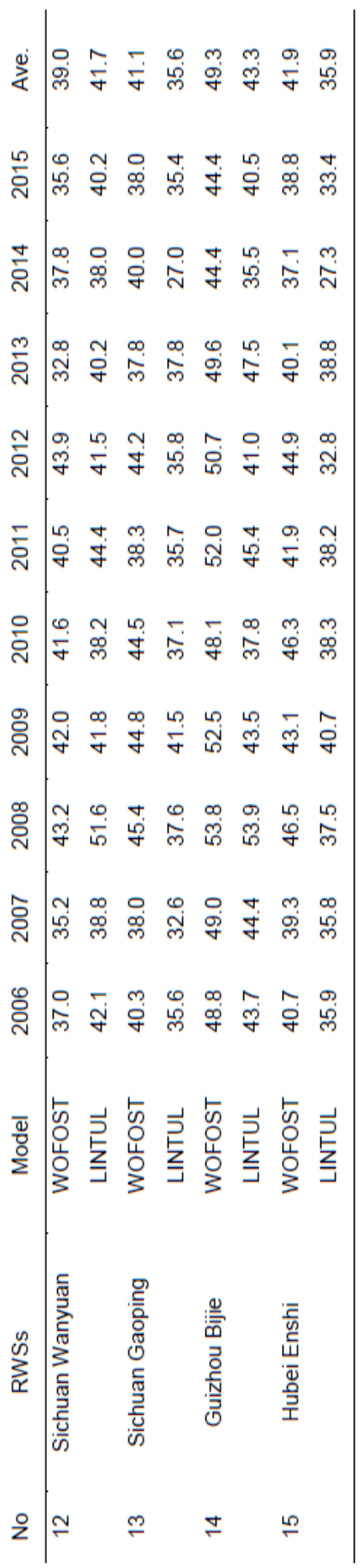




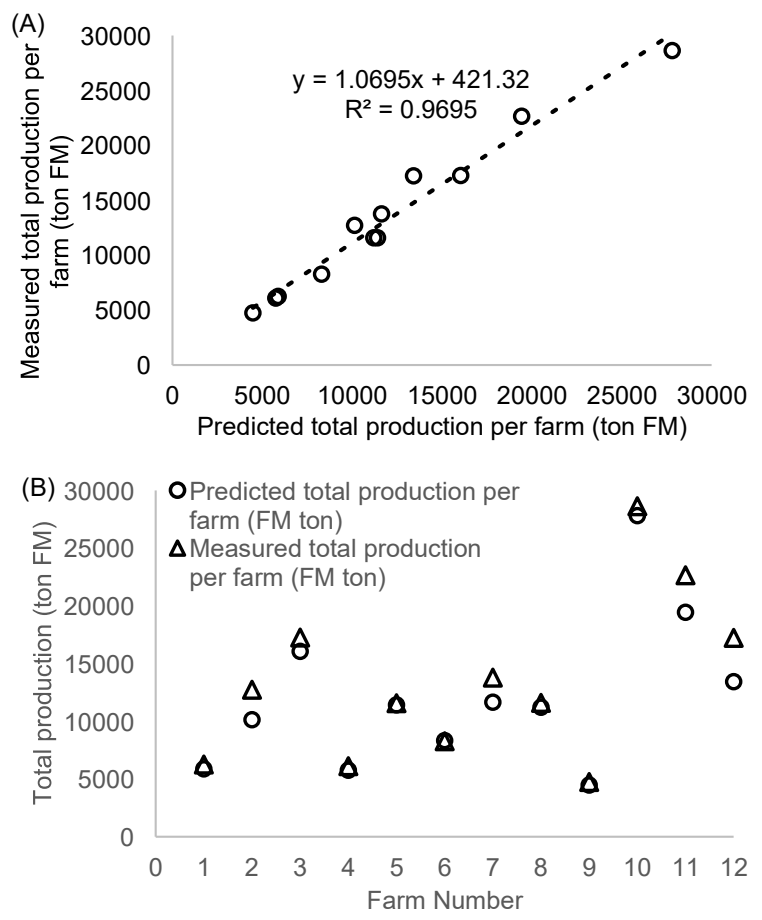

Figure C1. The total potato production in fresh matter per farm (ton FM) predicted based on 3 meter-samples per field, and the measured value in Inner Mongolia in 2018. Data were available for 12 out of 22 farmers. (A) The correlation between the predicted and measured total production per farm. (B) The predicted and measured total production per farm of 12 farmers.
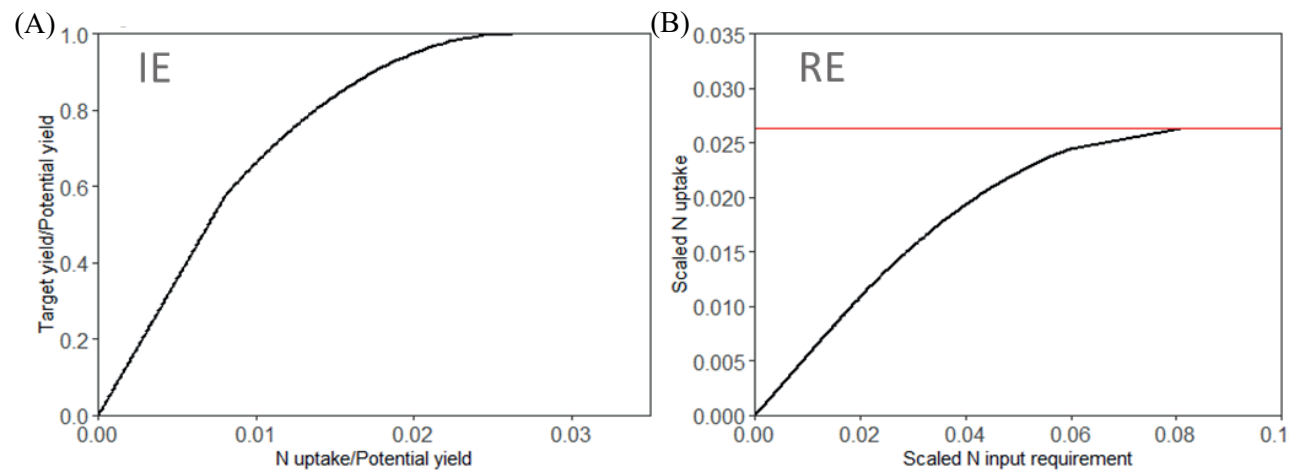

Figure C2. (A) The relationship between the scaled tuber dry matter yield and N uptake by crop (IE) and (B) the relationships between the scaled $\mathrm{N}$ uptake by crop and $\mathrm{N}$ fertiliser input requirement $\left(\mathrm{RE}^{\mathrm{F}}\right)$ as estimated by a linear-quadratic regression model based on the protocol by Ten Berge et al. (2019). The RE and IE for different target yield ( $\mathrm{Ya}$ and $\mathrm{Ye}$ ) in the three regions were estimated based on the regression model. 
Table C1. Soil texture and chemical properties of potato fields of Inner Mongolia, Heilongjiang and Gansu. The soil characteristics in Inner Mongolia and Heilongjiang were measured for the potato fields in the region. The soil samples were taken for a depth of $0-25 \mathrm{~cm}$. The soil $\mathrm{N}$ uptake (SNU) was estimated by Eurofins Laboratory from measured total nitrogen, $\mathrm{C} / \mathrm{N}$ ratio, $\mathrm{pH}$ and soil biological parameters, and it accounts for both mineral $\mathrm{N}$ accumulated in the soil (mineral $\mathrm{N}$, nitrate and ammonium, at the time of soil sample collection) and the mineralizable $\mathrm{N}$ from soil organic matter (mineral $\mathrm{N}$ becoming available during the growing season). Soil characteristics for the surveyed fields in Gansu is based on Shang et al., (2012).

\begin{tabular}{|c|c|c|c|c|c|c|c|c|}
\hline No. & Region & $\begin{array}{c}\text { Year of } \\
\text { sampling }\end{array}$ & $\begin{array}{l}\text { Field } \\
\text { No. }\end{array}$ & Soil type & $\begin{array}{c}\text { Total N } \\
\left(\mathrm{mg} \mathrm{kg}^{-1}\right)\end{array}$ & $\begin{array}{c}\text { SNU per } \\
\text { year }\left(\mathrm{kg} \mathrm{ha}^{-1}\right)\end{array}$ & $\begin{array}{c}\text { SOM } \\
(\%)\end{array}$ & $\mathrm{pH}$ \\
\hline 1 & Inner Mongolia & 2013 & 1 & Loam & 1150 & 90 & 1.2 & 7.4 \\
\hline 2 & Inner Mongolia & 2013 & 2 & Silt Loam & 880 & 56 & 1.6 & 7.5 \\
\hline 3 & Inner Mongolia & 2013 & 3 & Sandy & 530 & 23 & 1.5 & 7.8 \\
\hline 4 & Inner Mongolia & 2013 & 4 & Sandy & 800 & 54 & 1.1 & 6.6 \\
\hline 5 & Inner Mongolia & 2013 & 5 & Sandy & 1680 & 109 & 2.4 & 6.2 \\
\hline 6 & Inner Mongolia & 2013 & 6 & Silt Loam & 2270 & 97 & 5.4 & 6.6 \\
\hline 7 & Inner Mongolia & 2013 & 7 & Sandy & 1420 & 109 & 1.8 & 5.9 \\
\hline 8 & Inner Mongolia & 2013 & 8 & Silt Loam & 1860 & 97 & 3.7 & 7.8 \\
\hline 9 & Inner Mongolia & 2013 & 9 & Sandy & 1590 & 90 & 2.8 & 7.7 \\
\hline 10 & Inner Mongolia & 2013 & 10 & Loam & 850 & 41 & 2.3 & 7.9 \\
\hline 11 & Inner Mongolia & 2013 & 11 & Sandy & 1320 & 70 & 2.5 & 7.4 \\
\hline 12 & Inner Mongolia & 2013 & 12 & Loam & 520 & 38 & 0.8 & 7.6 \\
\hline 13 & Inner Mongolia & 2013 & 13 & Loam & 970 & 60 & 1.5 & 7.7 \\
\hline 14 & Inner Mongolia & 2013 & 14 & Loam & 1130 & 84 & 1.4 & 7.8 \\
\hline 15 & Inner Mongolia & 2014 & 1 & Sandy & 790 & 62 & 0.8 & 6.9 \\
\hline 16 & Inner Mongolia & 2014 & 2 & Loam & 630 & 37 & 1.1 & 7.5 \\
\hline 17 & Inner Mongolia & 2014 & 3 & Sandy & 560 & 41 & 0.7 & 7.5 \\
\hline 18 & Inner Mongolia & 2014 & 4 & Sandy & 1340 & 104 & 1.4 & 6.2 \\
\hline 19 & Inner Mongolia & 2014 & 5 & Loam & 1110 & 67 & 1.7 & 6.1 \\
\hline 20 & Inner Mongolia & 2014 & 6 & Silt Loam & 2430 & 119 & 2.7 & 6.6 \\
\hline 21 & Inner Mongolia & 2014 & 7 & Sandy & 1260 & 76 & 2.3 & 6 \\
\hline 22 & Inner Mongolia & 2014 & 8 & Loam & 1540 & 96 & 2.1 & 7.7 \\
\hline 23 & Inner Mongolia & 2014 & 9 & Silt Loam & 1510 & 96 & 2.5 & 7.5 \\
\hline 24 & Inner Mongolia & 2014 & 10 & Loam & 1150 & 68 & 2.1 & 7.6 \\
\hline 25 & Inner Mongolia & 2014 & 11 & Loam & 1310 & 83 & 2.2 & 7.7 \\
\hline 26 & Inner Mongolia & 2014 & 12 & Sandy & 1140 & 71 & 2.2 & 6.3 \\
\hline 27 & Inner Mongolia & 2014 & 13 & Sandy & 840 & 43 & 2 & 7.4 \\
\hline 28 & Inner Mongolia & 2014 & 14 & Loam & 1250 & 87 & 1.9 & 7.8 \\
\hline 29 & Inner Mongolia & 2014 & 15 & Loam & 1220 & 79 & 2 & 7.9 \\
\hline 30 & Heilongjiang & 2016 & 1 & Silty Clay & 2990 & 145 & 5.7 & 5.2 \\
\hline 31 & Heilongjiang & 2016 & 2 & Silty Clay & 2990 & 157 & 6.2 & 4.8 \\
\hline
\end{tabular}




\begin{tabular}{|c|c|c|c|c|c|c|c|c|}
\hline No. & Region & $\begin{array}{c}\text { Year of } \\
\text { sampling }\end{array}$ & $\begin{array}{l}\text { Field } \\
\text { No. }\end{array}$ & Soil type & $\begin{array}{c}\text { Total } \mathrm{N} \\
\left(\mathrm{mg} \mathrm{kg}^{-1}\right)\end{array}$ & $\begin{array}{c}\text { SNU per } \\
\text { year }\left(\mathrm{kg} \mathrm{ha}^{-1}\right)\end{array}$ & $\begin{array}{l}\text { SOM } \\
(\%)\end{array}$ & $\mathrm{pH}$ \\
\hline 32 & Heilongjiang & 2016 & 3 & Clay & 3300 & 150 & 7.1 & 4.7 \\
\hline 33 & Heilongjiang & 2016 & 4 & Clay & 3300 & 155 & 7.4 & 4.9 \\
\hline 34 & Heilongjiang & 2016 & 5 & Clay & 2840 & 150 & 5.9 & 4.7 \\
\hline 35 & Heilongjiang & 2016 & 6 & Silty Clay & 3330 & 171 & 7.0 & 5 \\
\hline 36 & Heilongjiang & 2016 & 7 & Silty Clay & 3030 & 144 & 6.7 & 5.2 \\
\hline 37 & Heilongjiang & 2016 & 8 & Clay & 2340 & 131 & 3.5 & 5 \\
\hline 38 & Heilongjiang & 2016 & 9 & Silty Clay & 3610 & 153 & 8.7 & 5.4 \\
\hline 39 & Heilongjiang & 2016 & 10 & Silty Clay & 3650 & 181 & 7.4 & 5 \\
\hline 40 & Heilongjiang & 2016 & 11 & Silty Clay & 3720 & 153 & 8.6 & 5 \\
\hline 41 & Heilongjiang & 2016 & 12 & Clay & 3930 & 167 & 9.6 & 5.3 \\
\hline 42 & Heilongjiang & 2016 & 13 & Silty Clay & 3680 & 167 & 8.1 & 4.8 \\
\hline 43 & Heilongjiang & 2016 & 14 & Silty Clay & 3840 & 172 & 8.4 & 5 \\
\hline 44 & Heilongjiang & 2016 & 15 & Clay & 3840 & 158 & 8.9 & 5.1 \\
\hline 45 & Heilongjiang & 2016 & 16 & Clay & 3680 & 173 & 8.4 & 4.8 \\
\hline 46 & Heilongjiang & 2016 & 17 & Silty Clay & 2610 & 129 & 5.0 & 4.6 \\
\hline 47 & Heilongjiang & 2016 & 18 & Clay & 3530 & 160 & 7.6 & 4.8 \\
\hline 48 & Heilongjiang & 2016 & 19 & Clay & 4000 & 175 & 8.6 & 4.9 \\
\hline 49 & Heilongjiang & 2016 & 20 & Clay & 3640 & 184 & 7.6 & 4.9 \\
\hline 50 & Heilongjiang & 2016 & 21 & Clay & 3760 & 157 & 8.9 & 5 \\
\hline 51 & Heilongjiang & 2016 & 22 & Silty Clay & 3600 & 162 & 7.8 & 4.8 \\
\hline 52 & Heilongjiang & 2016 & 23 & Silty Clay & 3160 & 117 & 8.6 & 5.1 \\
\hline 53 & Heilongjiang & 2016 & 24 & Clay & 3670 & 171 & 8.3 & 5 \\
\hline 54 & Heilongjiang & 2016 & 25 & Silty Clay & 3280 & 151 & 7.1 & 4.9 \\
\hline 55 & Heilongjiang & 2016 & 26 & Loam & 1090 & 64 & 1.9 & 5 \\
\hline 56 & Heilongjiang & 2016 & 27 & Silty Clay & 1940 & 106 & 3.3 & 5.6 \\
\hline 57 & Heilongjiang & 2016 & 28 & Clay & 1870 & 96 & 4.2 & 5.8 \\
\hline 58 & Heilongjiang & 2016 & 29 & Silty Clay & 2310 & 141 & 3.8 & 5.2 \\
\hline 59 & Heilongjiang & 2016 & 30 & Clay & 1380 & 77 & 2.8 & 5.2 \\
\hline 60 & Heilongjiang & 2016 & 31 & Silty Clay & 2070 & 107 & 4.0 & 5.6 \\
\hline 61 & Heilongjiang & 2016 & 32 & Silty Clay & 1480 & 79 & 2.9 & 5.2 \\
\hline 62 & Heilongjiang & 2016 & 33 & Silty Clay & 1470 & 84 & 3.1 & 5.4 \\
\hline 63 & Heilongjiang & 2016 & 34 & Silty Clay & 2640 & 136 & 5.3 & 5.4 \\
\hline 64 & Heilongjiang & 2016 & 35 & Silty Clay & 2250 & 108 & 4.8 & 5.2 \\
\hline 65 & Heilongjiang & 2016 & 36 & Silty Clay & 2530 & 142 & 4.7 & 5 \\
\hline 66 & Heilongjiang & 2016 & 37 & Silty Clay & 2720 & 138 & 5.4 & 4.8 \\
\hline 67 & Heilongjiang & 2016 & 38 & Silty Clay & 2080 & 122 & 3.9 & 5.4 \\
\hline 68 & Heilongjiang & 2016 & 39 & Clay & 2160 & 116 & 3.7 & 5.3 \\
\hline 69 & Heilongjiang & 2016 & 40 & Clay & 3260 & 159 & 6.4 & 5.1 \\
\hline 70 & Heilongjiang & 2016 & 41 & Silty Clay & 2920 & 147 & 5.8 & 4.8 \\
\hline
\end{tabular}




\begin{tabular}{|c|c|c|c|c|c|c|c|c|}
\hline No. & Region & $\begin{array}{c}\text { Year of } \\
\text { sampling }\end{array}$ & $\begin{array}{l}\text { Field } \\
\text { No. }\end{array}$ & Soil type & $\begin{array}{c}\text { Total N } \\
\left(\mathrm{mg} \mathrm{kg}^{-1}\right)\end{array}$ & $\begin{array}{c}\text { SNU per } \\
\text { year }\left(\mathrm{kg} \mathrm{ha}^{-1}\right)\end{array}$ & $\begin{array}{l}\text { SOM } \\
(\%)\end{array}$ & $\mathrm{pH}$ \\
\hline 71 & Heilongjiang & 2016 & 42 & Silty Clay & 2830 & 146 & 5.7 & 5 \\
\hline 72 & Heilongjiang & 2016 & 43 & Clay & 2130 & 118 & 3.8 & 5.1 \\
\hline 73 & Heilongjiang & 2016 & 44 & Clay & 3560 & 182 & 6.2 & 4.9 \\
\hline 74 & Heilongjiang & 2016 & 45 & Loam & 1330 & 75 & 2.7 & 5.4 \\
\hline 75 & Heilongjiang & 2016 & 46 & Clay & 3020 & 165 & 5.5 & 5 \\
\hline 76 & Heilongjiang & 2016 & 47 & Clay & 2880 & 162 & 5.4 & 4.7 \\
\hline 77 & Heilongjiang & 2016 & 48 & Clay & 2960 & 156 & 5.2 & 5 \\
\hline 78 & Heilongjiang & 2016 & 49 & Silty Clay & 3350 & 170 & 5.7 & 4.8 \\
\hline 79 & Heilongjiang & 2016 & 50 & Loam & 910 & 49 & 2.0 & 5.3 \\
\hline 80 & Heilongjiang & 2016 & 51 & Silty Clay & 3080 & 150 & 7.0 & 5.2 \\
\hline 81 & Heilongjiang & 2016 & 52 & Silty Clay & 2280 & 116 & 5.2 & 5.8 \\
\hline 82 & Heilongjiang & 2016 & 53 & Silty Clay & 2760 & 132 & 6.1 & 5.3 \\
\hline 83 & Heilongjiang & 2016 & 54 & Silty Clay & 2980 & 128 & 7.0 & 5.2 \\
\hline 84 & Heilongjiang & 2016 & 55 & Silty Clay & 2700 & 139 & 5.4 & 4.8 \\
\hline 85 & Heilongjiang & 2016 & 56 & Clay & 2460 & 120 & 5.4 & 5.5 \\
\hline 86 & Heilongjiang & 2016 & 57 & Silty Clay & 2370 & 114 & 5.1 & 5.9 \\
\hline 87 & Heilongjiang & 2016 & 58 & Clay & 2390 & 111 & 5.8 & 5.9 \\
\hline 88 & Heilongjiang & 2016 & 59 & Silty Clay & 2660 & 125 & 5.7 & 5.3 \\
\hline 89 & Heilongjiang & 2016 & 60 & Silty Clay & 2510 & 110 & 5.8 & 5.4 \\
\hline 90 & Heilongjiang & 2016 & 61 & Silty Clay & 2860 & 151 & 6.0 & 5.2 \\
\hline 91 & Heilongjiang & 2016 & 62 & Silty Clay & 2590 & 120 & 5.4 & 5.3 \\
\hline 92 & Heilongjiang & 2016 & 63 & Silty Clay & 2600 & 124 & 5.7 & 5.3 \\
\hline 93 & Heilongjiang & 2016 & 64 & Silty Clay & 2880 & 140 & 6.5 & 5.3 \\
\hline 94 & Heilongjiang & 2016 & 65 & Silty Clay & 2200 & 98 & 5.1 & 6 \\
\hline 95 & Heilongjiang & 2016 & 66 & Silty Clay & 2290 & 111 & 5.0 & 5.3 \\
\hline 96 & Heilongjiang & 2016 & 67 & Silty Clay & 2590 & 133 & 5.1 & 5.3 \\
\hline 97 & Heilongjiang & 2016 & 68 & Silty Clay & 2680 & 133 & 5.2 & 5.7 \\
\hline 98 & Heilongjiang & 2016 & 69 & Silty Clay & 2940 & 135 & 6.2 & 5.3 \\
\hline 99 & Heilongjiang & 2016 & 70 & Silty Clay & 2790 & 144 & 5.7 & 5.6 \\
\hline 100 & Heilongjiang & 2016 & 71 & Silty Clay & 2650 & 139 & 5.4 & 4.9 \\
\hline 101 & Heilongjiang & 2016 & 72 & Silty Clay & 2740 & 139 & 5.4 & 5 \\
\hline 102 & Heilongjiang & 2016 & 73 & Silty Clay & 3100 & 161 & 6.5 & 5.4 \\
\hline 103 & Heilongjiang & 2016 & 74 & Silty Clay & 2600 & 116 & 6.1 & 5.2 \\
\hline 104 & Heilongjiang & 2016 & 75 & Silty Clay & 2710 & 130 & 6 & 5.2 \\
\hline 105 & Gansu & 2012 & 1 & Silt Loam & No Data & 74 & 2.6 & 6.8 \\
\hline 106 & Gansu & 2012 & 2 & Silt Loam & No Data & 70 & 2.2 & 5.6 \\
\hline 107 & Gansu & 2012 & 3 & Silt Loam & No Data & 57 & 2.3 & 6.2 \\
\hline 108 & Gansu & 2012 & 4 & Silt Loam & No Data & 48 & 6.1 & 6.5 \\
\hline
\end{tabular}


Table C2. Soil characteristics of the three study regions. The soil characteristics in Inner Mongolia and Heilongjiang were measured for the potato fields in the region. The soil samples were taken for a depth of $0-25 \mathrm{~cm}$. The soil $\mathrm{N}$ uptake (SNU) in Inner Mongolia and Heilongjiang was estimated by a model, based on total nitrogen, $\mathrm{C} / \mathrm{N}$ ratio, $\mathrm{pH}$ and soil life measured in the field, and it accounts for both mineral $\mathrm{N}$ accumulated in the soil (mineral $\mathrm{N}$, nitrate and ammonium, at the time of soil sample collection) and the minerisable $\mathrm{N}$ from soil organic matter (mineral $\mathrm{N}$ becoming available during the growing season). Soil characteristics for the surveyed fields in Gansu is based on Shang et al., (2012).

\begin{tabular}{|c|c|c|c|c|c|c|c|c|c|c|c|c|}
\hline \multirow{2}{*}{ Regions } & \multicolumn{3}{|c|}{ SOM (\%) } & \multicolumn{3}{|c|}{$\mathrm{pH}$} & \multicolumn{3}{|c|}{ Total $\mathrm{N}\left(\mathrm{mg} \mathrm{kg}^{-1}\right)$} & \multicolumn{3}{|c|}{ SNU per year $\left(\mathrm{kg} \mathrm{ha}^{-1}\right)$} \\
\hline & Ave. & $5^{\text {th }}$ & $95^{\text {th }}$ & Ave. & $5^{\text {th }}$ & $95^{\text {th }}$ & Ave. & $5^{\text {th }}$ & $95^{\text {th }}$ & Ave. & $5^{\text {th }}$ & $95^{\text {th }}$ \\
\hline $\begin{array}{c}\text { Inner } \\
\text { Mongolia }\end{array}$ & 2.0 & 0.8 & 3.3 & 7.2 & 6.0 & 7.9 & 1209 & 542 & 2106 & 74 & 37 & 109 \\
\hline Gansu & 3.3 & 2.2 & 5.6 & 6.3 & 5.7 & 6.8 & - & - & - & 62 & 49 & 73 \\
\hline $\begin{array}{c}\text { Heilong } \\
\text { jiang }\end{array}$ & 5.9 & 2.9 & 8.6 & 5.2 & 4.8 & 5.8 & 2785 & 1443 & 3784 & 136 & 78 & 174 \\
\hline
\end{tabular}

Table C3. The recovery efficiency of $\mathrm{N}$ fertiliser $\left(\mathrm{RE}^{\mathrm{F}}\right)$, internal use efficiency of $\mathrm{N}(\mathrm{IE}), \mathrm{N}$ concentration in tuber dry matter (\%) for the two target yields in the long-term situation (Ya- actual yield of 2018, and Ye- exploitable yield, $85 \%$ of the potential yield) as estimated by the protocol by Ten Berge et al. (2019) (also see Fig. C2). The retention efficiency ( ${ }^{R E T E}$ ) was estimated based on the equilibrium model (Ten Berge et al., 2019) for the two target yields.

\begin{tabular}{|c|c|c|c|c|c|c|}
\hline Regions & $\begin{array}{l}\text { Target } \\
\text { yield }\end{array}$ & $\begin{array}{l}\text { Target } \\
\text { yield }\end{array}$ & IE & $\mathrm{RE}^{\mathrm{F}}$ & $\begin{array}{l}\mathrm{N} \text { concentration } \\
\text { in tubers }\end{array}$ & ${ }^{R E T} E$ \\
\hline & & $\begin{array}{c}\text { ton FM } \\
\text { ha }^{-1}\end{array}$ & $\begin{array}{l}\mathrm{kg} \text { tuber DM kg-1 } \\
\text { crop N uptake }\end{array}$ & $\%$ & $\%$ & $\%$ \\
\hline Inner & $\mathrm{Ya}$ & 42.6 & 62 & 55 & 1.38 & 86 \\
\hline Mongolia & $\mathrm{Ye}$ & 49.0 & 55 & 52 & 1.54 & 88 \\
\hline \multirow{2}{*}{ Gansu } & Ya & 42.5 & 68 & 55 & 1.25 & 86 \\
\hline & Ye & 57.2 & 55 & 52 & 1.54 & 88 \\
\hline \multirow{2}{*}{ Heilongjiang } & Ya & 32.6 & 70 & 55 & 1.21 & 86 \\
\hline & $\mathrm{Ye}$ & 46.2 & 55 & 52 & 1.55 & 88 \\
\hline
\end{tabular}


Appendix D Supplementary material (Chapter 5) 


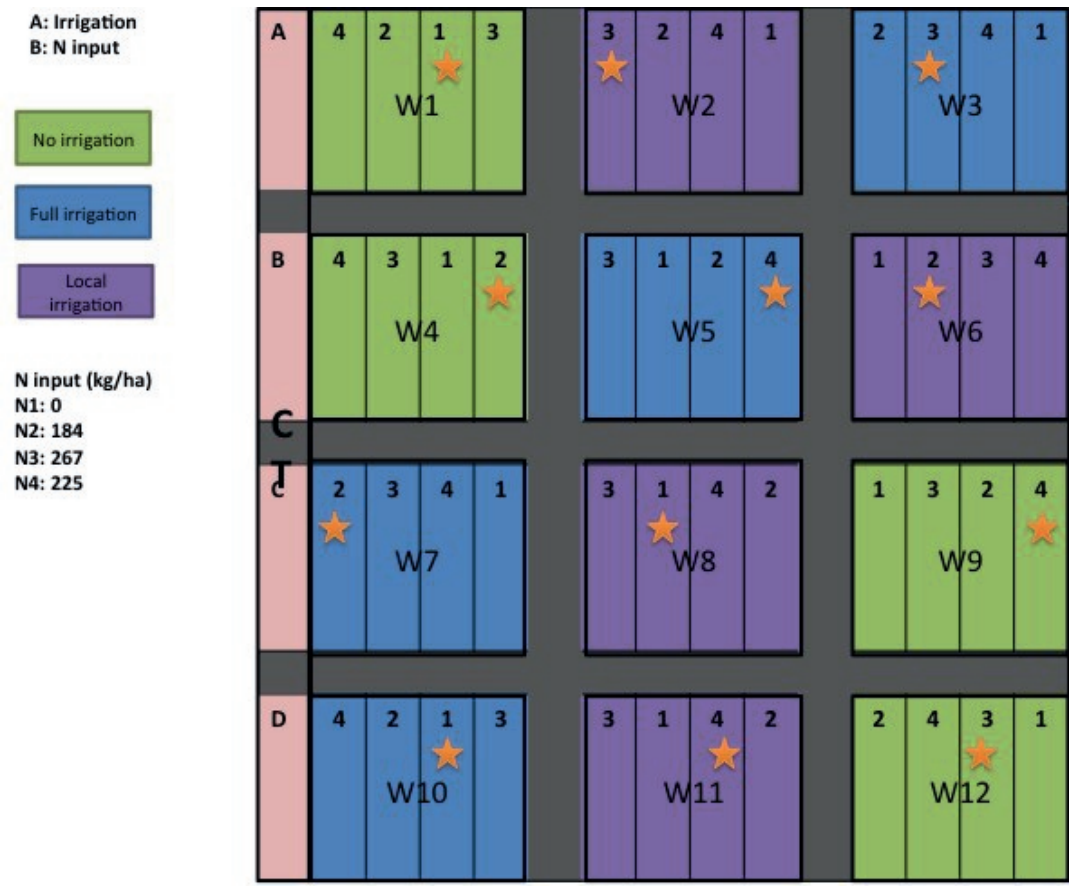

Figure D1. The diagram of the 2017 experimental design. The design was a randomized block split-plot design.

There were four blocks with three main plots (irrigation treatment) per block and four subplots (nitrogen $(\mathrm{N})$ treatment) per main plot. First, the three irrigation treatments were randomly assigned to the three main plots in each block, and the four $\mathrm{N}$ treatments were randomly assigned to each main plot. The yellow star indicates the location of the 12 soil moisture sensors (watermarks).

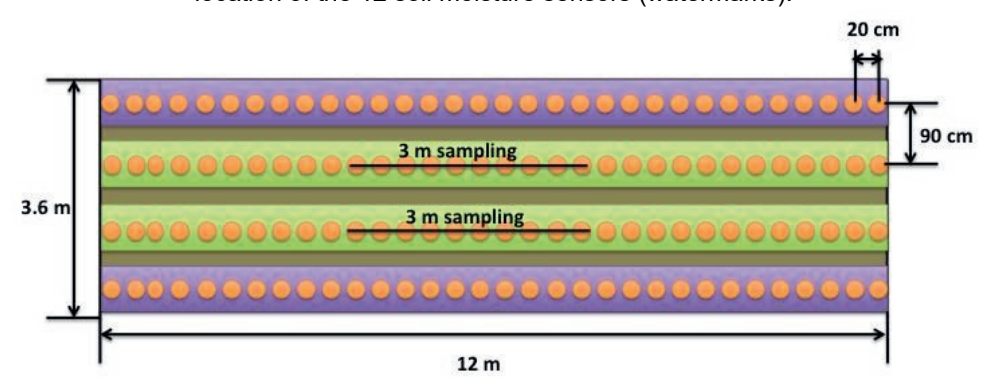

Figure D2. The "3-meter sample" collection for the 2017 field experiment. The figure represents a sub-plot unit, consisting of four ridges with $90 \mathrm{~cm}$ in width and 12 meters in length. The planting distance of the tubers was 20 $\mathrm{cm}$. The "3-meter samples" were collected from the center of the middle two ridges. 


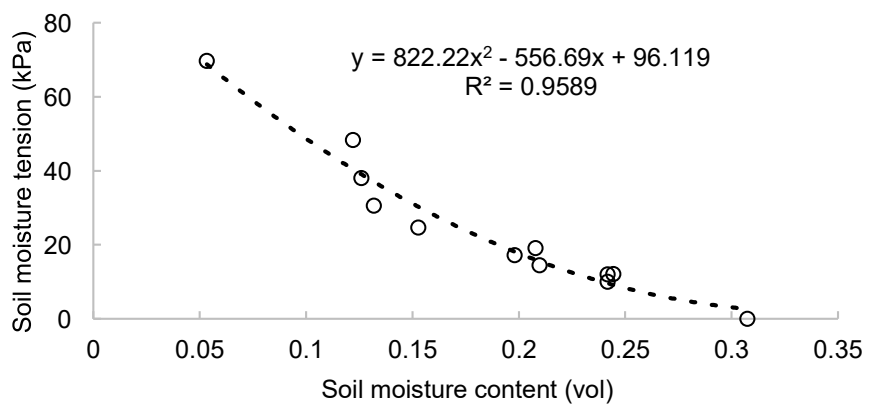

Figure D3. The relationship between soil moisture tension $(\mathrm{kPa})$ measured by the watermark and the corresponding soil moisture content (volume, \%) for the experimental field in 2017. For each soil moisture tension value, the soil sample (near the watermark) was collected using a cutting ring and was dried in the oven to measure the soil moisture content (volume, \%). This relationship was used to guide the irrigation schedule for the full irrigation treatment (i.e., to maintain the soil moisture content above $80 \%$ of field capacity (FC)). The field capacity of the experimental field was $24 \%$ (see Section 5.2 .2 Soil characteristics). In order to keep the soil moisture level above $80 \%$ FC (i.e., 19\%), the soil moisture tension should be below $20 \mathrm{kPa}$ during the entire growing period.

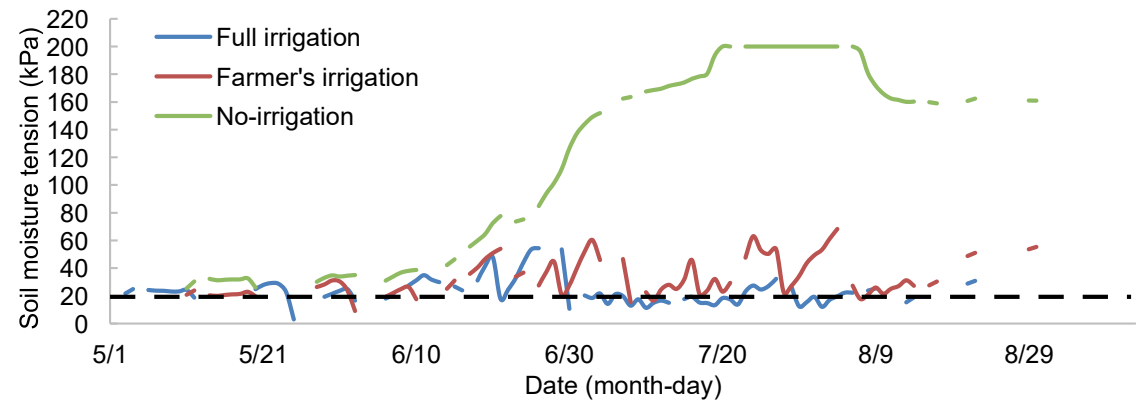

Figure D4. The daily soil moisture tension of the three irrigation treatments monitored by watermarks from planting till harvest in the 2017 field experiment. The average daily soil moisture tension of the four replications was calculated to represent the daily soil moisture tension of each irrigation treatment (i.e., Full irrigation, Farmer's irrigation, No-irrigation). For the full irrigation treatment, the irrigation was applied in order to keep the soil moisture tension below $20 \mathrm{kPa}$ (the soil moisture content was above $80 \%$ of field capacity, see Fig. D3). The dashed line indicates the $20 \mathrm{kPa}$ soil moisture tension. 


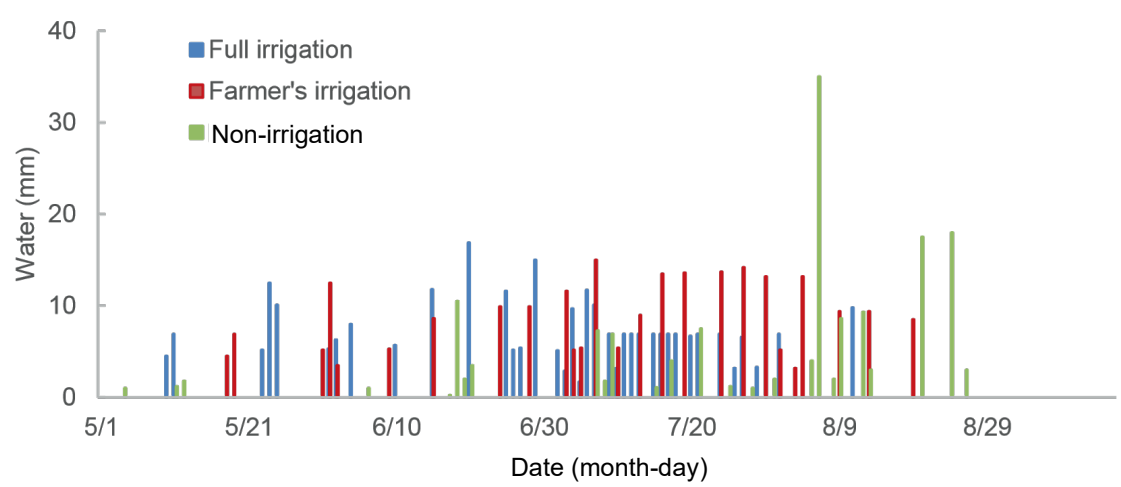

Figure D5. The daily rainfall and daily irrigation amount (for the farmer irrigation and full irrigation treatments) from planting till harvest in the 2017 experiment. For the no-irrigation treatment, the water input was rainfall water. For the farmer irrigation treatment, the irrigation time and amount of each irrigation followed the farmer's practice. For the full irrigation treatment, the irrigation time and amount depended on soil moisture condition. Irrigation was applied when the soil moisture tension (measured by watermark) approached $20 \mathrm{kPa}$. Approximately 7-10 mm water was applied at each irrigation.

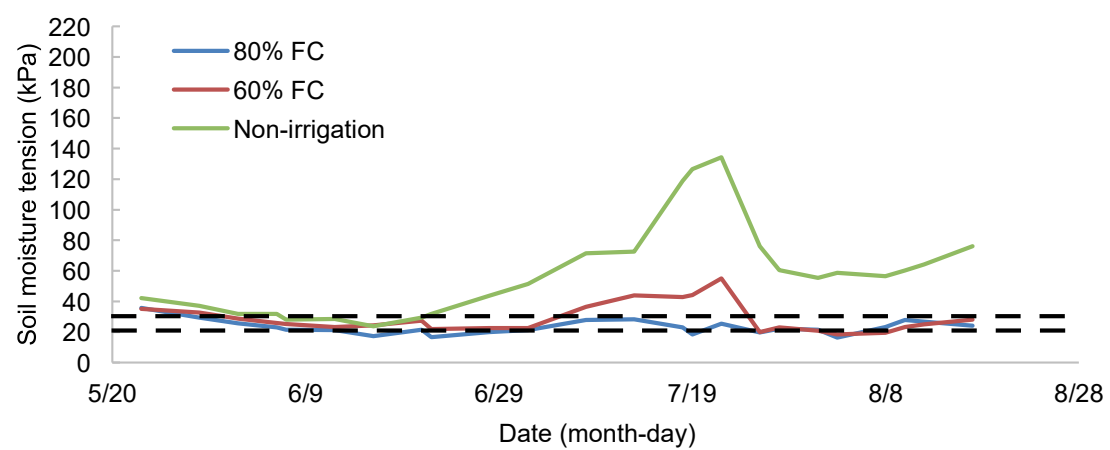

Figure D6. The daily soil moisture tension monitored by watermarks for the three irrigation treatments in the 2018 field experiment. For the two irrigation treatments $(60 \%$ of field capacity, $80 \%$ of field capacity), the irrigation was applied in order to keep the soil moisture tension below $33 \mathrm{kPa}(60 \%$ of field capacity, upper dashed line) and 20 $\mathrm{kPa}(80 \%$ of field capacity, lower dashed line), respectively. 


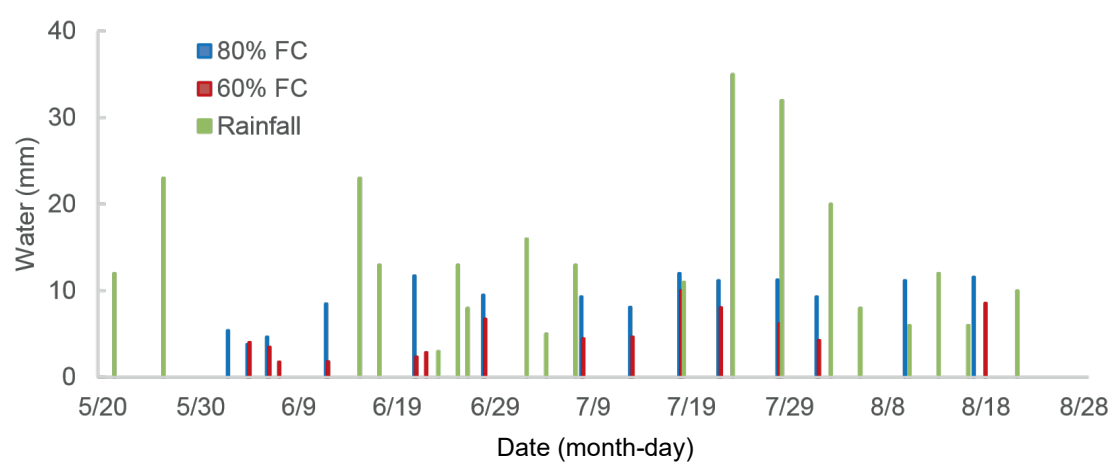

Figure D7. The daily water input from planting until harvesting for the three irrigation treatments of the 2018 experiment. The three irrigation treatments were (1) no-irrigation treatment, the water input was rainfall water; (2) $60 \%$ FC treatments, the soil moisture content was maintained above $60 \%$ of field capacity (FC) and (3) $80 \%$ FC treatments, the irrigation was applied to maintain the soil moisture content above $80 \%$ of FC.

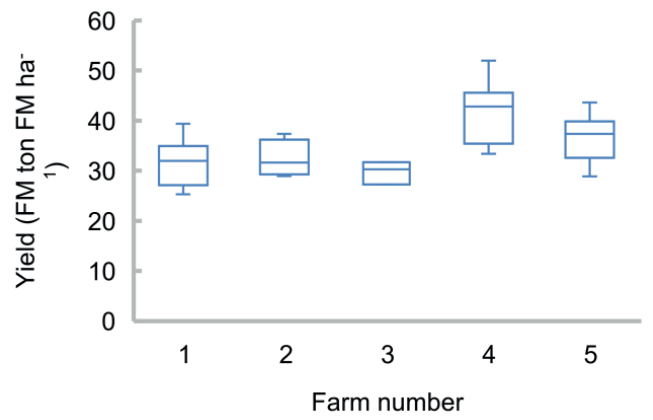

Figure D8. The variation in yield obtained in the different fields in 2017 of the five experimental farms in 2018

(Farm 1, 2, 3, 4 and 5). 


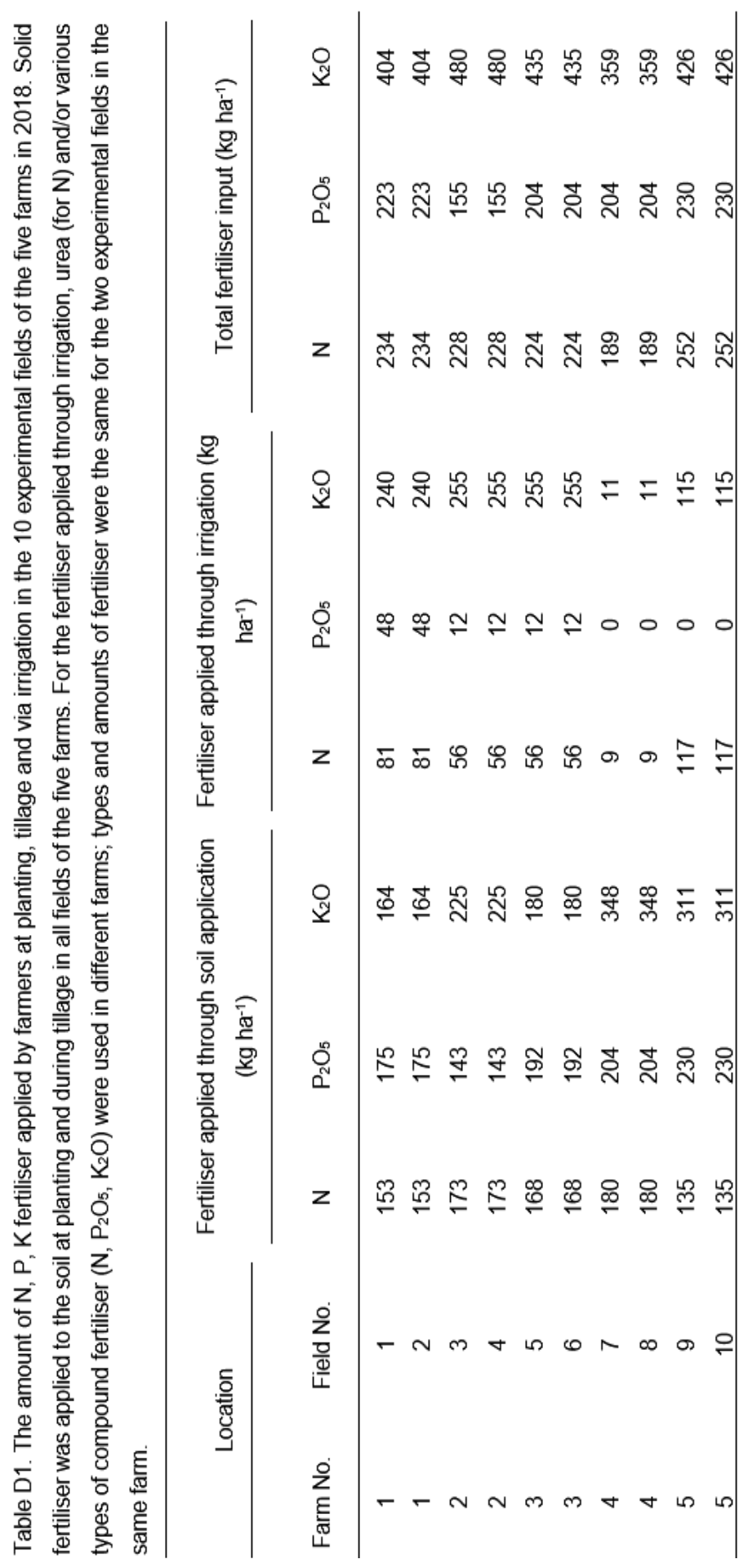




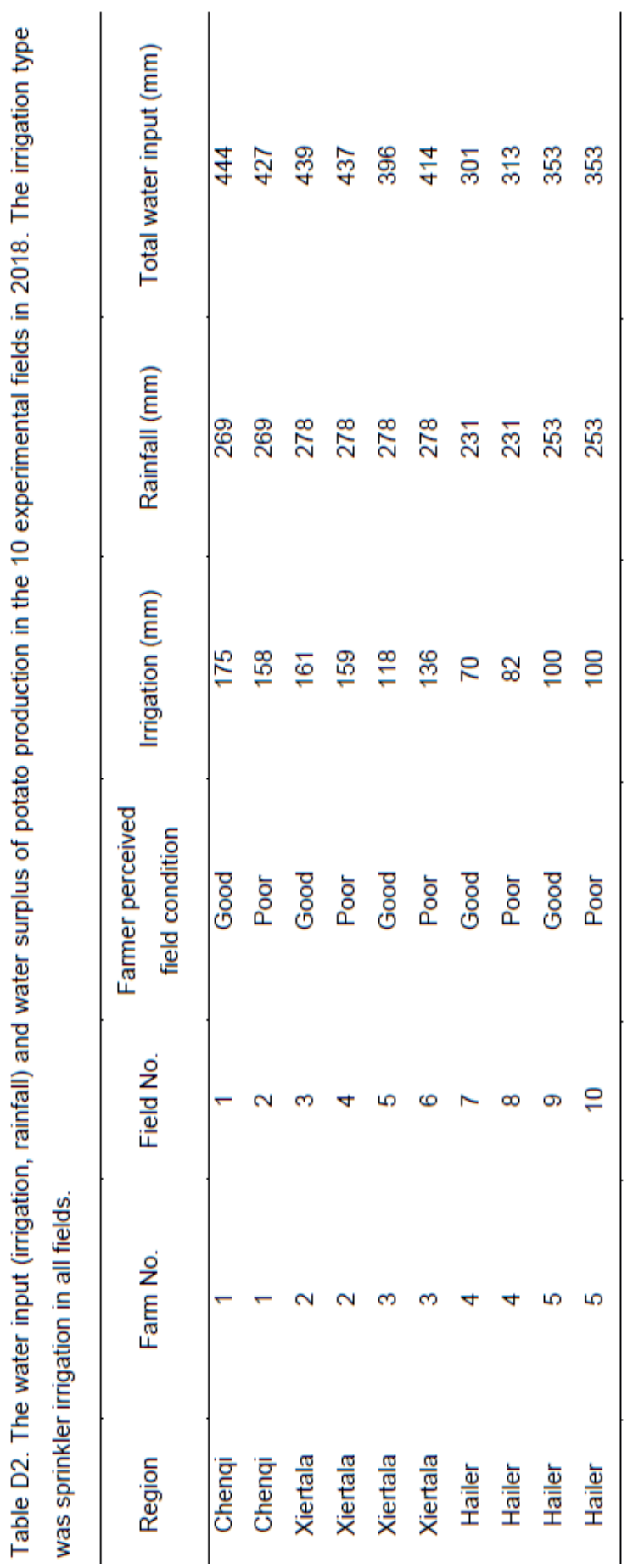




\section{Testing procedure for the Alkali-hydrolysable $\mathbf{N}$}

\section{Principles}

Soil alkali-hydrolysable $\mathrm{N}$ includes inorganic $\mathrm{N}\left(\mathrm{NH}_{4}-\mathrm{N}\right.$ and $\left.\mathrm{NO}_{3}-\mathrm{N}\right)$ and easy hydrolysed organic $\mathrm{N}$ (amino acid, ammonium amide and easy hydrolysed protein). When the soil is treated with lye, the easy hydrolysed organic $\mathrm{N}$ and ammonium $\mathrm{N}$ are converted to ammonia, and the nitrate $\mathrm{N}$ is converted to ammonium by ferrous sulfate. The ammonia is absorbed by boric acid and titrated with a standard acid to estimate the hydrolysable $\mathrm{N}$ in the soil.

\section{Preparing reagents:}

(1) $1 \mathrm{~mol} \mathrm{~L}^{-1} \mathrm{NaOH}$ : Weighting $40 \mathrm{~g}$ of $\mathrm{NaOH}$ and dissolving it in water $(1 \mathrm{~L})$.

(2) Ferrous sulfate powder: Grounding $\mathrm{FeSO}_{4} .7 \mathrm{H}_{2} \mathrm{O}$ (third grade), passing it through a $0.25 \mathrm{~mm}$ aperture sieve, and placing it in a brown glass bottle.

(3) Alkaline glycerol: Adding $40 \mathrm{~g}$ of gum arabic and $50 \mathrm{ml}$ of water in a beaker, and warming it to $70-80^{\circ} \mathrm{C}$, stirring to dissolve, and cooling (1 hour). Adding $20 \mathrm{ml}$ of glycerin and $20 \mathrm{ml}$ of saturated $\mathrm{K}_{2} \mathrm{CO}_{3}$ aqueous solution and stirring. Putting it in a centrifuge to remove foam and insoluble matter. The supernatant is stored in a glass bottle for use.

(4) $0.01 \mathrm{~mol} \mathrm{~L}^{-1} \mathrm{H}_{2} \mathrm{SO}_{4}$ standard solution: Taking $8.35 \mathrm{ml}$ of $\mathrm{H}_{2} \mathrm{SO}_{4}$ (1:9), and dissolving it in water (1 L).

(5) $20 \mathrm{~g} \mathrm{~L}^{-1}$ Boric acid solution.

(6) Indicator solution (bromocresol green and methyl red).

\section{Testing steps:}

1. Weighing 1-2 $\mathrm{g}$ of air-dried soil sample and $0.2 \mathrm{~g}$ of ferrous sulfate powder; uniformly spreading them on the outer chamber of the diffusion dish, and gently rotating the diffusion dish horizontally to flatten the soil sample.

2. Add $2 \mathrm{ml}$ of $20 \mathrm{~g} \mathrm{~L}^{-1}$ boric acid solution in the inner chamber of the diffusion dish, applying alkaline glycerin on the outer edge of the dish, covering the frosted glass, and rotating it so that the edge of the frosted glass and the diffuser is completely adhered. Slowly turning the side of the frosted glass, exposing the diffuser to a slit, quickly adding $10 \mathrm{ml}$ of $1 \mathrm{~mol} \mathrm{~L}^{-1}$ $\mathrm{NaOH}$ solution to the outer chamber of the diffuser, and immediately seal the frosted glass tightly.

3. Rotating the frosted glass horizontally on the bench. Gently rotating the diffuser to mix the solution thoroughly with the soil. Then carefully placing it in a $40^{\circ} \mathrm{C}$ incubator $(24+/-0.5$ hrs). 
4. Measuring the amount of ammonia absorbed by the boronic acid solution in the inner chamber of the diffusion dish using a microtiter tube and a droplet of $0.01 \mathrm{~mol} \mathrm{~L}^{-1}$ of $_{2} \mathrm{SO}_{4}$. The ending point is purple-red.

5. Taking another diffusion dish, do a blank test (no soil).

\section{Calculation}

Soil alkali-hydrolysable $\mathrm{N}$ is estimated according to the following formula:

Soil alkali-hydrolysable $\mathrm{N}\left(\mathrm{mg} \mathrm{kg}^{-1}\right)=\left[\mathrm{C} \times\left(\mathrm{V}-\mathrm{V}_{0}\right) \times 14 / \mathrm{W}\right] \times 1000$

C: concentration of $\mathrm{H}_{2} \mathrm{SO}_{4}$ standard solution $\left(\mathrm{mol} \mathrm{L}^{-1}\right)$

V: the volume of the $\mathrm{H}_{2} \mathrm{SO}_{4}$ standard solution used for sample determination

$V_{0}$ : the volume of the $\mathrm{H}_{2} \mathrm{SO}_{4}$ standard solution used for blank determination

14: molar mass of nitrogen

1000: conversion factor

W: soil sample weight (g) 



\section{Summary}

China is challenged to sustain food security for an increasing population and targets a large degree of self-sufficiency. The challenge of producing more is aggravated if at the same time other sustainability objectives must be maintained or enhanced. The production of major cereals (rice, wheat, and maize) was boosted by intensification of resource use, while the environmental consequences in the various aquatic and terrestrial ecosystems were tremendous. Meanwhile, agricultural production in China is increasingly restricted by the limited resources (i.e., land and water). Although the government claims to protect the socalled "red-line" of cultivated land (the minimum area of arable land) for the three major staples, China's arable land has been shrinking due to the continued urbanization. Water scarcity has long been one of the most important constraints to farming, particularly in the north. Northern China contributes to ca. $50 \%$ of crop production with only $18 \%$ of the country's water resources, while irrigation takes as much as $76 \%$ of the regional water supply.

Potato is a nutritious food that is rich in carbohydrates, protein, and various nutrients that human beings require. China is the largest potato grower in the world. For the Chinese, potato is an important crop for food self-sufficiency, and a critical cash crop for farmers to gain income. Potato is grown in a wide range of agroecological conditions by many low-income households in mountainous areas in northwest and southwest China. The scope for further increasing yield for the three cereal staples is projected to be limited, and the potato crop was promoted by the Chinese government to complement the three cereals in both production and consumption. However, both yield and quality of current potato cultivation in China is much lower than optimum. Future intensification in the potato sector should rely on sustainable practices that increase production while preserve natural resources and the environment.

The main objective of the present study was to explore the theoretical possibilities and demonstrate practical pathways towards a sustainable intensification of potato production in China that meets agronomic, economic, and environmental objectives simultaneously. The objective was approached based on: a comprehensive assessment of the biophysical potential of the potato crop and the scope for improving yield under both irrigated and rainfed conditions at national and sub-national levels (Chapter 2); a thorough understanding of the relationships between yield, quality and revenue of potato production (Chapter 3); an in-depth analysis of the current sustainability performance of potato farms and the feasible targets with respect to yield, resource use efficiencies and environmental impacts (Chapter 4); and finally, a deep insight into the options and challenges to adapt to more sustainable practices based on onfarm field experiments (Chapter 5). Chapters 3, 4 and 5 were focusing on large-scale commercial potato farms in northern China that commonly apply irrigation.

In Chapter 2, the potential yield (Yp, under irrigated conditions) and water-limited potential yield ( $\mathrm{Yw}$, under rainfed conditions) of the potato crop was estimated at various spatial scales (weather stations, climate zones, regional, and national levels) for the period 2005-2016 following the protocol of the Global Yield Gap Atlas (http://www.yieldgap.org). The yield gaps, 
i.e., the difference between $Y p$ (or $Y w$ ) and the actual yield obtained by farmers (Ya), were identified to understand the scope for improving yield across the country with current irrigation areas (Yg-p) and the current precipitation levels (Yg-w).

We also quantified the water input gaps and water productivity gaps to reveal the spatial variability concerning water supply and water demand to realize Yp rather than Yw. The capacity of potatoes to meet the future food demand, relative to the three cereal staples (rice, maize, and wheat), was assessed based on the energy gap (i.e., the additional calories provided by potatoes by closing the yield gaps to $80 \%$ of the Yp under irrigated conditions or Yw under rainfed conditions). The results suggest that, in general, there is a large scope for improving potato yield across the country under both irrigated and rainfed conditions (i.e., yield gap is $66 \%$ and $61 \%$ for irrigated and rainfed potatoes, respectively). Under rainfed conditions, the scope for enhancing yield at the current precipitation level is large, particularly for Heilongjiang and Qinghai in the north and Guizhou in the southwest. Due to its relatively large yield gap, potato has a higher potential to contribute to future food self-sufficiency in China than the major cereals. By closing the yield gap, the potato crop could contribute to an additional $1.110^{14}$ and $0.910^{14} \mathrm{kcal}$, respectively, under irrigated and rainded conditions, which is higher than that of the major cereals (between $0.210^{14}$ and $1.010^{14} \mathrm{kcal}$ under irrigated conditions; and $0.510^{14} \mathrm{kcal}$ under rainfed conditions).

In addition to yield, the quality aspects of potato tubers must be considered, as both are relevant for the potato industry, and influence revenue (i.e., the gross income growers receive by selling the products, without accounting for the costs). Therefore, in Chapter $\mathbf{3}$ a framework was proposed to assess the production performance in relation to yield, quality, and revenue of potato production. The framework consists of seven steps from identifying the important quality traits to quantifying quality gaps and yield gaps and their influence on revenue. The framework was applied in a case study for French Fries potato production in Inner Mongolia in northern China based on data collected at field level for three years (2015-2017). The results indicated that potato quality influenced the acceptability of the product (i.e., the product is qualified to be used for French Fries processing). Ca. 21-35\% (depending on years) of the surveyed fields received no price due to the poor quality performance (i.e., low tuber dry matter percentage and high small tuber weight percentage). It was concluded that enhancing yield up to the current maximum level obtained by farmers ( 55 ton fresh matter ha-1) was aligned with improvement in quality and revenue. A significant rise in revenue (revenue gap between the highest revenue obtained by farmers and average actual revenue was $43 \%$ ) can be achieved by enhancing the yield (yield gap between best performing farmers' yield and actual yield was $26 \%$ ) and improving quality at the same time.

In Chapter 4, the current performance of potato production with regard to yield, resource use efficiencies (nitrogen and water), and environmental impact (nitrogen and water surplus) was assessed using fieldlevel survey data from three major potato production regions in northern China (Inner Mongolia, Gansu and Heilongjiang). The scope for improvement was assessed based on a lower and upper target for yield (respectively, financial break-even point and $85 \%$ of the potential yield), water productivity (upper target is $85 \%$ of the potential water productivity), 
nitrogen use efficiency (between $50 \%$ and $90 \%$ ) and nitrogen surplus (upper threshold is 80 $\left.\mathrm{kg} \mathrm{ha}^{-1}\right)$. We also evaluated the feasible values of nitrogen use efficiency and nitrogen surplus based on currently available technologies in the long-term situations. The results showed that regions that achieved relatively higher yield tended to threaten the environment more in relation to nitrogen losses, implying a trade-off between crop production and environmental risks. The nitrogen use efficiency was moderate, and nitrogen surplus and water surplus was high, which was mainly related to large resource inputs. In the short-term, nitrogen fertiliser input can be largely reduced by allowing soil nitrogen mining, to improve the nitrogen use efficiency and reduce nitrogen surplus. Water productivity can be increased from 23-35 to 29$44 \mathrm{~kg}$ dry matter ha-1 $\mathrm{mm}^{-1}$, and water surplus can be reduced with more efficient irrigation systems. Results suggest that in the long-term, with more efficient management practice, it is possible to improve yield (from 33-43 to $46-57$ ton fresh matter ha ${ }^{-1}$ ), nitrogen use efficiency (from $47-68 \%$ to $84 \%$ ) and reduce nitrogen surplus (from $50-156$ to $16-34 \mathrm{~kg} \mathrm{ha}^{-1}$ ) at the same time.

Results from Chapter 4 were illustrative for the need for site-specific recommendations accounting for the large variability in biophysical conditions (e.g., soil nitrogen supply). Moreover, a deep understanding of the local socio-economic barriers is key to facilitate a widespread adaptation to the sustainable management practices. Therefore, in Chapter $\mathbf{5}$, on-farm field experiments were conducted on large-scale commercial farms in Inner Mongolia in two years (2017-2018) to explore the feasible options for more sustainable management practices and demonstrate the feasibility to farmers. We tested the effect of various nitrogen fertiliser inputs and water inputs (drip irrigation) on potato yield, quality, resource use efficiencies, and environmental impacts. We also conducted farmers' interviews to understand the opportunities and challenges of implementing more sustainable management practices from the perspectives of farmers. The results indicated that reducing nitrogen fertiliser input from the current rates (189-252 $\left.\mathrm{kg} \mathrm{ha}^{-1}\right)$ to lower levels (109-181 $\left.\mathrm{kg} \mathrm{ha}^{-1}\right)$ did not result in lower yield nor quality. Yet, a further reduction in nitrogen fertiliser rates (9-117 kg ha-1) should be considered with caution taking into account different growing conditions of fields. Farmers were willing to reduce nitrogen fertiliser input by $10-20 \%$. However, this idea seemed not to appeal to farmers due to the limited economic advantage as fertilisers are relatively cheap. Drip irrigation strongly increased yield and quality in both years, contributed to the efficient use of nitrogen and water resources, and moderated environmental risks. On the other hand, the wide-spread adaptation to drip irrigation was hindered by high cost and labor constraints.

In conclusion, the thesis showed there is a large scope to enhance potato yield across the country. The most important quality constraints for French Fries production in northern China were the low tuber dry matter percentage and high small tuber weight percentage. The environmental cost generated by large-scale potato farming was high, demonstrating the urgent need for mitigating management options. Yet, yield, resource use efficiencies and environmental impacts could be balanced with good agronomy including efficient nutrient and water management, and avoidance of weeds, pests and diseases. Reducing nitrogen fertiliser input while enhancing irrigation management with more efficient irrigation practice (drip irrigation) proved to be a promising solution for surveyed farms in Inner Mongolia. High cost 
and labor limitation, however, prevented farmers from adapting to more sustainable management practices. Policy interventions are needed to underpin the sustainable intensification on a broad scale, and the findings of the study contribute to identifying the target values and practical pathways for this purpose. 


\section{Samenvatting}

China wordt uitgedaagd om de voedselzekerheid voor een groeiende bevolking in stand te houden en het land streeft naar een grote mate van zelfvoorziening. De uitdaging om meer te produceren wordt groter als tegelijkertijd andere duurzaamheidsdoelstellingen moeten worden gehandhaafd of versterkt. De productie van belangrijke granen (rijst, tarwe en maïs) is gestimuleerd door intensivering van het gebruik van hulpbronnen, terwijl de gevolgen voor het milieu in de verschillende aquatische en terrestrische ecosystemen enorm waren. Ondertussen wordt de landbouwproductie in China in toenemende mate beperkt door de beperkte middelen (d.w.z. land en water). Hoewel de regering beweert de zogenaamde "rode lijn" van landbouwgrond (het minimumareaal landbouwareaal) voor de drie belangrijkste voedselgewassen te beschermen, is het landbouwareaal in China door de voortdurende verstedelijking aan het krimpen. Waterschaarste is sinds lange tijd een van de belangrijkste beperkingen voor de landbouw, vooral in het noorden. Noord-China draagt bij aan ca. 50\% van de gewasproductie met slechts $18 \%$ van de watervoorraden van het land, terwijl irrigatie maar liefst $76 \%$ van de regionale watervoorziening in beslag neemt.

Aardappel is een voedzaam gewas dat rijk is aan koolhydraten, eiwitten en verschillende voedingsstoffen die mensen nodig hebben. China is de grootste aardappelteler ter wereld. Voor de Chinezen is aardappel een belangrijk gewas voor voedselvoorziening en een cruciaal gewas voor boeren om inkomen te verwerven. Aardappel wordt in veel agro-ecologische omstandigheden geteeld door veel huishoudens met een laag inkomen in bergachtige gebieden in het noordwesten en zuidwesten van China. De mogelijkheden voor een verdere verhoging van de opbrengst voor de drie basisgraanproducten zullen naar verwachting beperkt zijn. Daarom is de aardappeloogst door de Chinese regering gepromoot als aanvulling op de drie graanproducten, zowel wat betreft productie als consumptie. De opbrengst en kwaliteit van de huidige aardappelteelt in China is echter veel lager dan optimaal. Toekomstige intensivering in de aardappelsector moet steunen op duurzame praktijken die de productie verhogen met behoud van natuurlijke hulpbronnen en het milieu.

Het hoofddoel van deze studie was om de theoretische mogelijkheden te onderzoeken en praktische trajecten aan te tonen voor een duurzame intensivering van de aardappelproductie in China, die tegelijkertijd voldoet aan de agronomische, economische en milieudoelstellingen. De doelstelling werd benaderd op basis van: een alomvattende beoordeling van het biofysische potentieel van het aardappelgewas en de mogelijkheden om de opbrengst onder zowel geïrrigeerde als regengevoede omstandigheden op nationaal en subnationaal niveau te verbeteren (Hoofdstuk 2); een grondig begrip van de relaties tussen opbrengst, kwaliteit en opbrengst van de aardappelproductie (Hoofdstuk 3); een diepgaande analyse van de huidige duurzaamheidsprestaties van aardappelboerderijen en de haalbare doelstellingen met betrekking tot opbrengst, efficiënt gebruik van hulpbronnen en milieueffecten (Hoofdstuk 4); en tot slot een diep inzicht in de opties en uitdagingen om aan te passen aan duurzamere praktijken op basis van veldproeven op boerderijen (Hoofdstuk 5). De hoofdstukken 3, 4 en 
5 waren gericht op grootschalige commerciële aardappelboerderijen in Noord-China die gewoonlijk irrigatie toepassen.

In Hoofdstuk 2 werd de potentiële opbrengst (Yp, onder geïrrigeerde omstandigheden) en de waterbeperkte potentiële opbrengst ( $\mathrm{Yw}$, onder regengevoede omstandigheden) van het aardappelgewas geschat op verschillende ruimtelijke schalen (weerstations, klimaatzones, regionaal en nationaal niveau) voor de periode 2005-2016 volgens het protocol van de Global Yield Gap Atlas (http://www.yieldgap.org). De verschillen in opbrengst, dat wil zeggen het verschil tussen $Y p$ (of $Y w$ ) en de werkelijke opbrengst van boeren ( $Y a$ ), werden geïdentificeerd om de mogelijkheden te begrijpen om de opbrengst in het hele land te verbeteren met de huidige irrigatiegebieden (Yg-p) en de huidige neerslag niveaus (Yg-w).

We hebben ook de verschillen gekwantificeerd in de watertoevoer en waterproductiviteit om $Y p$ te realiseren in plaats van $Y w$, om de ruimtelijke variabiliteit met betrekking tot watervoorziening en watervraag te beoordelen. Het vermogen van aardappelen om aan de toekomstige voedselbehoefte te voldoen, in verhouding tot de drie belangrijke granen (rijst, maïs en tarwe), is beoordeeld op basis van de het verschil in geleverde energie (calorieën) tussen de werkelijke opbrengst en $80 \%$ van de potentiële opbrengst (d.w.z. Yp onder geïrrigeerde omstandigheden of $Y w$ onder regengevoede omstandigheden). De resultaten suggereren dat er in het algemeen grote mogelijkheden zijn om de aardappelopbrengst in het hele land te verbeteren onder zowel geïrrigeerde als regengevoede omstandigheden (d.w.z. de opbrengstkloof is respectievelijk $66 \%$ en $61 \%$ voor geïrrigeerde en regengevoede aardappelen). In gebieden die afhankelijk zijn van regenwater is de ruimte voor het verhogen van de opbrengst bij het huidige neerslagniveau groot, met name voor Heilongjiang en Qinghai in het noorden en Guizhou in het zuidwesten. Vanwege het relatief grote verschil in potentiële en werkelijke opbrengsten heeft aardappel een groter potentieel om bij te dragen aan de toekomstige voedselvoorziening in China dan de belangrijkste granen. Door de opbrengstkloof te dichten, zou het aardappelgewas kunnen bijdragen tot een extra $1.110^{14}$ en $0.910^{14} \mathrm{kcal}$, respectievelijk onder geïrrigeerde en rauwe omstandigheden, wat hoger is dan die van de belangrijkste granen (tussen $0.210^{14}$ en $1.010^{14} \mathrm{kcal}$ onder geïrrigeerde omstandigheden en $0.510^{14} \mathrm{kcal}$ onder regengevoede omstandigheden).

Naast de opbrengst moeten ook de kwaliteitsaspecten van aardappelknollen in overweging worden genomen, aangezien beide relevant zijn voor de aardappelindustrie en de inkomsten beïnvloeden (d.w.z. het bruto-inkomen dat telers ontvangen door de producten te verkopen zonder de kosten te in ogenschouw te nemen). Daarom is in Hoofdstuk 3 een raamwerk voorgesteld om de productieprestaties te beoordelen in relatie tot opbrengst, kwaliteit en opbrengst van aardappelproductie. Het raamwerk bestaat uit zeven stappen, van het identificeren van de belangrijke kwaliteitskenmerken tot het kwantificeren van kwaliteitslacunes en rendementslacunes en hun invloed op de inkomsten. Het raamwerk werd toegepast in een gevalstudie voor de fritesaardappelproductie in Binnen-Mongolië in NoordChina op basis van gegevens die gedurende drie jaar (2015-2017) op veldniveau zijn verzameld. De resultaten gaven aan dat de aardappelkwaliteit de aanvaardbaarheid van het product beïnvloedde (d.w.z. het product is gekwalificeerd om te worden gebruikt voor 
fritesverwerking). Ca. 21-35\% (afhankelijk van jaar) van de onderzochte velden ontving geen prijs vanwege de slechte kwaliteitsprestaties (d.w.z. een laag percentage droge stof in de knol en een hoog percentage kleine knollen). Er werd geconcludeerd dat het verhogen van de opbrengst tot het huidige maximale niveau dat door boeren werd behaald ( 55 ton verse stof $\mathrm{ha}^{-1}$ ) in overeenstemming was met verbetering in kwaliteit en inkomsten. Een aanzienlijke stijging van de inkomsten (inkomstenkloof tussen de hoogste door boeren behaalde inkomsten en gemiddelde werkelijke inkomsten was 43\%) kan worden bereikt door de opbrengst te vergroten (de opbrengstkloof tussen de best presterende landbouwersopbrengst en de werkelijke opbrengst was $26 \%$ ) en tegelijkertijd de kwaliteit te verbeteren.

In Hoofdstuk 4 werden de huidige prestaties van de aardappelproductie met betrekking tot opbrengst, efficiënt gebruik van hulpbronnen (stikstof en water) en milieu-impact (stikstof en wateroverschot) beoordeeld aan de hand van veldgegevens uit drie belangrijke aardappelproductieregio's in Noord-China (Binnen-Mongolië, Gansu en Heilongjiang). De ruimte voor verbetering werd beoordeeld op basis van een laag en hoog streefcijfer voor opbrengst (respectievelijk financieel 'break-even' punt en $85 \%$ van het potentiële rendement), waterproductiviteit (bovenste streefcijfer is $85 \%$ van de potentiële waterproductiviteit), stikstofgebruiksefficiëntie (tussen 50\% en $90 \%$ ) en stikstofoverschot (bovenste drempel is 80 $\left.\mathrm{kg} \mathrm{ha}^{-1}\right)$. We hebben ook de haalbare waarden van de efficiëntie van het stikstofgebruik en het stikstofoverschot geëvalueerd op basis van de momenteel beschikbare technologieën in de lange termijn situaties. De resultaten toonden aan dat regio's met een relatief hogere opbrengst het milieu meer bedreigden wat betreft stikstofverliezen, wat een 'trade-off' tussen gewasproductie en milieurisico's impliceerde. De efficiëntie van het stikstofgebruik was matig en het stikstof- en wateroverschot was hoog, wat voornamelijk verband hield met de hoge toegepaste hoeveelheden van deze hulpbronnen. Op de korte termijn kan de stikstofbemesting grotendeels worden verminderd door gebruik te maken van de opgehoopte stikstof uit de bodem, zodat de efficiëntie van stikstofgebruik verbetert en het stikstofoverschot vermindert. De waterproductiviteit kan worden verhoogd van 23-35 tot 29-44 kg droge stof ha${ }^{1} \mathrm{~mm}^{-1}$ en het wateroverschot kan worden verminderd met efficiëntere irrigatiesystemen. De resultaten suggereren dat het op de lange termijn, met een efficiëntere managementpraktijk, mogelijk is om tegelijkertijd de opbrengst (van 33-43 tot 46-57 ton verse stof ha ${ }^{-1}$ ) en de efficiëntie van stikstofgebruik (van $47-68 \%$ tot $84 \%$ ) te verbeteren en het stikstofoverschot (van 50-156 tot 16-34 $\mathrm{kg} \mathrm{ha}^{-1}$ ) te verminderen.

De resultaten van Hoofdstuk 4 waren illustratief voor de behoefte aan locatiespecifieke aanbevelingen die rekening houden met de grote variabiliteit in biofysische omstandigheden (bijv. stikstofvoorziening in de bodem). Bovendien is een diepgaand begrip van de lokale sociaal-economische belemmeringen essentieel om een aanpassing aan de praktijk van duurzaam beheer op grote schaal te vergemakkelijken. Daarom zijn voor Hoofdstuk $\mathbf{5}$ in twee jaar tijd (2017-2018) veldproeven uitgevoerd op grootschalige commerciële boerderijen in Binnen-Mongolië om de haalbare opties voor duurzamere managementpraktijken te onderzoeken en de haalbaarheid voor boeren aan te tonen. We hebben het effect van verschillende inputs van stikstofmeststoffen en water (druppelirrigatie) getest op aardappelopbrengst, kwaliteit, efficiënt gebruik van hulpbronnen en milieueffecten. We hebben 
ook interviews gehouden met boeren om de kansen en uitdagingen van het implementeren van duurzamere managementpraktijken vanuit het perspectief van boeren te begrijpen. De resultaten gaven aan dat het verminderen van de toepassing van stikstofmeststoffen van de huidige hoeveelheden (189-252 kg ha ${ }^{-1}$ ) naar lagere niveaus (109-181 kg ha-1) niet resulteerde in een lagere opbrengst of kwaliteit. Toch moet voorzichtigheid worden betracht bij een verdere verlaging van het gehalte aan stikstofmeststoffen (9-117 kg ha-1), rekening houdend met de verschillende groeiomstandigheden van velden. Boeren waren bereid de input van stikstofmeststoffen met $10-20 \%$ te verminderen. Dit idee leek boeren echter niet aan te spreken vanwege het beperkte economische voordeel, omdat meststoffen relatief goedkoop zijn. Druppelirrigatie verhoogde de opbrengst en kwaliteit in beide jaren sterk, droeg bij tot een efficiënt gebruik van stikstof- en waterbronnen en matigde milieurisico's. Aan de andere kant werd de wijdverbreide toepassing van druppelirrigatie belemmerd door hoge kosten en arbeidsbeperkingen.

Concluderend toonde het proefschrift aan dat er een groot potentieel is om de aardappelopbrengst in China te verbeteren. De belangrijkste kwaliteitsbeperkingen voor de productie van frites in Noord-China waren het lage knolgehalte en het hoge kleine knolgewicht. De milieukosten van de grootschalige aardappelteelt waren hoog, wat aantoont dat het dringend noodzakelijk is de teelt aan te passen. Opbrengst, efficiënt gebruik van hulpbronnen en milieueffecten kunnen in evenwicht kunnen worden gebracht met een goede agronomie, waaronder efficiënt nutriënten- en waterbeheer en het vermijden van onkruid, ongedierte en ziekten. Het verminderen van de invoer van stikstofmeststoffen en het verbeteren van het irrigatiemanagement met efficiëntere irrigatiepraktijken (druppelirrigatie) bleek een veelbelovende oplossing voor onderzochte boerderijen in Binnen-Mongolië. Hoge kosten en arbeidsbeperking beletten boeren echter om zich aan te passen aan duurzamere managementpraktijken. Beleidsinterventies zijn nodig om de duurzame intensivering op brede schaal te ondersteunen, en de bevindingen van het onderzoek dragen bij aan het identificeren van de streefwaarden en praktische trajecten hiervoor. 


\section{Acknowledgements}

It has been four and a half years since I started my PhD on January 1, 2016. At the end of this long journey, I have much to say to people who have guided and supported me during this journey.

I want to first express my sincere gratitude to my supervisory team, Martin and Pytrik. To my promotor, Martin, thank you for your trust in me and for giving me this opportunity to pursue this $\mathrm{PhD}$ research. You have been a tremendous support to me from the beginning to the end. I still remember the day I came to you and expressed my intention to pursue a $\mathrm{PhD}$ targeting yield gap assessment in China. We talked about the three cereals, but finally, we chose potatoes, which is obviously your favorite crop! I once expressed my insecurity about the gono-go evaluation. You gave me comfort by showing great believe in me. You have been very supportive, patient, and understanding. I appreciate your timely advice and help whenever I encountered difficulties (sometimes in your camping days, I hope I did not spoil your holiday!). I benefited considerably from your expertise, your great dedication and commitment and rigorous attitude towards scientific research. You always came with constructive comments, on the scientific soundness of the research methods, or the use of proper language in writing the results, and these supported me to grow in science!

My sincere thanks goes to my co-promotor, Pytrik. Whenever I couldn't move on with my research, you had the magic to bring me out of trouble. Instead of giving me the answer directly, you encouraged me and provided me freedom to discover new ideas. I benefited from your broad scientific network. When an interdisciplinary question came up, you encouraged me to contact other experts and their expertise strengthened my research. Thank you for being my mentor and friend. I enjoyed every "lunch walk" with you (although I never really eat my lunch while walking :)). I liked chatting with you in that informal way. We talked about working progress and also shared life experiences. I said that I admire you as the mother of two kids. And now as a new mother, I can better understand how challenging it is to balance work, family and health. You are a good example for me! Your optimistic spirit towards life inspires me and encourages me to move forward courageously! Thank you!

I am grateful for the support of the other members of the research team - the potato experts! To Corne and Anton, I sincerely appreciate your assistance in coordinating the field work with the local partners in China. Corne, thank you for inviting me to the Sino-Dutch potato conferences, which brought many inspiring ideas to my work. To Geert, Huub, Yutong, and Thomas, I enjoyed the trips with you to the conferences and to visit the potato farms in Heilongjiang, Hebei, and Yunnan in China. To Annette, thank you for sharing your opinions and ideas on my research work. I enjoyed our discussions about the potato crop, and I'm grateful that you provided me with critical comments on my work. Thanks to the colleagues of 黑龙江省农科院 (HAAS) for your hospitality. It was nice to meet many "potato people" at HAAS! My special thanks to Joop and Iwan for the inspiring discussions on the crop growth model; to Hein, for the constructive comments and advice on Chapter 4; to Oene and Wim for the 
discussion on applying the EU Expert Panel framework to potato production in China. I also thank Evert Jan Bakker for providing suggestions on the set up of field experiments with statistical eyes.

It was a big adventure travelling across three provinces in northern China, visiting hundreds of potato fields and asking for precious time from farmers during the busy growing season! My warmest thanks go to the local partners in China. Thank you for your hospitality and for coordinating and assisting the field work. I would like to thank the farmers for their participation in the field work and farmer interviews. Thanks for your patience in answering the "one hundred thousand why" from me. Thank you for pulling me out from the mud, and guiding me the way when I was lost in the village. My special thanks to 小寒 for doing all the hard work together in the potato field in Inner Mongolia. We had to "fight" to get our experimental plot irrigated. There were a few weeks that we worked in the field from 7.30 a.m. till 10 p.m. and at the end of the day we had nothing more than 泡面 for dinner. I'm grateful having you by my side to deal with all these challenges!

I wish to express my deepest gratitude to my fellow $\mathrm{PhD}$ students and staff at the Plant Production Systems group: Linda, Karen, Alex-Jan, and Charlotte, thank you for your administrative advice and support; Bert, thank you for your arrangement on desks so that they are used more efficiently (and for taking care of the plants at office); Renske, Esther R, Esther M, Lotte W, Marieke, Wytze, Jiska, Michael, Jannike, Joao, Hanna, Lenny, Juliana, Eva T, Eva $\mathrm{H}$, Wim, Samuel, Comfort, Ashenafi, Arouna, Elias, Violet, Dennis, Joy, Workneh, Anne, Travis, Linda V, Gerrie, Maja, Bert R, Bert J, Marcel, Mink Z, Andy, Katrien, Tom, Joost, Marloes, Antoine, Harmen, Paul, Ken, Danaë, Jens, Aart, Siriluk, Banchayehu, Wilson, Urcil, Tamara, Faustina, Rika, Deo, Danny, Rosa, Bastiaen, Inge. Thank you for listening, sharing frustrations and fun, and for your sincere consideration for me and my family, especially during the pandemic period. Special thanks to the PV (Renske, Luuk, Peter, Jochem, Eva) for organizing many exciting activities and Christmas events. Special thanks to Joost, Bastiaen, and Eva T for their support in statistical analysis and R programming. Special thanks to Bert Janssen, who inspired me that the pathway towards excellence is not about intelligence, but about curiosity, passion, and dedication. Special thanks to Ken, for providing advice on soil measurement and data collection, and for leading a great group!

Thank you, my friends, for making my life in the Netherlands rich and colourful. Thanks to my roommates in Asserpark (corridor 16B), Sam, 夏琳, 乐乐, 陈璇, Matthews, Sandra, Diana, Elackiya, Olim, Callum. Now we are apart around the world striving to achieve our dreams. I hope we meet up somewhere in the future. I enjoyed the corridor dinner every weekend, when we shared food, culture, stories and fun times. Thanks to my neighbours in Rijnveste, 玉柱 and 梦帆 for the Chinese New Year's Eves we spent together. It was enjoyable to watch the Spring Festival Gala and eating New Year's Eve dinner together. To my friends, 昊哥, 兰兰, 晓 芗姐, 大月, 崔阳, 刘彬, 晓菲, 海涛, 龄桐, Jan, Halder, Yutaka, 张杰, 静宜, 旭哥, 小寒, 梦婷 (小 端端), 佳慧, 万哥, Nancy; 樱桃王子和公主们: 丹妮, 高厦, 刘玉, 钱蓉, 冯浩, William, 梦茹, 许斌, Lesly, 李哥, 范姐, thank you for sharing life, experience and happiness with me. To my fellow PhD students, 冯晨, 文静, 双伟, 小古, 邵丽萍, 王旗, 董蓓, 王子申, 周振祥, 王东, 乔否, 高华金鍂, 
王金, 方亮, 刍淳妹, 李倩, 阿如汗, Luuk, Ali and many others, it was nice having lunches with you at our shared coffee room. To my Sweet Potato family, 舒航, 若玉, 小雪颜, 小芳, 诗凡, 雨 廷, 老王, 俊楠, 晓芸, 王子豪, 小徐, and many others, thank you for bringing the traditional Chinese folk music to the international stage. The times of playing music with you are memorable.

Special thanks to my paranymphs, colleagues and friends, Marloes and Paul, for accepting my invitation and wanting to sit by my sides on the stage during my defence! Special thanks to Jiska, for being a good colleague and a good friend. Thank you and Gerrit for the nice dinners you organized at Christmas Eves and many other occasions. Now you are expecting a new member of your family, how exciting, I feel so happy for you two! To 冯晨, I'm greatful for your company duing the final stage of my PhD journey, thanks for your great support and encouragement! To Beyene, thank you for being a good friend already from my MSc study! You inspired me to explore more about Africa, and I did! To Violet, we shared a room in a PhD course during our first-year $\mathrm{PhD}$ and became good friends. It's such a pity that we haven't seen each other since then, but I'm happy for you that you are with your family and started a new research career. I also want to thank Joost Wolf, who was my supervisor of my MSc internship. You were the first to make me know that it is possible to build friendships with my supervisor, which is a shocking idea in my home country! Thank you for providing ideas when I developed my PhD proposals, for your guidance and discussion about the crop growth models, and for thinking along with my potato research!

My deepest gratitude goes to my parents, 晓峰 and 王静. Thank you for bringing me to the world and being my constant supporters since then! I used to believe that you expect much from me, and want me to achieve something big, which sometimes made me stressful as I feared to let you down. But my mind changed when Chu was born and you visited me in the Netherlands. You taught me how to be a mother, which made me start thinking how to be your daughter. I now can assure you with the successful completion of my $\mathrm{PhD}$, and more importantly the fact that I realize what is the most important thing of my life! Thanks to my mother-in-law for providing great help in taking care of Chu so that I could focus on my thesis work. You made super delicious food for us and filled the house with laugher!

To my husband, 竟然. Thank you for your unlimited efforts and company. I'm so lucky that you were by my side during all the adventures of my life. You left your job, family and friends and came along with me to an unfamiliar place. I know it is a great sacrifice. You experienced many hardships facing language problems, job searching difficulties, and many lonely times. Thanks to your positive spirit and dedication, we were able to get over hard times and finally came to this achievement. Thank you for your effort in distracting me from the daily stresses. I particularly enjoyed the bike tours with you to the surrounding towns of Wageningen. The natural beauties and the peaceful villages made me forget about the pressure (for a while). I love the videos you made that recorded the happy moments of our life in the Netherlands. Thank you for supporting me to fulfil my dream. Thank you for making me a better women!

To my daughter, 李初 (Li Chu), you came as a surprise and brought another challenge to me while I was struggling with my $\mathrm{PhD}$. But I never hesitated and never regretted of having you. 
We made a list of names for you, but finally we wanted to call you “李初”. “初” in Chinese means early, first, original, at the beginning. We hope you enjoy all the "first times" in your life, 初次尝试, 初次遇见, 初次相爱...Thank you for bringing a new chapter to my life.

\section{感谢你陪我一起成长!}




\section{About the author}

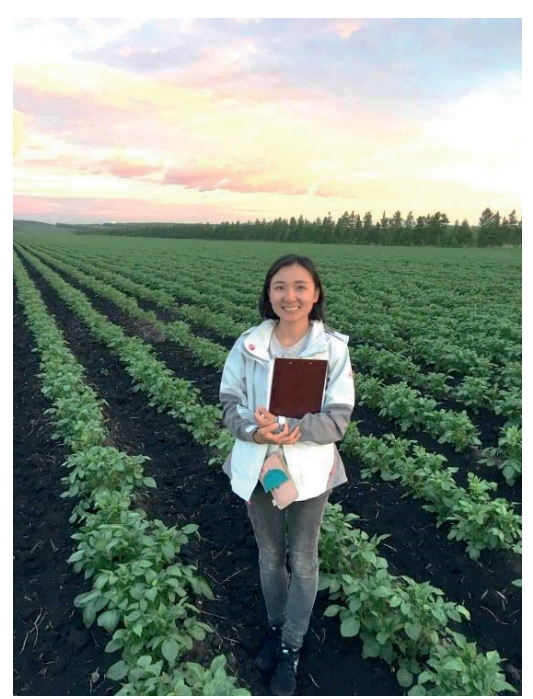

$\mathrm{Na}$ Wang was born on the 31st of January 1989 in China's "Ice City", Harbin, in Heilongjiang province, in the northeast part of China. She followed higher education in the No.60 Middle School (2000-2004) and the No.1 Senior High School (2004-2007) in Harbin. In 2007, she entered the Northeast Agricultural University (NEAU) and spent four years on the Bachelor's study in Horticulture. After obtaining a Bachelor's degree (Agronomy) in 2011, she came to the Netherlands starting an MSc program Plant Sciences (Natural Resource Management) at Wageningen University. She did her MSc thesis at the Plant Production Systems Group (PPS), working on coffee and banana intercropping systems. The field works were conducted in the International Institute of Tropical Agriculture (IITA)

in Kampala, Uganda. Later, she did her internship (a minor thesis) at the same group on a research project entitled "Benchmarking nutrient and water resource use efficiency of crops". After completing her MSc study in July 2014, she worked as a Guest Researcher at the PPS group on "Sustainable apple production in China" in collaboration with the Chinese Agricultural University. Studying and living abroad was life-enriching in many aspects. The overseas experience also provided her opportunities in the international job market. In 2015, she joined NAFTC China (Netherlands Agro \& Food Technology Centre) as a project assistant to coordinate research and business projects in the agro-food sector. After a year of working, she decided to pursue an academic career. In 2016 she started the PhD project aiming to enhance the sustainability performance of potato production in China. The $\mathrm{PhD}$ research was conducted at the PPS group of Wageningen University. In July 2020, she started a new position at the Horticulture and Product Physiology group (HPP) at Wageningen Univerity. 


\section{Publications}

Wang, N., Reidsma, P., Van Ittersum, M.K., 2020. Scope and strategies for sustainable intensification of potato production in northern China. Agronomy Journal.

https://doi.org/10.1002/agj2.20269.

Wang, N., Reidsma, P., Wang, Z.Q., Van Ittersum, M.K., 2019. Synergy or trade-off? A framework and application to benchmark yield, quality and revenue of potato production. Field Crops Research, Volume 240, Pages 116-124. ISSN 0378-4290, https://doi.org/10.1016/j.fcr.2019.05.020.

Wang, N., Reidsma, P., Pronk, A.A., de Wit, A.J.W., Van Ittersum, M.K., 2018. Can potato add to China's food self-sufficiency? The scope for increasing potato production in China. European Journal of Agronomy, Volume 101, Pages 20-29. ISSN 1161-0301, https://doi.org/10.1016/j.eja.2018.07.002.

Wang, N., Wolf, J., Zhang, F.S., 2016. Towards sustainable intensification of apple production in China - Yield gaps and nutrient use efficiency in apple farming systems. Journal of Integrative Agriculture, Volume 15, Issue 4, Pages 716-725. ISSN 2095-3119, https://doi.org/10.1016/S2095-3119(15)61099-1.

Wang, N., Jassogne, L., van Asten, P.J.A., Mukasa, D., Wanyama, I., Kagezi, G., Giller, K.E., 2015. Evaluating coffee yield gaps and important biotic, abiotic, and management factors limiting coffee production in Uganda. European Journal of Agronomy, Volume 63, Pages 1-11. ISSN 1161-0301, https://dx.doi.org/10.1016/j.eja.2014.11.003.

Wang, N., Li, H.J., Zhang, X.Y., Bai, J., Che, D.D., 2014. Contrastive analysis on core competitiveness of floriculture in China and the Netherlands. Northern Horticulture, 38 (03), Pages 185-190. In Chinese with English Abstract. 


\section{PE\&RC PhD Education Certificate}

With the training and education activities listed below the $\mathrm{PhD}$ candidate has complied with the requirements set by the C.T. de Wit Graduate School for Production Ecology and Resource Conservation (PE\&RC) which comprises of a minimum total of 32 ECTS $(=22$ weeks of activities)

\section{Review of literature (6 ECTS)}

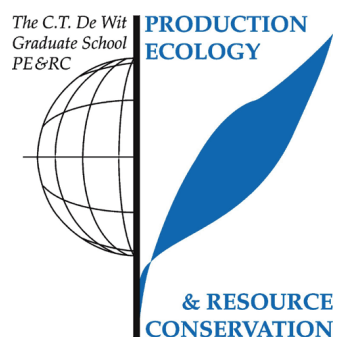

- Evaluating potato yields and resources use efficiencies for a variety of potato cropping systems in different regions of China

\section{Writing of project proposal (4.5 ECTS)}

- Trade-offs of yield and input gaps and resources use efficiencies of potato production systems in different regions of China

\section{Post-graduate courses (3 ECTS)}

- Grasping sustainability; SENSE (2016)

- Root ecology; PE\&RC and University of Copenhagen (2020)

\section{Methodological / statistical postgraduate courses (0.6 ECTS)}

- Introduction to R for statistics; PE\&RC and WIMEK (2016)

\section{Invited review of (unpublished) journal manuscript (4 ECTS)}

Field Crops Research - Resource use efficiencies as indicators of ecological sustainability in potato production: a South African case study (2016)

- Potato Research - The collaborative influence of elevated $\mathrm{CO}_{2}$ concentration and atmospheric warming on potato physiology and ecology in the semi-arid region of Loess Plateau (2017)

- European Journal of Agronomy - Yield potential, yield gaps and optimal agronomic managements for rice production system in different regions of China (2017)

- Field Crops Research - Optimum fertilization rates to maximize yield and nitrogen use efficiency for regional sustainable potato production in China (2020)

\section{Deficiency, refresh, brush-up courses (9 ECTS)}

- Quantitative research methodology and statistics; WUR (2016)

- Advanced statistics; WUR (2016)

\section{Competence strengthening / skills courses (2.2 ECTS)}

- Essentials of scientific writing and presenting; Wageningen in'to Languages (2016)

- Data management planning; Wageningen UR Library (2016)

- Research integrity; WGS (2016) 
PE\&RC Annual meetings, seminars and the PE\&RC weekend (2.1 ECTS)

- PE\&RC Workshop carousel (2016)

- PE\&RC First years weekend (2016)

- $3^{\text {rd }}$ Wageningen PhD symposium: diversity in science (2016)

- Plant-soil-microbe interactions workshop (2016)

- PE\&RC Day: PE\&RC's got talent (2016)

Discussion groups / local seminars / other scientific meetings (9 ECTS)

- Sustainable intensification of agricultural systems (2016)

- Plant and soil discussion group (2016)

- WaCaSa meetings (2016-2019)

\section{International symposia, workshops and conferences (3.8 ECTS)}

- The $2^{\text {nd }}$ Sino-Europe workshop on potato sustainable production and technical cooperation; Hebei, China (2016)

- The $3^{\text {rd }}$ Sino-Europe potato conference on potato sustainable production and technical cooperation; Yunnan, China (2018)

Lecturing / supervision of practicals / tutorials (10.8 ECTS)

- Quantitative analysis of land use systems $(2017,2018,2019)$

\section{Supervision of MSc students (3 ECTS)}

- Analysis of nitrogen and water use efficiencies of potato production with a field experiment in Hailar, Inner Mongolia, China 


\section{Final page}

The research described in this thesis was financially supported by China Scholarship Council (CSC) [grant number 201506610003], and by the Plant Production Systems Group of Wageningen University \& Research.

Printed by: ProefschriftMaken || www.proefschriftmaken.nl 


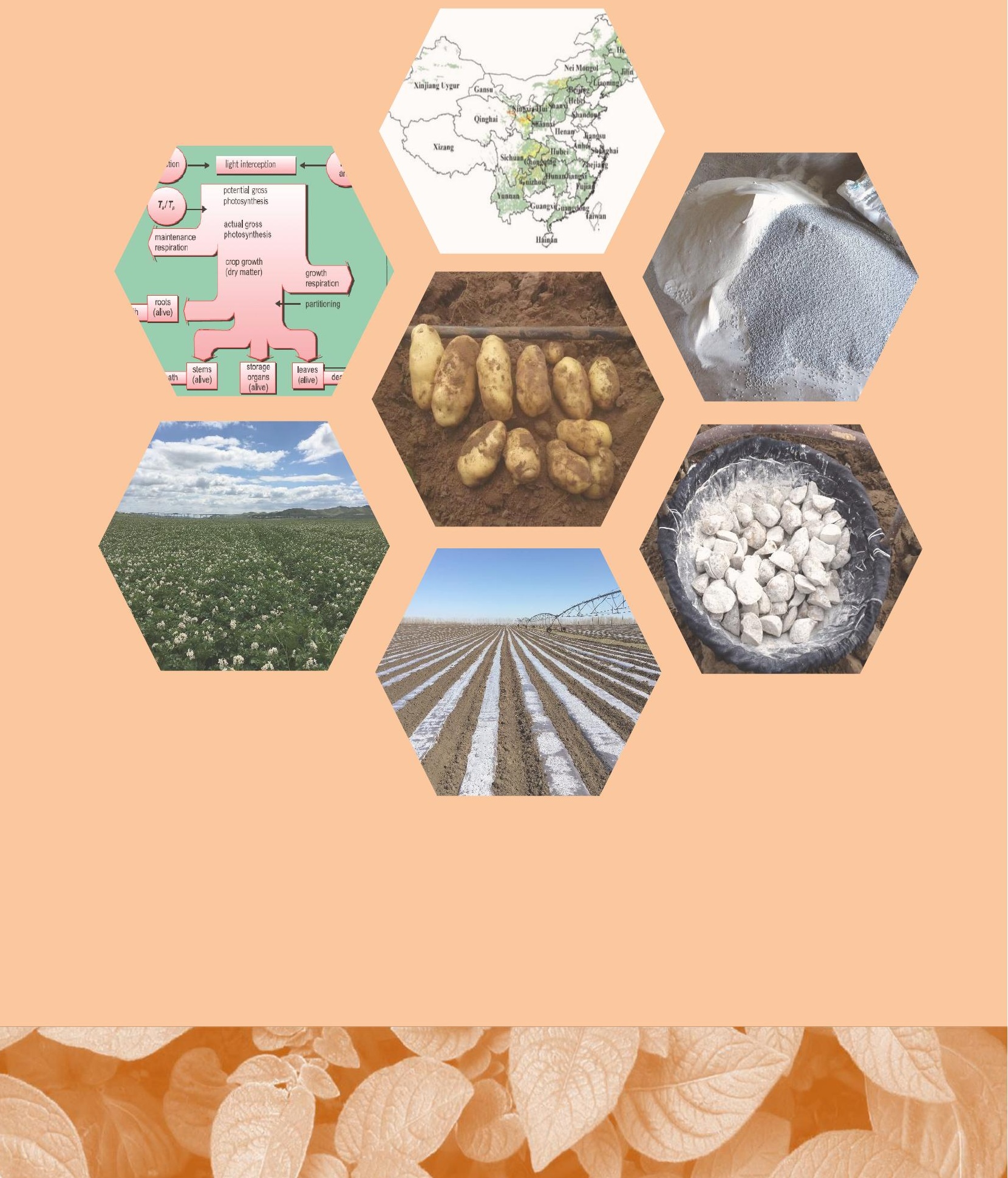